\title{
The occlusal plane inclination relative to craniofacial form: $A$ cephalometric investigation
}

\author{
Holly Eppard \\ West Virginia University
}

Follow this and additional works at: https://researchrepository.wvu.edu/etd

\section{Recommended Citation}

Eppard, Holly, "The occlusal plane inclination relative to craniofacial form: A cephalometric investigation" (2012). Graduate Theses, Dissertations, and Problem Reports. 572.

https://researchrepository.wvu.edu/etd/572

This Thesis is protected by copyright and/or related rights. It has been brought to you by the The Research Repository @ WVU with permission from the rights-holder(s). You are free to use this Thesis in any way that is permitted by the copyright and related rights legislation that applies to your use. For other uses you must obtain permission from the rights-holder(s) directly, unless additional rights are indicated by a Creative Commons license in the record and/ or on the work itself. This Thesis has been accepted for inclusion in WVU Graduate Theses, Dissertations, and Problem Reports collection by an authorized administrator of The Research Repository @ WVU. For more information, please contact researchrepository@mail.wvu.edu. 


\title{
THE OCCLUSAL PLANE INCLINATION \\ RELATIVE TO CRANIOFACIAL FORM:
}

\section{A CEPHALOMETRIC INVESTIGATION}

Holly Eppard D.D.S.

\author{
A THESIS \\ Submitted to: \\ The School of Dentistry \\ at West Virginia University \\ in partial fulfillment of the requirements \\ for the degree of \\ Master of Science \\ In \\ Orthodontics
}

Tim Tremont D.M.D., M,S, Advisor

Peter Ngan, D.M.D., Chair

Chris Martin, D.D.S., M.S.

Bryan Weaver, D.D.S., M.D.

West Virginia University

Department of Orthodontics

Morgantown, West Virginia

2012

Keywords: occlusal plane; cephalometrics 


\title{
ABSTRACT
}

\section{The occlusal plane inclination relative to craniofacial form: A cephalometric investigation}

\author{
Holly Eppard, DDS., Tim Tremont D.M.D., M,S, Peter Ngan, D.M.D., Chris Martin, D.D.S., \\ M.S.Bryan Weaver, D.D.S., M.D., and Erdogan Gunel, Ph.D.
}

Background Objectives: The occlusal plane has been given much attention throughout the orthodontic literature. Studies have shown that the occlusal plane inclination varies relative to vertical and sagittal skeletal discrepencies. The Six Elements of Orofacial Harmony does not address the occlusal plane inclination as a parameter in diagnosis and treatment planning despite its spatial influence on the position of the chin. The occlusal plane inclination is considered a critical factor in treatment planning for orthognathic surgery. The objective of this study was to systematically evaluate the inclination of the occlusal plane $\left(\mathrm{Op}^{\circ}\right)$ relative to various skeletal and dental cephalometric parameters. Methods: A sample of 105 pretreatment cephalometric radiographs, in subjects with a range of skeletal and dental morphological characteristics, was appraised. Differences in the $\mathrm{Op}^{\circ}$ and AP measurements of pogonion relative to the GALL were evaluated among the various anteroposterior, vertical, and soft tissue facial convexity groups were compared. Correlation coefficients evaluating relationships among the cephalometric measurements were calculated. A stepwise regression analysis was performed to further elucidate the variables which contribute to changes in the $\mathrm{Op}^{\circ}$. Results: The occlusal plane inclination was most significantly correlated with SN-MP', $\mathrm{MP}^{\mathrm{o}}$, Pog'GALL, Pog-GALL, Pogc'GALL, TVL-Pog, and S-Go. The regression analysis indicated that SN-MP' ${ }^{\circ} \mathrm{PP}^{\circ}$, Element IV Md Ant, PP-Msc, PP-1, Mp-Mic, Sn'-Me', SNº, Element IV Mx Ant and Co-Gn are good predictors of $\mathrm{Op}^{\circ}$. There were statistically significant differences among all vertical groups for the mean $\mathrm{Op}^{\circ}$. The mean $\mathrm{Op}^{\circ}$ was found to differ among Class II and III skeletal profiles and convex and concave soft tissue facial convexities. Conclusions: $\mathrm{Op}^{\circ}$ varies relative to sagittal and vertical jaw dimensions. There is a strong relationship between the occlusal plane inclination and the vertical dimension. Hyperdivergent profiles tend to have steeper occlusal plane inclinations. Hypodivergent profiles tend to have flatter occlusal plane inclinations. There is a tendency towards steeper occlusal planes in Class II skeletal subjects and a flatter occlusal plane in Class III skeletal subjects. There is a tendency towards steeper occlusal planes in subjects with convex profiles and flatter occlusal planes in patients with concave profiles. The occlusal plane inclination is highly correlated with the measurement of soft tissue pogonion to the GALL. There is a strong correlation between the occlusal plane inclination and maxillary incisor inclination. The occlusal plane inclination should be considered when diagnosis and treatment planning to maximize dental and facial esthetics. 


\section{DEDICATION}

In memory of my father, Charles Eppard. Dad, thanks for your selfless and hardworking nature. I love you and miss you more than words can say.

To my Mother, Judy Eppard, for your endless support. I truly could not have made it this far without your unconditional love. Thanks for your persistence and confidence. I love you.

To my siblings, Brad, Tracy and Jeffrey, for always being there; and for the hard times you gave me as a kid and an adult. I love you all. 


\section{ACKNOWLEDGEMENTS}

Heartfelt thanks go out to the following people:

Dr. Peter Ngan, for your commitment to our program and orthodontic research. I am both blessed and honored to work with you on this research project and in the orthodontic clinic. You are truly a great person.

Dr. Tim Tremont, for being such a dedicated educator. Thank you for your insight and efforts towards this project.

Dr. Chris Martin, for being a friend and educator. I appreciate your calm nature and patience during my time here.

Dr. Bryan Weaver, for being such a great educator. Thank you for your honesty and willingness to be a part of my research project.

Dr. Erdogan Gunel, for your statistical expertise, patience and willingness to explain concepts.

Drs Hazey, Jarrett, Kirsch, Foley, Gilmore, Boyles, McFarland, Sebbahi, Dempsey, Wright, and Little, for the time you dedicate to this program. The clinical skills gained here will last a lifetime. That is greatly appreciated.

Karen, Hillary, Marsha, Leona and Carrie, for taking care of me during the daily grind. Without all of you, I would be miles behind.

Jung Mee Kim and Ronnie Sparks, for your constant understanding and support. I wish you both the best of luck in the future!

Kolin Weaver, for your mentoring and endless patience in answering my questions during my first year here in this program. You absence was missed.

Dean, Mike, Maggie, Rob, Erica, DoYoung, Alice, Chad, Nicole, Deepa and Lance, for being great friends and co-residents. I will never forget all of our travels. Best of luck to each of you. 


\section{TABLE OF CONTENTS}

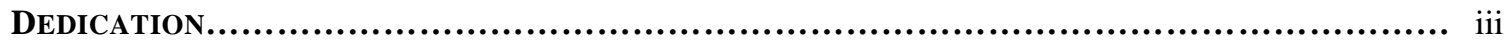

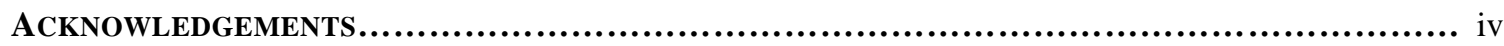

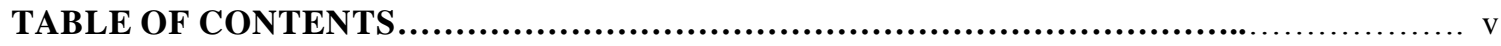

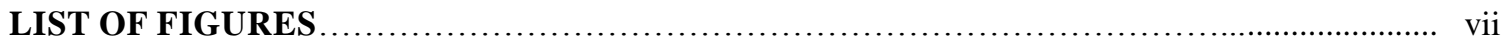

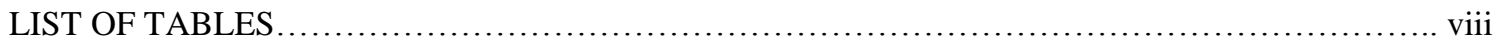

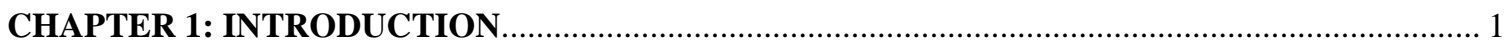

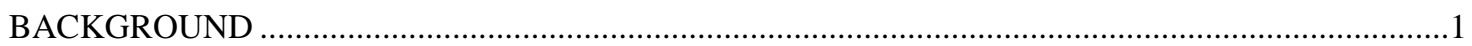

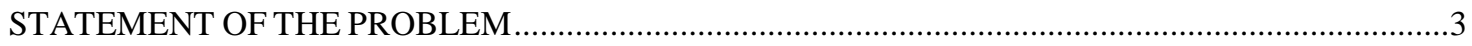

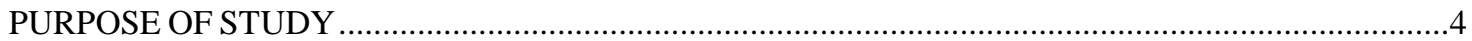

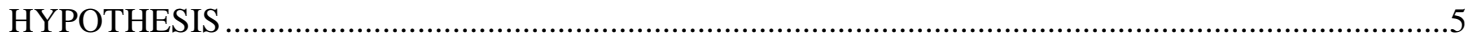

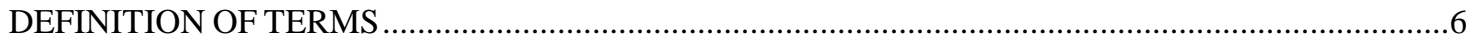

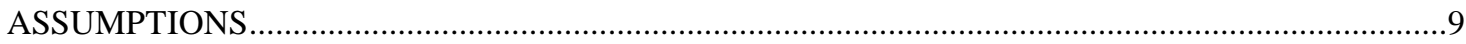

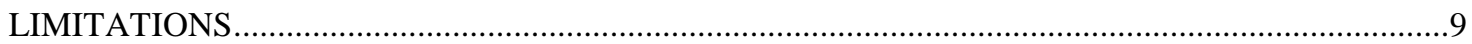

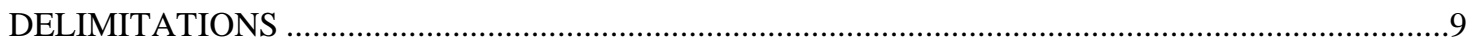

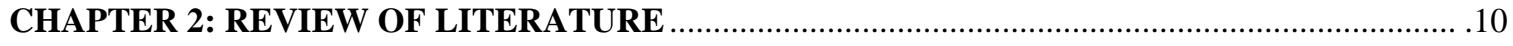

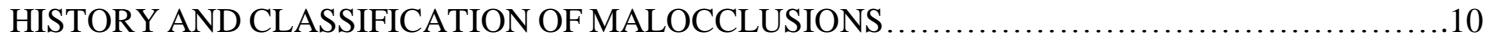

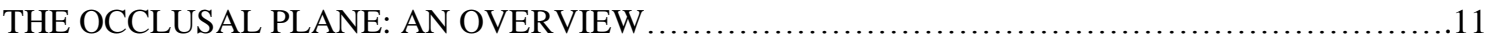

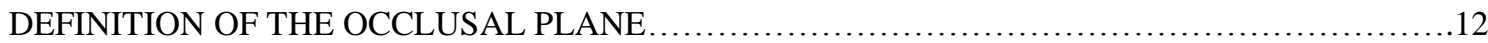

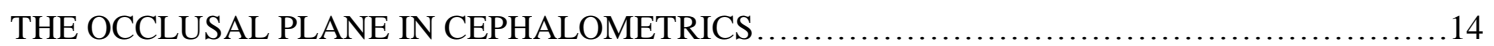

THE RELATIONSHIP OF THE OCCLUSAL PLANE TO CRANIOFACIAL FORM ..................15

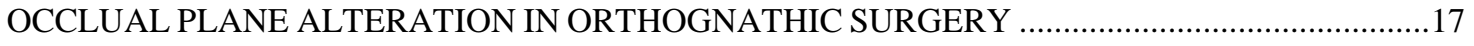

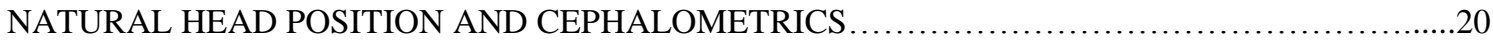

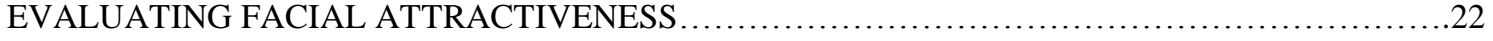

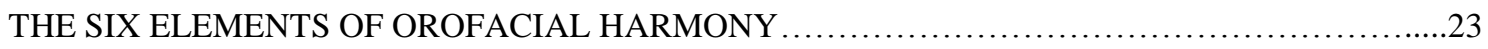

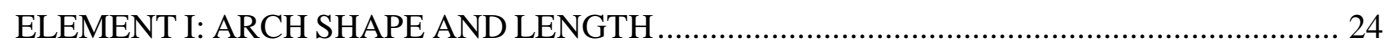

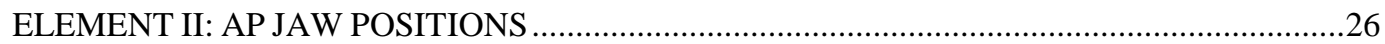

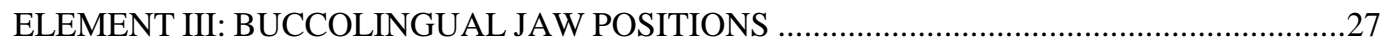

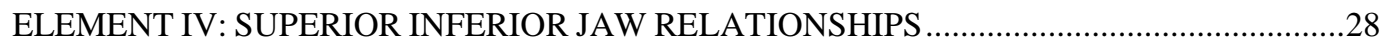

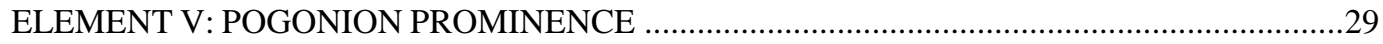

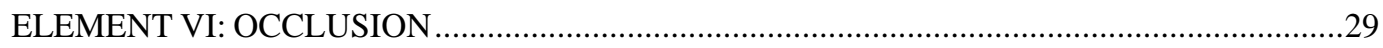

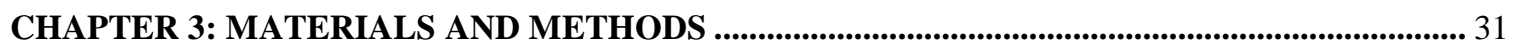

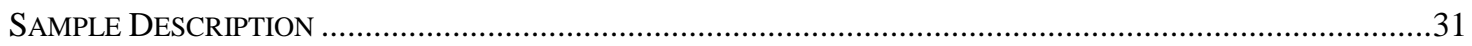

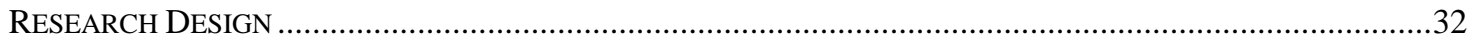

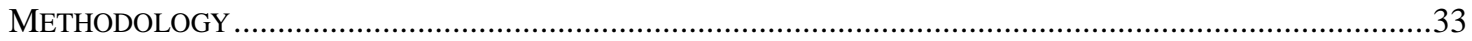

CONSTRUCTION OF THE GALL AND TRUE HORIZONTAL (TH) …….............................................33

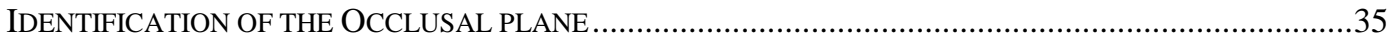

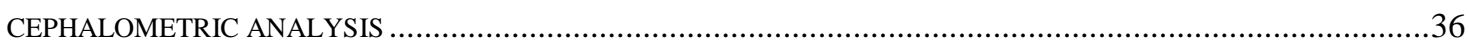

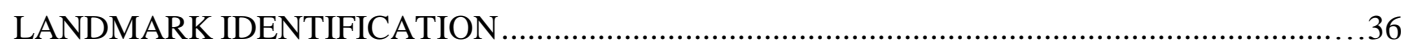

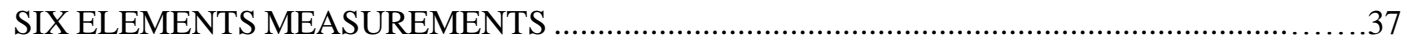

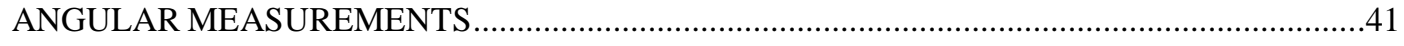

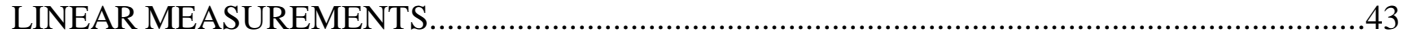

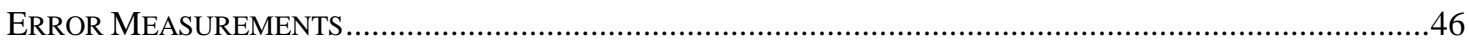

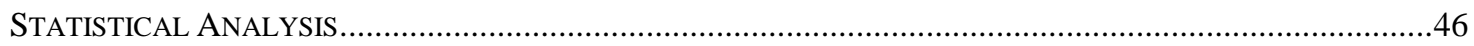




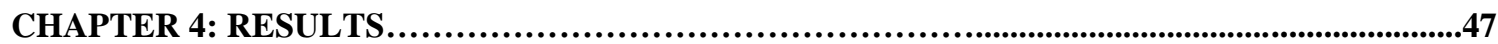

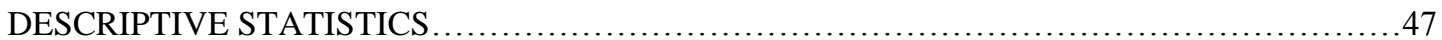

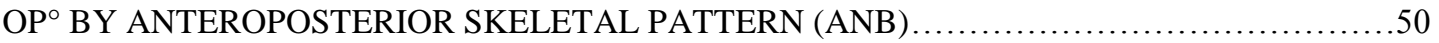

$\mathrm{OP}^{\circ}$ BY SIX ELEMENTS ANTEROPOSTERIOR SKELETAL PATTERN ........................51

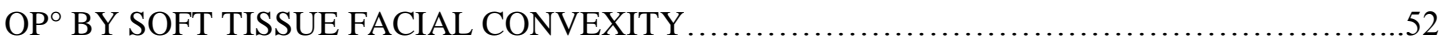

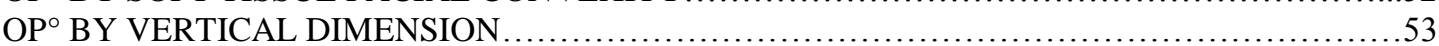

CORRELATIONAL ANALYSIS OF Op ${ }^{\circ}$ TO CEPHALOMETRIC VARIABLES $\ldots \ldots \ldots \ldots \ldots \ldots \ldots . \ldots \ldots$

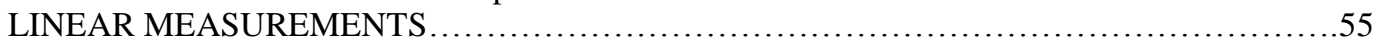

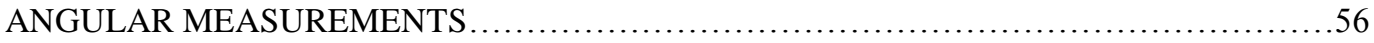

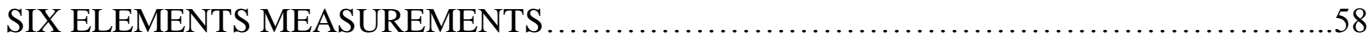

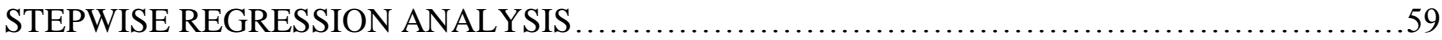

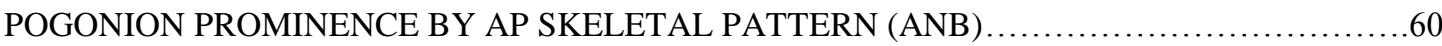

POGONION PROMINENCE BY SIX ELEMENTS AP SKELETAL PATTERN $\ldots \ldots \ldots \ldots \ldots \ldots \ldots \ldots 1$

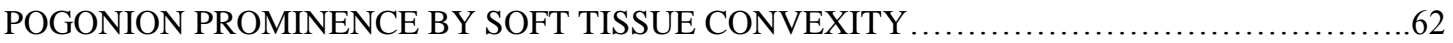

POGONION PROMINENCE BY VERTICAL PATTERN ....................................6

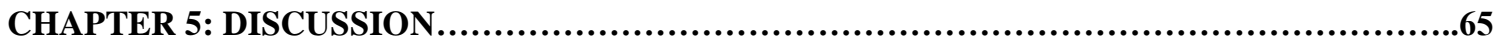

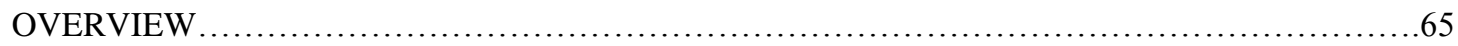

CRANIOFACIAL REFERENCE PLANES RELATIVE TO TRUE HORIZONTAL ..................66

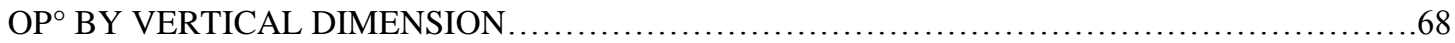

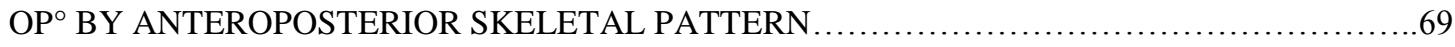

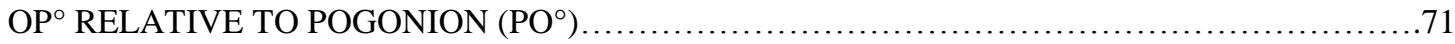

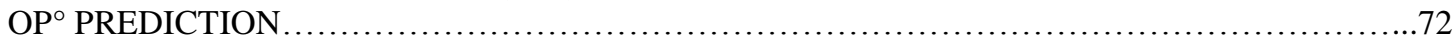

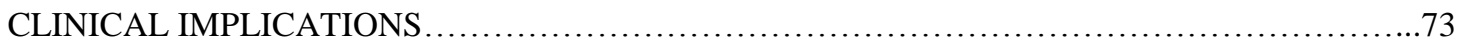

CHAPTER 6: SUMMARY AND CONCLUSIONS.............................................75

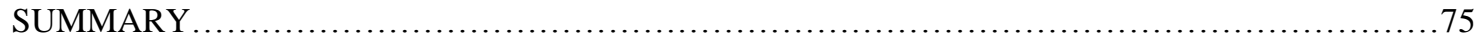

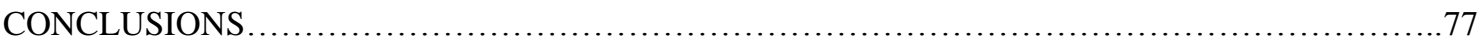

CHAPTER 7: SUGGESTIONS FOR FUTURE RESEARCH.....................................78

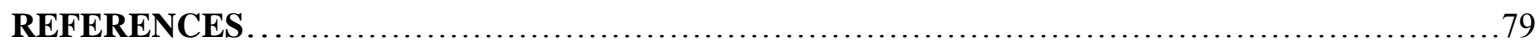

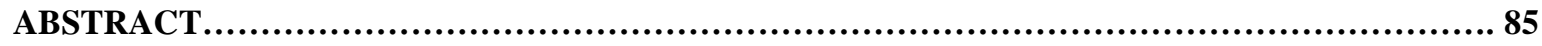

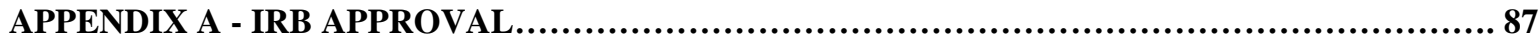

APPENDIX B

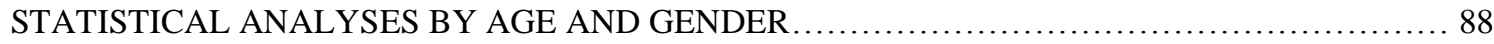

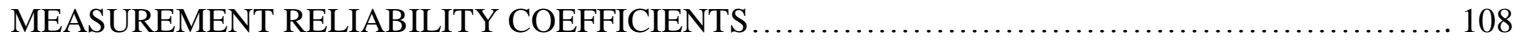

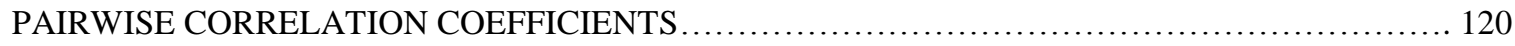

STATISTICAL ANALYSES - OCCLUSAL PLANE INCLINATION .......................... 137

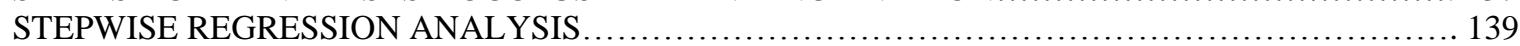

STATISTICAL ANALYSIS - POGONION PROMINENCE MEASUREMENTS ......................142

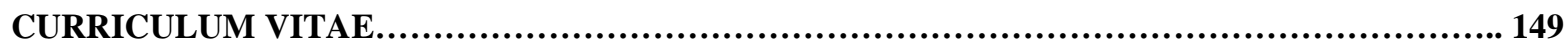

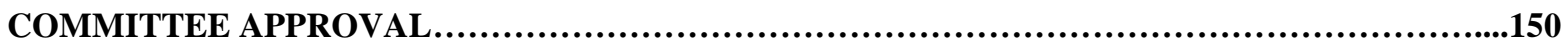




\section{LIST OF FIGURES}

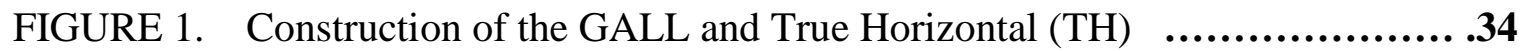

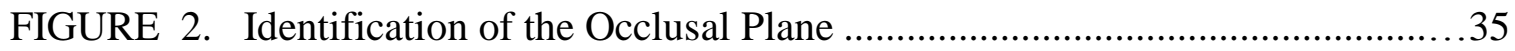

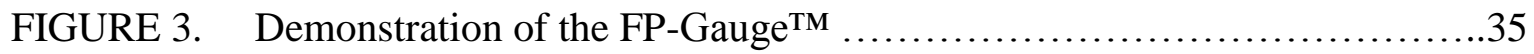

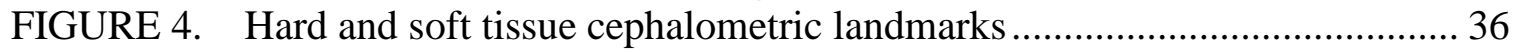

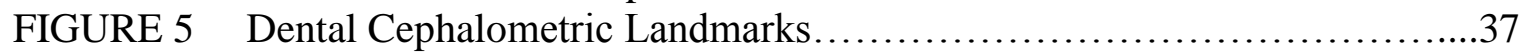

FIGURE6 Illustration of Element II Mx..............................................

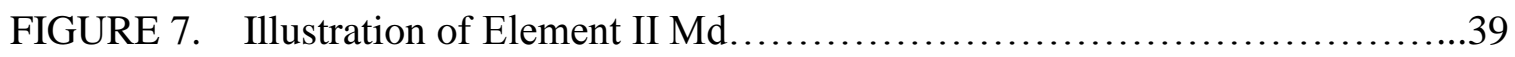

FIGURE 8. Illustration of Element IV Mx Ant..................................40

FIGURE 9. Illustration of Element IV Md Ant................................ 40

FIGURE 10. Illustration of Element V ........................................ 41

FIGURE 11. Angular Measurements.................................................42

FIGURE 12. Vertical Facial Heights.........................................44

FIGURE 13. Chin Prominence Measurement to the GALL ...........................44

FIGURE 14. Soft Tissue Chin Measurement to TVL ................................45

FIGURE 15. Vertical Eruption .............................................45

FIGURE 16. Mean occlusal plane inclination $\left({ }^{\circ}\right)$ by anteroposterior skeletal groups....50

FIGURE 17. Mean occlusal plane inclination $\left(^{\circ}\right)$ by Six Elements Skeletal Pattern......51

FIGURE 18. Mean occlusal plane inclination $\left({ }^{\circ}\right)$ by Soft Tissue Convexity.............52

FIGURE 19. Mean occlusal plane inclination $\left({ }^{\circ}\right)$ by Vertical Skeletal Pattern...........53

FIGURE 20. Occlusal plane inclination $\left(^{\circ}\right)$ plotted against measurements of the........55 anteroposterior chin position $(\mathrm{mm})$

FIGURE 21. Occlusal plane inclination $\left(^{\circ}\right)$ plotted against soft tissue convexity.........56

FIGURE 22. Occlusal plane inclination $\left(^{\circ}\right)$ plotted against Sella-Nasion to MP..........57

FIGURE 23. Mean Pog'c-GALL (mm) by Anteroposterior Skeletal Class................60

FIGURE 24. Mean Pog'c-GALL (mm) by Six Element Anteroposterior.................61

Skeletal Pattern

FIGURE 25. Mean Pog-c-GALL (mm) by Soft Tissue Convexity $\ldots \ldots \ldots \ldots \ldots \ldots \ldots \ldots . . \ldots 3$

FIGURE 26. Mean Pog'c-GALL $(\mathrm{mm})$ by Vertical Dimension........................64 


\section{LIST OF TABLES}

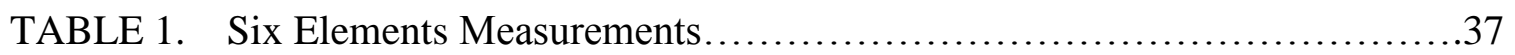

TABLE 2. Angular Cephalometric Measurements.................................42

TABLE 3. Linear Cephalometric Measurements................................. 43

TABLE 4. Descriptive Statistics by Gender.....................................48

TABLE 5. Descriptive Statistics by Age Group..................................48

TABLE 6. Descriptive Statistics of Pooled Sample..............................49

TABLE 7. Mean $\mathrm{Op}^{\circ}$ by ANB Anteroposterior Skeletal Classification................50

TABLE 8. Mean $\mathrm{Op}^{\circ}$ by Six Elements Anteroposterior Category ....................51

TABLE 9. Mean Op ${ }^{\circ}$ by Soft Tissue Convexity....................................52

TABLE 10. Mean Op ${ }^{\circ}$ by Vertical Dimension....................................53

TABLE 11. Correlation Coefficients related to the Occlusal Plane $\left(\mathrm{Op}^{\circ}\right) \ldots \ldots \ldots \ldots \ldots . \ldots 54$

TABLE 12. Pogonion prominence by AP Skeletal Pattern (ANB) .....................60

TABLE 12. Pogonion prominence by Six Elements Anteroposterior Skeletal Pattern...661

TABLE 13. Pogonion prominence by Soft Tissue Convexity........................62

TABLE 14. Pogonion prominence by Vertical Pattern.............................63

TABLE 15. Comparison of studies reporting craniofacial reference planes measured....67 Relative to true horizontal 


\section{CHAPTER 1: INTRODUCTION}

\section{Background}

The importance of the occlusal plane is underscored by the abundance of publications within the orthodontic literature. The occlusal plane is evaluated relative to craniofacial form ${ }^{1-3}$, craniofacial growth ${ }^{4}$, masticatory function ${ }^{5,6}$, dental occlusion ${ }^{7,8}$, mechanotherapy ${ }^{9,10}$, and orthognathic surgery. ${ }^{11-15}$

It is well established that a relationship exists between the inclination of the occlusal plane and the various skeletal profiles. ${ }^{3,4,16}$ Studies have shown that steeper occlusal planes are associated with Class II malocclusions whereas flatter occlusal planes are associated with Class III malocclusions. ${ }^{4,16}$ The inclination of the occlusal plane also varies relative to vertical jaw discrepancies. ${ }^{17}$ Steeper occlusal plane inclinations are reported to be associated with the hyperdivergent (long-face) individuals and flatter occlusal plane inclinations are associated with the hypo-divergent (short-face) individuals. In addition, the vertical dimension of the posterior maxilla, due to dentoalveolar compensation, has been attributed to effect the vertical and sagittal position of the mandible. ${ }^{3}$

The variability observed in the inclination of the occlusal plane is described as a compensatory mechanism that exists to achieve a Class I dental relationship in the presence of a sagittal jaw discrepancy. ${ }^{2}$ However, if the sagittal discrepancy exceeds certain limits dentoalveolar compensation will be inadequate and a Class I relationship will not be achieved. ${ }^{2}$ Casko and Shepherd ${ }^{18}$ evaluated 75 adult patients in an attempt to examine the skeletal variation that exists in naturally occurring optimal occlusions. He noted that as the ANB angle increased, the inclination of the occlusal plane likewise increased. 
Additionally, many authors have reported on the need to alter the occlusal plane inclination in orthognathic surgery to achieve an acceptable esthetic outcome with adequate chin projection. ${ }^{11,13,15,19}$ Arnett reported that the inclination of the maxillary occlusal plane to the true vertical line (TVL) in a sample of adult white models is $95.6 \pm 1.8^{\circ}$ in females and $95.0 \pm$ $1.4^{\circ}$ in males. ${ }^{19}$ Furthermore, Arnett ${ }^{20}$ advocates surgical correction of the occlusal plane, within a range of $93-97^{\circ}$ to produce an optimal profile.

Practitioners using various virtual treatment planning software, such as Invisalign ClinCheck, OrthodCad iQ, and Ormco Insignia, have recognized the effect of various occlusal plane inclinations on the incisor inclination relative to the face. ${ }^{21}$ A report by Batwa et al. ${ }^{22}$ demonstrated that large alterations in the the occlusal plane inclination has an effect on smile attractiveness. Smiles with occlusal planes at $10^{\circ}$ to true horizontal were deemed most attractive by patients.

The Andrews® Six Elements Orthodontic Philosophy ${ }^{\mathrm{TM}}{ }^{23}$ attempts to overcome the shortcomings of traditional cephalometric analyses by proposing a complete analysis uniqe to each individual. The strength of the Andrews analysis when compared to other approaches is that the forehead serves as a fixed landmark from which to evaluate the spatial position of the jaws. A complete analysis requires an accurate description of the anteroposterior and vertical jaw positions. Andrews considers the AP position of the mandible to be optimal based on coupling of maxillary and mandibular incisors that are placed at their proper inclination, centered in basal bone, and with the maxillary central incisor facial axis point on the GALL. Andrews separates the vertical jaw position, Element IV, into anterior and posterior components within each jaw. The anterior maxilla Element IV is defined as optimal based on appropriate maxillary incisor display in repose. The posterior maxilla Element IV is considered optimal when the 
anterior maxilla and mandible are optimal and there is an absence of an anterior or posterior open bite. The relationship between the anterior and posterior Element IV position of the maxilla thus establishes the inclination of the occlusal plane.

\section{Statement of the Problem}

Studies on the inclination of the occlusal plane relative to true horizontal have not evaluated the soft tissue chin prominence and maxillary incisor inclination relative to the face. The need to surgically correct the inclination of the occlusal plane to achieve optimal facial harmony suggests that there is an optimal range of occlusal plane inclinations. Does an optimal range of occlusal plane inclinations exist?

Furthermore, Andrews does not suggest an optimal inclination for the occlusal plane despite its influence on the spatial position of the chin or incisor inclination. In addition, he does not indicate an optimal AP position of the chin relative to the GALL. He does however; address the effect of varying the inclination of the occlusal plane on the incisor inclination. Based on his sample of optimally occurring natural dentitions, the average maxillary incisor inclination was $7^{\circ}$ to the occlusal plane. An occlusal plane inclination of $7^{\circ}$, therefore, would have a maxillary incisor positioned $0^{\circ}$ to the frontal plane of the head. Steepening the occlusal plane would result in a negative inclination to the maxillary central incisors. Likewise, a flattening of the occlusal plane would result in a maxillary incisor with increased positive inclination to the face. 


\section{Purpose of Study}

The objectives of this study are:

1. To evaluate the relationship between the inclination of the occlusal plane and soft tissue pogonion prominence measured relative to Andrew's GALL.

2. To evaluate the relationship between the inclination of the occlusal plane and maxillary incisor inclination.

3. To evaluate the relationship between the inclination of the occlusal plane and the anteroposterior and vertical jaw dimensions.

4. To evaluate the relationship between the inclination of the occlusal plane and soft tissue facial convexity.

5. To evaluate if there is a group of cephalometric variables that explain the change in the occlusal plane inclination. 


\section{Null Hypothesis}

1. The inclination of the occlusal plane does not correlate with the AP relationship of the chin relative to the GALL.

2. The inclination of the occlusal plane does not correlate with the inclination of the maxillary incisor

3. The inclination of the occlusal plane does not correlate with the AP position of the jaws.

4. The inclination of the occlusal plane does not correlate with facial soft tissue convexity.

5. The inclination of the occlusal plane does not correlate with the vertical jaw dimension.

6. There are no cephalometric variables that will explain the change in the inclination of the occlusal plane.

7. There is no significant difference in the occlusal plane inclination among the three anteroposterior groups (Class I, Class II, and Class III).

8. There is no significant difference in the occlusal plane inclination among the three vertical groups (normodivergent, hypodivergent, hyperdivergent).

9. There is no significant difference in the occlusal plane inclination among the three groups of soft tissue convexity (normal, convex, concave). 


\section{Definition of Terms}

Adjusted natural head position - the clinician's judgment of the subject's natural head position when the patient is looking at a distant point at eye level, synonymous to natural head orientation and upright head position

Anatomical forehead - the exposed skin from trichion (hairline or where the hairline once was) to glabella

Arnett's TVL - True Vertical Line that is placed through subnasale and perpendicular to the natural head position ${ }^{20}$

Basal bone - the osseous tissue of the maxilla and mandible that does not include the alveolar process.

Centric relation - the maxillomandibular relationship in which the condyles articulate with the thinnest avascular portion of their respective disks with the complex in the most anterior-superior position against the shapes of the articular eminencies.

Clinical forehead - the portion of the forehead that is related more with the face than the scalp. For straight foreheads, it is between trichion and glabella. For rounded or angular foreheads, it is between superion and glabella.

DALL (dentition's anterior limit line) - a line that parallels the head's frontal plane and passes through the maxillary incisor's facial axis (FA) point.

Element I - the position in which a tooth is centered in basal bone with proper inclination for optimal occlusion

Element II - the anteroposterior position of the maxilla and mandible judged as optimal based on the FA point of an Element I maxillary incisor that touches the GALL and is coupled with an Element I mandibular incisor. 
FA point (tooth) - the point on the facial axis of the clinical crown that is midway between the gingival and occlusal borders.

FALL (forehead's anterior limit line) - a line that parallels the head's frontal plane and passes through the FFA point.

FALL-DALL - the difference between the FALL and DALL measured in millimeters. A negative number will correspond to a DALL that is posterior to the FALL. A positive number will correspond to a DALL that is anterior to the FALL. Zero will indicate that the FALL and DALL coincide.

FFA point (forehead facial axis point) - the midpoint of the clinical forehead that is between superion and glabella for round and angular foreheads and is between trichion and glabella for straight foreheads.

GALL (goal anterior limit line) - a line that parallels the head's frontal plane and represents the optimal anterior border for the FA point of an Element I maxillary incisor. This line passes through the FFA point when the forehead inclination is $7^{\circ}$ or less. For every degree the forehead inclination is beyond $7^{\circ}$, the GALL passes through a line that is $0.6 \mathrm{~mm}$ more anterior to the FFA point; without exceeding the glabella point.

Glabella: a point on the frontal bone that lies above nasion and between the eyebrows; the most inferior border of the clinical forehead.

Gonion: A point on the angle of the mandible formed by bisecting the angle formed by lines drawn tangent to the posterior ramus and the inferior border of the mandible.

Key I - Interarch relationships: (1) the mesiobuccal cusp of the maxillary first molar occludes in the mesio-buccal groove of the mandibular first molar; (2) the distal marginal ridge of the maxillary first molar occludes on the mesial marginal ridge of the mandibular first molar; (3) the 
mesiolingual cusp of the maxillary first molar occludes in the central fossa of the mandibular first molar; (4) the buccal cusps of the maxillary premolars rest in the embrasures of the mandibular premolars; (5) the lingual cusps of the maxillary premolars rest in the fossae of the mandibular premolars; (6) the maxillary incisors overlap the mandibular incisors and the midlines of the maxillary and mandibular arch are coincident.

Natural Head Orientation - the head orientation of the subject perceived by the clinician, based on general experience, as the natural head position in a standing, relaxed body and head posture, when the subject is looking at a distant point at eye level. Same as Adjusted Natural Head position and upright head position.

Natural Head Position - a standardized and reproducible orientation of the head when the subject is focusing on a distant point at eye level.

Occlusal Plane - The occlusal plane defined by as Andrews as a line connecting the distal marginal ridge of the maxillary first premolar and the distal marginal ridge of the maxillary first molar.

Superion - the point on the angular or round forehead that, judged in profile, represents the superior boundary of the clinical forehead.

The FP Gauge ${ }^{\mathrm{TM}}$ (The Frontal-Plane Gauge ${ }^{\mathrm{TM}}$ ) - A measuring device developed by Dr.

Timothy Tremont to accurately judge the FALL-DALL measurement.

Trichion - The superior border of an anatomical straight forehead (hairline) .

WALA ridge - a band of soft tissue immediately superior to the mucogingival junction in the mandible 


\section{Assumptions}

1. The occlusal plane, as identified in this study, is an accurate representation of the line of occlusion and can be accurately identified.

2. The lateral cephalometric radiographs are taken with the mandible in centric relation.

3. The GALL, as determined by the FALL-DALL measurement and forehead inclination, represents a true vertical reference plane.

4. The FALL-DALL measurement was accurately recorded with the patient positioned in the adjusted natural head position.

\section{Limitations}

1. Geometrically a plane is a flat surface. The plane of occlusion is in reality a curved surface in three dimensions, but will be represented as a flat plane.

2. The adjusted natural head position and FALL-DALL measurement will be judged by a single operator.

3. The sample group may not provide an adequate number of patients to discern an optimal profile range because the sample is selected from a biased population of patient's with malocclusions.

\section{Delimitations}

1. The FALL-DALL measurement will be determined utilizing a novel measuring device (The FP Gauge ${ }^{\mathrm{TM}}$ ).

2. All landmark identification and cephalometric measurements will be completed by a single investigator. 


\section{CHAPTER 2: REVIEW OF THE LITERATURE}

\section{History and Classification of Malocclusion}

The origin of orthodontics can be traced back thousands of years. Archaeological remains of ancient Egyptians revealed metal bands, proposed to be used for tooth alignment, wrapped individually around each tooth. Primitive orthodontic appliances were found in Greek and Etruscan belongings. Hippocrates (460-377 BC), in $400 \mathrm{BC}$ described irregularities of the teeth. He wrote, “... others have strongly arched palates thus teeth are disposed to irregularity, crowding, one on the other." 24

Pierre Fauchard, in 1723, invented the first orthodontic appliance, the bandeau; which was designed as an expansion arch. Fauchard is called the "Father of Modern Dentistry". Norman Kingsley published the first text, Oral Deformities, to recommend etiology, diagnosis and treatment planning in orthodontics. Kingsley also contributed to the profession with the use of occipital traction to correct incisor protrusion as well as in the treatment of cleft lip and palate. The orthodontist goals during this period of time were focused on tooth alignment and facial proportions. $^{25}$

Edward H. Angle (1855-1930), the "Father of Modern Orthodontics" is considered to be one of the most influential figures within the orthodontic profession. It was he that proposed the field of orthodontics be recognized as a specialty. He founded the first post-graduate orthodontic educational program (Angle School of Orthodontia, 1900), the first orthodontic society (currently known as the American Association of Orthodontists) and the first orthodontic journal 
(The American Orthodontist, 1907). He held numerous patents which include the Edgewise Appliance (1925). ${ }^{25}$

One of the most notable contributions of Angle is his classification of malocclusions, published in Dental Cosmos in 1899. The Angle classification system relates the mesiobuccal cusp tip of the maxillary first molar to the mesiobuccal groove of the mandibular first molar. The system consists of four distinct classes: normal Class I occlusion, Class I malocclusion, Class II malocclusion and Class III malocclusion. A Class I malocclusion is defined as a normal molar relationship, whereby the mesiobuccal cusp tip of the maxillary first molars occludes in the mesiobuccal groove of the mandibular first molar, with the presence of tooth malpositions and/or rotations. A Class II malocclusion is defined as a distal position of the mandibular first molar relative to the maxillary first molar. A Class III malocclusion consists of a mesial position of the mandibular first molar relative to the maxillary first molar. Angle advocated the use of elastics to obtain a Class I occlusion and opposed extractions despite negative consequences to facial esthetics. The Angle terminology is still the most widely accepted classification system in use today. $^{26}$

\section{The Occlusal Plane: An Overview}

The concept of a normal occlusion stimulated a shift in orthodontic goals from simple tooth alignment to correction of the occlusion. Normal occlusion lead to the idea of a line of occlusion. Angle defined the line of occlusion as a catenary curve ${ }^{26}$. In the maxilla the line of occlusion passes through the central fossae of each molar and across the cingulum of the anterior teeth. In the mandible, the line of occlusion passes through the buccal cusps and incisal edges of 
the dentition. The line of occlusion represents the interface of the maxillo-mandibular complex. This interface is multi-dimensional as represented by the curve of Spee and curve of Wilson within the dentition itself. The multi-dimensional nature of the plane of occlusion is also represented by its orientation within the craniofacial skeleton. To characterize dentofacial characteristics the plane of occlusion must be assessed relative to the sagittal, vertical and transverse planes. Ackerman et al ${ }^{27}$ further suggested the use of the aeronautical rotational terms pitch, roll and yaw to evaluate the spatial orientation of the occlusal plane.

The importance of the occlusal plane is underscored by the abundance of publications within the orthodontic literature. The occlusal plane is evaluated relative to craniofacial form ${ }^{1-3}$, craniofacial growth $^{4}$, masticatory function ${ }^{5,6}$, dental occlusion ${ }^{7,8}$, mechanotherapy ${ }^{9,10}$, orthognathic surgery ${ }^{11-15}$, and in prosthodontic rehabilitation ${ }^{28}$. However, the concept of a cephalometric occlusal plane has received much attention with little regard to a consistent definition or reference plane from which to measure it.

The advent of cephalometrics by Broadbent in $1931,{ }^{29}$ enabled researchers and clinicians to assess craniofacial characteristics. Fundamental to these assessments was to relate the threedimensional line of occlusion to the two-dimensional cephalometric radiograph.

\section{Definition of the Occlusal Plane}

Downs was the first to reference the occlusal plane in a cephalometric analysis designed to evaluate the dentoskeletal profile ${ }^{16}$. Downs defined the occlusal plane as "a line bisecting the occlusion of the first molars and central incisors". Downs also suggested a modified definition of the occlusal plane in cases where the incisors exhibit an obvious infra- or supra-occlusion. In 
such cases the plane is identified through the buccal cusp tips of the first molar and the premolars. This definition was later adopted and referred to as the functional occlusal plane (FOP).

Abraham ${ }^{30}$ defined the FOP as the central reference plane in his "Occlusal Reference System", utilized to evaluate longitudinal craniofacial growth. Abraham stated that the FOP "located by inspection, approximates the occlusal surfaces, in functioning relation, of the maxillary and mandibular first and second deciduous molars and first permanent molars or the first and second premolars and first permanent molars". Jenkins ${ }^{31}$ had previously defined the occlusal plane as "the average occlusal plane of the buccal teeth, including the canine and first permanent molar". Ricketts ${ }^{32}$ stated a similar definition for the occlusal plane as "the overlap of buccal occlusion".

Traditionally, either the bisected occlusal plane or the functional occlusal plane is used, arbitrarily, in various cephalometric analyses and studies evaluating craniofacial growth and form. However, some studies evaluate the maxillary or mandibular plane individually. These studies define the occlusal plane as a line connecting the mesiobuccal cusp tip of the maxillary first molar to the incisal tip within its respective arch. Wolford et al. ${ }^{26}$ defines the functional occlusal plane as a line tangent to the cusp tips of the lower premolars and the buccal groove of the second molar ${ }^{1126}$. In addition, several studies separate the maxillary occlusal plane into anterior and posterior components due to the presence of a curve of Spee ${ }^{2,4}$.

The glossary of prosthodontic terms defines the occlusal plane as "the average plane established by the incisal and occlusal surfaces of the teeth. Generally, it is not a plane but represents the planar mean of the curvature of these surfaces" ${ }^{33}$. Di Paolo ${ }^{34}$ described an 
individualized approach to identifying the occlusal plane that requires the use of the quadrilateral analysis; an evaluation of the skeletal pattern of the lower face.

\section{The Occlusal Plane in Cephalometrics}

In addition to the variability in which the occlusal plane is defined, the reference plane from which the inclination is measured in the various cephalometric analyses also varies. The two most common reference planes are the Frankfort horizontal plane and the sella-nasion plane. Frankfort horizontal is identified by a line connecting porion to orbitale.

The Downs analysis evaluates the inclination of the occlusal plane with reference to the Frankfort horizontal plane. Downs reports the inclination of the occlusal plane, in subjects he determined to exhibit an excellent clinical occlusion, to have a mean of $9.3^{\circ}$, with a range of $1.5^{\circ}$ to $14^{\circ}{ }^{16}$. His analysis also utilized the occlusal plane to evaluate incisor inclination. The lower incisor to occlusal plane angle showed a range of $3^{\circ}$ to $20^{\circ}$ with a mean of $14.5^{\circ}{ }^{16}$. The Steiner analysis evaluates the FOP relative to the sella-nasion cranial base reference plane. Steiner reports the average inclination of the occlusal plane relative to sella-nasion in patients with normal occlusions is $14^{\circ}{ }^{35}$.

Ricketts noted that the vertical position of the occlusal plane has a relationship to the $\mathrm{Xi}$ point of the mandible posteriorly and stomion (the point of contact of the upper and lower lips) anteriorly ${ }^{32}$. The Xi point is defined by Ricketts as the "centroid of the ramus... which approximates the functional center of the mandible as well as the entrance of the mandibular nerve into the mandible" ${ }^{32}$. 
The Wits appraisal is a measurement of the anteroposterior jaw discrepancy that utilizes

the functional occlusal plane as the reference line ${ }^{35}$. Perpendicular lines from point $\mathrm{A}$ and point $\mathrm{B}$ are projected onto the occlusal plane. A measurement is made of the distance between the intersections of each line on the occlusal plane. The Wits appraisal was developed to complement the ANB measurement of sagittal jaw discrepancy.

\section{The Relationship of the Occlusal Plane to Craniofacial Form}

It is well established that a relationship exists between the inclination of the occlusal plane and the various anteroposterior skeletal profiles. ${ }^{3,4,16}$ Studies have shown that steeper occlusal planes are associated with Class II malocclusions whereas flatter occlusal planes are associated with Class III malocclusions ${ }^{4,16}$.

Tanaka and Sato ${ }^{4}$ conducted a longitudinal cephalometric study evaluating the occlusal plane in skeletal Class I, II, and III subjects. The occlusal plane, measured relative to Frankfort horizontal, was identified both conventionally and also separated into anterior (OP (A)) and posterior $(\mathrm{OP}(\mathrm{P}))$ planes. The posterior occlusal plane was found to be significantly steeper in the skeletal Class II group and significantly flatter in the skeletal Class III group beginning at the age of 12 to 14 years. This relationship held constant throughout the age range of 18 to 20 years. At this age the average posterior occlusal plane inclination was $11.3^{\circ} \pm 2.7^{\circ}$ in the Class I group, $13.8^{\circ} \pm 3.3^{\circ}$ in the Class II group and $8.7 \pm 3.3^{\circ}$ in the Class III group.

These findings have been corroborated by other studies. Fushima et al. ${ }^{3}$ studied a group of 50 adult females with Class II, division I malocclusions and showed a strong correlation between the steep inclination of the posterior occlusal plane to a small, retruded and backward 
rotation of the mandible. The steep inclination of the posterior occlusal plane was correlated with a short vertical height of the maxillary second molars. Therefore, the authors suggest that the vertical dimension of the posterior maxilla contributes to the development of various skeletal profiles.

The inclination of the occlusal plane also varies relative to vertical jaw discrepancies. Anwar and Fida ${ }^{17}$ grouped 185 patients into hyperdivergent $\left(\mathrm{SN}-\mathrm{MP}>36^{\circ}\right)$, normodivergent $\left(\mathrm{SN}-\mathrm{MP} 28-36^{\circ}\right)$ and hypodivergent $\left(\mathrm{SN}-\mathrm{MP}<28^{\circ}\right)$ profiles. The study showed statistically significant differences $(\mathrm{p}<.001)$ in the inclination of the occlusal plane $(\mathrm{SN}-\mathrm{OP})$ between the groups. The mean sella-nasion to occlusal plane angle for the groups was: hypodivergent $\left(13.85^{\circ} \pm 4.3\right)$, normodivergent $\left(17.81^{\circ} \pm 9.1\right)$ and hyperdivergent $\left(21.08^{\circ} \pm 3.6\right)$. Therefore, steeper occlusal plane inclinations are associated with the hyperdivergent (long-face) individuals and flatter occlusal plane inclinations are associated with the hypo-divergent (short-face) individuals.

Studies suggest that dentoalveolar compensations in incisor inclinations and occlusal plane inclinations exist to compensate for sagittal jaw discrepancies. Casko and Shepherd ${ }^{18}$ evaluated 75 adult patients in an attempt to examine the skeletal variation that exists in naturally occurring optimal occlusions. He noted that as the ANB angle increased, the inclination of the occlusal plane likewise increased. The variability observed in the inclination of the occlusal plane is described as a compensatory mechanism that exists to attain a Class I dental relationship in the presence of a sagittal jaw discrepancy. ${ }^{2}$ Ishikawa et al. ${ }^{2}$ performed a cephalometric analysis on forty-four adult females with either a skeletal Class I or skeletal Class III jaw relationship, and normal incisor relationships. The study demonstrated a correlation between the sagittal jaw discrepancy (SN-AB) and upper and lower incisor inclinations. The lower incisor 
inclination showed the strongest relationship to the $\mathrm{SN}-\mathrm{AB}$ angle; which led the authors to suggest that the lower incisor inclination is largely attributed to achieving normal incisor relationships when a jaw discrepancy exists. The study also showed a relationship between the inclination of the occlusal plane (SN-OP) and two measurements of sagittal jaw discrepancy (SN-AB and the anteroposterior dysplasia indicator (ADPI)). The authors noted that when the angle $\mathrm{SN}-\mathrm{AB}$ was greater than $84^{\circ}$ the presence of a Class I molar relationship was uncommon. Therefore, if the sagittal discrepancy exceeds certain limits this compensation will be inadequate and a Class I relationship will not be achieved. ${ }^{2}$

\section{Occlusal Plane Alteration in Orthognathic Surgery}

Single-jaw mandibular surgical correction of anteroposterior jaw discrepancies is accomplished by advancement or setback along the occlusal plane of the patient. In cases of vertical maxillary excess or vertical maxillary deficiency, the maxilla can be appropriately positioned superiorly or inferiorly. Autorotation of the mandible then establishes the postsurgical occlusal plane inclination. Although, optimal dental occlusion can be obtained with single-jaw surgery, in some instances facial esthetics and balance is not achieved. ${ }^{36}$

The need to selectively alter the inclination of the occlusal plane to achieve improved facial balance in the surgical correction of dentofacial deformities is advocated ${ }^{11-15,19,37}$. Occlusal plane alteration requires double-jaw surgery and either clockwise or counter-clockwise rotations of the maxillo-mandibular complex. McCollum et al. ${ }^{37}$ suggested increasing the occlusal plane angle in patients with a Class II deep-bite and low mandibular plane angle to achieve optimal esthetic outcomes following orthognathic surgery. The proposed method 
involved posterior maxillary impaction in conjunction with a bilateral sagittal split ramus osteotomy (BSSO) to raise the posterior body of the mandible and an advancement to obtain a Class I dental relationship. The clockwise rotation of the maxillo-mandibular complex permits both optimal dental function and facial esthetics. Reyneke and Evans ${ }^{14}$ demonstrated the esthetic advantages to a deliberate increase in the occlusal plane inclination in patients with Class I, Class II and Class III malocclusions.

Clockwise rotations are shown to remain stable long-term post-surgically. Thus, the method is also advocated for the correction of the Class II open-bite malocclusions, despite the compromise to facial esthetics. Furthermore, the increase in the occlusal plane angle in patients with an initial steep occlusal plane can also result in functional disturbances such as loss of canine and incisal guidance and the introduction of working and balancing interferences. The effects, relative to the face, of clockwise maxillomandibular jaw rotations include the following:

1. The occlusal plane inclination increases.

2. The mandibular plane inclination increases.

3. The chin rotates down and backward, thus

a. Decreasing chin prominence, and

b. Increasing lower facial height.

4. Maxillary incisor inclination decreases.

5. Mandibular incisor inclination increases.

Reyneke ${ }^{15}$ discusses the option to vary the center of rotation to either increase or decrease the effects based on the individual circumstances and desired outcomes.

Rosen ${ }^{13}$ published the results of 11 patients with severe mandibular deficiency that underwent counterclockwise surgical correction of the maxillo-mandibular complex. Counter- 
clockwise rotations involve a deliberate decrease to the occlusal plane inclination. The counterclockwise rotation allowed for a greater advancement of pogonion and preservation of the posterior facial height. Several additional authors ${ }^{11,12,14,15}$ have discussed the need to decrease the occlusal plane inclination in patients with a high-occlusal plane facial type to achieve optimal function and esthetics. Decreasing the occlusal plane inclination facilitates the amount of mandibular chin projection that can be achieved. The effects, relative to the face, of counterclockwise maxillomandibular jaw rotations include the following:

1. The occlusal plane inclination decreases.

2. The mandibular plane inclination decreases.

3. The chin rotates upward and forward, thus

a. Increasing chin prominence, and

b. Decreasing lower facial height

4. Maxillary incisor inclination increases.

5. Mandibular incisor inclination decreases.

The stability of counter-clockwise maxillomandibular jaw rotations is controversial. Traditionally, such a movement of the distal segment of the mandible is considered unstable post-surgically. However, several authors claim stability of counter-clockwise jaw rotations ${ }^{38,}$ 39. Reyneke et al. ${ }^{38}$ compared skeletal stability of patients who underwent deliberate clockwise and counter-clockwise jaw rotations with patients who underwent conventional orthognathic surgery. A total of eighty-eight patients were included and were recalled within 6-60 months post-surgery to assess stability. Skeletal stability between the groups was determined to be statistically insignificant. Chemello et al ${ }^{39}$ demonstrated skeletal stability at an average of 21 
months post-surgically in group of forty-one patients who underwent either surgical increase or decrease of the occlusal plane inclination.

The surgical increase or decrease of the occlusal plane is an attempt to "normalize" the occlusal plane in low occlusal plane and high occlusal plane facial types. The overall objective is not to conform to a norm, but to maximize facial harmony.

\section{Natural Head Position and Cephalometrics}

The advent of cephalometrics enabled researchers and clinicians to assess craniofacial characteristics. Downs was the first to propose a cephalometric analysis designed to evaluate the dentoskeletal profile. ${ }^{1}$ The Down's analysis stimulated a plethora of cephalometric analyses to evaluate characteristics of the craniofacial skeleton and aid in orthodontic diagnosis and treatment planning. Numerous soft ${ }^{2-6}$ and hard tissue ${ }^{1,40}$ cephalometric analyses $^{41-45}$ seek to quantify the features that constitute ideal dentofacial characteristics. These analyses, however, measured relative to internal landmarks and reference planes that were shown to be inherently unreliable for orthodontic treatment planning. ${ }^{46}$

Downs in $1956{ }^{1}$ discussed the large variation $\left(+9^{\circ}\right.$ to $\left.-7^{\circ}\right)$ in the Frankfort horizontal plane when patients were placed in natural head position. Lundstrom and Lundstrom ${ }^{47}$ have shown that both the sella-nasion plane and Frankfort horizontal plane exhibit a large amount of variability as measured to the horizontal plane in both natural head position and natural head orientation. ${ }^{47}$ Furthermore, longitudinal growth studies have shown that the soft tissue profile does not directly reflect changes in the underlying hard tissue profile. ${ }^{48,49}$ In addition, many came to realize that treating patients to dentoskeletal norms does not guarantee an esthetic soft 
tissue outcome. ${ }^{50}$ Therefore, the use of natural head position in cephalometric treatment planning is advocated due to the large degree of variability of intracranial reference planes.

Natural head position (NHP) was defined by Broca ${ }^{51}$ in 1862 as the position of the head when a person is standing and the "visual axis is horizontal". ${ }^{52}$ Lundstrom et al ${ }^{53}$ defines NHP as "the registered, mirror orientated head position in a relaxed body and head posture". NHP contrasts natural head posture. Natural head posture is a dynamic and variable position depending upon the activity of the person, such as sitting or standing. ${ }^{54}$

The strength in the use of natural head position is its reproducibility. Lundstrom and Lundstrom ${ }^{55}$ evaluated the reproducibility of NHP using pretreatment lateral photographs and cephalometric radiographs. A plumb line identified the true vertical on the photograph, and is then transferred to the lateral ceph. A reproducibility of NHP between the two photographs of $2^{\circ}$ was demonstrated. When compared to the variability of the intracranial reference planes, sellanasion (SD. 5-5.6), basion-nasion (SD of 4.5 -5.0), and porion-orbitale (SD of 4.7-5.3) relative to the true horizontal reference line; the use of NHP to establish accurate vertical and horizontal reference lines is supported. ${ }^{55}$

These findings are corroborated by additional studies demonstrating short-term ${ }^{64,65}$ and long-term reproducibility of $\mathrm{NHP}^{56,57}$. Cooke et al. ${ }^{58}$ showed that the method error of NHP after 1 to 2 hours was $1.9^{\circ}$. At the 5 -yr point ${ }^{56}$ and $15 \mathrm{yr}$ point ${ }^{57}$ of a longitudinal study, the method error of NHP was found to be $3.04^{\circ}$ and $2.2^{\circ}$, respectively. Therefore the variance of NHP, which equals the square of the method error, is $3.61^{\circ}, 9.24^{\circ}$, and $4.8^{\circ}$ after $1-2$ hours, 5 years and 15 years, respectively. Therefore, registrations of NHP are significantly less variable than that of intracranial reference planes $\left(25^{\circ}-36^{\circ}\right) .{ }^{57}$ 
It has been noted by researchers that certain individuals will habitually assume a NHP that may be either flexed or extended. It is therefore recommended that in these instances the clinician should make the appropriate adjustments. Lundstrom and Lundstrom ${ }^{47}$ define Natural Head Orientation (NHO) as "the head orientation of the subject perceived by the clinician, based on general experience, as the NHP in a standing, relaxed body and head posture, when the subject is looking at a distant point at eye level". The use of NHO is shown to be valid and reproducible. ${ }^{53}$

The upright head position described by Andrews ${ }^{23}$ is an adjusted natural head position that is equivalent to Lundstrom and Lundstrom's description of natural head orientation. For purposes of this study, the term NHP will be assumed to be the clinician's adjusted natural head position.

\section{Evaluating Facial Attractiveness}

Facial esthetics is considered an essential goal in orthodontic treatment planning. Factors such as complexion, hair-style and color, and eye color have been attributed to influence perceptions of facial attractiveness. Despite their significance, these factors cannot be controlled. Therefore, the clinician's focus in treatment planning for facial esthetics is to obtain optimal dento-facial harmony. This is accomplished by evaluating facial profile harmony. A study by Spyropoulos and Halazonetis ${ }^{59}$ attempted to evaluate the relative importance of the soft tissue profile in ratings of facial attractiveness. Profile photographs of twenty female orthodontic patients were scanned, digitized and warped to conform to the average outline of the original twenty photographs. Ratings of facial attractiveness were assessed on the twenty original photographs, the twenty warped photographs, and three additional photographs that represented 
the average outline, each with a different hairstyle. The authors concluded that soft tissue outline form did influence ratings of facial attractiveness. The warped images were rated higher than the non-warped images. However, the improvement in the rating was not as high as the composite images. Therefore, the authors concluded that there are factors in addition to profile form that influence perceptions of facial attractiveness. ${ }^{59}$

Harmony can be related to the divine proportion, also called the golden ratio $(1.618: 1){ }^{60}$ This proportion is universal concept that applies to nature as well as the human face and body. ${ }^{60}$ One study evaluated the divine proportion and ratings of facial attractiveness in fifty females, deemed to have acceptable profiles. ${ }^{70}$ Although none of the subjects conformed to the ideal divine proportion, subjects with higher esthetic scores did have proportions closer to the divine proportion for the vertical ratios; trichion-menton: trichion-subnasale and trichion-mention: nasion-menton. ${ }^{61}$ Although it can be argued that facial attractiveness is subjective, the significance of proportion cannot be denied.

\section{The Six Elements of Orofacial Harmony}

The Andrews ${ }^{\circledR}$ Six Elements Orthodontic Philosophy ${ }^{\mathrm{TM}}{ }^{23}$ attempts to overcome the shortcomings of traditional cephalometric analyses by proposing a complete analysis unique to each individual. The Six Elements of Orofacial Harmony ${ }^{\mathrm{TM}}$ is defined by Lawrence F. Andrews as "six characteristics (within dentistry's milieu) that are essential for optimal orofacial health and appearance" 23 . The six characteristics include Element I: dental arch shape and length; Element II: anteroposterior jaw positions; Element III: buccolingual jaw positions; Element IV: superoinferior jaw positions; Element V: pogonion prominence and Element VI: dental 
occlusion. Andrews established a set of objectives, goals, landmarks and referents to define the optimality of each element. The Six Elements ${ }^{\mathrm{TM}}$ allows for a comprehensive classification system representing the position of both the teeth and the jaws. Andrews suggests that each Element be "uniquely correct for each person" ${ }^{23}$. This classification system differs from traditional analyses; in that the position of the jaws and teeth are not based on cephalometric norms.

Unique to the Six Elements is the evaluation of the lateral smiling profile. Andrews noted that a relationship exists between the forehead prominence and inclination and the AP position of the maxillary central incisor in patients with harmonious profiles. This relationship can be used to construct a frontal plane, the Goal Anterior Limit Line (GALL), to judge the optimal AP position of the jaws. A recent study confirmed that $91 \%$ of the individuals with a good to excellent facial profile fall within the GALL and FA point of the forehead. ${ }^{62}$ Schlosser et al. ${ }^{63}$ reported on the rating of facial attractiveness using the position of the maxillary central incisors with reference to the forehead. These studies support the use of the forehead to determine the AP position of the maxilla; which is fundamental to the Six Elements classification system.

Below is a brief summary of each Element. For a comprehensive guide to the Six Elements of Orofacial Harmony, please refer to the Andrews® Foundation course syllabus ${ }^{23}$.

\section{Element I:}

Element I concerns the shape and length of the dental arches. Teeth should be positioned with proper inclination, roots centered in basal bone and a level core line depth (curve of Spee between $0-2.5 \mathrm{~mm})$. The dental arch shape of the mandible is determined by evaluating the bucco-lingual distance between each tooth's facial-axis (FA) point and the WALA Ridge. The 
WALA ridge is the ridge of soft tissue directly superior to the mucogingival junction and is suggested to approximate the center of rotation of each tooth. The buccolingual distance between the FA point and the WALA ridge progressively decreases from posterior to anterior. The distance averages $2.2 \mathrm{~mm}$ at the second molar and $0.1 \mathrm{~mm}$ at the central incisor. A recent study by Ronay et al. has corroborated the relationship between the tooth's FA point and the WALA ridge. The shaping of arch wires to the WALA ridge not only allows the mandibular arch form to be unique for each patient, but is proposed to ensure a stable position relative to the periodontium. The maxillary arch form is then established based on the mandibular arch form.

The lateral cephalometric radiograph is essential to the evaluation of Element I. The occlusal plane must first be identified on the lateral cephalogram. The Andrews template is then utilized to determine the proper inclination of the maxillary and mandibular central incisors with the roots centered in basal bone. The template incisor inclination relative to the occlusal plane ensures an optimal inclination $\left(7^{\circ}\right.$ for the maxillary incisor and $-1^{\circ}$ for the mandibular incisor) relative to the dental arch's perimeter line.

A 2" x 3" acetate overlay is placed over the maxilla and secured. The occlusal plane and outline of the maxilla is traced on the acetate overlay. The occlusal plane of the Andrews template is superimposed on the occlusal plane of the patient, and the Element I maxillary incisor is drawn once the template incisor root is centered in maxillary basal bone. A second piece of acetate paper is then placed over the body of the mandible. The occlusal plane, outline of the mandible and the Element I mandibular incisor is also traced as described for the maxilla. Measurement of the distance between the FA point of the original incisor and the Element I incisor is recorded. 
An evaluation of Element I requires an analysis of the core discrepancy (crowding). Calculations must be made to determine the effects that leveling the curve of Spee, uprighting the molars, expanding the maxilla and proclining/retroclining the incisors will have on the core discrepancy. These effects are then recorded as the interim core discrepancy (ICD). For example, leveling the curve of Spee will require space within the arch and thus will ultimately decrease the space available within the arch and increase the ICD. Proclining incisors to an optimal Element I position, centered in basal bone will increase the space available within the arch and decrease the ICD. A negative ICD indicates crowding, whereas a positive ICD indicates spacing. The ICD is then utilized for treatment decisions; such as the need for space closure, extractions, interproximal reduction or an alternative compromise treatment.

\section{Element II:}

An evaluation of the anteroposterior position of the jaws is the objective of Element II. The Goal Anterior Limit Line (GALL) represents the frontal plane of the head, and is identified based on an evaluation of the forehead shape and inclination. Three forehead shapes predominate; straight, round and angular. The forehead points, trichion, superion, glabella and the foreheads facial axis point, are identified for the patient based on forehead shape. The distance between the face anterior limit line (FALL) and the dentition's anterior limit line (DALL) is evaluated clinically with the patient in the upright head position and recorded. The FALL is a line passing through the FFA point of the forehead that parallels the frontal plane of the head. The DALL is a line passing through the FA point of the maxillary incisor that parallels the frontal plane of the head. The angular measurement determined by the forehead inclination (superion and/or trichion to glabella) relative to the FALL is recorded. The FALL is equivalent 
to the GALL with a forehead inclination equal to or less than $+7^{\circ}$. For every degree beyond $+7^{\circ}$, the GALL lies $0.6 \mathrm{~mm}$ anterior to the FALL, without exceeding glabella.

An optimal Element II maxilla requires the FA point of the maxillary central incisor to touch the GALL. The maxilla can be classified as red (prognathic) or black (retrognathic) by measuring the distance from the maxillary incisor FA point to the GALL. An optimal Element II mandible is determined relative to an optimal Element II maxilla, with the teeth in an Element I position and a Key I dental relationship. The mandible can be classified as red (prognathic) or black (retrognathic) by measuring the distance from the optimal Element I and Element II maxillary incisor to the Element I mandibular incisor.

The anteroposterior jaw classification proposed by Andrews represents the jaw discrepancy relative to optimally positioned incisors. This varies from traditional cephalometric assessments which evaluate the jaw positions based on linear measurements or angles of specific jaw landmarks; such as the A point and B point.

\section{Element III:}

Element III is an evaluation of the bucco-lingual (transverse) position of the maxilla relative to the mandible. The mandible represents the basis from which to measure the optimal bucco-lingual position of the maxilla. If a discrepancy exists, the maxilla can be orthopedically or surgically expanded to match the mandibular width. The cusp-cusp and fossa-fossa distances are measured within the maxilla and mandible with the teeth in an Element I position. The distance between FA point of the mandibular posterior teeth and WALA ridge, is used to determine the Element I tooth position. For instance, if the mandibular posterior teeth are inclined to the lingual, the amount of uprighting should be incorporated into the fossa-fossa 
transverse mandibular measurements. Andrews states that the transverse measurement of FA point to FA point should be 2 to $4 \mathrm{~mm}$ greater in the maxillary arch than the mandibular arch.

\section{Element IV:}

The superoinferior position of each jaw is evaluated within Element IV. The measurement from glabella to subnasale (midfacial height) should equal the measurements from subnasal to menton (lower facial height) and condylion to gonion (ramus height). Andrews separates the vertical jaw position, Element IV, into anterior and posterior components within each jaw. The anterior maxilla Element IV is defined as optimal based on appropriate maxillary incisor display in repose. The FA point of the maxillary incisor should be at the same level as the inferior border of the maxillary lip in repose. The anterior mandible Element IV is defined as optimal when the distance from the FA point of the mandibular incisor to hard-tissue menton is equal to one-half the distance of the midfacial height. The posterior maxilla Element IV is considered optimal when the anterior maxilla and mandible are optimal and there is an absence of an anterior or posterior open bite. The posterior mandible Element IV is considered optimal when the ramus height equals midfacial height. The extent of deviation from optimal should be recorded.

To determine the extent that the anterior maxilla Element IV deviates from optimal, the acetate overlay should be released and moved up or down, ensuring that the occlusal plane remains parallel to the original, until the FA point of the maxillary incisor is level with the inferior border of the maxillary lip. If the acetate is moved down the distance is recorded as negative and if moved up the distance is recorded as positive. 
To determine the extent that the anterior mandible Element IV deviates from optimal the difference between one-half the midfacial height and the mandibular incisor FA point to menton is recorded. If the anterior mandible is less than or greater than the midfacial height this number is recorded as a negative number or positive number, respectively. The anterior mandible Element IV can be corrected surgically.

To determine the extent of deviation from optimal for the posterior Element IV, the mandibular acetate overlay should be extended to include the condyle. The overlay should then be rotated until the amount of incisor overbite is corrected. The maxillary overlay should be released and the occlusal planes should then be superimposed. The distance of the original posterior position to the new position should be recorded.

The relationship between the anterior and posterior Element IV of the maxilla thus establishes the inclination of the occlusal plane. However, Andrews does not designate an optimal inclination for the occlusal plane.

\section{Element V:}

Element $\mathrm{V}$ concerns an evaluation of hard-tissue pogonion prominence. Element $\mathrm{V}$ is defined as optimal based on a pogonion prominence that lies on a line $90^{\circ}$ to the occlusal plane that passes through the FA point of the Element I mandibular incisor. The amount of deviation anterior or posterior to this line is recorded as positive or negative, respectively.

\section{$\underline{\text { Element VI: }}$}

The Six Keys to Optimal Occlusion is the basis for Element VI. When all six keys are present, with the mandible in centric relation and functional excursions include canine disclusion, Element VI is considered optimal. In 1967, Lawrence F. Andrews published The Six Keys to Normal Occlusion, ${ }^{64}$ which he later referred to as the Six Keys to Optimal Occlusion. 
Andrews studied 120 dental casts with optimal occlusions to assess if there were any universal characteristics. Within these casts variability did exist, however, the constancy of features are defined as Key; I) correct interarch relationships; II) correct crown angulation; III) correct crown inclination; IV) absence of rotations; V) tight contacts; and VI) a flat curve of Spee. The characteristics which define an optimal occlusion are now widely accepted.

Andrews' study of optimal dental casts established the basis from which he developed the fully programmed Straight Wire Orthodontic Appliance. Introduction of the preadjusted appliance in conjunction with advances in material science, such as development of nickel titanium wire, revolutionized contemporary orthodontic treatment. 


\section{CHAPTER 3: MATERIALS AND METHODS}

\section{Sample Description}

Study Group:

105 patients were randomly selected from the private orthodontic practice of Dr. Timothy

Tremont, White Oak, PA. Subject selection was based on the following:

Inclusion Criteria:

- Any patient 12 years of age or greater in the permanent dentition.

- A pretreatment lateral cephalometric radiograph taken prior to orthodontic treatment.

Exclusion Criteria:

- Presence of any craniofacial anomalies; eg: Cleft lip and palate.

- Absence of maxillary and/or mandibular first molars.

- Presence of an obvious transverse (right to left) cant of the maxilla which would make accurate identification of the occlusal plane difficult.

- Presence of obvious mentalis strain on the lateral cephalometric radiograph.

- Inability to visual soft-tissue profile on the lateral cephalometric radiograph.

- Any previous orthodontic treatment. 


\section{Research Design}

Overview

IRB approval for the use of human research subjects was obtained prior to the start of this study (Appendix A). A lateral cephalometric radiograph was obtained for each research subject and scanned using an Epson Scan.Ink scanner (Long Beach, CA, USA) at 300 dpi. The FALLDALL measurement was obtained from the corresponding patient record. The lateral cephalometric radiograph was digitized utilizing the Dolphin Imaging Software Version 10.5. (Chatsworth, CA, USA) Once digitized, the lateral cephalometric radiograph was printed at a 1:1 ratio on HP Premium Photo Paper (Palo Alto, CA, USA). The GALL was constructed utilizing the FALL-DALL measurement as described by Andrews. ${ }^{23}$ (Fig. 1). The GALL represents the true frontal plane of the head from which a true horizontal was constructed via a perpendicular to the GALL. All linear measurements were measured with a Neiko Platinum Series digital LCD caliper and recorded to the nearest $0.1 \mathrm{~mm}$. All angular measurements were measured with the (C) 1996 Lawrence F. Andrews Foundation protractor (San Diego, CA, USA) and recorded to the nearest $0.5^{\circ}$. The occlusal plane inclination was measured relative to the $\mathrm{TH}$ (Fig. 2).

The sample of 105 was divided into three anteroposterior groups (Class I, II, and III) according to the ANB angle. Class I subjects were those with an ANB angle from $0-5^{\circ}$. Class II subjects were those with an ANB angle $>5^{\circ}$. Class III subjects were those with an ANB angle $<$ $0^{\mathbf{o}}$

The sample was also divided into three anteroposterior groups (Category I, II, and III) based on jaw base differences evaluated with the Six Elements measurements (Element II Mx and Element II Md). Please refer to table 1 and figures 5 and 6 for an explanation of the Six 
Elements. Category I subjects were those with jaw positions (II Mx and II Md) $\pm 2 \mathrm{~mm}$ of each other. Category II subjects were those with an Element II Md positioned posteriorly $>2 \mathrm{~mm}$, relative to the Element II Mx. Category III subjects were those with an Element II Md positioned anteriorly $>2 \mathrm{~mm}$, relative to the Element II Mx.

The sample was divided into vertical groups based on the measure of SN-MP. Subjects were considered normodivergent with a $\mathrm{SN}-\mathrm{MP}^{\circ}$ from $28-36^{\circ}$. Subjects were considered hypodivergent with a $\mathrm{SN}-\mathrm{MP}^{\circ}<28^{\circ}$ and hyperdivergent with a $\mathrm{SN}-\mathrm{MP}^{\circ}>36^{\circ}$.

Subjects were divided into groups based on soft tissue facial convexity (G'-Sn'-Pog'). Subjects were grouped as normal based on a G'-Sn'-Pog’o $165-175^{\circ}$. Subjects were grouped as convex based on a G'-Sn'-Pog' ${ }^{\circ}>175^{\circ}$. Subjects were grouped as concave based on a G'-Sn'$\operatorname{Pog}{ }^{\circ}<165^{\circ}$

\section{Methodology}

\section{Construction of the GALL and True Horizontal (TH)}

The patient was placed in the upright head position and the lateral smiling profile was used to clinically determine the FALL-DALL measurement. This measurement was confirmed utilizing a novel device, The FP Gauge ${ }^{\mathrm{TM}}$ (Pittsburgh, PA, USA). (Fig. 3) The FALL-DALL measurement and lateral cephalometric radiograph were obtained from the patient record. The GALL was then constructed on the lateral cephalometric radiograph as described by Andrews. ${ }^{23}$ The angular measurement determined by the forehead inclination (superion and/or trichion to glabella) relative to the FALL was calculated. The FALL is equivalent to the GALL with a forehead inclination $+7^{\circ}$ or less. For every degree beyond $+7^{\circ}$, the GALL lies $0.6 \mathrm{~mm}$ anterior to the FALL, not exceeding glabella. The GALL represents a true frontal plane with the patient 
in the adjusted natural head position. True horizontal (TH) was constructed from a line drawn perpendicular to the GALL.

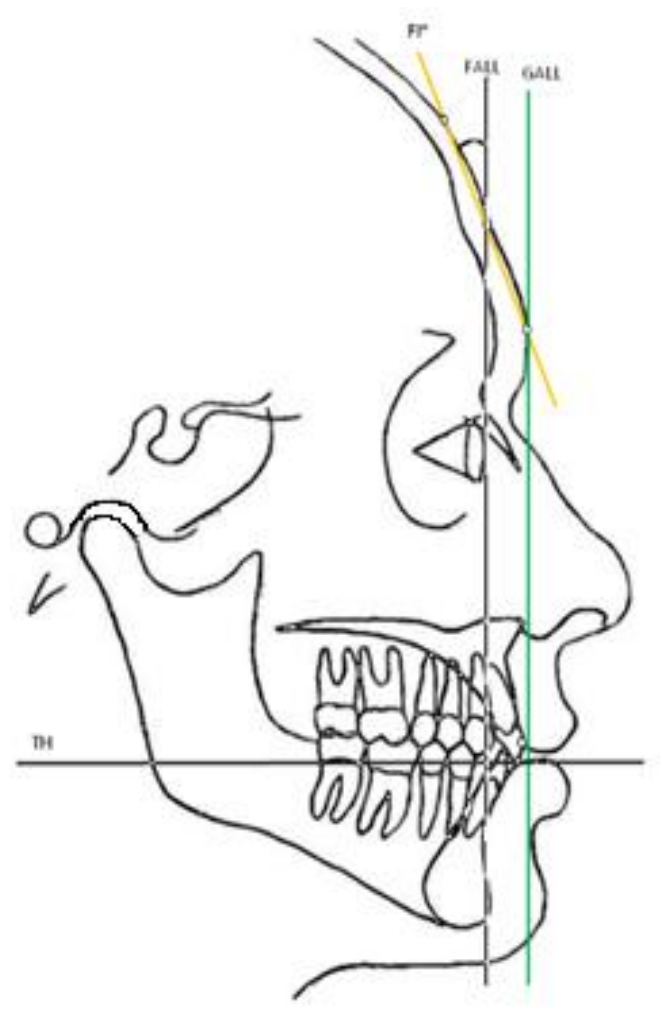

Fig. 1: Construction of the GALL and True Horizontal (TH) 


\section{Identification of the Occlusal Plane}

The occlusal plane was constructed as the functional occlusal plane. The occlusal plane is represented as a line drawn from the distal marginal ridge of the maxillary first permanent molar (MR6) to the distal marginal ridge of the maxillary first premolar (MR4), as described by Andrews. ${ }^{23}$

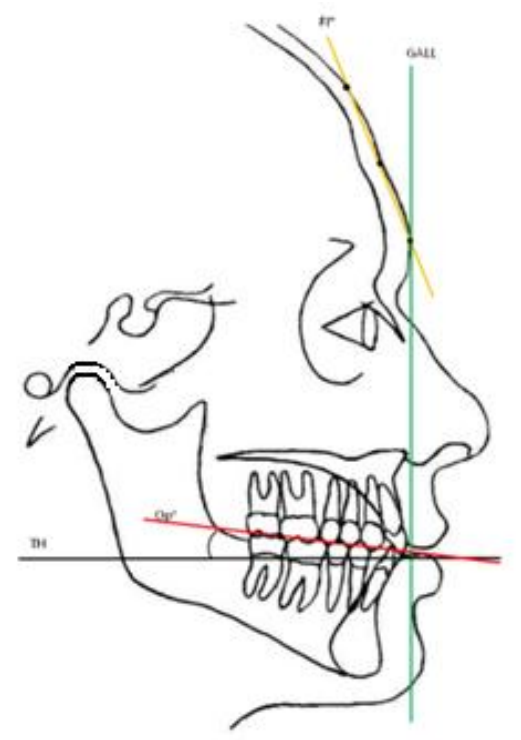

Fig. 2: Identification of the Occlusal Plane

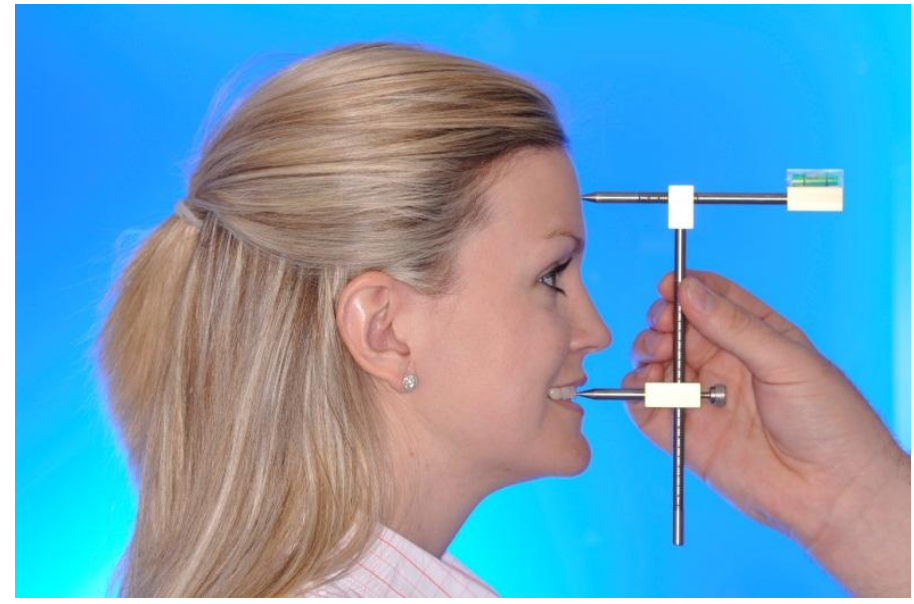

Fig. 3: Demonstration of the FP-Gauge ${ }^{\mathrm{TM}}$ to judge the FALL-DALL measurement 


\section{Cephalometric Analysis}

\section{Landmark Identification:}

The lateral cephalometric radiograph was used for analysis of the cephalometric variables.

Landmark identification (Fig. 4 and Fig. 5), tracings and measurements were completed by a single investigator.

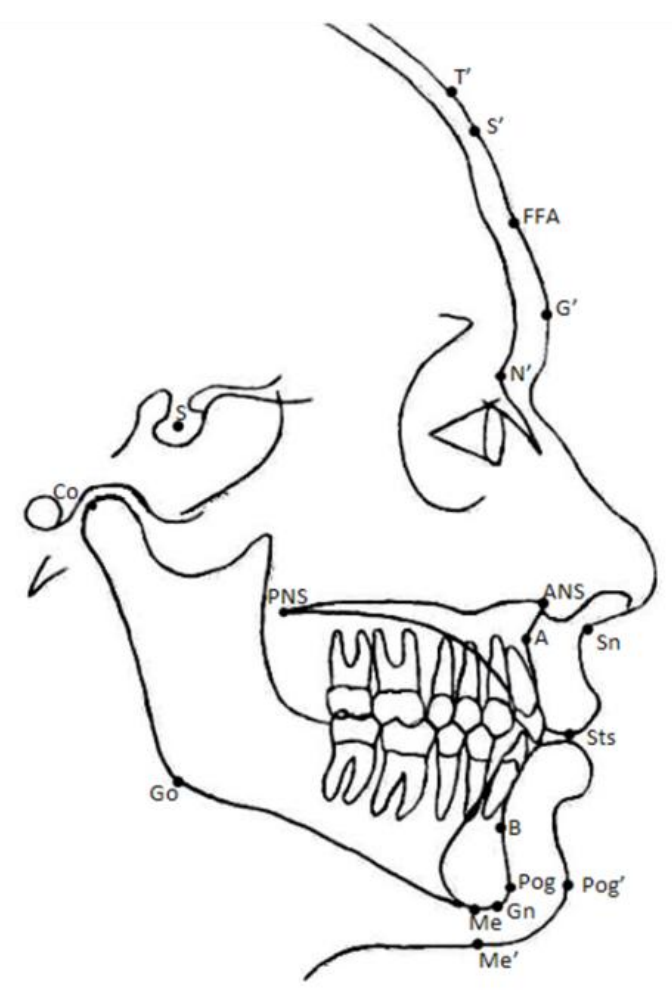

Fig. 4: Hard and Soft Tissue Cephalometric Landmarks 


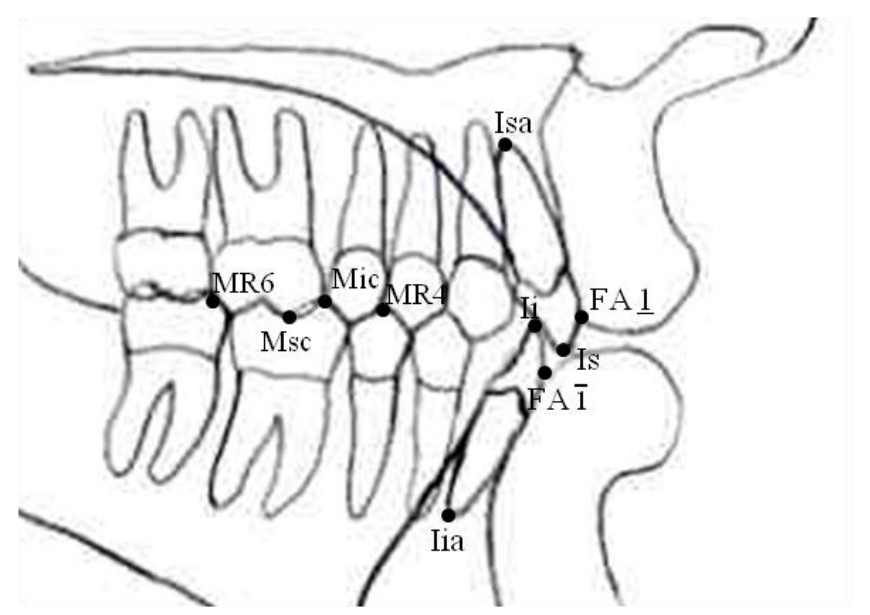

Fig 5: Dental Cephalometric Landmarks

\section{Six Elements Measurements:}

The cephalometric analysis included a measurement of several of Andrew's Six

Elements. For an overview of these measurements please refer to table 1 below.

Table 1: Six Elements Measurements

\begin{tabular}{cl}
\hline Variable & Definition \\
\hline \hline II Mx & $\begin{array}{l}\text { The antero-posterior position of the Element I maxillary central incisor relative to } \\
\text { the GALL; measured in millimeters from the GALL to the Element I maxillary } \\
\text { central incisor FA point. A negative value indicates that the FA point is posterior } \\
\text { to the GALL. A positive value indicates that the FA point is anterior to the } \\
\text { GALL. } \\
\text { The antero-posterior position of the Element I mandibular central incisor } \\
\text { measured relative to an optimal Element I maxillary central incisor and Element } \\
\text { II maxilla. A negative number indicates the measurement in millimeters of } \\
\text { overjet. A positive number indicates the measurement in millimeters of anterior } \\
\text { crossbite. }\end{array}$ \\
TV Mx Ant & $\begin{array}{l}\text { The vertical position of the anterior maxilla. Measured as the vertical distance of } \\
\text { the FA point of the Element I maxillary central incisor relative to Sts. A positive } \\
\text { number indicates that the FA point is more inferior to Sts. A negative number } \\
\text { indicates that the FA point is more superior to Sts. }\end{array}$ \\
IV Md Ant & $\begin{array}{l}\text { The vertical position of the anterior mandible. Measured as the vertical distance } \\
\text { from the FA point of the Element I mandibular central incisor to Me. }\end{array}$ \\
& $\begin{array}{l}\text { Pogonion Prominence. The distance between Pog to a line formed tangent to the } \\
\text { FA pt of an Element I mandibular central incisor and perpendicular to the } \\
\text { occlusal plane. }\end{array}$ \\
\hline
\end{tabular}


Element II was recorded by utilizing the (C) 1996 Lawrence F. Andrews Foundation tracing template, superimposed on the occlusal plane to draw a hypothetically positioned Element I maxillary and mandibular incisor. The Element II position of the maxilla was measured as a linear distance from the FA point of the Element I maxillary incisor to the GALL. A positive measurement was recorded with the FA point anterior to the GALL. A negative measurement was recorded with the FA point posterior to the GALL. (Fig. 6)
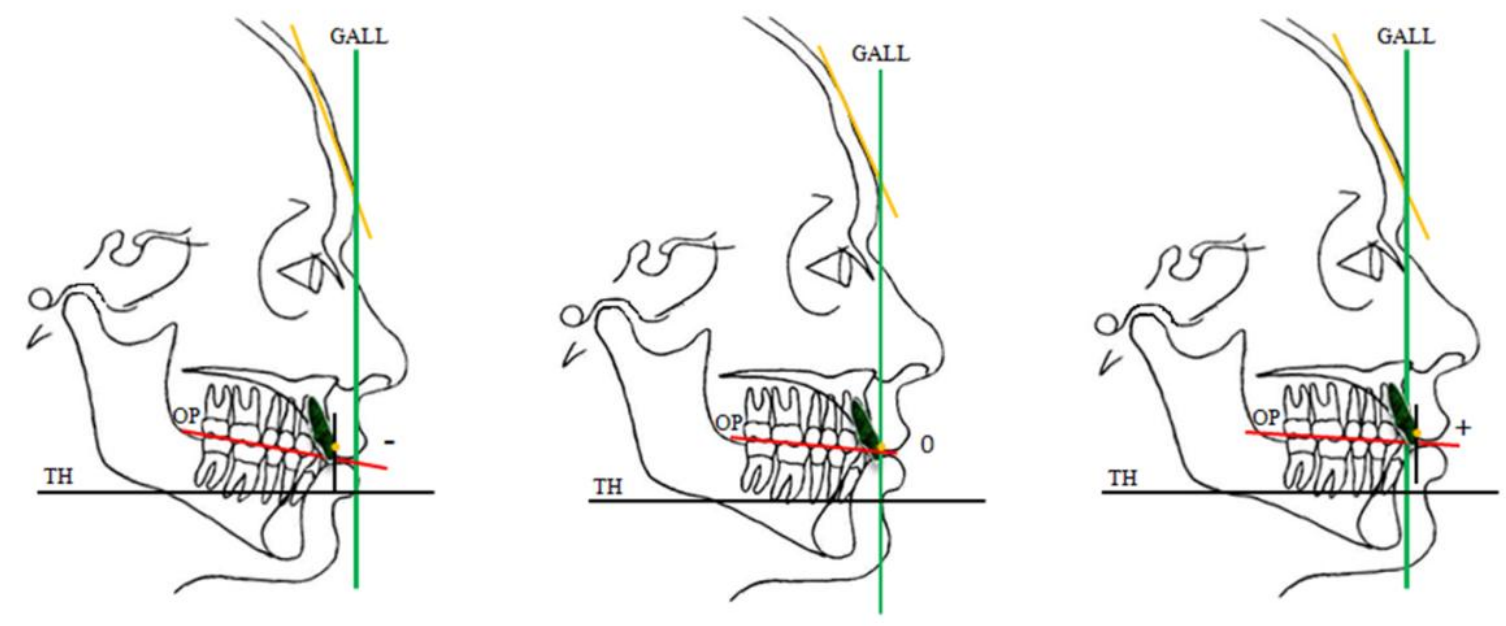

Fig. 6: Illustration of Element II Mx 
The Element II position of the mandible was recorded as the AP distance of the Element I mandibular central incisor measured relative to an optimal Element I maxillary central incisor and Element II maxilla. A negative number indicates the measurement in millimeters of overjet. A positive number indicates the measurement in millimeters of anterior crossbite. (Fig. 7)
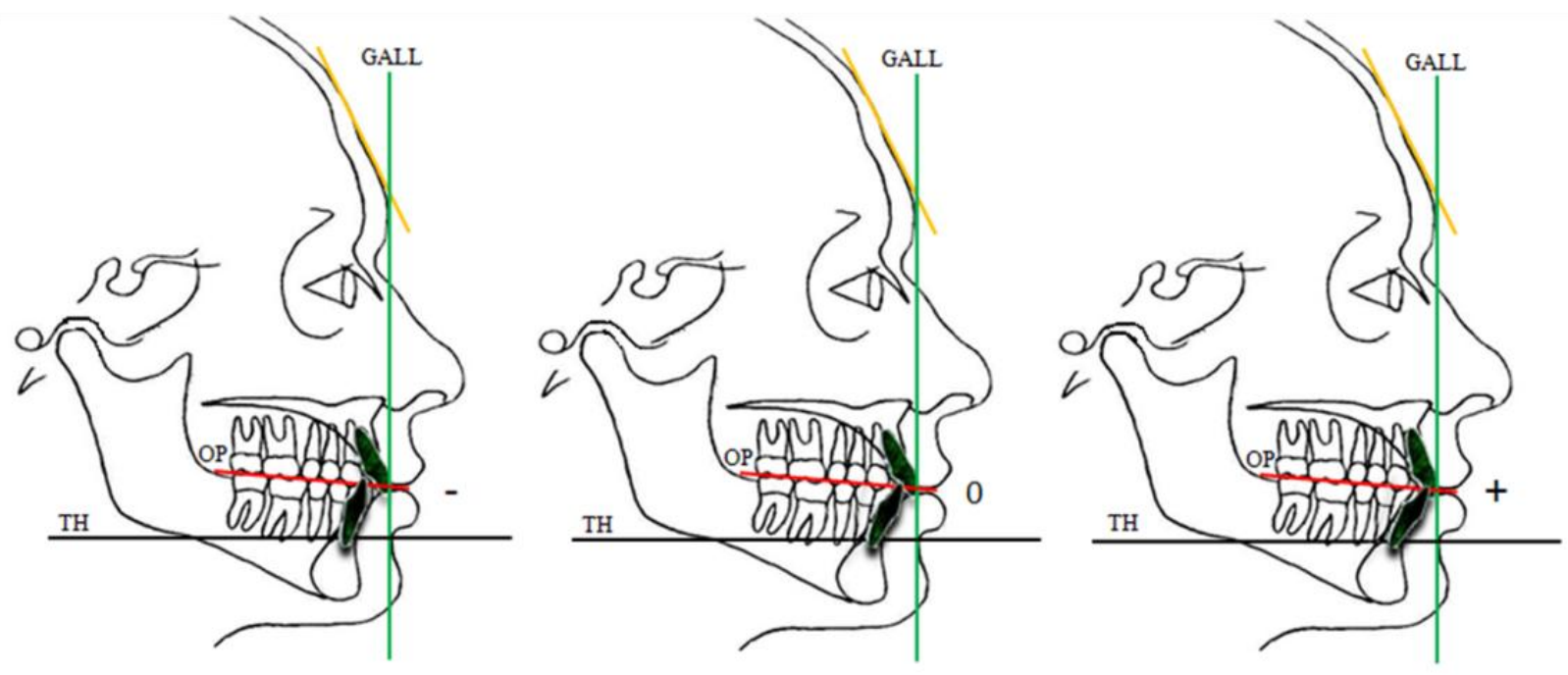

Fig. 7: Illustration of Element II Md

Element IV Max Ant is the vertical position of the anterior maxilla. It was measured as the vertical distance of the FA point of the Element I maxillary central incisor relative to Sts. A positive number indicates that the FA point is more inferior to Sts. A negative number indicates that the FA point is more superior to Sts. (Fig. 8) 

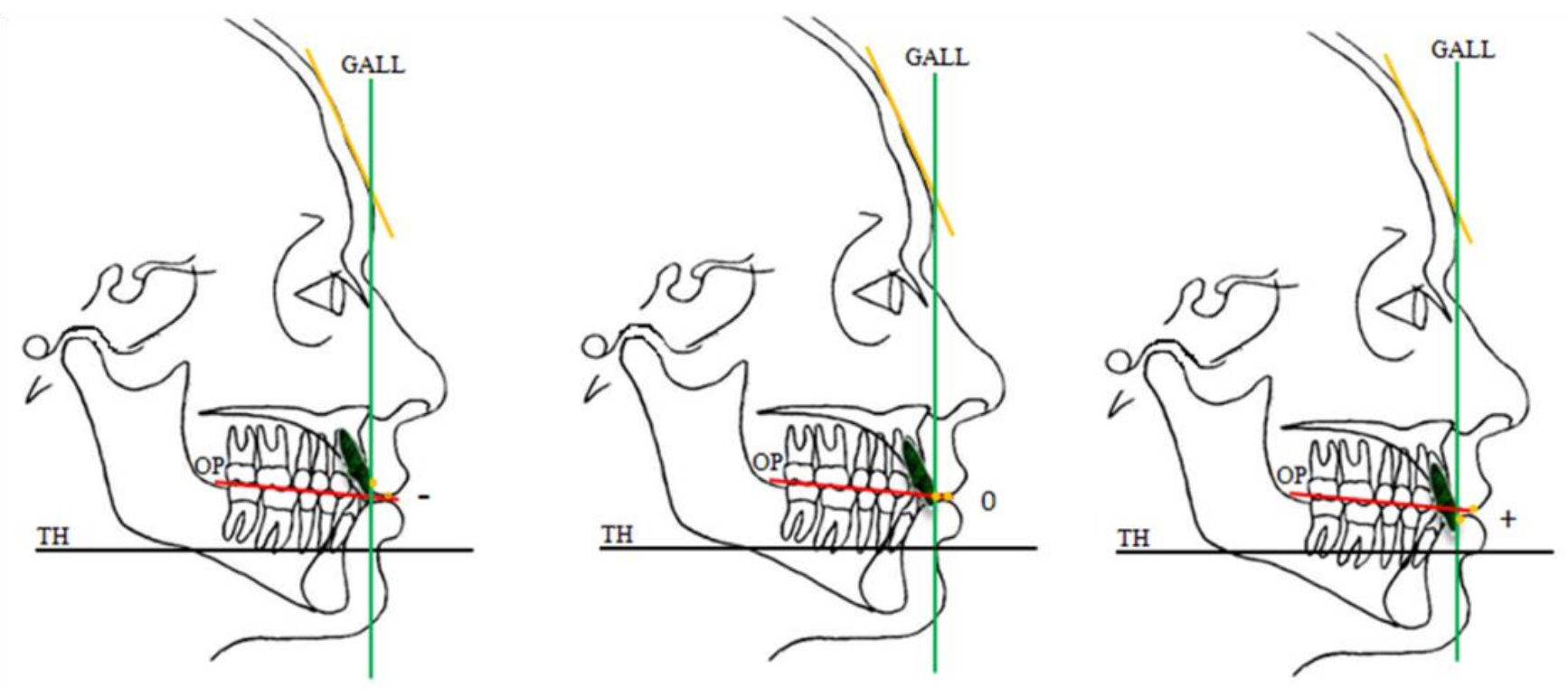

Fig. 8: Illustration of Element IV Mx Ant

Element IV Md Ant is the vertical position of the anterior mandible. It was measured as the vertical distance from the FA point of the Element I mandibular central incisor to Me. (Fig.

9)

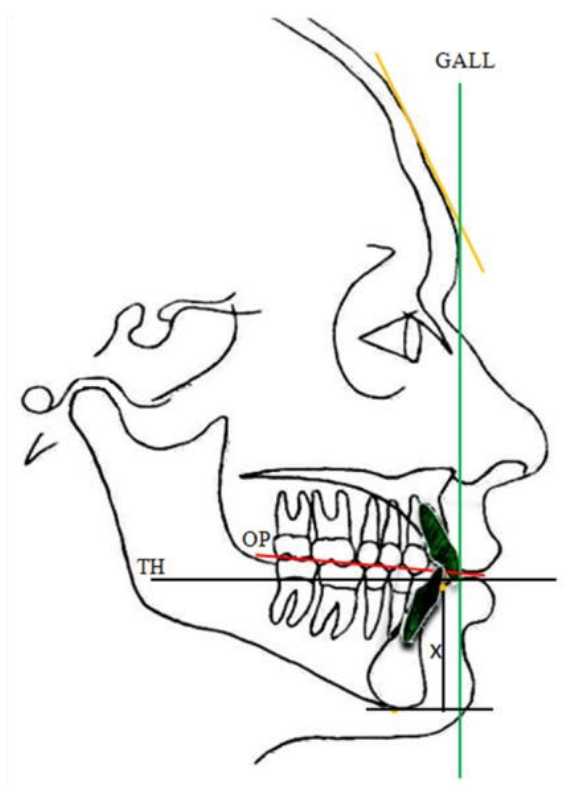

Fig. 9: Illustration of Element IV Md Ant 
Element $\mathrm{V}$ is the pogonion prominence, and is a measure of the prominence of the hard tissue chin. It was measured as the distance between Pog to a line formed tangent to the FA pt of an Element I mandibular central incisor and perpendicular to the occlusal plane. (Fig. 10)
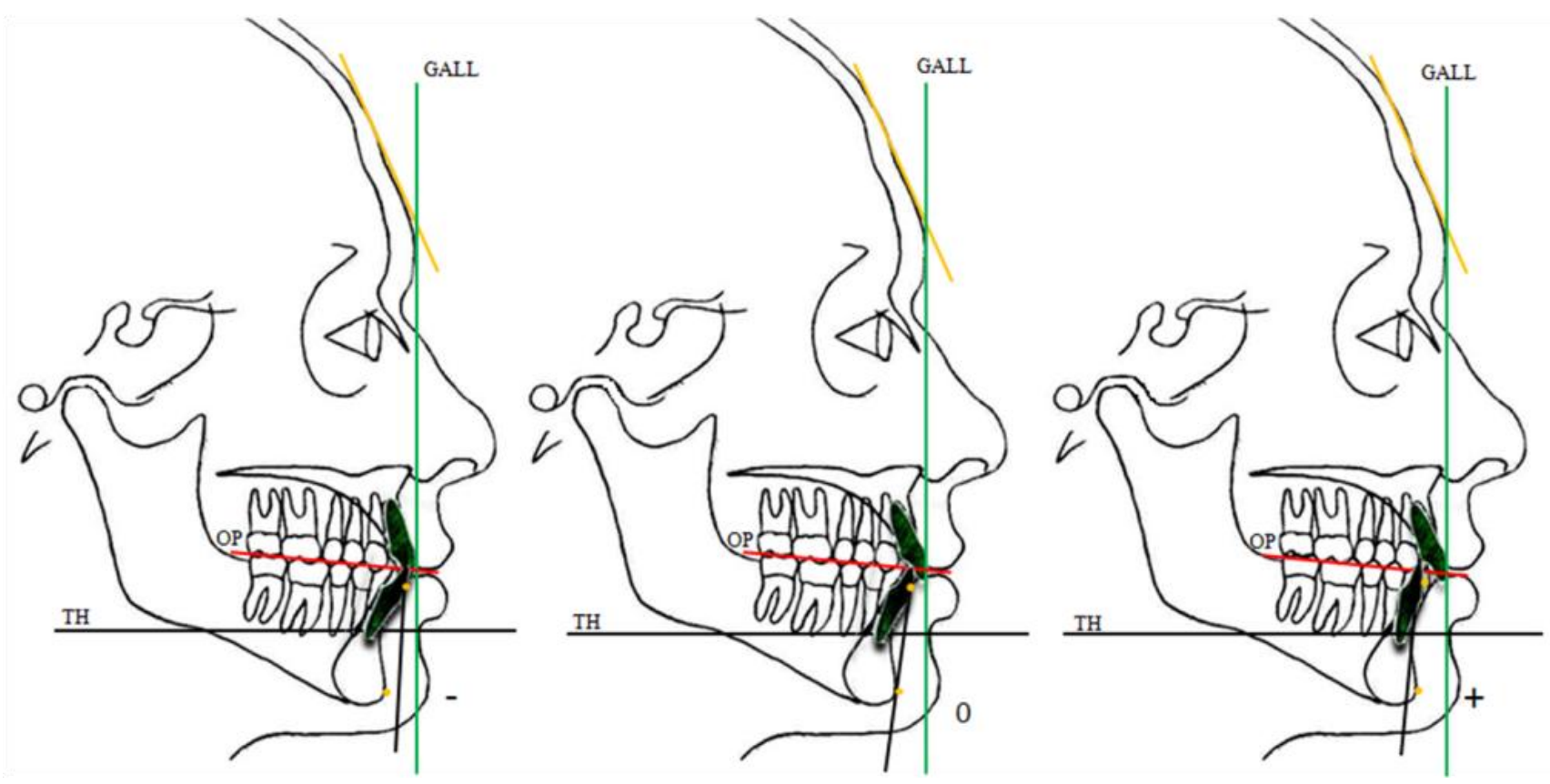

Fig. 10: Illustration of Element V

Angular Measurements:

The angular cephalometric measurements (Table 2) were measured utilizing @ 1996 Lawrence F. Andrews Foundation protractor, and recorded to the nearest $0.5^{\circ}$. These measurements included the inclinations of the $\mathrm{OP}^{\circ}, \mathrm{PP}^{\circ}, \mathrm{MP}^{\circ}, \mathrm{SN}^{\circ}, \mathrm{U}^{\circ}$, and $\mathrm{L}^{\circ}$ measured relative to TH. (Fig. 11A) In addition the gonial angle $\left(\mathrm{Go}^{\circ}\right)$, soft tissue facial convexity convexity $\left(\mathrm{G}^{\prime}-\mathrm{Sn}-\mathrm{Pog}^{\circ}\right), \mathrm{Sn}-\mathrm{Mp}^{\circ}, \mathrm{Op}^{\circ} \mathrm{Sn}^{\circ}, \mathrm{U1}-\mathrm{Op}^{\circ}, \mathrm{L} 1-\mathrm{Op}^{\circ}, \mathrm{SNA}^{\circ}, \mathrm{SNB}^{\circ}$ and $\mathrm{ANB}^{\circ}$ angles were measured (Fig. 11A, B). The reference planes measured relative to $\mathrm{TH}\left(\mathrm{MP}^{\mathrm{o}}, \mathrm{Op}^{\mathrm{o}}\right.$, and $\left.\mathrm{PP}^{\mathrm{o}}\right)$ 
were assigned a positive value for a clockwise rotation (anterior end of plane is inferior) and a negative value for an anticlockwise rotation. $\mathrm{SN}^{\circ}$ was assigned a positive value for an anticlockwise rotation.

Table 2: Angular Cephalometric Measurements

\begin{tabular}{|c|c|}
\hline Variable & Defintion \\
\hline $\mathbf{S N A}^{\circ}$ & The position of the maxilla relative to the cranial base. The angle formed by Sella-Nasion-Point A \\
\hline $\mathbf{S N B}^{\circ}$ & The position of the mandible relative to the cranial base. The angle of Sella-Nasion-Point B \\
\hline $\mathbf{A N B}^{\circ}$ & The relative position of the maxilla to the mandible. The difference between SNA and SNB \\
\hline G'-Sn'-Pog $^{\circ}$ & Soft tissue angle of convexity \\
\hline SN-MPo & The angular measurement of the sella-nasion to mandibular plane \\
\hline $\mathbf{S N}^{\circ}$ & The inclination of the sella to nasion plane relative to $\mathrm{TH}$ \\
\hline Op-Sn ${ }^{o}$ & The angular measurement of the occlusal plane to the sella-nasion plane \\
\hline $\mathbf{M P} \mathbf{P}^{\circ}$ & Inclination of the mandibular plane measured relative to $\mathrm{TH}$ \\
\hline $\mathbf{O p}{ }^{\circ}$ & Inclination of the occlusal plane measured relative to $\mathrm{TH}$ \\
\hline $\mathbf{P P}^{\circ}$ & The inclination of the palatal plane measured relative to $\mathrm{TH}$ \\
\hline $\mathbf{G o}^{\circ}$ & $\begin{array}{l}\text { The gonial angle measured as the angle of a line tangent to the posterior ramus and the mandibular } \\
\text { plane }\end{array}$ \\
\hline $\mathbf{U} 1^{\circ}$ & Inclination of long axis of an Element I maxillary central incisors measured relative to $\mathrm{TH}$ \\
\hline $\mathbf{L} 1^{\circ}$ & Inclination of long axis of an Element I mandibular central incisors measured relative to TH \\
\hline $\mathbf{U} 1-\mathbf{O p} \mathbf{p}^{\mathbf{2}}$ & The angular measurement of the maxillary central incisor to the occlusal plane \\
\hline L1 - Op ${ }^{o}$ & The angular measurement of the mandibular central incisor to the occlusal plane \\
\hline
\end{tabular}

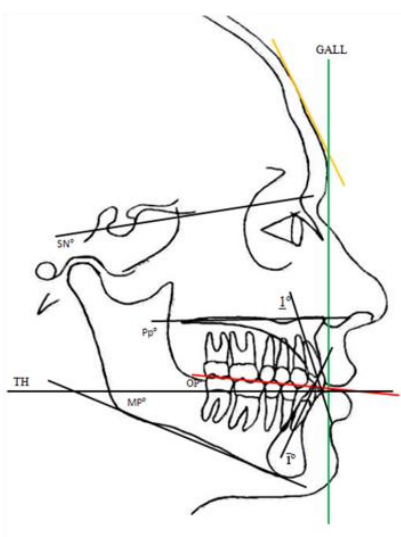

A.

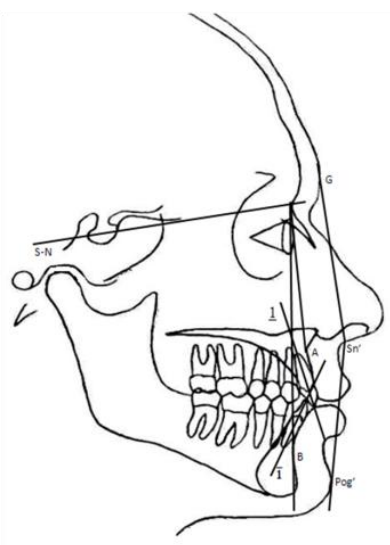

B.

Fig. 11: Angular cephalometric measurements 


\section{Linear Measurements:}

The linear cephalometric measurements (Table 3) were measured using a Neiko Platinum Series digital LCD caliper and recorded to the nearest 0.1 millimeter. Soft and hard tissue vertical facial heights were recorded (Fig. 12). The anteroposterior position of the hard tissue and soft tissue chin was measured relative to Andrew's GALL (Fig. 13) and Arnett's TVL (Fig. 14,); Pog'-GALL, Pog-GALL, and Pog'c-GALL, TVL-Pog. The vertical eruption of the maxillary and mandibular first molars and maxillary and mandibular central incisors were recorded; PP-Msc, MP-Mic, PP - $\underline{\mathrm{U} 1}$, and MP-L1 (Fig. 15).

Table 3: Linear Cephalometric Measurements

\begin{tabular}{|c|c|}
\hline Variable & Definition \\
\hline \multicolumn{2}{|l|}{ Soft Tissue } \\
\hline $\mathbf{G}^{\prime}-\mathbf{M e}^{\prime}$ & Soft tissue total facial height \\
\hline$G^{\prime}-\mathbf{S n} \mathbf{n}^{\prime}$ & Soft tissue upper anterior facial height \\
\hline Sn'-Me' & Soft tissue lower anterior facial height \\
\hline Pog-GALL & $\begin{array}{l}\text { Anteroposterior position of hard tissue pogonion. The distance in millimeters of hard tissue } \\
\text { pogonion } \\
\text { realtive to the GALL measured parallel to TH }\end{array}$ \\
\hline Pog'-GALL & $\begin{array}{l}\text { Anteroposterior position of soft tissue pogonion. The distance in millimeters of soft tissue } \\
\text { pogonion } \\
\text { relative to the GALL measured parallel to TH }\end{array}$ \\
\hline Pog'c-GALL & $\begin{array}{l}\text { Distance in millimeters of the corrected soft tissue pogonion to the GALL, determined by the } \\
\text { deviation from an } \\
\text { optimal Element V (Pog'C-GALL = Pog'-GALL - Element V) }\end{array}$ \\
\hline \multicolumn{2}{|l|}{ Hard Tissue } \\
\hline N-ANS & Hard tissue upper anterior facial height \\
\hline N-Me & Hard tissue total facial height \\
\hline ANS-Me & Hard tissue lower anterior facial height \\
\hline Co-Go & Posterior facial height as defined by Andrews \\
\hline S-Go & Hard tissue posterior facial height \\
\hline Co-GN & Mandibular length measured from condylion to gnathion \\
\hline \multicolumn{2}{|l|}{ Dental } \\
\hline PP-U1 & $\begin{array}{l}\text { Vertical height of the maxillary central incisor measured as a linear distance from the palatal } \\
\text { plane }\end{array}$ \\
\hline PP-Mic & Vertical height of maxillary first measured as a linear distance from the palatal plane \\
\hline Mp-L1 & $\begin{array}{l}\text { Vertical height of the mandibular central incisor measured as a linear distance from the } \\
\text { mandibular plane }\end{array}$ \\
\hline MP-Mic & $\begin{array}{l}\text { Vertical height of the mandibular first molar measured as a linear distance from the mandibular } \\
\text { plane }\end{array}$ \\
\hline
\end{tabular}




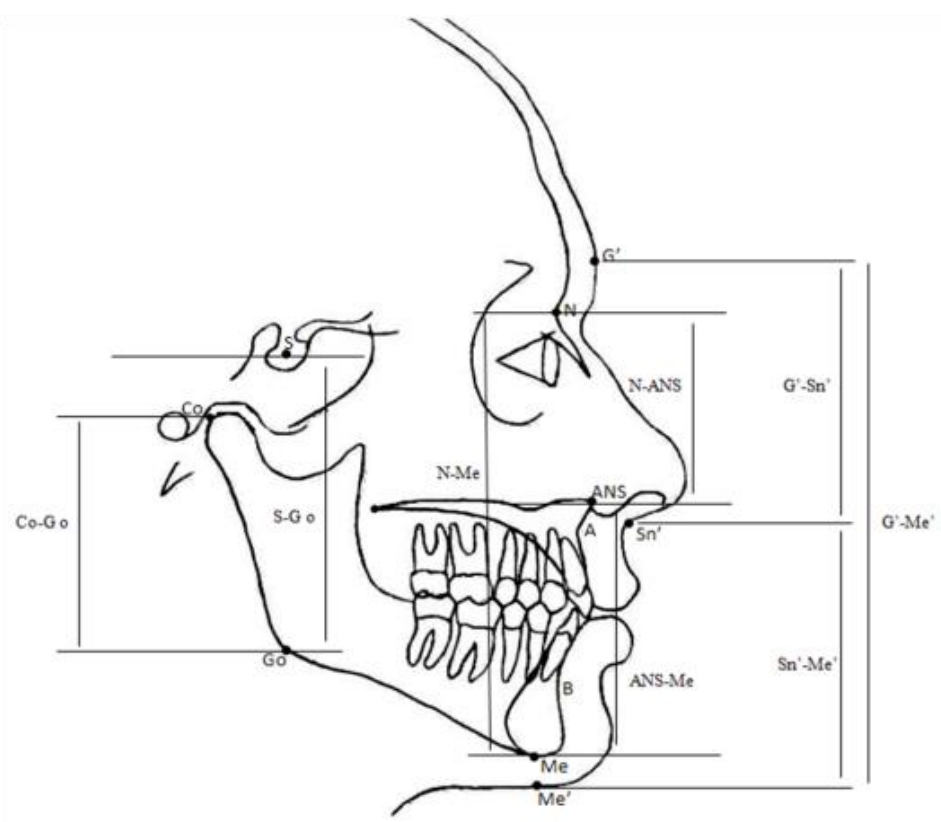

Fig. 12: Vertical Facial Heights
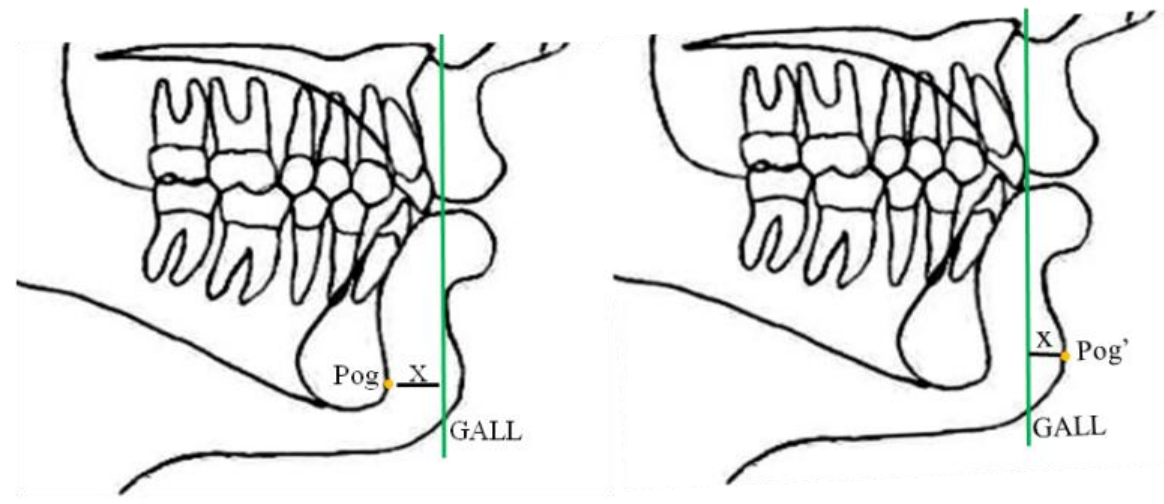

Fig. 13: Chin Prominence Measurement to the GALL 


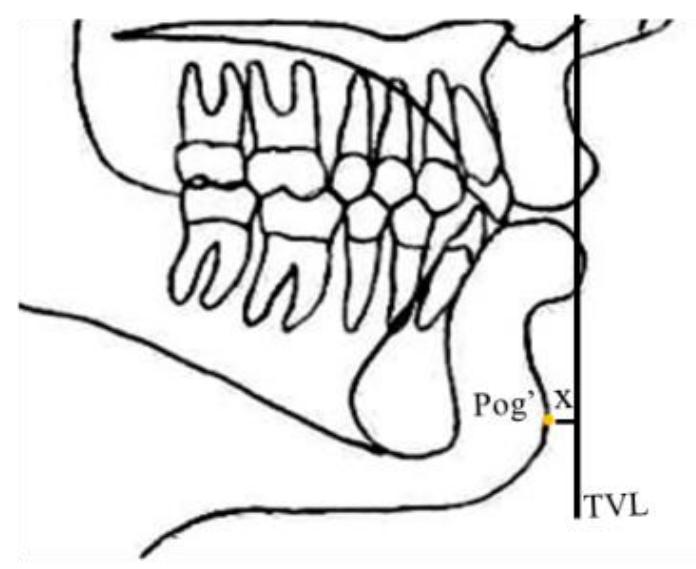

Fig. 14: Soft Tissue Chin Measurement to TVL

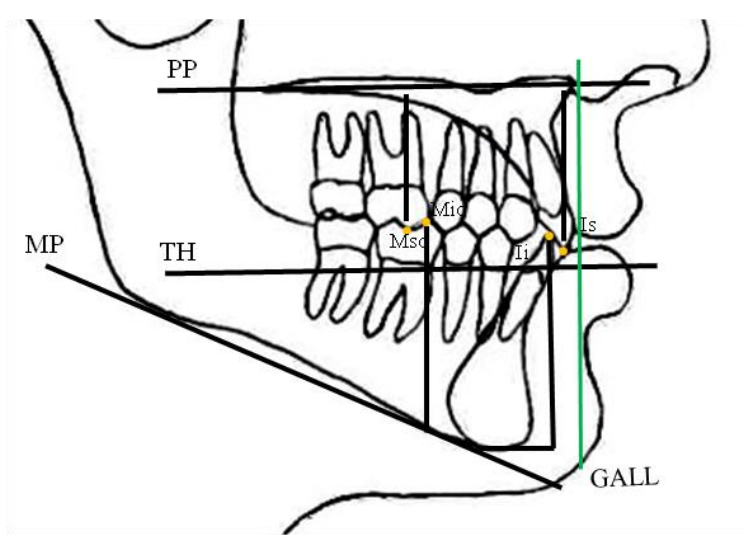

Fig. 15: Vertical Eruption 


\section{Error Measurements}

All cephalometric measurements were repeated on ten subjects six weeks after the initial measurements. The reliability of landmark identification and measurements of all cephalometric variables used in this study was tested by comparing the differences between the initial measurements and repeated measurements. Coefficients of reliability and Cronbach's $\alpha$ were calculated between the initial and repeated measurements. (Appendix B) For all cephalometric variables, the coefficients of reliability were found to be greater than .95 . For all cephalometric variables, the Cronbach's $\alpha$ was found to be greater than .97 . This indicates reliability of all measurements.

\section{Statistical Analysis}

The statistical analysis was carried about by the statistician (E.G.) utilizing the JMP version 9.0.0 SAS Software (Cary, NC, USA). An Analysis of Variance (ANOVA) was used for comparison of the anteroposterior, vertical and soft tissue facial convexity groups. A post-hoc comparison of means with the Student's t-test and Tukey Kramer Test was used to account for differences among groups. Pairwise correlation coefficients were calculated to quantitatively evaluate the relationship among the $\mathrm{Op}^{\circ}$ and all linear, angular and Six Elements cephalometric variables. A stepwise regression analysis was used to determine the cephalometric variables that can be used to predict $O \mathrm{p}^{\circ}$. A stepwise variable selection was used to identify predictive variables. The significance level was set at $\mathrm{p}<.05$. 


\section{CHAPTER 4: RESULTS}

\section{Descriptive Statistics}

The study sample $(n=105)$ consisted of 65 female and 40 male subjects. A t-test was used to evaluate the presence of any gender differences (Table 4, appendix B). There were statistically significant differences for the variables N-ANS, N-Me, G'-Me', Co-Go, So-Go, MpMic, Mp-L1, Co-Gn, Element IV Md Ant, and Element V between males and females. These linear measurements indicated differences due to larger mean values for males; indicating a larger overall size in the male group. Pog'-GALL, Pog-GALL, Pog'-TVL, Pog'c-GALL, Element II Mx, Element II Md, and were also different among the male and female groups. The male group consisted of subjects that were had larger mean values for the maxilla, mandible and pogonion measured relative to the GALL. However the mean soft tissue facial convexity, G'Sn'-Pog', was larger in the female group.

The age distribution ranged from age 10.1 to 53.8. A t-test was used to evaluate the presence of any differences among the age groups $<18(\mathrm{n}=78)$ and $\geq 18(\mathrm{n}=27)$ (Table 5, appendix C). The mean age of the group $<18$ was $13.2 \pm 1.53$ S.D. with a minimum age of 10.1 and maximum age of 17.5 . The $\geq 18$ group had a mean age of $33.7 \pm 10.0$ with a minimum age of 18.7 and maximum age of 53.8. There were statistically significant differences among the following variables when grouped by age; ANS-Me, N-Me, G'-Sn', Sn'-Me', G'-Me, Co-Go, SGo, PP-U1, PP-Msc, MP-Mic, MP-L1 and Element II Mx. The differences in mean values between the age groups indicated larger vertical dimensions and dental eruptions in the $\geq 18$ age group. The mean values for $\mathrm{Go}^{\circ}, \mathrm{MP}^{\circ}$, and $\mathrm{Op}^{\circ}$ were found to be larger in the $<18$ age group. 
The descriptive statistics were used to determine the mean, standard deviation, minimum and maximum for each of the linear, angular and Six Elements cephalometric variables of the pooled study sample (Table 6). The mean $\mathrm{Op}^{\circ}$ for the pooled sample was $8.83^{\circ}$ with a S.D. of 3.5. The mean $\mathrm{Op}^{\circ}$ for the $<18$ age group was $9.42^{\circ} \pm 3.39$; and for the $\geq 18$ age group was $7.11^{\circ} \pm 3.29$

\begin{tabular}{|c|c|c|c|c|c|}
\hline \multirow[b]{2}{*}{ Variable } & \multicolumn{2}{|c|}{ Female } & \multicolumn{2}{|c|}{ Male } & \multirow[b]{2}{*}{ p-Value } \\
\hline & Mean & S.D. & Mean & S.D. & \\
\hline \multicolumn{6}{|l|}{ Linear } \\
\hline Pog-GALL & -8.69 & 5.71 & -12.17 & 5.61 & $0.0029 *$ \\
\hline Pog'-GALL & 2.06 & 4.32 & -0.12 & 5.47 & $0.0359 *$ \\
\hline Pog'c-GAL & 0.94 & 4.05 & -1.99 & 4.98 & $0.0025^{*}$ \\
\hline TVL-Pog' & -5.32 & 5.31 & -8.34 & 5.78 & $0.0090^{*}$ \\
\hline N-ANS & 49.69 & 2.93 & 51.41 & 3.89 & $0.0188^{*}$ \\
\hline ANS-Me & 60.87 & 5.34 & 62.49 & 5.95 & 0.1652 \\
\hline $\mathrm{N}-\mathrm{Me}$ & 110.57 & 6.02 & 113.90 & 8.37 & $0.0318^{*}$ \\
\hline G'-Sn' & 62.26 & 3.96 & 63.92 & 4.87 & 0.0736 \\
\hline Sn'-Me' & 64.83 & 5.17 & 66.79 & 7.19 & 0.1367 \\
\hline G'-Me' & 127.09 & 6.54 & 130.72 & 9.80 & $0.0425^{*}$ \\
\hline Co-Go & 53.27 & 4.34 & 55.42 & 5.77 & $0.0469 *$ \\
\hline S-Go & 71.01 & 5.02 & 73.71 & 7.32 & $0.0442^{*}$ \\
\hline Co-Gn & 107.53 & 18.63 & 113.56 & 6.17 & $0.0258^{*}$ \\
\hline PP-U1 & 27.08 & 2.55 & 27.82 & 3.09 & 0.2065 \\
\hline PP-Mic & 21.88 & 2.22 & 21.83 & 2.60 & 0.94 \\
\hline MP-L1 & 37.58 & 3.04 & 39.67 & 3.76 & $0.0041^{*}$ \\
\hline Mp-Mic & 31.36 & 3.46 & 33.37 & 4.55 & $0.0196^{*}$ \\
\hline \multicolumn{6}{|l|}{ Angular } \\
\hline$O p^{\circ}$ & 8.63 & 3.24 & 9.15 & 3.90 & 0.4853 \\
\hline SNA $^{\circ}$ & 80.88 & 3.59 & 81.29 & 3.68 & 0.5838 \\
\hline $\mathrm{SNB}^{\circ}$ & 78.62 & 4.74 & 77.91 & 4.79 & 0.4609 \\
\hline $\mathrm{ANB}^{\circ}$ & 2.26 & 3.82 & 3.38 & 3.42 & 0.1245 \\
\hline G'-Sn-Pog & 166.94 & 7.26 & 163.68 & 6.97 & $0.0243^{*}$ \\
\hline SN-MP & 32.14 & 6.30 & 30.88 & 7.02 & 0.3548 \\
\hline Op-Sn & 18.22 & 4.36 & 18.08 & 5.16 & 0.8802 \\
\hline Sn & 9.50 & 3.22 & 8.73 & 3.18 & 0.2311 \\
\hline $\mathrm{MP}^{\circ}$ & 24.23 & 12.77 & 22.39 & 5.76 & 0.7876 \\
\hline $\mathrm{PP}^{\circ}$ & -1.55 & 3.24 & -1.14 & 3.09 & 0.5199 \\
\hline $\mathrm{Go}^{\circ}$ & 123.67 & 7.10 & 122.08 & 8.41 & 0.3208 \\
\hline $\mathrm{U} 1^{\circ}$ & 66.64 & 9.24 & 67.43 & 8.89 & 0.6649 \\
\hline $\mathrm{L}^{\circ}{ }^{\circ}$ & 65.48 & 8.54 & 63.94 & 9.46 & 0.4013 \\
\hline $1^{\circ}-O p$ & 58.01 & 9.15 & 58.28 & 8.54 & 0.8781 \\
\hline $\bar{I}^{\circ}-O p$ & 74.12 & 8.38 & 73.09 & 9.19 & 0.5658 \\
\hline \multicolumn{6}{|c|}{ Six Elements } \\
\hline II Mx & -3.52 & 3.02 & -4.75 & 3.08 & $0.0493^{*}$ \\
\hline II Md & -3.00 & 3.57 & -5.19 & 4.84 & $0.0157^{*}$ \\
\hline IV Mx Ant & -0.73 & 1.79 & -1.18 & 1.91 & 0.2276 \\
\hline IV Md Ant & 31.62 & 3.49 & 33.25 & 3.99 & $0.0373^{*}$ \\
\hline V & 1.12 & 1.66 & 1.86 & 1.68 & $0.0288^{*}$ \\
\hline
\end{tabular}

Table 5: Descriptive statistics of variables by age group

\begin{tabular}{|c|c|c|c|c|c|}
\hline \multirow[b]{2}{*}{ Variable } & \multicolumn{2}{|c|}{$<18$} & \multicolumn{2}{|c|}{$\geq 18$} & \multirow[b]{2}{*}{ p-Value } \\
\hline & Mean & S.D. & Mean & S.D. & \\
\hline \multicolumn{6}{|l|}{ Linear } \\
\hline Pog-GALL & -10.25 & 5.08 & -9.34 & 7.86 & 0.5757 \\
\hline Pog'-GALL & 0.97 & 4.25 & 1.96 & 6.42 & 0.4587 \\
\hline $\begin{array}{l}\text { Pog'c- } \\
\text { GALL }\end{array}$ & -0.52 & 4.29 & 0.82 & 5.45 & 0.2562 \\
\hline TVL-Pog' & -6.69 & 4.96 & -5.84 & 7.39 & 0.5821 \\
\hline N-ANS & 50.04 & 3.47 & 51.24 & 3.13 & 0.1013 \\
\hline ANS-Me & 60.29 & 5.22 & 64.95 & 5.32 & $0.0003 *$ \\
\hline $\mathrm{N}-\mathrm{Me}$ & 110.33 & 6.80 & 116.19 & 6.42 & $0.0002 *$ \\
\hline G'-Sn' & 62.46 & 4.66 & 64.17 & 3.20 & 0.0390* \\
\hline Sn'-Me' & 64.31 & 5.60 & 69.24 & 5.94 & $0.0005^{*}$ \\
\hline G'-Me' & 126.77 & 7.67 & 133.40 & 7.34 & $0.0002 *$ \\
\hline Co-Go & 52.88 & 4.29 & 57.58 & 5.41 & $0.0002 *$ \\
\hline S-Go & 70.43 & 4.93 & 76.69 & 6.87 & $0.0001^{*}$ \\
\hline Co-Gn & 110.74 & 6.79 & 107.17 & 28.28 & 0.5212 \\
\hline PP-1 & 26.96 & 2.63 & 28.51 & 2.93 & 0.0199* \\
\hline PP-Mic & 21.22 & 2.20 & 23.72 & 1.76 & $<.0001^{*}$ \\
\hline MP-L1 & 37.73 & 3.18 & 40.25 & 3.65 & $0.0027^{*}$ \\
\hline Mp-Mic & 31.27 & 3.42 & 34.61 & 4.58 & $0.0013^{*}$ \\
\hline \multicolumn{6}{|l|}{ Angular } \\
\hline $\mathrm{Op}^{\circ}$ & 9.42 & 3.39 & 7.11 & 3.29 & $0.0031 *$ \\
\hline $\mathrm{SNA}^{\circ}$ & 81.01 & 3.43 & 81.13 & 4.16 & 0.8906 \\
\hline $\mathrm{SNB}^{\circ}$ & 78.46 & 4.77 & 78.04 & 4.75 & 0.6913 \\
\hline $\mathrm{ANB}^{\circ}$ & 2.54 & 3.55 & 3.09 & 4.12 & 0.5412 \\
\hline $\begin{array}{l}\text { G'-Sn- } \\
\text { Pog' }\end{array}$ & 165.35 & 7.00 & 166.69 & 8.14 & 0.4521 \\
\hline SN-MP & 32.17 & 6.39 & 30.17 & 6.99 & 0.1961 \\
\hline Op-Sn & 18.59 & 4.70 & 16.94 & 4.38 & 0.1054 \\
\hline Sn & 9.05 & 3.31 & 9.65 & 2.93 & 0.3823 \\
\hline $\mathrm{MP}^{\circ}$ & 24.46 & 11.81 & 20.85 & 5.59 & $0.0385^{*}$ \\
\hline $\mathrm{PP}^{\circ}$ & -1.13 & 3.10 & -2.13 & 3.33 & 0.1801 \\
\hline $\mathrm{U} 1^{\circ}$ & 66.96 & 8.92 & 66.87 & 9.66 & 0.9663 \\
\hline $\mathrm{L}^{\circ}$ & 65.15 & 7.94 & 64.15 & 11.34 & 0.6726 \\
\hline $\mathrm{Go}^{\circ}$ & 124.45 & 7.42 & 119.06 & 6.87 & $0.0012 *$ \\
\hline$U 1^{\circ}-O p$ & 57.54 & 8.62 & 59.76 & 9.58 & 0.1414 \\
\hline$L 1^{\circ}-O p$ & 74.58 & 7.84 & 71.26 & 10.50 & 0.2933 \\
\hline \multicolumn{6}{|c|}{ Six Elements } \\
\hline II Mx & -4.29 & 3.03 & -3.10 & 3.15 & 0.0954 \\
\hline II Md & -3.75 & 4.00 & -4.08 & 4.87 & 0.7522 \\
\hline IV Mx Ant & -0.82 & 1.81 & -1.12 & 1.96 & 0.4896 \\
\hline IV Md Ant & 31.50 & 3.50 & 34.38 & 3.72 & $0.0011 *$ \\
\hline V & 1.49 & 1.61 & 1.15 & 1.94 & 0.4188 \\
\hline
\end{tabular}




\begin{tabular}{|c|c|c|c|c|}
\hline \multicolumn{5}{|l|}{ Linear } \\
\hline Variable & Mean & Std Dev & Minimum & Maximum \\
\hline Pog-GALL & -10.02 & 5.89 & -29.95 & 12.02 \\
\hline Pog'-GALL & 1.23 & 4.88 & -19.18 & 14.14 \\
\hline Pog'c-GALL & -0.17 & 4.63 & -16.68 & 12.80 \\
\hline TVL-Pog' & -6.47 & 5.66 & -30.70 & 7.76 \\
\hline N-ANS & 50.35 & 3.41 & 38.81 & 60.69 \\
\hline ANS-Me & 61.49 & 5.61 & 44.82 & 78.31 \\
\hline N-Me & 111.84 & 7.15 & 90.80 & 132.83 \\
\hline G'-Sn' & 62.90 & 4.38 & 50.11 & 74.99 \\
\hline Sn'-Me' & 65.58 & 6.06 & 48.66 & 86.92 \\
\hline G'-Me' & 128.47 & 8.09 & 106.31 & 153.14 \\
\hline Co-Go & 54.09 & 5.02 & 40.92 & 70.87 \\
\hline S-Go & 72.04 & 6.11 & 59.89 & 91.52 \\
\hline Co-Gn & 111.73 & 6.79 & 93.02 & 128.81 \\
\hline PP-U1 & 27.36 & 2.78 & 21.10 & 36.35 \\
\hline PP-Mic & 21.86 & 2.36 & 16.16 & 27.21 \\
\hline MP-L1 & 38.38 & 3.47 & 27.80 & 49.51 \\
\hline Mp-Mic & 32.13 & 4.01 & 22.60 & 45.78 \\
\hline \multicolumn{5}{|l|}{ Angular } \\
\hline Variable & Mean & Std Dev & Minimum & Maximum \\
\hline Op ${ }^{\circ}$ & 8.83 & 3.50 & 0.00 & 18.00 \\
\hline SNA $^{\circ}$ & 81.04 & 3.61 & 72.00 & 90.50 \\
\hline SNB $^{\circ}$ & 78.35 & 4.75 & 67.00 & 92.00 \\
\hline ANB $^{\circ}$ & 2.69 & 3.69 & -8.00 & 11.00 \\
\hline G'-Sn-Pog $^{\prime 0}$ & 165.70 & 7.29 & 144.00 & 181.50 \\
\hline SN-MP ${ }^{\circ}$ & 31.66 & 6.58 & 17.00 & 49.00 \\
\hline Op-Sn & 18.17 & 4.66 & 7.00 & 31.50 \\
\hline $\mathrm{Sn}^{\circ}$ & 9.20 & 3.21 & 0.00 & 16.00 \\
\hline $\mathrm{MP}^{\circ}$ & 22.58 & 5.49 & 10.00 & 36.00 \\
\hline $\mathbf{P P}^{\circ}$ & -1.39 & 3.17 & -9.00 & 7.00 \\
\hline $\mathrm{Go}^{\circ}$ & 123.06 & 7.62 & 103.00 & 142.00 \\
\hline $\mathbf{L 1}^{\circ}$ & 64.90 & 8.89 & 43.00 & 90.00 \\
\hline $\mathrm{U} 1^{\circ}$ & 66.94 & 9.07 & 51.50 & 95.50 \\
\hline L1 - Op & 73.72 & 8.67 & 54.00 & 95.00 \\
\hline U1 - Op & 58.11 & 8.88 & 42.00 & 89.00 \\
\hline \multicolumn{5}{|l|}{$\underline{\text { Six Elements }}$} \\
\hline Variable & Mean & Std Dev & Minimum & Maximum \\
\hline II Mx & -3.99 & 3.09 & -11.51 & 1.03 \\
\hline II Md & -3.83 & 4.22 & -14.87 & 9.50 \\
\hline IV Mx Ant & -0.90 & 1.84 & -5.25 & 3.26 \\
\hline IV Md Ant & 32.24 & 3.76 & 20.32 & 42.24 \\
\hline v & 1.40 & 1.70 & -3.00 & 6.00 \\
\hline
\end{tabular}

Descriptive statistics were used to determine the mean, standard deviation, minimum and maximum for each of the three anteroposterior groups (Class I, II, and III) (Table 7); the three anteroposterior (Category I, II and III) Six Elements groups (Table 8), the three facial soft tissue convexity groups (normal, concave, and convex) (Table 9) and the three vertical groups (normodivergent, hypodivergent, and hyperdivergent) (Table 10) measured relative to Op ${ }^{\circ}$, Pog'GALL, Pog'c-GALL and Pog'-TVL. 


\section{$O p^{\circ}$ by Anteroposterior Skeletal Pattern (ANB)}

Of the pooled sample $(n=105) 58 \%(n=61)$ were Class I $\left(\right.$ ANB $\left.0-5^{\circ}\right), 27 \%(n=28)$ were Class II $\left(\mathrm{ANB}>5^{\circ}\right)$ and $15 \%(\mathrm{n}=16)$ were Class III $\left(\mathrm{ANB}<0^{\circ}\right)$. Descriptive statistics and results of ANOVA and comparison of means (Appendix B) are summarized in Table 7.

Table 7: $\mathbf{O p}^{\circ}$ by ANB Anteroposterior Skeletal Classification

\begin{tabular}{cccc|cccc|ccccccccc}
\hline \multicolumn{4}{c}{ Class I $(\mathrm{n}=61)$} & \multicolumn{4}{c}{ Class II $(\mathrm{n}=28)$} & \multicolumn{3}{c}{ Class III $(\mathrm{n}=16)$} & \multicolumn{1}{c}{ ANOVA } & I-II & I-III & II-III \\
\hline \hline Mean & S.D. & Min. & Max. & Mean & S.D. & Min. & Max. & Mean & S.D. & Min. & Max. & Prob>F & p-Value & p-Value & p-Value \\
8.61 & 3.63 & 1.5 & 18 & 10.09 & 3.05 & 4 & 17 & 7.44 & 3.21 & 0 & 12.5 & $0.0393^{*}$ & 0.0617 & 0.2243 & $0.0151^{*}$ \\
\hline
\end{tabular}

p-Value determined by Student's t-test.

* statistically significant at $\mathrm{p}<.05$

The mean $\mathrm{Op}^{\circ}$ for Class I, II and III subjects was $8.61^{\circ} \pm 3.63,10.09^{\circ} \pm 3.05$, and $7.44^{\circ} \pm$ 3.21, respectively. A comparison of means revealed that there was not a statistically significant difference among Class I and II, nor Class I and III groups. However, there was a stastistically significant difference between Class II and III groups $(\mathrm{p}=0.0151)$ for the mean Op ${ }^{\circ}$ (Fig. 16).

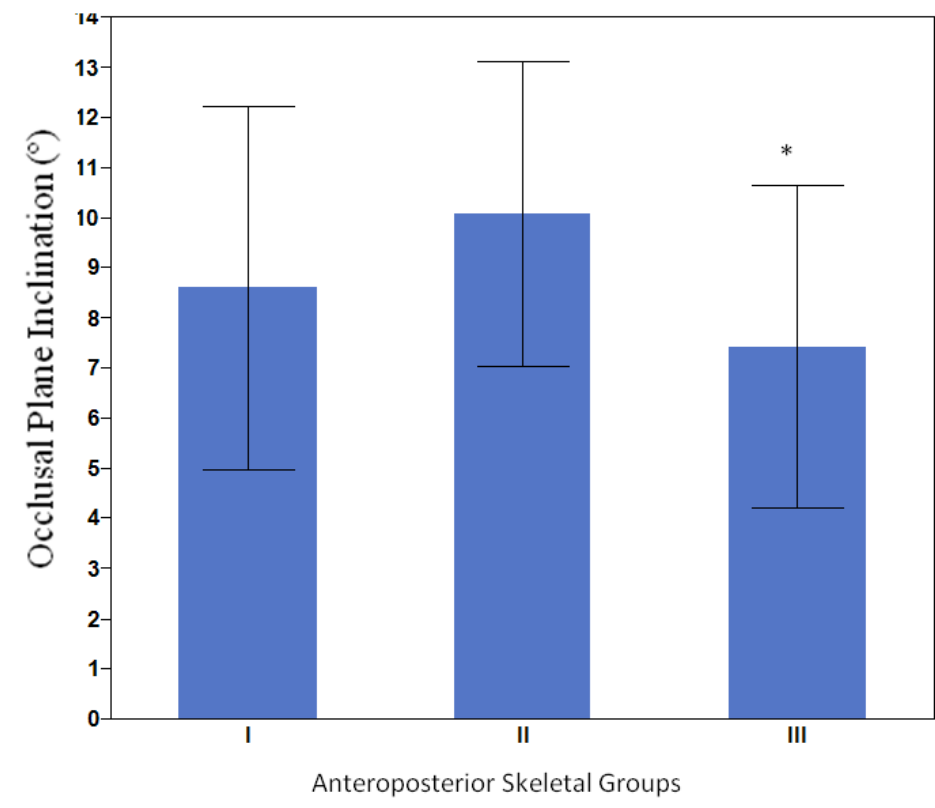

Figure 16: Mean occlusal plane inclination $\left(^{\circ}\right)$ by anteroposterior skeletal groups, $*=$ Class III statistically significant from Class II at $\mathrm{p}<0.05$ 


\section{Op by Six Elements Anteroposterior Skeletal Pattern}

Of the pooled sample $(n=105) 38 \%(n=40)$ were Category I, 32\% $(n=34)$ were Category

II and 30\% ( $n=31)$ were Category III. Descriptive statistics and results of ANOVA (Appendix

B) and comparison of means are summarized in Table 8 .

Table 8: Mean $\mathrm{Op}^{\circ}$ by Six Elements Anteroposterior Category

\begin{tabular}{|c|c|c|c|c|c|c|c|c|c|c|c|c|c|c|c|}
\hline \multicolumn{4}{|c|}{$\begin{array}{c}\text { Category I } \\
(\mathrm{n}=40)\end{array}$} & \multicolumn{4}{|c|}{$\begin{array}{c}\text { Category II } \\
(\mathrm{n}=34)\end{array}$} & \multicolumn{4}{|c|}{$\begin{array}{c}\text { Category III } \\
(\mathrm{n}=31)\end{array}$} & ANOVA & I-II & I-III & II-III \\
\hline Mean & S.D. & Min. & Max. & Mean & S.D. & Min. & Max. & Mean & S.D. & Min. & Max. & Prob $>F$ & p-Value & $\mathrm{p}$-Value & p-Value \\
\hline
\end{tabular}

p-Value determined by Student's t-test.

* statistically significant at $\mathrm{p}<.05$

The mean $\mathrm{Op}^{\circ}$ for Class I, II and III Six Elements skeletal patterns was $8.95^{\circ} \pm 3.56$, $8.43^{\circ} \pm 2.91$, and $9.11^{\circ} \pm 4.04$, respectively. There were no significant differences among the groups (Fig. 17).

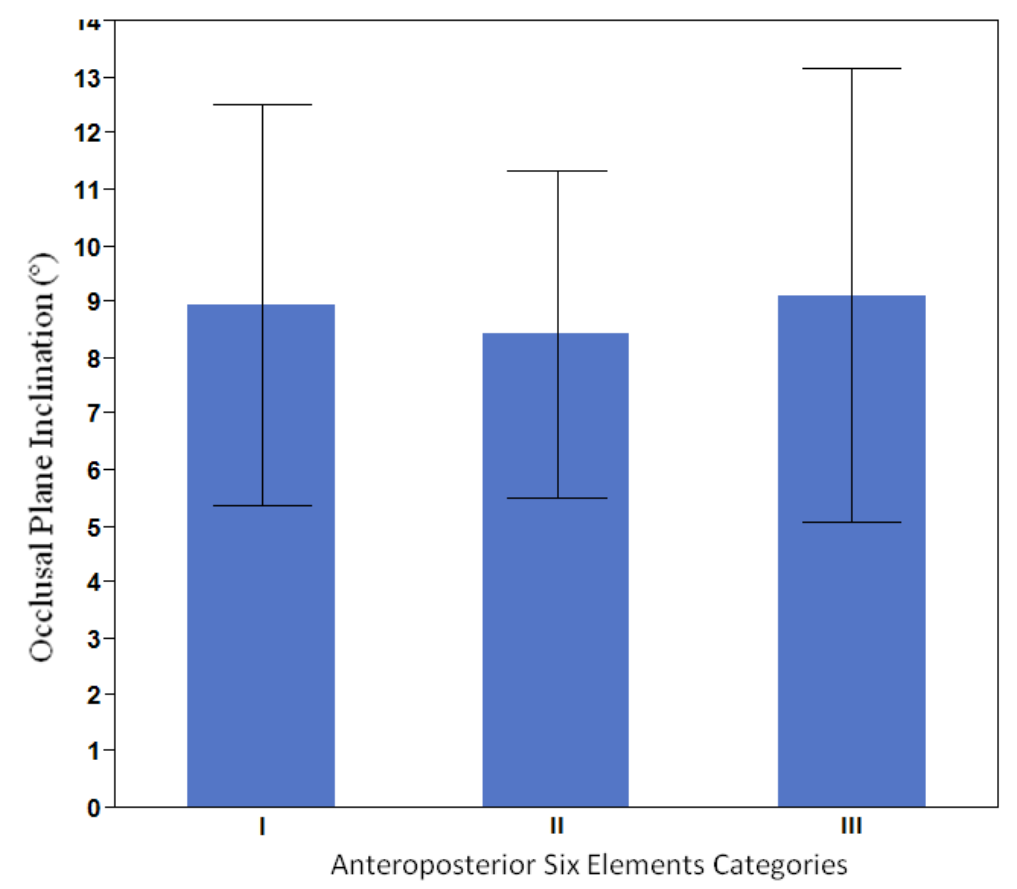

Fig. 17: Mean occlusal plane inclination $\left({ }^{\circ}\right)$ by Six Elements Skeletal Pattern. No statistically significant differences among groups 


\section{Op ${ }^{\circ}$ by Soft Tissue Facial Convexity}

Of the pooled sample $(n=105) 39 \%(n=41)$ were normal $\left(G^{\prime}-S^{\prime} n^{\prime}-P o g{ }^{\circ}=165-175^{\circ}\right)$, $48 \%(n=50)$ were convex $\left(G^{\prime}-S^{\prime}{ }^{\prime}-P_{0}{ }^{\circ}{ }^{\circ}>175^{\circ}\right)$ and 13\% $(n=14)$ were concave $\left(G^{\prime}-S^{\prime} n^{\prime}-P_{0 g}{ }^{\circ}<\right.$ $165^{\circ}$ ). Descriptive statistics, results of ANOVA and comparison of means (Appendix B) are summarized in Table 9.

Table 9: Mean $\mathrm{Op}^{\circ}$ by Soft Tissue Convexity

\begin{tabular}{|c|c|c|c|c|c|c|c|c|c|c|c|c|c|c|c|}
\hline \multicolumn{4}{|c|}{$\begin{array}{c}\text { Normal }(\mathrm{N}) \\
(\mathrm{n}=41)\end{array}$} & \multicolumn{4}{|c|}{$\begin{array}{c}\text { Convex }(\mathrm{Cx}) \\
(\mathrm{n}=50)\end{array}$} & \multicolumn{4}{|c|}{$\begin{array}{c}\text { Concave }(\mathrm{Cv}) \\
(\mathrm{n}=14)\end{array}$} & \multirow{2}{*}{$\frac{\text { ANOVA }}{\text { Prob }>F}$} & \multirow{2}{*}{$\frac{\mathrm{N}-\mathrm{Cx}}{\mathrm{p} \text {-Value }}$} & \multirow{2}{*}{$\frac{\mathrm{N}-\mathrm{CV}}{\mathrm{p}-\mathrm{Value}}$} & \multirow{2}{*}{$\frac{\mathrm{Cx}-\mathrm{Cv}}{\mathrm{p}-\mathrm{Value}}$} \\
\hline Mean & S.D. & Min. & Max. & Mean & S.D. & Min. & Max. & Mean & S.D. & Min. & Max. & & & & \\
\hline 8.37 & 3.23 & 2.00 & 15.00 & 9.77 & 3.53 & 0.00 & 18.00 & 6.82 & 3.23 & 1.50 & 12.50 & $0.0103 *$ & 0.0516 & 0.1428 & $0.0048 *$ \\
\hline
\end{tabular}

p-Value determined by Student's t-test.

* statistically significant at $\mathrm{p}<.05$

The mean $\mathrm{Op}^{\circ}$ for normal, convex and concave groups was $8.37^{\circ} \pm 3.20,9.77^{\circ} \pm 3.53$,

and $6.82^{\circ} \pm 3.23$, respectively. A comparison of means demonstrated that there was no statistically significant difference between normal and convex profiles, or between normal and concave profiles. However, there was a statistically significant difference $(p=0.0048)$ in the mean $\mathrm{Op}^{\circ}$ between the concave and convex groups (Fig. 18).

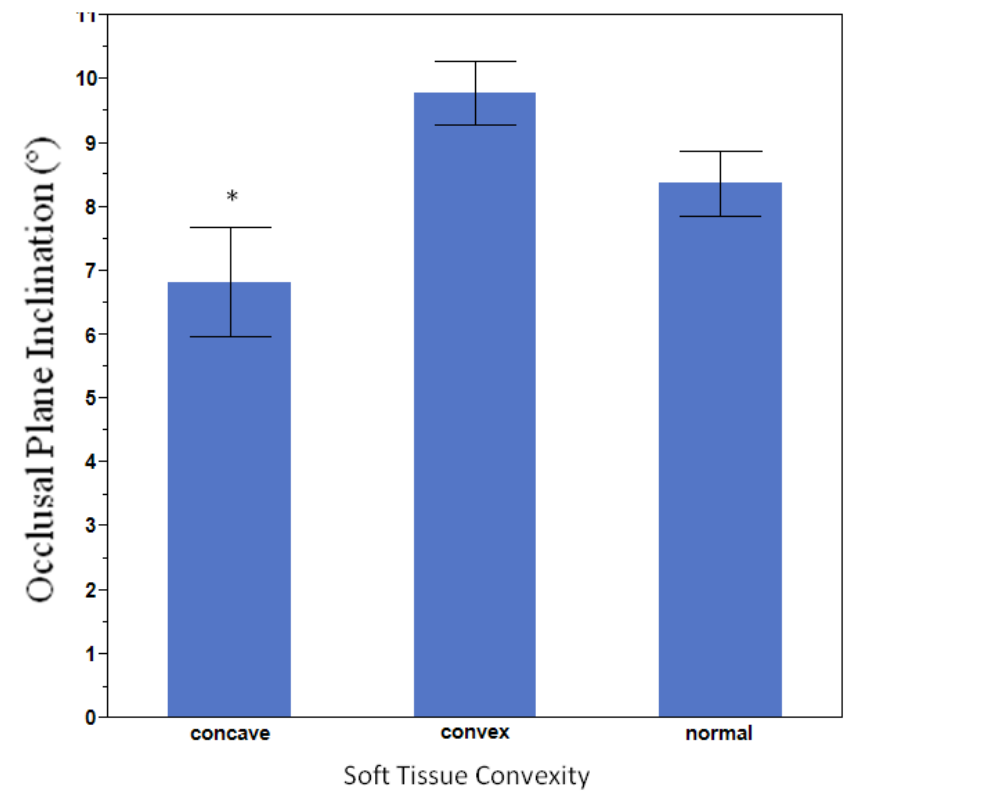

Figure 18: Mean occlusal plane inclination $\left({ }^{\circ}\right)$ by Soft Tissue Convexity.

$*=$ concave statistically different from convex at $p<0.05$ 


\section{$O p^{\circ}$ by Vertical Dimension}

Of the pooled sample $(n=105) 55 \%(n=58)$ were normodivergent $\left(\right.$ SN-MP $\left.20-32^{\circ}\right), 28 \%$ $(n=29)$ were hypodivergent $\left(\mathrm{SN}-\mathrm{MP}<20^{\circ}\right)$ and $21 \%(\mathrm{n}=22)$ were hyperdivergent $(\mathrm{SN}-\mathrm{MP}>$ $32^{\circ}$ ). Descriptive statistics and results of ANOVA and comparison of means (Appendix B) are summarized in Table 10.

Table 10: Mean $\mathrm{Op}^{\circ}$ by Vertical Dimension

\begin{tabular}{|c|c|c|c|c|c|c|c|c|c|c|c|c|c|c|c|}
\hline \multicolumn{4}{|c|}{$\begin{array}{c}\text { Normodivergent }(\mathrm{N}) \\
(\mathrm{n}=58)\end{array}$} & \multicolumn{4}{|c|}{$\begin{array}{c}\begin{array}{l}\text { Hypodivergent (Ho) } \\
(\mathrm{n}=29)\end{array} \\
\end{array}$} & \multicolumn{4}{|c|}{$\begin{array}{c}\begin{array}{c}\text { Hyperdivergent }(\mathrm{Hr}) \\
(\mathrm{n}=22)\end{array} \\
\end{array}$} & \multirow{3}{*}{$\begin{array}{c}\text { ANOVA } \\
\text { Prob }>\mathrm{F} \\
<.0001 *\end{array}$} & \multirow{3}{*}{$\begin{array}{c}\text { N-Ho } \\
\text { p-Value } \\
0.0045^{*}\end{array}$} & \multirow{3}{*}{$\begin{array}{c}\mathrm{N}-\mathrm{Hr} \\
\mathrm{p}-\text { Value } \\
0.0019 *\end{array}$} & \multirow{3}{*}{$\begin{array}{c}\mathrm{Ho}-\mathrm{Hr} \\
\mathrm{p} \text {-Value } \\
<.0001^{*}\end{array}$} \\
\hline Mean & S.D. & Min. & Max. & Mean & S.D. & Min. & Max. & Mean & S.D. & Min. & Max. & & & & \\
\hline 8.88 & 3.20 & 2.00 & 18.00 & 6.78 & 3.36 & 0.00 & 14.00 & 11.41 & 2.62 & 5.50 & 17.00 & & & & \\
\hline
\end{tabular}

The mean $\mathrm{Op}^{\circ}$ for normodivergent, hypodivergent and hyperdivergent groups was $8.88^{\circ}$ $\pm 3.20,6.78^{\circ} \pm 3.36$, and $11.41^{\circ} \pm 2.62$, respectively. The results of the ANOVA and comparisons of means demonstrated that there was a statistically significant difference in mean $\mathrm{Op}^{\circ}$ among all vertical groups (Fig. 19)

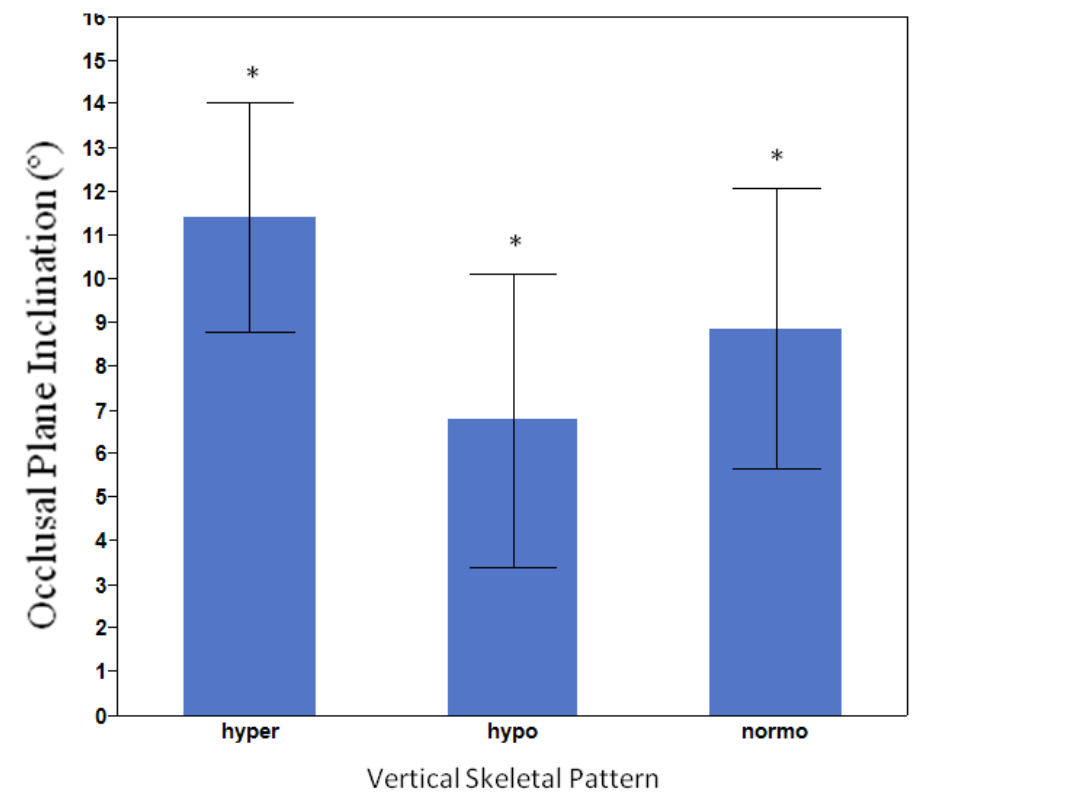

Figure 19: Mean occlusal plane inclination $\left(^{\circ}\right)$ by Vertical Skeletal Pattern. $*=$ all groups statistically different at $\mathrm{p}<0.05$ 


\section{Correlational Analysis of $\mathrm{Op}^{\circ}$ to Cephalometric Variables}

Correlation coefficients between the linear, angular and Six Elements cephalometric

variables are shown in Table 11. For a comprehensive report of all pairwise correlations for all cephalometric variables, refer to Appendix B.

Table 11: Correlation Coefficients related to the Occlusal Plane $\left(\mathrm{Op}^{\circ}\right)$

\begin{tabular}{|c|c|c|c|c|c|}
\hline \multicolumn{6}{|l|}{ Linear } \\
\hline Variable & By Variable & Correlation & Lower $95 \%$ & Upper $95 \%$ & Signif Prob \\
\hline Pog-GALL & $\mathrm{Op}^{\circ}$ & -0.4114 & -0.559 & -0.2386 & $<.0001^{*}$ \\
\hline $\begin{array}{l}\text { Pog'-GALL } \\
\text { Pog'c- }\end{array}$ & $\mathrm{Op}^{\circ}$ & -0.4578 & -0.5971 & -0.2917 & $<.0001 *$ \\
\hline GALL & $\mathrm{Op}^{\circ}$ & -0.4182 & -0.5646 & -0.2463 & $<.0001 *$ \\
\hline Pog'-TVL & $\mathrm{Op}^{\circ}$ & -0.4166 & -0.5633 & -0.2445 & $<.0001^{*}$ \\
\hline N-ANS & $\mathrm{Op}^{\circ}$ & 0.1127 & -0.0807 & 0.2979 & 0.2523 \\
\hline ANS-Me & $\mathrm{Op}^{\circ}$ & -0.0281 & -0.2186 & 0.1645 & 0.776 \\
\hline $\mathrm{N}-\mathrm{Me}$ & $\mathrm{Op}^{\circ}$ & 0.0318 & -0.1609 & 0.2221 & 0.7476 \\
\hline $\mathrm{G}^{\prime}-\mathrm{Sn}^{\prime}$ & $\mathrm{Op}^{\circ}$ & 0.0839 & -0.1096 & 0.2712 & 0.395 \\
\hline $\mathrm{Sn}^{\prime}-\mathrm{Me}^{\prime}$ & $\mathrm{Op}^{\circ}$ & -0.0474 & -0.2369 & 0.1456 & 0.6311 \\
\hline $\mathrm{G}^{\prime}-\mathrm{Me}^{\prime}$ & $\mathrm{Op}^{\circ}$ & 0.01 & -0.1821 & 0.2012 & 0.9197 \\
\hline Co-Go & $\mathrm{Op}^{\circ}$ & -0.3231 & -0.4847 & -0.1401 & $0.0008 *$ \\
\hline S-Go & $\mathrm{Op}^{\circ}$ & -0.3825 & -0.5349 & -0.2059 & $<.0001^{*}$ \\
\hline Co-Gn & $\mathrm{Op}^{\circ}$ & -0.2566 & -0.4272 & -0.0683 & $0.0082 *$ \\
\hline PP-U1 & $\mathrm{Op}^{\circ}$ & 0.1914 & -0.0002 & 0.3695 & $0.0504 *$ \\
\hline PP-Msc & $\mathrm{Op}^{\circ}$ & -0.1304 & -0.3143 & 0.0628 & 0.1847 \\
\hline MP-L1 & $\mathrm{Op}^{\circ}$ & -0.1789 & -0.3582 & 0.0133 & 0.0679 \\
\hline Mp-Mic & $\mathrm{Op}^{\circ}$ & 0.1442 & -0.0488 & 0.3268 & 0.1422 \\
\hline \multicolumn{6}{|l|}{ Angular } \\
\hline Variable & By Variable & Correlation & Lower $95 \%$ & Upper $95 \%$ & Signif Prob \\
\hline $\mathrm{SNA}^{\circ}$ & $\mathrm{Op}^{\circ}$ & -0.0354 & -0.2255 & 0.1573 & 0.7199 \\
\hline $\mathrm{SNB}^{\circ}$ & $\mathrm{Op}^{\circ}$ & -0.2355 & -0.4088 & -0.046 & $0.0156^{*}$ \\
\hline $\mathrm{ANB}^{\circ}$ & $\mathrm{Op}^{\circ}$ & 0.2684 & 0.0809 & 0.4375 & $0.0056^{*}$ \\
\hline $\mathrm{G}^{\prime}-\mathrm{Sn}-\mathrm{Pog}^{\prime \circ}$ & $\mathrm{Op}^{\circ}$ & -0.3539 & -0.5109 & -0.1741 & $0.0002 *$ \\
\hline $\mathrm{SN}-\mathrm{MP}^{\circ}$ & $\mathrm{Op}^{\circ}$ & 0.4798 & 0.3174 & 0.6149 & $<.0001^{*}$ \\
\hline $\mathrm{Op}-\mathrm{Sn}^{\circ}$ & $\mathrm{Op}^{\circ}$ & 0.7245 & 0.6188 & 0.8045 & $<.0001^{*}$ \\
\hline $\mathrm{Sn}^{\circ}$ & $\mathrm{Op}^{\circ}$ & -0.0046 & -0.1961 & 0.1873 & 0.9631 \\
\hline $\mathrm{MP}^{\circ}$ & $\mathrm{Op}^{\circ}$ & 0.5626 & 0.4158 & 0.6809 & $<.0001^{*}$ \\
\hline $\mathrm{PP}^{\circ}$ & $\mathrm{Op}^{\circ}$ & 0.3273 & 0.1447 & 0.4883 & $0.0007^{*}$ \\
\hline $\mathrm{Go}^{\circ}$ & $\mathrm{Op}^{\circ}$ & 0.288 & 0.1019 & 0.4546 & $0.0029 *$ \\
\hline $\mathrm{L} 1^{\circ}$ & $\mathrm{Op}^{\circ}$ & -0.259 & -0.4294 & -0.0709 & $0.0076^{*}$ \\
\hline $\mathrm{U} 1^{\circ}$ & $\mathrm{Op}^{\circ}$ & 0.2461 & 0.0571 & 0.418 & $0.0114 *$ \\
\hline $\mathrm{L} 1-\mathrm{Op}^{\circ}$ & $\mathrm{Op}^{\circ}$ & 0.1381 & -0.055 & 0.3212 & 0.1601 \\
\hline $\mathrm{U} 1-\mathrm{Op}^{\circ}$ & $\mathrm{Op}^{\circ}$ & -0.1427 & -0.3254 & 0.0504 & 0.1466 \\
\hline \multicolumn{6}{|l|}{$\underline{\text { Six Elements }}$} \\
\hline Variable & By Variable & Correlation & Lower $95 \%$ & Upper 95\% & Signif Prob \\
\hline II Mx & $\mathrm{Op}^{\circ}$ & -0.2048 & -0.3815 & -0.0137 & $0.0361 *$ \\
\hline II Md & $\mathrm{Op}^{\circ}$ & -0.0052 & -0.1966 & 0.1867 & 0.9584 \\
\hline IV Mx Ant & $\mathrm{Op}^{\circ}$ & 0.4288 & 0.2584 & 0.5734 & $<.0001^{*}$ \\
\hline IV Md Ant & $\mathrm{Op}^{\circ}$ & -0.1776 & -0.3571 & 0.0145 & 0.0699 \\
\hline V & $\mathrm{Op}^{\circ}$ & -0.1767 & -0.3563 & 0.0155 & 0.0714 \\
\hline
\end{tabular}




\section{Linear Measurements:}

The $\mathrm{Op}^{\circ}$ demonstrated statistically significant negative correlations for several linear cephalometric variables (Table 11).

The $\mathrm{Op}^{\circ}$ exhibits a highly statistically significant $(\mathrm{p}<.0001)$ negative correlation with all linear measures of pogonion; Pog-GALL $(r=-0.4114)$, Pog'-GALL $(r=-0.4578)$, Pog'c-GALL $(\mathrm{r}=0.4182), \mathrm{TVL}-\mathrm{Pog}{ }^{\prime}(\mathrm{r}=-0.4166)$. There is a relationship between increased posterior distances of both soft tissue and hard tissue pogonion, measured relative to Andrew's GALL and Arnett's TVL, and steeper occlusal plane inclinations (Fig. 20).

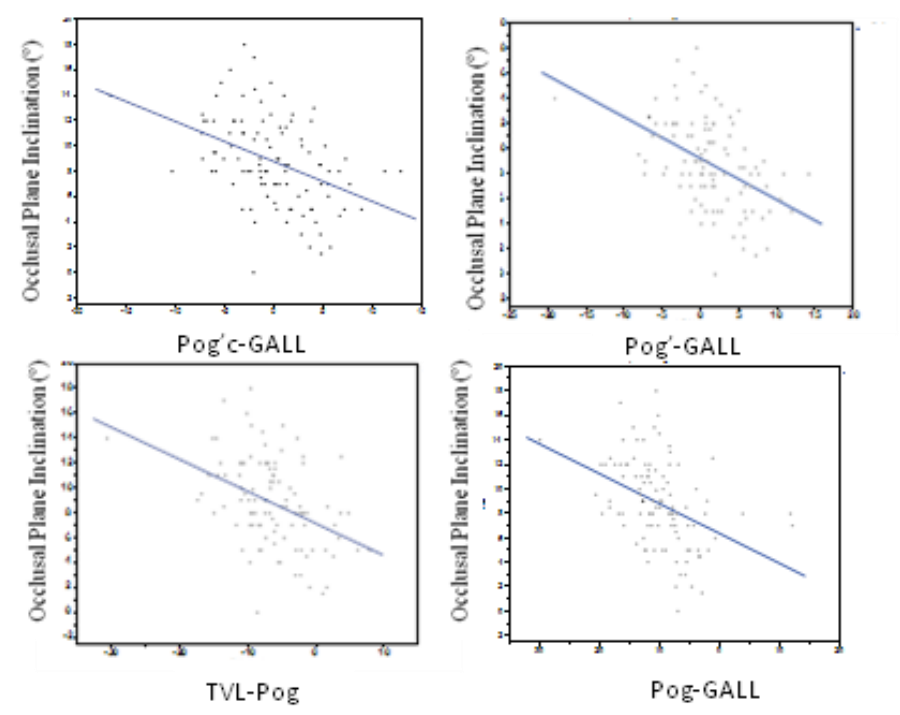

Figure 20: Occlusal plane inclination plotted against measurements of the anteroposterior chin position $(\mathrm{mm})$

The $\mathrm{Op}^{\circ}$ exhibits a statistically significant negative correlation with measures of posterior facial height (Table 11). Co-Go $(r=-0.3231)$ was statistically significant with a $p$-Value of 0.0008. S-Go was statistically significant with a p-Value $<.0001$. Therefore, there is a relationship between shorter posterior facial heights and steeper occlusal plane inclinations. 
The $\mathrm{Op}^{\circ}$ is significantly correlated with mandibular length (Table 11). Co-Gn ( $\mathrm{r}=-$ 0.2566) was statistically significant with a $\mathrm{p}$-Value equal to 0.0082 . This relationship indicates that shorter mandibular lengths are associated with steeper occlusal plane inclinations.

\section{Angular Measurements:}

The $\mathrm{Op}^{\circ}$ demonstrated statistically significant positive and negative correlations for several angular cephalometric variables (Table 11).

The $\mathrm{Op}^{\circ}$ is negatively correlated with $\mathrm{SNB}(\mathrm{r}=-0.2355, \mathrm{p}=0.0156)$ and positively correlated with ANB $(r=0.2684, p=0.0056)$. This indicates that there is a relationship between more retrusive mandibles, measured relative to the cranial base, and steeper occlusal plane inclinations.

The $\mathrm{Op}^{\circ}$ is negatively correlated with $\mathrm{G}^{\prime}-\mathrm{Sn}^{\prime}-\mathrm{Pog}{ }^{\prime}(\mathrm{r}=-0.3539, \mathrm{p}=0.0002)$. There is an association between subjects with convex facial profiles and steeper occlusal plane inclinations. Likewise, there is an association with concave profiles and flatter occlusal plane inclinations. See Fig. 21 below. This correlational association is in agreement with the comparison of $\mathrm{Op}^{\circ}$ means by soft tissue facial convexity, convex is stastistically different from concave (Table 9, Fig. 18).

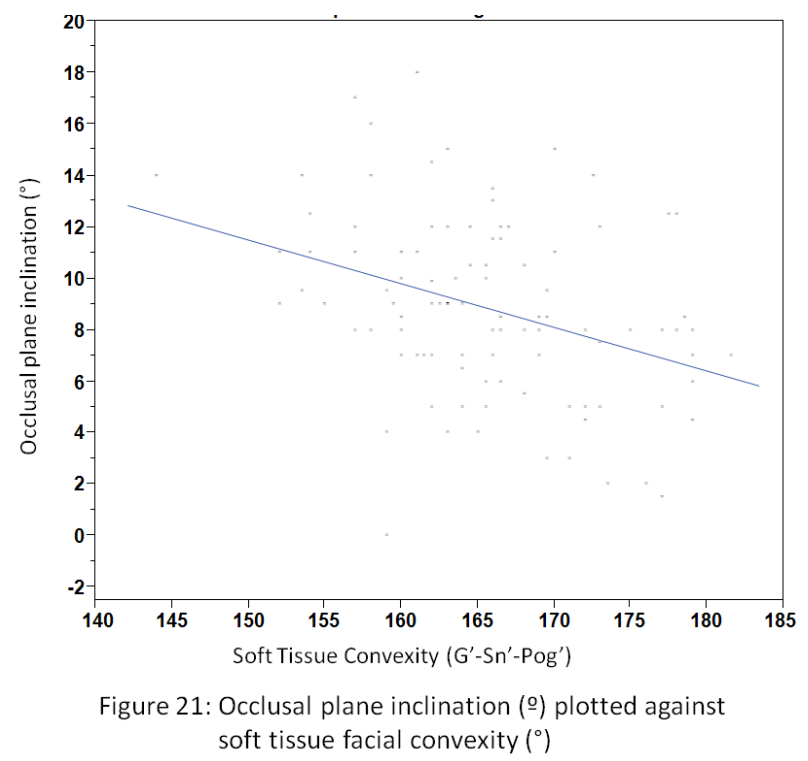


There is a highly statistically significant positive correlation between the $\mathrm{Op}^{\circ}$ and $\mathrm{SN}$ $\mathrm{MP}^{\mathrm{o}}(\mathrm{r}=0.4798, \mathrm{p}<.0001)$ and $\mathrm{MP}^{\circ}(\mathrm{r}=0.5626, \mathrm{p}<.0001)$, (Table 11). This demonstrates a relationship between steeper mandibular plane and occlusal plane inclinations (Fig. 22). This corresponds with the findings evaluating the comparison of $\mathrm{Op}^{\circ}$ mean by vertical facial pattern (normodivergent, hypodivergent, hypodivergent) discussed above (Table 10, Fig. 19).

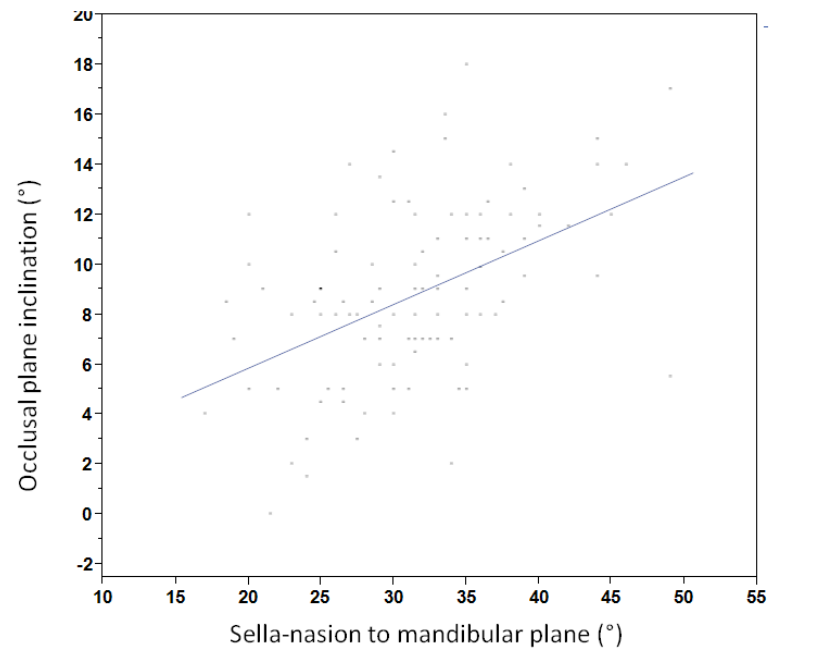

Figure 22: Occlusal plane inclination plotted against Sella-Nasion to mandibular plane $\left({ }^{\circ}\right)$

The $\mathrm{Op}^{\circ}$ demonstrates a statistically significant positive correlation with $\mathrm{PP}^{\circ}(\mathrm{r}=0.3273$, $\mathrm{p}=0.0007),($ Table 11). Therefore, there is a relationship between a steep palatal plane (ANS down in the front) and a steeper occlusal plane inclination.

There is a statistically significant positive correlation between the $\mathrm{Op}^{\circ}$ and $\mathrm{Go}^{\circ}(\mathrm{r}=$ $0.288, \mathrm{p}=0.0029),($ Table 11$)$. There is an association between larger gonial angles and steeper occlusal planes. Likewise, there is an association between smaller gonial angles and flatter occlusal planes. Although, statistically significant, the correlation is weak.

The $\mathrm{Op}^{\circ}$ demonstrates statistically significant correlations with incisor inclinations (Table 11). $\mathrm{U} 1^{\circ}(\mathrm{r}=.2461, \mathrm{p}=0.0114)$ shows a weak positive correlation with the $\mathrm{Op}{ }^{\circ} . \mathrm{U} 1^{\circ}$ is a measure of the maxillary central incisor inclination relative to $\mathrm{TH}$. This indicates that the larger 
the $\mathrm{U} 1^{\circ}$, the more retroclined the incisor; and the smaller the $\mathrm{U} 1^{\circ}$ the more proclined the incisor. Therefore, steeper occlusal planes are associated with greater retroclination of the maxillary incisors. $\mathrm{L}^{\circ}(\mathrm{r}=-0.259, \mathrm{p}=0.0076)$ is negatively correlated with $\mathrm{Op}^{\circ} . \mathrm{L}^{\circ}$ is a measure of the mandibular central incisor inclination relative to $\mathrm{TH}$. This indicates that the larger the $\mathrm{L}^{\circ}$, the more retroclined the lower incisor and vice versa. Therefore, there is an association between greater proclination of the lower incisors and steeper occlusal plane inclinations.

\section{Six Elements Measurements:}

$\mathrm{The}_{\mathrm{Op}}{ }^{\circ}$ demonstrates a statistically significant negative correlation with Element II Mx $(\mathrm{r}=-0.2048, \mathrm{p}=0.0361)$ and a positive correlation with Element IV Mx Ant $(\mathrm{r}=0.4288, \mathrm{p}<$ .001). A larger measure of Element IV Mx Ant indicates a greater amount of tooth display. Therefore, there is a moderate relationship between the amount of tooth display and the occlusal plane inclination.

The Element II Mx, although a measure of jaw position, is measured as a distance from a hypothetically positioned Element I maxillary central incisor's facial axis point relative to the GALL. The positioning of the Element I incisor is completed using the occlusal plane and the weak correlation may be explained as a confounding result of the measurement itself. 


\section{Stepwise Regression Analysis}

The step-wise regression analysis (Appendix B) was performed to further evaluate the relationship between cephalometric variables and $\mathrm{Op}^{\circ}$. $\mathrm{Op}^{\circ}$ was held as the dependent variable and the regression analysis resulted in the following equation:

$\mathrm{Op}^{\circ}=5.232+0.277\left(\mathrm{SN}-\mathrm{MP}^{\circ}\right)+0.615\left(\mathrm{PP}^{\circ}\right)-0.684(\mathrm{IV} \mathrm{Md} \mathrm{Ant})-0.541$ (PP-Msc) +0.487 (PP1) $+0.279(\mathrm{Mp}-\mathrm{Mic})+0.207\left(\mathrm{Sn}^{\prime}-\mathrm{Me}^{\prime}\right)-0.223\left(\mathrm{SN}^{\circ}\right)+0.215(\mathrm{IV} \mathrm{Mx} \mathrm{Ant})-0.037$ (Co-Gn)

The $\mathrm{R}^{2}=0.78$, which indicates that $78 \%$ of the variation in Op can be explained by changes in SN-MP, PP ${ }^{\circ}$ IV Md Ant, PP-Msc, PP-U1, MP-Mic, Sn'-Me', SN- IV Mx Ant, and Co-Gn. As $\mathrm{Op}^{\circ}$ increases the following variables likewise increase; SN-MP, PP-U1, MpMic, Sn'-Me', and IV Mx Ant. As the Op ${ }^{\circ}$ decreases IV Md Ant, PP-Msc, SN ${ }^{\circ}$, Co-Gn increases. 


\section{Pogonion prominence by AP Skeletal Pattern (ANB)}

Within the pooled sample $(n=105) 38 \%(n=40)$ were Category I, 32\% $(n=34)$ were Category II $\left(\mathrm{ANB}>5^{\circ}\right)$ and $30 \%(\mathrm{n}=31)$ were Category III $\left(\mathrm{ANB}<0^{\circ}\right)$. Descriptive statistics, results of the ANOVA, and comparison of means (Appendix B) for all measures of the anteroposterior position of pogonion (Pog-GALL, Pog'-GALL, Pog'c-GALL, Pog'-TVL) are summarized in Table 12.

Table 12: Pogonion Prominence by Anteroposterior (ANB) Skeletal Pattern

\begin{tabular}{lcccccccccc}
\hline & \multicolumn{2}{c}{$\begin{array}{c}\text { Class I } \\
(\mathrm{n}=61)\end{array}$} & \multicolumn{2}{c}{$\begin{array}{c}\text { Class II } \\
(\mathrm{n}=28)\end{array}$} & \multicolumn{2}{c}{$\begin{array}{c}\text { Class III } \\
(\mathrm{n}=16)\end{array}$} & ANOVA & I-II & I-III & II-III \\
\cline { 2 - 14 } Variable & Mean & S.D. & Mean & S.D. & Mean & S.D. & Prob $>$ F & p-Value & p-Value & p-Value \\
Pog'-GALL & 1.79 & 4.05 & -2.18 & 4.86 & 5.05 & 4.32 & $<.0001^{*}$ & $0.0001^{*}$ & $0.0084^{*}$ & $<.0001^{*}$ \\
Pog'c-GALL & 0.46 & 4.21 & -3.47 & 3.99 & 3.17 & 3.89 & $<.0001^{*}$ & $<.0001^{*}$ & $<.0001^{*}$ & $0.0206^{*}$ \\
Pog'-TVL & -5.88 & 4.23 & -10.87 & 5.34 & -1.00 & 5.45 & $<.0001^{*}$ & $<.0001^{*}$ & $<.0001^{*}$ & $0.0004^{*}$ \\
Pog-GALL & -9.50 & 4.86 & -14.17 & 4.74 & -4.71 & 6.52 & $<.0001^{*}$ & $<.0001^{*}$ & $0.0012^{*}$ & $0.0001^{*}$ \\
\hline
\end{tabular}

p-Value determined by Student's t-test.

* statistically significant at $\mathrm{p}<.05$

There were stastistically significant differences among all groups, Class I, II and III, for all measurements of the pogonion prominence (Pog'-GALL, Pog'c-GALL, Pog'-TVL, PogGALL). Figure 23 demonstrates the mean Pog'c-GALL by Skeletal Class.

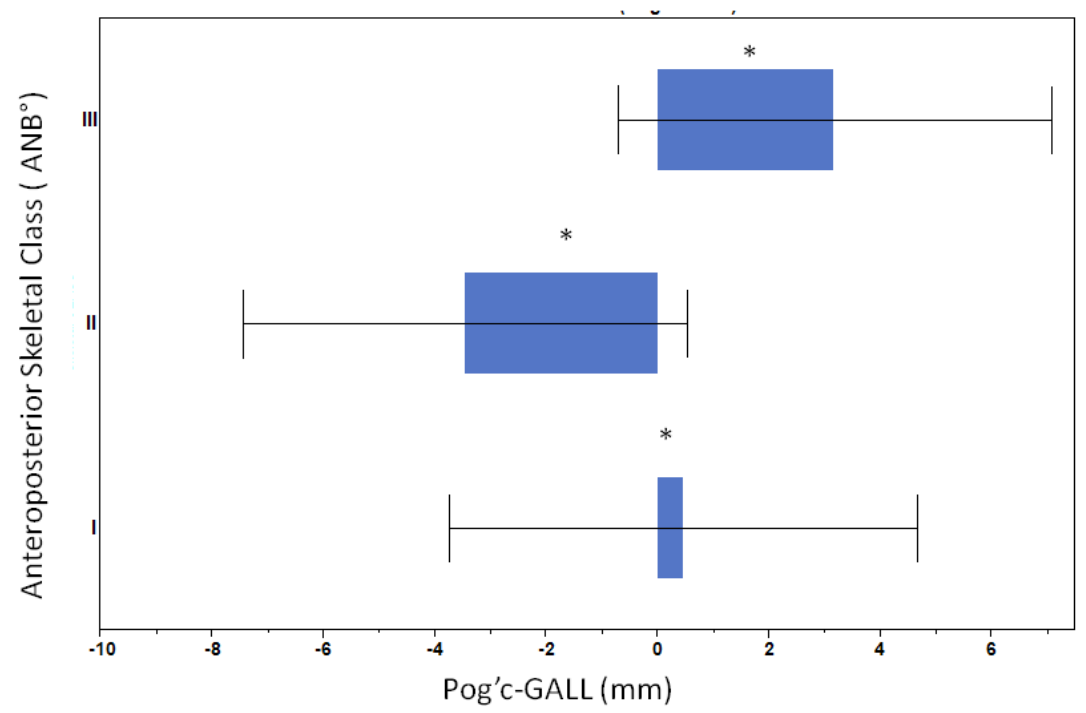

Figure 23: Mean Pog'c-GALL(mm) by Anteroposterior Skeletal Class *Stastically significant differences detected between all groups 


\section{Pogonion prominence by Six Elements AP Skeletal Pattern}

Within the pooled sample $(n=105) 38 \%(n=40)$ were Category I, $32 \%(n=34)$ were

Category II and 30\% ( $\mathrm{n}=31)$ were Category III. Descriptive statistics, results of the ANOVA,

and comparison of means (Appendix B) for all measures of the anteroposterior position of pogonion are summarized in Table 13.

Table 13: Pogonion Prominence by Six Elements Anteroposterior Skeletal Pattern

\begin{tabular}{|c|c|c|c|c|c|c|c|c|c|c|}
\hline \multirow[b]{2}{*}{ Variable } & \multicolumn{2}{|c|}{$\begin{array}{c}\text { Category I } \\
(n=40)\end{array}$} & \multicolumn{2}{|c|}{$\begin{array}{c}\text { Category II } \\
(n=34)\end{array}$} & \multicolumn{2}{|c|}{$\begin{array}{c}\text { Category III } \\
(n=31)\end{array}$} & \multirow{2}{*}{$\begin{array}{l}\text { ANOVA } \\
\text { Prob }>F\end{array}$} & \multirow{2}{*}{$\frac{\mathrm{I}-\mathrm{II}}{\mathrm{p} \text {-Value }}$} & \multirow{2}{*}{$\frac{\text { I-III }}{\text { p-Value }}$} & \multirow{2}{*}{$\frac{\text { II-III }}{\text { p-Value }}$} \\
\hline & Mean & S.D. & Mean & S.D. & Mean & S.D. & & & & \\
\hline Pog'GALL & 1.66 & 3.79 & -1.89 & 4.99 & 4.08 & 4.11 & $<.0001$ & $0.0006^{*}$ & $0.0211^{*}$ & $<.0001^{*}$ \\
\hline Pog'c-GALL & 0.34 & 3.77 & -3.11 & 4.35 & 2.38 & 4.26 & $<.0001^{*}$ & $0.0005^{*}$ & 0.0399* & $<.0001^{*}$ \\
\hline Pog'-TVL & -6.60 & 4.41 & -10.07 & 5.36 & -2.36 & 4.69 & 0.0034 & $0.0026^{*}$ & $0.0004^{*}$ & $<.0001^{*}$ \\
\hline Pog-GALL & -9.74 & 3.38 & -12.48 & 7.99 & -7.67 & 4.76 & $<.0001$ & $0.0394^{*}$ & 0.127 & $0.0008 *$ \\
\hline
\end{tabular}

$\mathrm{p}$-Value determined by Student's t-test. * statistically significant at $\mathrm{p}<.05$

Statistically significant differences among all Six Elements AP categories were shown for Pog'GALL, Pog'c-GALL, and Pog'-TVL. For the measure Pog-GALL there were statistically significant differences between the category I and II groups, and category II and III groups.

There was not a difference among category I and III groups for Pog-GALL. Figure 24 demonstrates the mean Pog'c-GALL by Six Element AP category.

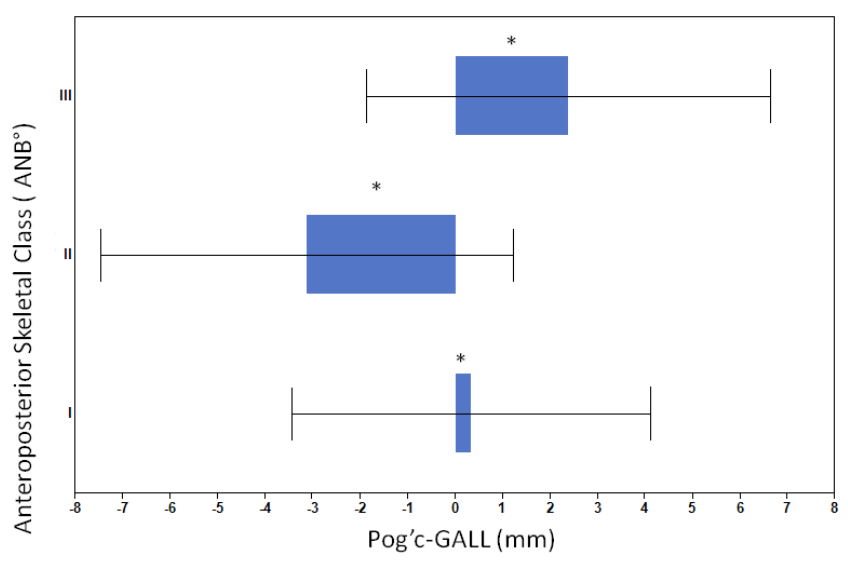

Figure 24: Mean Pog'c-GALL (mm) by Six Element Anteroposterior Skeletal Category. *Stastically significant differences detected between all groups 


\section{Pogonion prominence by Soft Tissue Convexity}

Within the pooled sample $(n=105)$ the distribution of soft tissue convexity resulted in $39 \%(n=41)$ normal $\left(G^{\prime}-S^{\prime}{ }^{\prime}-P_{0}{ }^{\circ}{ }^{\circ}=165-175^{\circ}\right), 48 \%(n=50)$ convex $\left(G^{\prime}-S^{\prime}-P^{\prime}{ }^{\prime}{ }^{\circ}>175^{\circ}\right)$ and $13 \%(n=14)$ concave $\left(G^{\prime}-S^{\prime} n^{\prime}-P_{0 g}{ }^{\circ}<165^{\circ}\right)$. Descriptive statistics, results of the ANOVA, and comparison of means (Appendix B) for all measures of the anteroposterior position of pogonion (Pog-GALL, Pog'-GALL, Pog'c-GALL, Pog'-TVL) are summarized in Table 14.

Table 14: Pogonion Prominence by Soft Tissue Convexity

\begin{tabular}{lcccccccccc}
\hline & \multicolumn{2}{c}{$\begin{array}{c}\text { Normal }(\mathrm{N}) \\
(\mathrm{n}=41)\end{array}$} & \multicolumn{2}{c}{$\begin{array}{c}\text { Convex }(\mathrm{Cx}) \\
(\mathrm{n}=50)\end{array}$} & \multicolumn{2}{c}{$\begin{array}{c}\text { Concave }(\mathrm{Cv}) \\
(\mathrm{n}=14)\end{array}$} & ANOVA & N-Cx & N-Cv & Cx-Cv \\
\cline { 2 - 13 } Variable & Mean & S.D. & Mean & S.D. & Mean & S.D. & Prob>F & p-Value & p-Value & p-Value \\
Pog'GALL & 2.65 & 3.54 & -1.40 & 4.44 & 6.42 & 4.00 & $<.0001^{*}$ & $<.0001^{*}$ & $0.0033^{*}$ & $<.0001^{*}$ \\
Pog'C-GALL & 1.17 & 3.44 & -2.57 & 4.20 & 4.42 & 4.23 & $<.0001^{*}$ & $<.0001^{*}$ & $0.0087^{*}$ & $<.0001^{*}$ \\
Pog'-TVL & -4.45 & 3.03 & -10.50 & 4.25 & 2.00 & 2.68 & $<.0001^{*}$ & $<.0001^{*}$ & $<.0001^{*}$ & $<.0001^{*}$ \\
Pog-GALL & -8.66 & 5.22 & -12.22 & 5.83 & -6.12 & 5.02 & $0.0003^{*}$ & $0.0028^{*}$ & 0.1376 & $0.0004^{*}$ \\
\hline
\end{tabular}

p-Value determined by Student's t-test.

* statistically significant at $p<.05$

Statistically significant differences among all groups of soft tissue facial convexity were shown for Pog'-GALL, Pog'c-GALL, and Pog'-TVL. There was a statistically significant difference between the normal and convex groups, and between the convex and concave groups for Pog-GALL. There was no difference between the normal and concave for Pog-GALL. Figure 25 demonstrates the mean Pog'c-GALL by soft tissue convexity. 


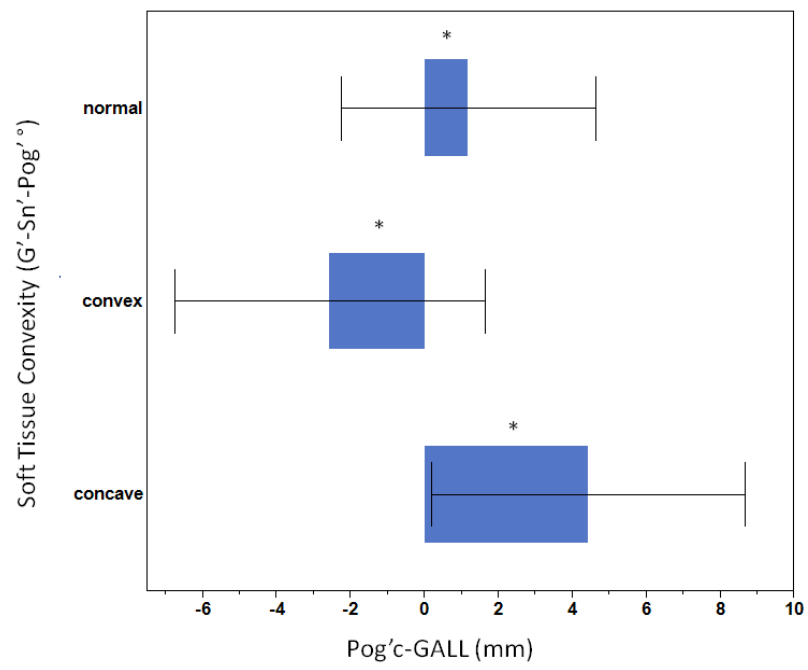

Figure 25: Mean Pog'c-GALL ( $\mathrm{mm}$ ) by Soft Tissue Convexity *Stastically significant differences detected between all groups

\section{Pogonion prominence by Vertical Pattern}

Within the pooled sample $(n=105)$ the distribution of the vertical pattern resulted in $55 \%$ $(\mathrm{n}=58)$ normodivergent $\left(\mathrm{SN}-\mathrm{MP} 20-32^{\circ}\right), 28 \%(\mathrm{n}=29)$ hypodivergent $\left(\mathrm{SN}-\mathrm{MP}<20^{\circ}\right)$ and $21 \%$ $(n=22)$ hyperdivergent $\left(\mathrm{SN}-\mathrm{MP}>32^{\circ}\right)$. Descriptive statistics, results of the ANOVA, and comparison of means (Appendix $G$ ) for all measures of the anteroposterior position of pogonion (Pog-GALL, Pog'-GALL, Pog'c-GALL, Pog'-TVL) are summarized in Table 15.

Table 15: Pogonion Prominence by Vertical Dimension

\begin{tabular}{|c|c|c|c|c|c|c|c|c|c|c|}
\hline \multirow[b]{2}{*}{ Variable } & \multicolumn{2}{|c|}{$\begin{array}{c}\text { Normodivergent } \\
(N) \\
(n=58)\end{array}$} & \multicolumn{2}{|c|}{$\begin{array}{c}\text { Hypodivergent } \\
(\mathrm{Ho}) \\
(\mathrm{n}=29) \\
\end{array}$} & \multicolumn{2}{|c|}{$\begin{array}{c}\text { Hyperdivergent } \\
(\mathrm{Hr}) \\
(\mathrm{n}=22) \\
\end{array}$} & \multirow{2}{*}{$\begin{array}{l}\text { ANOVA } \\
\text { Prob>F }\end{array}$} & \multirow{2}{*}{$\begin{array}{c}\text { N-Ho } \\
\text { p-Value }\end{array}$} & \multirow{2}{*}{$\begin{array}{c}\mathrm{N}-\mathrm{Hr} \\
\mathrm{p} \text {-Value }\end{array}$} & \multirow{2}{*}{$\begin{array}{c}\text { Ho-Hr } \\
\text { p-Value }\end{array}$} \\
\hline & Mean & S.D. & Mean & S.D. & Mean & S.D. & & & & \\
\hline Pog'GALL & 1.04 & 4.37 & 3.55 & 4.07 & -1.38 & 5.76 & $0.0011^{*}$ & $0.0197^{*}$ & $0.0409 *$ & $0.0003^{*}$ \\
\hline Pog'c-GALL & -0.35 & 4.33 & 1.02 & 4.35 & -1.31 & 5.48 & 0.1896 & 0.1982 & 0.4111 & 0.0759 \\
\hline Pog'-TVL & -6.95 & 4.41 & -3.37 & 5.02 & -9.38 & 7.30 & $0.0004^{*}$ & $0.0041 *$ & 0.0721 & $0.0001^{*}$ \\
\hline Pog-GALL & -9.86 & 5.41 & -7.74 & 5.93 & -13.40 & 5.66 & $0.0024^{*}$ & 0.1028 & $0.0142 *$ & $0.0005^{*}$ \\
\hline
\end{tabular}

$\mathrm{p}$-Value determined by Student's t-test. ${ }^{*}$ statistically significant at $p<.05$ 
There are significant differences among all the vertical groups for Pog'-GALL. There are significant differences between the normodivergent and hyperdivergent; and between the hypodivergent and hyperdivergent groups for Pog'-TVL. There was no difference between the normal and hyperdivergent groups for Pog'-TVL. There were no significant differences among any of the groups for Pog'c-GALL (Fig. 26). The measure of hard tissue pogonion (Pog-Gall) showed differences between the normal and hyperdivergent groups and the hypo- and hyperdivergent groups.

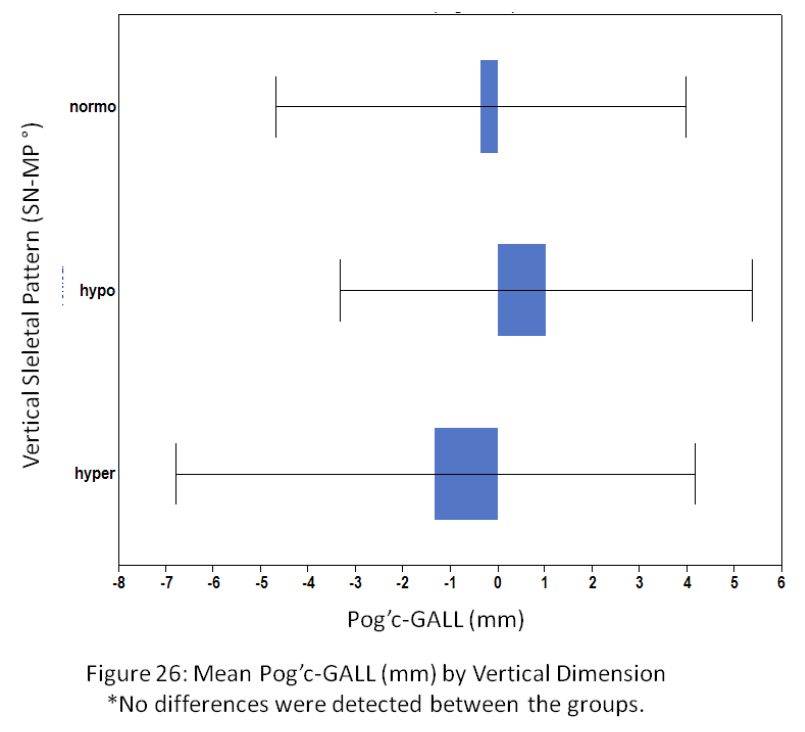




\section{CHAPTER 5: Discussion}

\section{Overview}

Historically, the occlusal plane has received much interest throughout the literature, which is substantiated by numerous publications relating it to craniofacial form ${ }^{1-3}$, craniofacial growth $^{4}$, masticatory function ${ }^{5,6}$, dental occlusion ${ }^{7,8}$, mechanotherapy ${ }^{9,10}$, orthognathic surgery ${ }^{11-15}$, and prosthodontic rehabilitation ${ }^{28}$. Studies have shown that the occlusal plane varies relative to skeletal form. ${ }^{18,1,2,17,65,4}$ These studies attribute the vertical eruption of the dentition, and ultimately the resultant occlusal plane inclination, as a mechanism by which the dentoalveolar structure adapts or compensates for vertical and sagittal jaw discrepancies. Studies evaluating the skeletal variability in normal occlusions note the varying degrees of occlusal plane inclinations that exist. ${ }^{18,66}$ Some argue that there is an ideal range for the inclination of the occlusal plane, and utilize these guidelines in orthognathic surgery treatment planning. ${ }^{20}$ Furthermore, some advocate "normalizing" the occlusal plane in orthognathic surgery to attain ideal facial esthetics and adequate anteroposterior projection of soft tissue pogonion in certain facial types. ${ }^{11,12,38}$ In 1964, Schudy discussed the complex interaction between anteroposterior and vertical growth. ${ }^{67}$ He writes, "Vertical growth is trying to carry pogonion downward while anteroposterior growth is attempting to carry it forward". ${ }^{67}$ He presented the pogonion formula to predict the anteroposterior position of pogonion. This measure relied on condylar growth, vertical growth of the maxilla, and vertical growth of both the maxillary and mandibular first molar. Despite the relevance of the occlusal plane to facial form, Andrews does not address it as a component within the Six Elements of Orofacial Harmony. Andrews advocates that there are “six characteristics (within dentistry's milieu) that are essential for optimal orofacial health and appearance" 23 . These six characteristics do not address the need for an optimal inclination for 
the occlusal plane despite its influence on the spatial position of the chin. The need to surgically correct the inclination of the occlusal plane to achieve optimal facial harmony suggests that there is an optimal range of occlusal plane inclinations. Does an optimal range of occlusal plane inclinations exist?

The objective of this study was to systematically evaluate the inclination of the occlusal plane $\left(\mathrm{Op}^{\circ}\right)$ relative to various skeletal and dental cephalometric parameters. A sample of 105 pretreatment cephalometric radiographs, in subjects with a range of skeletal and dental morphological characteristics, was appraised. Differences in the $\mathrm{Op}^{\circ}$ and $\mathrm{AP}$ measurements of pogonion relative to the GALL were evaluated among the various anteroposterior, vertical, and soft tissue facial convexity groups were compared. Correlation coefficients evaluating relationships among the cephalometric measurements were calculated. A stepwise regression analysis was performed to further elucidate the variables which contribute to changes in the Op ${ }^{\circ}$.

\section{Craniofacial reference planes relative to true horizontal}

The mean occlusal plane inclination measured relative to a horizontal reference plane in the pooled study sample was $8.83^{\circ} \pm 3.5$ with a range of $0^{\circ}-18^{\circ}$. Our study is in agreement with other studies reporting the average occlusal plane inclinations utilizing other methods to

construct true horizontal and vertical reference planes. ${ }^{52,68}$ Leitao and Nanda ${ }^{68}$ reported the functional occlusal plane to a true vertical (FOP/VER) constructed with a bubble air device, with the patient in the natural head position, to be $98.32^{\circ} \pm 4.61$ with a range of $85.8-110.2^{\circ}$. When corrected as a measure relative to the horizontal (as opposed to the vertical) by subtracting $90^{\circ}$, the mean of $8.32^{\circ}$ and a range from -4.2 to $20.2^{\circ}$ agrees with our mean of $8.83^{\circ}$, but reports a larger range of inclinations than our study. Madsen et al ${ }^{52}$ reported a mean functional occlusal 
plane measured relative to a true horizontal, constructed utilizing a plumb line in a sample of 57 patients, to be $-11.18^{\circ} \pm 5.27$ with a range of -1.11 to -23.82 . Their study designated an anticlockwise direction as negative with the patient facing left. Therefore, the study conducted by Madsen et al reported a similar range of occlusal plane inclinations in their sample but a steeper mean inclination.

The additional reference planes $\mathrm{PP}^{\circ}, \mathrm{SN}^{\circ}$ and $\mathrm{MP}^{\circ}$ in our study were also in close agreement with the aforementioned studies. Table 14 displays an overview of the craniofacial reference planes measured relative to true horizontal in this study compared to the previously reported studies by Leitao and Nanda ${ }^{68}$ and Madsen et al. ${ }^{52}$ The values reported in the table were corrected for variations in measurements between the studies as described above.

Table 14: Comparison of studies reporting craniofacial reference planes measured relative to true horizontal

\begin{tabular}{lcccc|ccccc|rcccc}
\hline & \multicolumn{4}{c}{ Eppard, et al } & \multicolumn{4}{c}{ Leitao and Nanda } & \multicolumn{4}{c}{ Madsen et al. ${ }^{52}$} \\
\cline { 2 - 13 } Variable & Mean & S.D. & Min. & Max. & Mean & S.D. & Min. & Max. & Mean & S.D. & Min. & Max. \\
\hline \hline$O p^{o}$ & 8.83 & 3.50 & 0.00 & 18.00 & 8.32 & 4.61 & -4.20 & 20.20 & 11.18 & 5.27 & -1.11 & 23.87 \\
$P P^{o}$ & -1.39 & 3.17 & -9.00 & 7.00 & 0.48 & 4.38 & -10.1 & 15.1 & 0.97 & 5.04 & -9.77 & 13.37 \\
$S N^{o}$ & 9.20 & 3.21 & 0.00 & 16.00 & 8.19 & 4.45 & 22.50 & 6.50 & 5.19 & 5.13 & -14.86 & 9.88 \\
$M P^{o}$ & 22.58 & 5.49 & 10.00 & 36.00 & n/a & n/a & n/a & n/a & 25.54 & 6.84 & 10.49 & 42.77 \\
\hline
\end{tabular}

Measurements reported for Leitao and $\mathrm{Nanda}^{68}$ and Madsen et al ${ }^{52}$ studies are corrected for variations in methods of measurements to more easily visualize similarities. Please refer to references for exact measurements reported by these studies.

The similarity between these studies support the validity and reproducibility of utilizing natural head position and a true vertical / horizontal reference planes from which to judge craniofacial characteristics. Furthermore, the similarity also supports the use of the FP gauge ${ }^{\mathrm{TM}}$ and FALL-DALL measurement to construct a true vertical reference plane. Future studies comparing the accuracy of the FALL-DALL measurement utilizing the FP gauge ${ }^{\mathrm{TM}}$ is warranted. However, the outlook for it to be an accurate measurement is positive. 


\section{Op by Vertical Dimension}

The occlusal plane inclination demonstrates a significant relationship with variations in the vertical dimension. $\mathrm{Op}^{\circ}$ exhibited a statistically significant positive correlation with SN-MP $(\mathrm{r}=0.4798, \mathrm{p}<.0001)$. When grouped relative to facial divergence $\left(\mathrm{SN}-\mathrm{MP}^{\circ}\right)$ there were statistically significant differences among all groups (normodivergent, hyperdivergent, and hypodivergent) for $\mathrm{Op}^{\mathrm{o}}$. The mean $\mathrm{Op}^{\mathrm{o}}$ for hypodivergent, normodivergent, and hyperdivergent groups was $6.78^{\circ} \pm 3.36,8.88^{\circ} \pm 3.20$, , and $11.41^{\circ} \pm 2.62$, respectively. This indicates a steepening of the occlusal plane inclination with increasing facial divergence. This is in agreement with a study conducted by Anwar and Fida ${ }^{17}$ investigating skeletal and dental factors in subjects with various vertical skeletal patterns grouped by SN-MP. Their study reported that the mean $\mathrm{SN}^{-\mathrm{OP}^{\circ}}$ likewise increased with facial divergence, and reported a statistically significant difference among the groups. There are no studies that have measured the occlusal plane inclination relative to a true horizontal and related to vertical skeletal dysplasias.

$\mathrm{Op}^{\mathrm{o}}$ demonstrated a statistically significant negative correlation for measurements of posterior facial height, $\mathrm{S}-\mathrm{Go}^{\circ}(\mathrm{r}=-0.3825, \mathrm{p}<.0001)$ and $\mathrm{Co}-\mathrm{Go}^{\circ}(\mathrm{r}=-0.3231, \mathrm{p}=0.0008)$. However, there was no correlation between the occlusal plane inclination and measurements of anterior facial height. The exception was that the Element IV Mx Ant did demonstrate a statistically significant correlation with the $\mathrm{Op}^{\circ}$.

Anwar and Fida ${ }^{17}$ reported similar findings. They reported a significant negative correlation of SN-OP with posterior facial height (S-Go); but no correlation was noted with respect to lower anterior facial height or total anterior facial height.

$\mathrm{Op}^{\mathrm{o}}$ also demonstrated a positive correlation with the gonial angle $\left(\mathrm{Go}^{\circ}\right)(\mathrm{r}=0.288, \mathrm{p}=$ 0.0029). This does not agree with the findings of Anwar and Fida. ${ }^{17}$ In summary, the occlusal 
plane inclination is closely associated with the vertical dimension. Steeper occlusal plane inclinations are associated with hyperdivergent profiles; whereas, flatter occlusal plane inclinations are associated with hypodivergent profiles.

\section{Op ${ }^{\circ}$ by Anteroposterior Skeletal Pattern}

The occlusal plane inclination demonstrates a relationship with anteroposterior jaw relationships. The $\mathrm{Op}^{\circ}$ exhibited statistically significant positive correlation with ANB $(\mathrm{r}=$ $0.2684, p=0.0056)$ and a negative correlation with $\operatorname{SNB}(r=-0.2355, \mathrm{p}=0.0156)$ The mean $\mathrm{Op}^{\circ}$ for Class I, II and III subjects categorized by ANB was $8.61^{\circ} \pm 3.63,10.09^{\circ} \pm 3.05$, and $7.44^{\circ} \pm 3.21$, respectively. This demonstrates a trend for the occlusal plane inclination to be steeper in skeletal Class II patients and flatter in skeletal Class III patients. However, Op ${ }^{\circ}$ was found to only be statistically different between the Class II and Class III skeletal groups.

The findings that the occlusal plane inclination varies relative to the anteroposterior dimension are in agreement with several authors. Downs in $1949^{16}$ may have been the first to note that the occlusal plane has a tendency to be steep in the skeletal Class II profile and flatter in the skeletal Class III profile. Studies evaluating the variation in skeletal patterns among subjects with normal occlusion report the same tendencies. These studies individually report that normal Class I occlusions exist within a framework of an ANB that ranges from -3 to $8^{\circ}$. Each of these studies reports the tendency for flat occlusal planes in those with a Class III skeletal pattern and steep occlusal planes in those with Class II skeletal patterns.

One study evaluating the dentoalveolar factors that contribute to the skeletal Class II malocclusion, report the occlusal plane (SN-OP) and lower incisor position (L1-OP) to be the most likely compensating factors. ${ }^{65}$ Ishikawa et al. ${ }^{2}$ reported that the upper incisor inclination 
(SN-U1), lower incisor inclination (SN-L1) and occlusal plane inclination (SN-OP) were important factors in dentoalveolar compensation comparing skeletal Class I and III subjects. These reports of variations in the occlusal plane inclination with different skeletal profiles are consistent with the findings of our study.

It is interesting to note that when the sample was grouped based on skeletal base differences according to the Six Elements approach, there were no statistically significant differences among the groups based on the anteroposterior dimension (Table 6, Fig. 17). The Six Elements approach is analogous to the Wits Appraisal ${ }^{35}$ in that the inter-jaw relationships are measured along the occlusal plane. Del Santo ${ }^{69}$ addresses the influence the occlusal plane has on the consistency or lack of consistency between assessments made using ANB and the Wits appraisal. ${ }^{69}$ He reported an inconsistency between ANB and Wits in subjects with a high occlusal plane. Likewise, comparison of sagittal jaw relationships utilizing the ANB and the Six Elements method would demonstrate inconsistencies. It is also interesting to note that the occlusal plane had a stronger relationship with the vertical dimension. As an angular measurement, ANB, as the difference of SNA and SNB, is influenced by the vertical dimension, and thus exhibits a relationship with the occlusal plane, whereas the Six Elements method does not. Therefore, the rotational aspects of the jaws, due to the interaction of the vertical and anteroposterior dimension cannot be overlooked when evaluating craniofacial form. This further demonstrates the need for the incorporation of an optimal occlusal plane inclination in the Six Elements method of diagnosis and treatment planning. 


\section{Op related to pogonion $\left(\mathrm{Po}^{\circ}\right)$}

Soft tissue and hard tissue measurements of pogonion were made relative to the GALL. No studies have evaluated the distance of pogonion relative to the GALL. In addition, Andrews does not designate an optimal measurement of soft tissue pogonion to the GALL. The interaction between vertical and anteroposterior jaw relationships suggests that there is an association between the inclination of the occlusal plane and the position of pogonion relative to the GALL. In this study, $\mathrm{Op}^{\circ}$ demonstrated a highly statistically significant negative correlation for all measurements of pogonion (Table 9). This indicates that steeper occlusal plane inclinations are associated with more posteriorly positioned pogonions relative to the GALL and TVL. Likewise, flatter occlusal plane inclinations are associated with a more anteriorly positioned pogonion relative to the GALL and TVL.

As one would expect, the measurement of the soft tissue pogonion relative to the GALL varies with the anteroposterior dimension measured by ANB (Table 10), the Six Elements method (Table 11) and soft tissue facial convexity (Table 12). Pog'-GALL was also different among all the groups based on the vertical dimension. The mean soft tissue pogonion measured relative to the GALL when corrected for the deviation in hard tissue pogonion from ideal (Element V) for the Class I sample was $0.46 \mathrm{~mm} \pm 4.21$, for the Category I sample was $0.34 \mathrm{~mm}$ \pm 3.77 , for the normal soft tissue convexity sample was $1.17 \mathrm{~mm} \pm 3.44$ and for the normodivergent sample was $-0.35 \mathrm{~mm} \pm 4.33$. These groups represent those that conform more to a balanced dentofacial profile. Therefore, we can assume an optimal soft tissue pogonion measured relative to the GALL may be $\pm 1 \mathrm{~mm}$ to the GALL. Future studies using judgments of harmonious profiles are warranted to determine the optimal range for soft tissue pogonion measured relative to the GALL. 


\section{Op ${ }^{\circ}$ Prediction}

The strongest predictor of $\mathrm{Op}^{\mathrm{o}}$, according to the results of the regression analysis, is SN-MP ${ }^{o}$, followed in descending order by PP $^{\mathrm{o}}$, Element IV Md Ant, PP-Msc, PP-1, Mp-Mic, Sn'-Me', SN', Element IV Mx Ant and Co-Gn. This supports the basis that the occlusal plane inclination varies relative to both skeletal and dental factors. The occlusal plane steepens with increasing facial divergence $(\mathrm{SN}-\mathrm{MP})$. $\mathrm{As} \mathrm{Op}^{\circ}$ increases the following variables likewise increase; PP', PP-U1, Mp-Mic, Sn’-Me', and IV Mx Ant. As the Op ${ }^{\circ}$ decreases IV Md Ant, PP-Msc, $\mathrm{SN}^{\circ}, \mathrm{Co}-\mathrm{Gn}$ increases.

Therefore, as the profile tends towards hyperdivergence, the occlusal plane, mandibular plane and palatal planes have the tendency to rotate in an anticlockwise direction; lower tnterior facial height is larger, mandibular length is smaller, and there is increased dental eruption of the mandibular molar and greater maxillary tooth display of the maxillary incisor. Likewise, as the profile tends to be more hypodivergent, the occlusal plane, mandibular plane and palatal planes have the tendency to rotate in a clockwise direction; lower anterior facial height is smaller, mandibular length is larger, and there is an increased dental eruption of the maxillary molar, decreased eruption of the mandibular molar, increased eruption of the the mandibular incisor and less maxillary incisor tooth display. 


\section{Clinical Implications}

The findings of the study demonstrate statistically significant correlations with various skeletal and dental parameters; however, the correlations are at best moderate to weak. This is evidence of the large variability in craniofacial form; and suggests that each patient be examined on an individual basis. This gives support to the use of the Six Elements of Orofacial Harmony as a method of diagnosis and treatment planning. The Six Elements approach produces a diagnosis based on each Element that is unique to the individual.

The findings also demonstrate that the occlusal plane inclination is a fundamental aspect of diagnosis and treatment planning for both combined orthodontic / orthopedic and orthodontic / orthognathic surgery. A report by Batwa et al. demonstrated that altering the occlusal plane inclination has an effect on smile attractiveness. Smiles with occlusal planes at $10^{\circ}$ to the occlusal plane were deemed most attractive. The $\mathrm{Op}^{\circ}$ in this study was significantly correlated with the inclination of the maxillary incisor. This suggests that changes in the occlusal plane induced by orthodontic biomechanics or during orthognathic surgical procedures should be properly evaluated to produce the most esthetic outcome.

In addition to the maxillary incisor inclination, alterations in the occlusal plane can have profound effects on the anteroposterior position of pogonion. Biomechanics which cause eruption of the molars in patients with hyperdivergent profiles will result in a downward and backward movement of pogonion and can worse profile esthetics in patients with mandibular deficiency. It was discussed previously that Class I normal occlusions can exists in a range of skeletal profiles. Therefore, a patient presenting for orthognathic surgery with a steep occlusal plane inclination and mandibular retrognathia would require a flattening of the occlusal plane inclination to obtain an adequate AP projection of pogonion, without the need for an additional 
genioplasty procedure. Despite the positive impact that a counterclockwise surgical procedure may have on the final esthetic outcome, long-term stability of these types of movements have not been documented in the literature. 


\section{CHAPTER 6: SUMMARY AND CONCLUSIONS}

\section{Summary}

The objective of this study was to systematically evaluate the inclination of the occlusal plane $\left(\mathrm{Op}^{\circ}\right)$ relative to various skeletal and dental cephalometric parameters. A sample of 105 pretreatment cephalometric radiographs, in subjects with a range of skeletal and dental morphological characteristics, was appraised. Differences in the $\mathrm{Op}^{\circ}$ and AP measurements of pogonion relative to the GALL were evaluated among the various anteroposterior, vertical, and soft tissue facial convexity groups were compared. Correlation coefficients evaluating relationships among the cephalometric measurements were calculated. A stepwise regression analysis was performed to further elucidate the variables which contribute to changes in the $\mathrm{Op}^{\circ}$.

The following null hypotheses were rejected:

1. The inclination of the occlusal plane does not correlate with the AP relationship of the chin relative to the GALL.

2. The inclination of the occlusal plane does not correlate with the inclination of the maxillary incisor

3. The inclination of the occlusal plane does not correlate with the AP position of the jaws.

4. The inclination of the occlusal plane does not correlate with facial soft tissue convexity.

5. The inclination of the occlusal plane does not correlate with the vertical jaw dimension. 
6. There are no predictive variables to determine the occlusal plane inclination.

7. There is no significant difference in the occlusal plane inclination among the three anteroposterior groups (Class II and Class III).

8. There is no significant difference in the occlusal plane inclination among the three vertical groups (normodivergent, hypodivergent, hyperdivergent).

9. There is no significant difference in the occlusal plane inclination among the three groups of soft tissue convexity (convex and concave).

The following null hypotheses were accepted:

1. There is no significant difference in the occlusal plane inclination among the three anteroposterior groups (Class I and II, Class I and III).

2. There is no significant difference in the occlusal plane inclination among the three groups of soft tissue convexity (convex and normal, concave and normal). 


\section{Conclusions}

The results of this study lead to the following conclusions:

1. There is a strong relationship between the occlusal plane inclination and the vertical dimension. Hyperdivergent profiles tend to have steeper occlusal plane inclinations. Hypodivergent profiles tend to have flatter occlusal plane inclinations

2. There is a tendency towards steeper occlusal planes in Class II skeletal subjects and a flatter occlusal plane in Class III skeletal subjects.

3. There is a tendency towards steeper occlusal planes in subjects with convex profiles and flatter occlusal planes in patients with concave profiles.

4. The occlusal plane inclination is highly correlated with the measurement of soft tissue pogonion to the GALL.

5. There is a strong correlation between the occlusal plane inclination and maxillary incisor inclination.

6. The occlusal plane inclination should be considered when diagnosis and treatment planning to maximize dental and facial esthetics. 


\section{CHAPTER 7: SUGGESTIONS FOR FUTURE RESEARCH}

The present study confirmed that the occlusal plane inclination is related to craniofacial form. The question of whether an optimal occlusal plane inclination exists remains unanswered. A study should be conducted that measures the occlusal plane inclination in a sample of patients that are judged to have harmonious profiles and normal dental occlusions. From such a sample the optimal range of occlusal plane inclinations can be obtained in addition to an optimal measurement of soft tissue pogonion relative to the GALL.

This study utilized the FP Gauge to ${ }^{\mathrm{TM}}$ assess the FALL-DALL judgment to construct a frontal reference plane. The accuracy and reliability of the FP Gauge ${ }^{\mathrm{TM}}$ as a measure of the frontal plane should be investigated. 


\section{References}

1. Downs WB. Analysis of the dentofacial profile. Angle Orthod 1956 10/01;26(4):191-212.

2. Ishikawa H, Nakamura S, Iwasaki H, Kitazawa S, Tsukada H, Sato Y. Dentoalveolar compensation related to variations in sagittal jaw relationships. Angle Orthod 1999 12/01;69(6):534-8.

3. Fushima K, FAU - Kitamura Y, Kitamura Y, FAU - Mita H, Mita H, FAU - Sato S, Sato S, FAU - Suzuki Y, Suzuki Y, FAU - Kim YH, et al. Significance of the cant of the posterior occlusal plane in class II division 1 malocclusions. - Eur J Orthod.1996 Feb;18(1):2740.(0141-5387 (Print); 0141-5387 (Linking)).

4. Tanaka EM, FAU - Sato S, Sato S. Longitudinal alteration of the occlusal plane and development of different dentoskeletal frames during growth. - Am J Orthod Dentofacial Orthop.2008 Nov;134(5):602.e1-11; Discussion 602-3.(1097-6752 (Electronic); 0889-5406 (Linking)).

5. Sato M, Motoyoshi M, Hirabayashi M, Hosoi K, Mitsui N, Shimizu N. Inclination of the occlusal plane is associated with the direction of the masticatory movement path. Eur J Orthod $2007 \mathrm{Feb} ; 29(1): 21-5$.

6. Ogawa T, Koyano K, Suetsugu T. The relationship between inclination of the occlusal plane and jaw closing path. J Prosthet Dent 1996 12;76(6):576-80.

7. THOMPSON WJ. Occlusal plane and overbite. Angle Orthod 1979 01/01;49(1):47-55.

8. Schudy FF. Cant of the occlusal plane and axial inclinations of teeth. Angle Orthod 1963 04/01;33(2):69-82.

9. Marsan G. Effects of activator and high-pull headgear combination therapy: Skeletal, dentoalveolar, and soft tissue profile changes. Eur J Orthod 2007 April 1;29(2):140-8.

10. Ulger G, Arun T, Sayınsu K, Isik F. The role of cervical headgear and lower utility arch in the control of the vertical dimension. American Journal of Orthodontics and Dentofacial Orthopedics 2006 10;130(4):492-501.

11. Wolford LM, FAU - Chemello PD, Chemello PD, FAU - Hilliard F, Hilliard F. Occlusal plane alteration in orthognathic surgery--part I: Effects on function and esthetics. - Am J Orthod Dentofacial Orthop.1994 Sep;106(3):304-16.(0889-5406 (Print); 0889-5406 (Linking)).

12. Wolford LM, FAU - Chemello PD, Chemello PD, FAU - Hilliard FW, Hilliard FW. Occlusal plane alteration in orthognathic surgery. - J Oral Maxillofac Surg.1993 Jul;51(7):730-40; Discussion 740-1.(0278-2391 (Print); 0278-2391 (Linking)). 
13. Rosen HM. Occlusal plane rotation: Aesthetic enhancement in mandibular micrognathia. Plast Reconstr Surg.1993 Jun;91(7):1231-40; Discussion 1241-4.(0032-1052 (Print); 00071226 (Linking)).

14. Reyneke JP, Evans WG. Surgical manipulation of the occlusal plane. Int J Adult Orthodon Orthognath Surg 1990;5(2):99-110.

15. Reyneke JP. Surgical manipulation of the occlusal plane: New concepts in geometry. - Int J Adult Orthodon Orthognath Surg.1998;13(4):307-16.(0742-1931 (Print); 0742-1931 (Linking)).

16. Downs WB. Variations in facial relationship: Their significance in treatment and Prognosis1. Angle Orthod 1949 07/01;19(3):145-55.

17. Anwar N, Fida M. Compensation for vertical dysplasia and its clinical application. Eur J Orthod 2009 October 1;31(5):516-22.

18. Casko JS, Shepherd WB. Dental and skeletal variation within the range of normal. Angle Orthod 1984 Jan;54(1):5-17.

19. Arnett GW, Jelic JS, Kim J, Cummings DR, Beress A, Worley CM,Jr, Chung B, Bergman R. Soft tissue cephalometric analysis: Diagnosis and treatment planning of dentofacial deformity. Am J Orthod Dentofacial Orthop 1999 Sep;116(3):239-53.

20. Arnett GW, Mclaughlin RP. Facial and dental planning for orthodontists and oral surgeons. Spain: Mosby; 2004. .

21. Paquette DE. Importance of the occlusal plane in virtual treatment planning. J Clin Orthod 2011 Apr;45(4):217,21; quiz 236.

22. Batwa W, Hunt NP, Petrie A, Gill D. Effect of occlusal plane on smile attractiveness. Angle Orthodontist 2012;82(2):218-23.

23. Andrews LF, Andrews WA. Syllabus of the andrews orthodontic philosophy. Ninth ed. U.S.: ;2001. .

24. Wahl N. Orthodontics in 3 millenia. chapter 1: Antiquity to the mid-19th century. Am J Orthod Dentofacial Orthop 2005;127:255-9.

25. Wahl N. Orthodontics in 2 millenia. chapter 2: Entering the modern era. Am J Orthod Dentofacial Orthop 2005;127:510-5.

26. Proffit WR, Fields HW, Ackerman JL, L'Tanya JB, Tulloch JFC, editors. Contemporary orthodontics. 3rd ed. St. Louis, Missouri: Mosby; 1999. . 
27. Ackerman JL, Proffit WR, Sarver DM, Ackerman MB, Kean MR. Pitch, roll, and yaw: Describing the spatial orientation of dentofacial traits. American Journal of Orthodontics and Dentofacial Orthopedics 2007 3;131(3):305-10.

28. Jayachandran S, FAU - Ramachandran CR, Ramachandran CR, FAU - Varghese R, Varghese R. Occlusal plane orientation: A statistical and clinical analysis in different clinical situations. - J Prosthodont.2008 Oct;17(7):572-5.Epub 2008 Aug 26.(1532-849X (Electronic); 1059-941X (Linking)).

29. Broadbent BH. A new x-ray technique and its application to orthodontia. Angle Orthod $1931 ; 1: 45-66$.

30. Abraham RA. A cephalometric investigation of craniofacial growth based on an occlusal reference system. Angle Orthod 1969 07/01;39(3):198-208.

31. Jenkins DH. Analysis of orthodontic deformity employing lateral cephalostatic radiography. Am J Orthod 1955;41:442-52.

32. Ricketts RM. A detailed consideration of the line of occlusion. Angle Orthod 1978 Oct;48(4):274-82.

33. The glossary of prosthodontic terms. J Prosthet Dent 2005 Jul;94(1):10-92.

34. Di Paolo RJ. An individualized approach to locating the occlusal plane. - Am J Orthod Dentofacial Orthop.1987 Jul;92(1):41-5.(0889-5406 (Print); 0889-5406 (Linking)).

35. Jacobson A, Jacobson RL, editors. Radiographic cephalometry: From basics to 3-D. Hanover Park, IL: Quintessence Publishing Co, Inc; 2006. .

36. Rosen HM. Aesthetic perspectives in jaw surgery. New York, NY: Springer; 1999. .

37. McCollum AG, Reyneke JP, Wolford LM. An alternative for the correction of the class II low mandibular plane angle. Oral Surg Oral Med Oral Pathol 1989 Mar;67(3):231-41.

38. Reyneke JP, FAU - Bryant RS, Bryant RS, FAU - Suuronen R, Suuronen R, FAU - Becker PJ, Becker PJ. Postoperative skeletal stability following clockwise and counter-clockwise rotation of the maxillomandibular complex compared to conventional orthognathic treatment. - Br J Oral Maxillofac Surg.2007 Jan;45(1):56-64.Epub 2006 Feb 9.(0266-4356 (Print); 0266-4356 (Linking)).

39. Chemello PD, FAU - Wolford LM, Wolford LM, FAU - Buschang PH, Buschang PH. Occlusal plane alteration in orthognathic surgery--part II: Long-term stability of results. Am J Orthod Dentofacial Orthop.1994 Oct;106(4):434-40.(0889-5406 (Print); 0889-5406 (Linking)). 
40. Steiner CC. The use of cephalometrics as an aid to planning and assessing orthodontic treatment. Am J Orthod 1960;46:721-35.

41. Arnett GW, Bergman RT. Facial keys to orthodontic diagnosis and treatment planning. part I. Am J Orthod Dentofacial Orthop 1993 Apr;103(4):299-312.

42. Arnett GW, Bergman RT. Facial keys to orthodontic diagnosis and treatment planning--part II. Am J Orthod Dentofacial Orthop 1993 May;103(5):395-411.

43. Bergman RT. Cephalometric soft tissue facial analysis. Am J Orthod Dentofacial Orthop 1999;116:373-9.

44. Holdaway RA. A soft-tissue cephalometric analysis and its use in orthodontic treatment planning. part I. Am J Orthod 1983 Jul;84(1):1-28.

45. Merrifield LL. The profile line as an aid in critically evaluating facial esthetics. - Am J Orthod.1966 Nov;52(11):804-22.(0002-9416 (Print); 0002-9416 (Linking)).

46. Richardson A. An investigation into the reproducibility of some points, planes, and lines used in cephalometric analysis. Am J Orthod 1966 Sep;52(9):637-51.

47. Lundstrom A, FAU - Lundstrom F, Lundstrom F. The frankfort horizontal as a basis for cephalometric analysis. - Am J Orthod Dentofacial Orthop.1995 may;107(5):537-40.(08895406 (Print); 0889-5406 (Linking)).

48. Subtelny JD. A longitudinal study of soft tissue facial structures and their profile characteristics, defined in relation to underlying skeletal structures. Am J Orthod 1959;45(7):481-507.

49. Nanda RS, FAU - Meng H, Meng H, FAU - Kapila S, Kapila S, FAU - Goorhuis J, Goorhuis J. Growth changes in the soft tissue facial profile. - Angle Orthod.1990 Fall;60(3):17790.(0003-3219 (Print); 0003-3219 (Linking)).

50. Park YC, FAU - Burstone CJ, Burstone CJ. Soft-tissue profile--fallacies of hard-tissue standards in treatment planning. - Am J Orthod Dentofacial Orthop.1986 Jul;90(1):5262.(0889-5406 (Print); 0889-5406 (Linking)).

51. Broca M. Sur les projections de la tete, et sur un nouveau procede de cephalometric. Bull De La Societe d' Anthropologie De Paris 1862;3:514--544.

52. Madsen DP, Sampson WJ, Townsend GC. Craniofacial reference plane variation and natural head position. Eur J Orthod 2008 Oct;30(5):532-40.

53. Lundstrom A, FAU - Lundstrom F, Lundstrom F, FAU - Lebret LM, Lebret LM, FAU Moorrees CF, Moorrees CF. Natural head position and natural head orientation: Basic 
considerations in cephalometric analysis and research. - Eur J Orthod.1995 Apr;17(2):11120.(0141-5387 (Print); 0141-5387 (Linking)).

54. Solow B, Tallgren A. Head posture and craniofacial morphology. Am J Phys Anthropol 1976 May;44(3):417-35.

55. Lundstrom F, Lundstrom A. Natural head position as a basis for cephalometric analysis. Am J Orthod Dentofacial Orthop 1992 Mar;101(3):244-7.

56. Cooke MS. Five-year reproducibility of natural head posture: A longitudinal study. Am J Orthod Dentofacial Orthop 1990 Jun;97(6):489-94.

57. Peng L, Cooke MS. Fifteen-year reproducibility of natural head posture: A longitudinal study. Am J Orthod Dentofacial Orthop 1999 Jul;116(1):82-5.

58. Cooke MS, Wei SH. The reproducibility of natural head posture: A methodological study. Am J Orthod Dentofacial Orthop 1988 Apr;93(4):280-8.

59. Spyropoulos MN, Halazonetis DJ. Significance of the soft tissue profile on facial esthetics. Am J Orthod Dentofacial Orthop 2001 May;119(5):464-71.

60. Ricketts RM. The biological significance of the divine proportion and fibonacci series. Am J Orthod 1982;81(5):351-70.

61. Jahanbin A, Basafa M, Alizadeh Y. Evaluation of the divine proportion in the facial profile of young females. Indian J Dent Res 2008 Oct-Dec;19(4):292-6.

62. Andrews WA. AP relationship of the maxillary central incisors to the forehead in adult white females. - Angle Orthod.2008 Jul;78(4):662-9.(0003-3219 (Print); 0003-3219 (Linking)).

63. Schlosser JB, Preston CB, Lampasso J. The effects of computer-aided anteroposterior maxillary incisor movement on ratings of facial attractiveness. Am J Orthod Dentofacial Orthop 2005 Jan;127(1):17-24.

64. Andrews LF. The six keys to normal occlusion. Am J Orthod 1972 Sep;62(3):296-309.

65. Anwar N, Fida M. Evaluation of dentoalveolar compensation in skeletal class II malocclusion in pakistani university hospital setting. J Coll Physicians Surg Pak 2009;19(1):11-6.

66. Kim JY, Lee SJ, Kim TW, Nahm DS, Chang YI. Classification of the skeletal variation in normal occlusion. Angle Orthod 2005 May;75(3):311-9.

67. Schudy FF. Vertical growth versus anteroposterior growth as related to function and treatment. Angle Orthodontist 1964;34(2):75-93. 
68. Leitao P, Nanda RS. Relationship of natural head position to craniofacial morphology. Am J Orthod Dentofacial Orthop 2000 Apr;117(4):406-17.

69. Del Santo Jr M. Influence of occlusal plane inclination on ANB and wits assessments of anteroposterior jaw relationships. American Journal of Orthodontics and Dentofacial Orthopedics 2006 5;129(5):641-8. 


\title{
ABSTRACT
}

\section{The occlusal plane inclination relative to craniofacial form: A cephalometric investigation}

\author{
Holly Eppard, DDS., Tim Tremont D.M.D., M,S, Peter Ngan, D.M.D., Chris Martin, D.D.S., \\ M.S.Bryan Weaver, D.D.S., M.D., and Erdogan Gunel, Ph.D.
}

Background Objectives: The occlusal plane has been given much attention throughout the orthodontic literature. Studies have shown that the occlusal plane inclination varies relative to vertical and sagittal skeletal discrepencies. The Six Elements of Orofacial Harmony does not address the occlusal plane inclination as a parameter in diagnosis and treatment planning despite its spatial influence on the position of the chin. The occlusal plane inclination is considered a critical factor in treatment planning for orthognathic surgery. The objective of this study was to systematically evaluate the inclination of the occlusal plane $\left(\mathrm{Op}^{\circ}\right)$ relative to various skeletal and dental cephalometric parameters. Methods: A sample of 105 pretreatment cephalometric radiographs, in subjects with a range of skeletal and dental morphological characteristics, was appraised. Differences in the $\mathrm{Op}^{\circ}$ and AP measurements of pogonion relative to the GALL were evaluated among the various anteroposterior, vertical, and soft tissue facial convexity groups were compared. Correlation coefficients evaluating relationships among the cephalometric measurements were calculated. A stepwise regression analysis was performed to further elucidate the variables which contribute to changes in the $\mathrm{Op}^{\circ}$. Results: The occlusal plane inclination was most significantly correlated with SN-MP', $\mathrm{MP}^{\mathrm{o}}$, Pog'GALL, Pog-GALL, Pogc'GALL, TVL-Pog, and S-Go. The regression analysis indicated that SN-MP' ${ }^{\circ} \mathrm{PP}^{\circ}$, Element IV Md Ant, PP-Msc, PP-1, Mp-Mic, Sn'-Me', SNº, Element IV Mx Ant and Co-Gn are good predictors of $\mathrm{Op}^{\circ}$. There were statistically significant differences among all vertical groups for the mean $\mathrm{Op}^{\circ}$. The mean $\mathrm{Op}^{\circ}$ was found to differ among Class II and III skeletal profiles and convex and concave soft tissue facial convexities. Conclusions: $\mathrm{Op}^{\circ}$ varies relative to sagittal and vertical jaw dimensions. There is a strong relationship between the occlusal plane inclination and the vertical dimension. Hyperdivergent profiles tend to have steeper occlusal plane inclinations. Hypodivergent profiles tend to have flatter occlusal plane inclinations. There is a tendency towards steeper occlusal planes in Class II skeletal subjects and a flatter occlusal plane in Class III skeletal subjects. There is a tendency towards steeper occlusal planes in subjects with convex profiles and flatter occlusal planes in patients with concave profiles. The occlusal plane inclination is highly correlated with the measurement of soft tissue pogonion to the GALL. There is a strong correlation between the occlusal plane inclination and maxillary incisor inclination. The occlusal plane inclination should be considered when diagnosis and treatment planning to maximize dental and facial esthetics. 
APPENDICES 
Appendix A - IRB Exemption

IRB PROTOCOL - Details

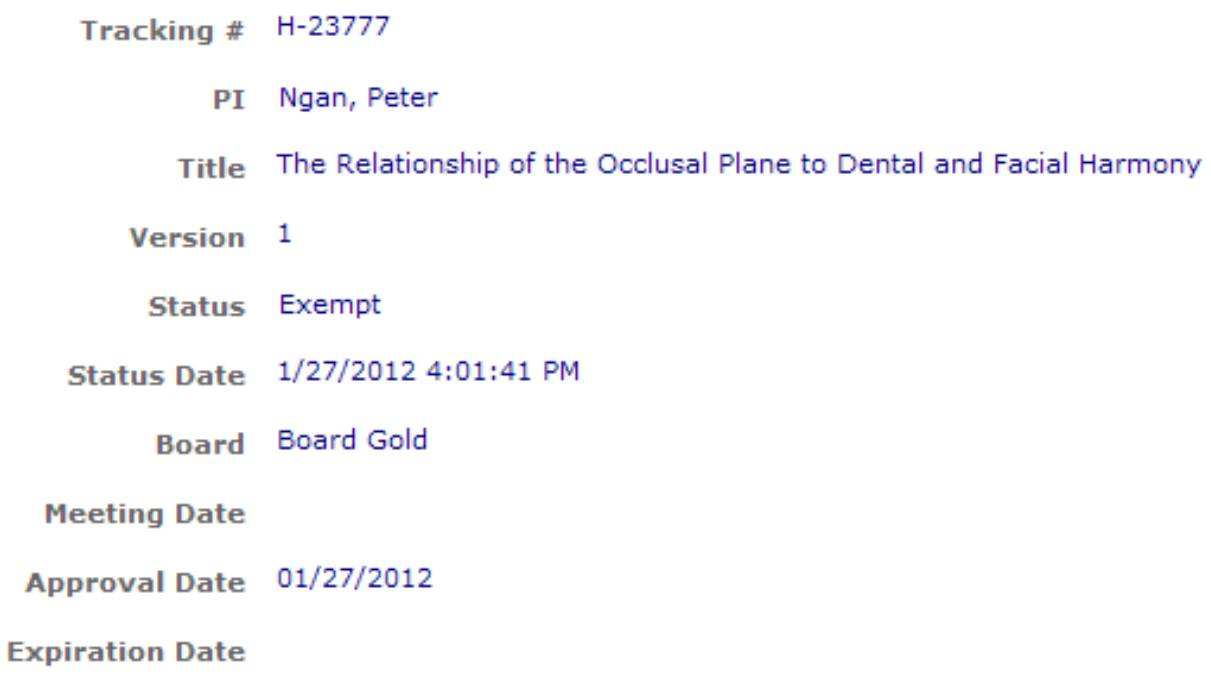




\section{Appendix B}

\section{Statistical Analyses by Age and Gender}

$\mathrm{G}=<18$ years of age

$N G=\geq 18$ years of age

Oneway Analysis of ANS-Me By AGE

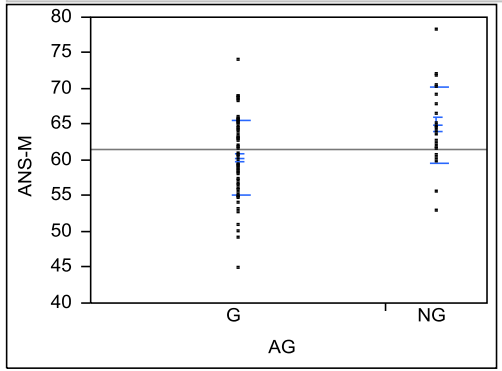

Means and Std Deviations

Std Err

Level Number Mean Std Dev Mean Lower 95\% Upper 95\%

$\begin{array}{llrr}5.22183 & 0.5913 & 59.110 & 61.465\end{array}$

$\begin{array}{lllllll}\text { NG } & 27 & 64.9537 & 5.31908 & 1.0237 & 62.850 & 67.058\end{array}$

t Test

NG-

Assuming unequal variance

Difference 4.66588 t Ra

Std Err Dif 1.18214 DF

Lower CL Di 228429 Prob >t 0.0001

Confidence $\quad 0.95$ Prob $<t \quad 0.9999$

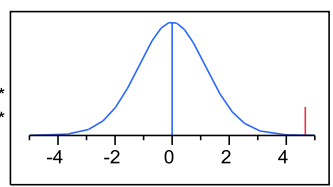

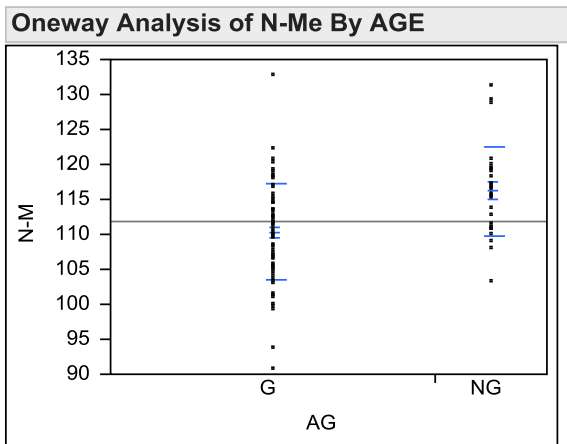

Means and Std Deviations

Level Number Mean Std Dev $\begin{gathered}\text { Std Err } \\ \text { Mean Lower 95\% Upper 95\% }\end{gathered}$

$\begin{array}{lllllrr}\text { G } & 78 & 110.326 & 6.79927 & 0.7699 & 108.79 & 111.86\end{array}$

$\begin{array}{lllllll}\text { NG } & 27 & 116.194 & 6.42422 & 1.2363 & 113.65 & 118.74\end{array}$

t Test

NG-

Assuming unequal variance

Difference 5.86803 t Ratio 4.029009

Std Err Dif 1.45645 DF

Upper $\mathrm{CLIi} 8.79697$ Prob $>\mathrm{It} \quad 0.0002 *$

Lower CL Di 2.93910 Prob $>$ t 0.0001 *

$\begin{array}{lrl}\text { Confidence } & 0.95 \text { Prob }<\mathrm{t} \quad 0.9999\end{array}$

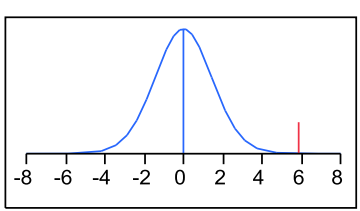



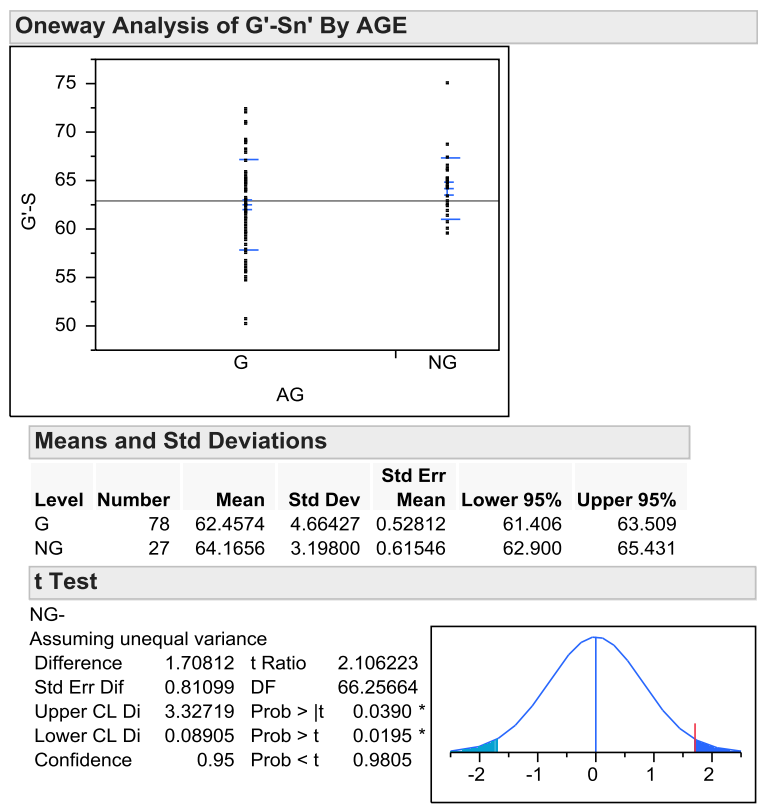

Oneway Analysis of Co-Go By AGE

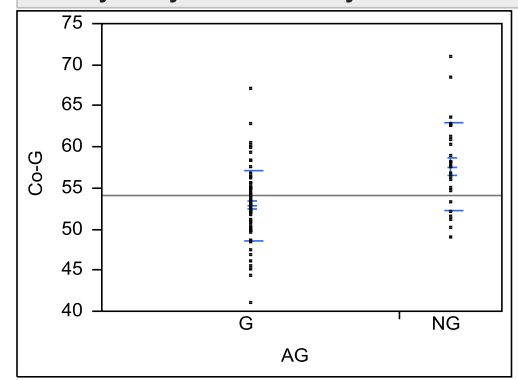

Means and Std Deviations

\begin{tabular}{lrrrrrr} 
& & \multicolumn{5}{c}{ Std Err } \\
Level Number & Mean & Std Dev & Mean & Lower 95\% & Upper 95\% \\
G & 78 & 52.8765 & 4.28531 & 0.4852 & 51.910 & 53.843 \\
NG & 27 & 57.5815 & 5.41008 & 1.0412 & 55.441 & 59.722
\end{tabular}

$\begin{array}{llll}27 & 57.5815 & 5.41008 & 1.0412\end{array}$

t Test

NG-

Assuming unequal variance

$\begin{array}{lll}\text { Difference } 4.70494 \text { t Ratio } 4.095947 & 4.91602\end{array}$

\begin{tabular}{llll|} 
Difference & 4.70494 & t Ratio & 4.095947 \\
Std Err Dif & 1.14868 & DF & 37.91602 \\
\hline
\end{tabular}

Upper CL Di $\begin{array}{lll}7.03050 & \text { Prob }>\mid t \quad & 0.0002 \\ \text { Std }\end{array}$

$\begin{array}{lrll}\text { Upper CL Di } & 7.03050 & \text { Prob }>\mid t & 0.0002 \text { * } \\ \text { Lower CL Di } & 2.37939 & \text { Prob }>t & 0.0001 \text { * }\end{array}$

Confidence $\quad 0.95$ Prob $<t \quad 0.9999$

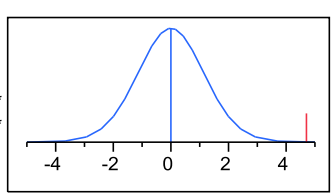

Oneway Analysis of Sn'-Me' By AGE

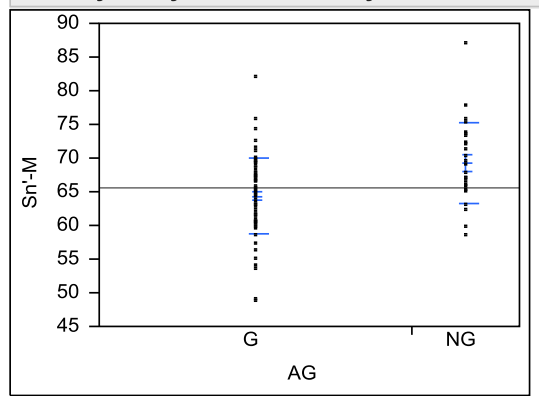

Means and Std Deviations

Std Err

Level Number Mean Std Dev Mean Lower 95\% Upper 95\%

$\begin{array}{rrrrrrr}\text { G } & 78 & 64.3099 & 5.59669 & 0.6337 & 63.048 & 65.572\end{array}$

$\begin{array}{lllllll}\text { NG } & 27 & 69.2363 & 5.94287 & 1.1437 & 66.885 & 71.587\end{array}$

t Test

NG-

Assuming unequal variance

Difference $\quad 4.92642$ t Ratio 3.767727

Std Err Dif 1.30753 DF 43.04459

Upper CL Di 7.56324 Prob $>$ |t 0.0005

Lower CL Di 2.28961 Prob $>$ t 0.0002

Confidence

0.95 Prob $<\mathrm{t} \quad 0.9998$

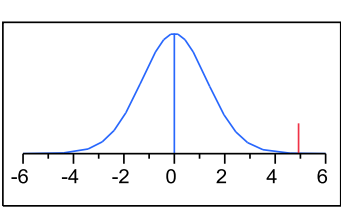

Oneway Analysis of S-Go By AGE

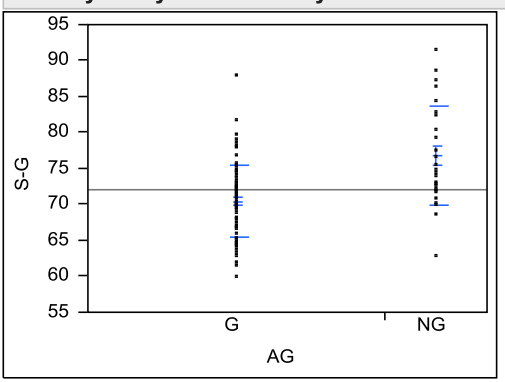

Means and Std Deviations

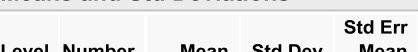

Level Number Mean Std Dev Mean Lower 95\% Upper 95\% $\begin{array}{llllllr}\text { G } & 78 & 70.4273 & 4.92731 & 0.5579 & 69.316 & 71.538 \\ \text { NG } & 27 & 76.6944 & 6.87201 & 1.3225 & 73.976 & 79.413\end{array}$ t Test

NG-

Assuming unequal variance

Difference $\quad 6.26714$ t Ratio 4.366183

Std Err Dif 1.43538 DF 35.6956

Upper CL Di 9.17909 Prob $>\mid t \quad 0.0001$ *

$\begin{array}{llll}\text { Lower CL Di } 3.35519 & \text { Prob }>t & <.0001\end{array}$ *

Confidence $\quad 0.95$ Prob $<t \quad 0.9999$

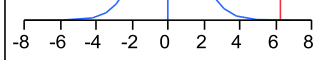


Oneway Analysis of PP-1 By AGE

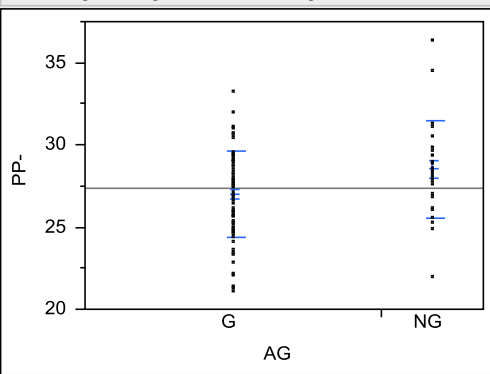

Means and Std Deviations \begin{tabular}{lrlrrr} 
& & \multicolumn{3}{c}{ Std Err } \\
Level Number & Mean Std Dev & Mean Lower 95\% Upper 95\%
\end{tabular} $\begin{array}{lllllrr}G & 78 & 26.9647 & 2.62621 & 0.29736 & 26.373 & 27.557\end{array}$ $\begin{array}{lllllll}\text { t Test } & & & & \end{array}$

NG-

Assuming unequal variance

Difference $\quad 1.54340$ t Ratio 2.422853 41.42027 $\begin{array}{llll}\text { Upper CL Di } & 2.82950 & \text { Prob }>\mid t & 0.0199 * \\ \text { Lower CL Di } & 0.25731 & \text { Prob }>t & 0.0099 \text { * }\end{array}$ Confidence $\quad 0.95$ Prob $<\mathrm{t} \quad 0.9901$ $-2.0-1.5-1.0-0.50 .0 \quad 0.5 \quad 1.01 .52 .0$
Oneway Analysis of PP-Mic By AGE

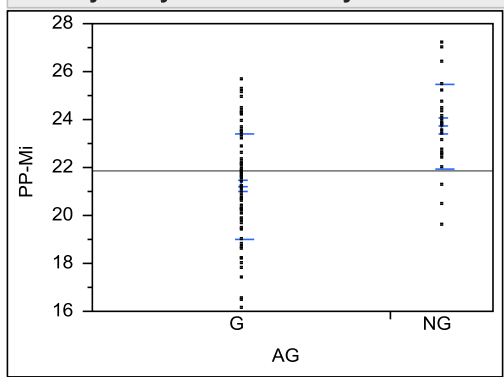

Means and Std Deviations $\begin{array}{lrlrl}\text { Level Number } & \text { Mean Std Dev } & \begin{array}{r}\text { Std Err } \\ \text { Mean }\end{array} \text { Lower 95\% Upper 95\% }\end{array}$ $\begin{array}{lllllll}\text { G } & 78 & 21.2164 & 2.19858 & 0.24894 & 20.721 & 21.712 \\ \text { NG } & 27 & 23.7181 & 1.75845 & 0.33841 & 23.023 & 24.414\end{array}$ t Test

NG-

Assuming unequal variance

Difference 2.50174 t Ratio $\quad 5.954906$ Std Err Dif 0.42011 DF 56.19502

Upper CL Di $\begin{array}{lll}3.34326 & \text { Prob }>\mid t \quad<.0001\end{array}$

$\begin{array}{llll}\text { Lower CL Di } & 1.66021 & \text { Prob }>t & <.0001\end{array}$

Confidence $\quad 0.95$ Prob $<t \quad 1.0000$

1.0000

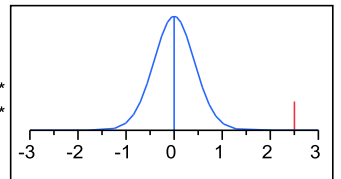

Oneway Analysis of Mp-Mic By AGE

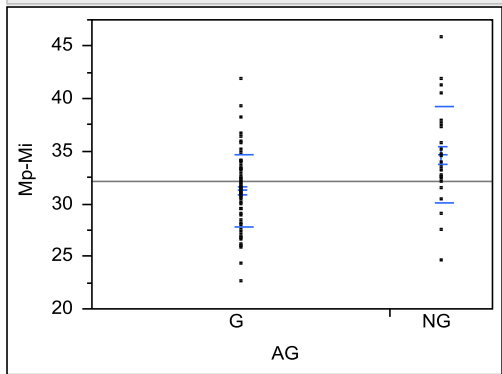

Means and Std Deviations

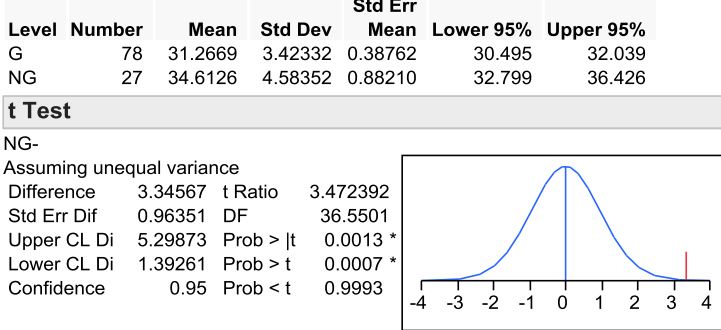

\section{Oneway Analysis of Pog'-GALL By AGE}

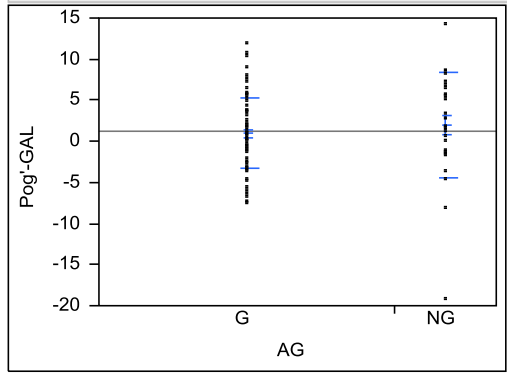

Means and Std Deviations

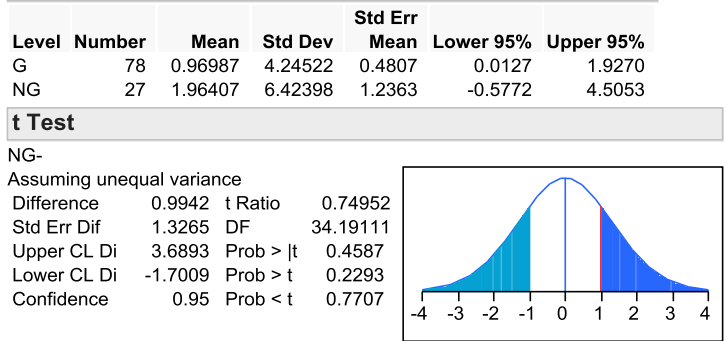




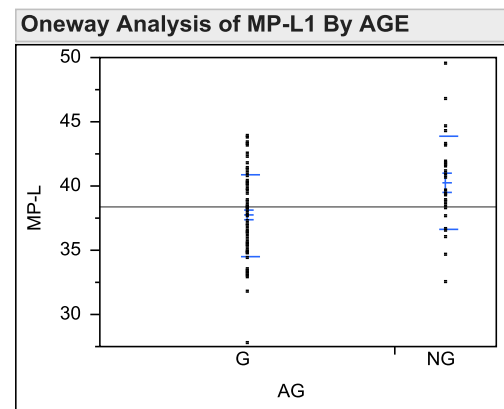

Means and Std Deviations

\section{Std Err}

Level Number Mean Std Dev Mean Lower 95\% Upper 95\%

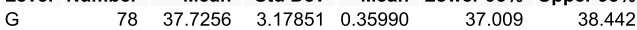
$\begin{array}{lllllll}\text { NG } & 27 & 40.2515 & 3.65450 & 0.70331 & 38.806 & 41.697\end{array}$ t Test

NG-

Assuming unequal variance

Difference 2.52584 t Ratio 3.19709 Std Err Dif 0.79004 DF

Upper CL Di 4.12201 Prob $>$ t 0.0027

Lower CL Di 0.92967 Prob $>t \quad 0.0013$ *

0.95 Prob $<\mathrm{t} 0.9987$

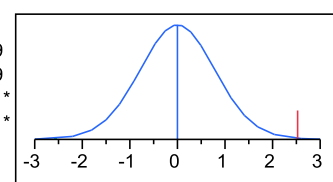

Oneway Analysis of TVL-Pog' By AGE

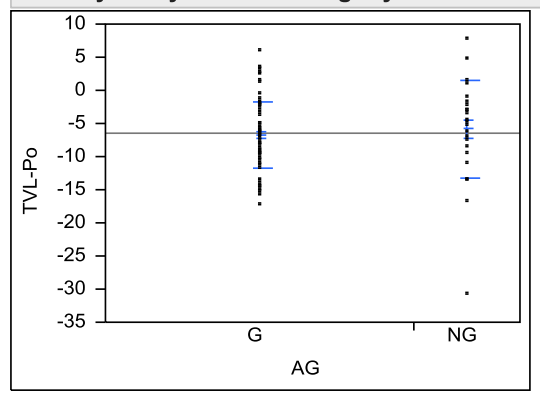

Means and Std Deviations

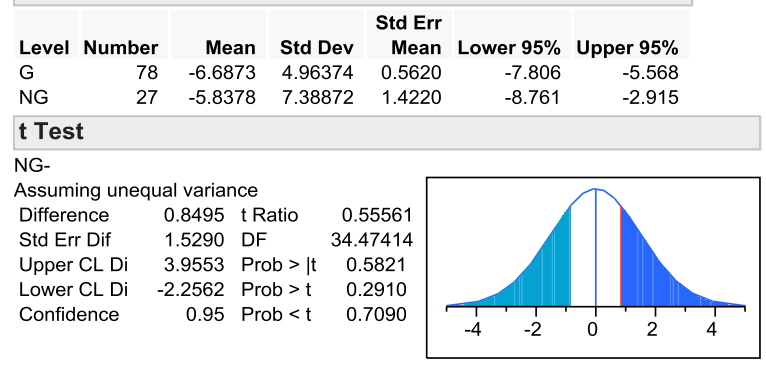

Oneway Analysis of $\bar{I}^{\circ}$ By AGE

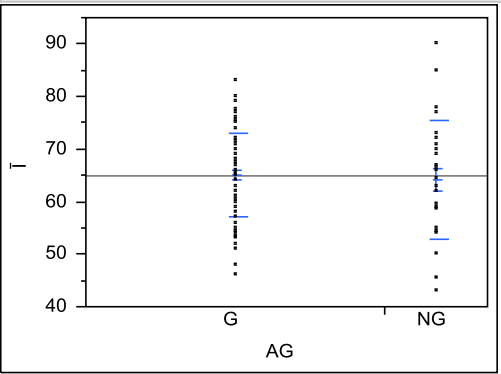

Means and Std Deviations

Std Err

Level Number Mean Std Dev Mean Lower 95\% Upper 95\%

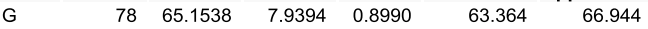

$\begin{array}{llllllll}\text { NG } & 27 & 64.1481 & 11.3407 & 2.1825 & 59.662 & 68.634\end{array}$

t Test

NG-

Assuming unequal variance

Assuming unequal variance

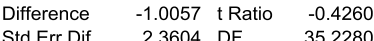

$\begin{array}{lrlr}\text { Std Err Dif } & 2.3604 & \text { DF } & 35.22803 \\ \text { Upper CL Di } & 3.7851 & \text { Prob }>\mid t & 0.6726 \\ & & \end{array}$

$\begin{array}{lrll}\text { Upper CL Di } & 3.7851 & \text { Prob }>\mid t & 0.6726 \\ \text { Lower CL Di } & -5.7965 & \text { Prob }>t & 0.6637 \\ \text { Conf } & & & \end{array}$

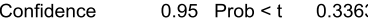

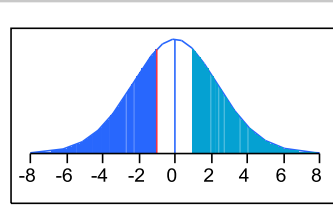

Oneway Analysis of Pog'c-GALL By AGE

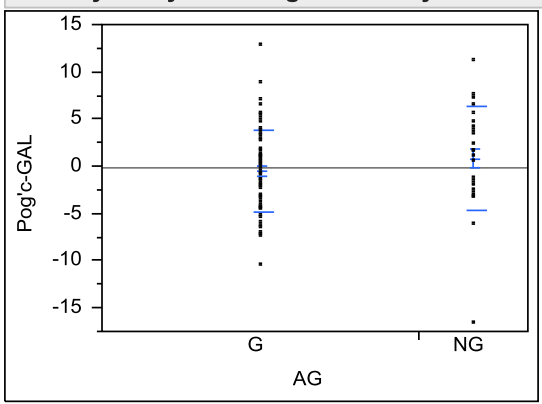

Means and Std Deviations

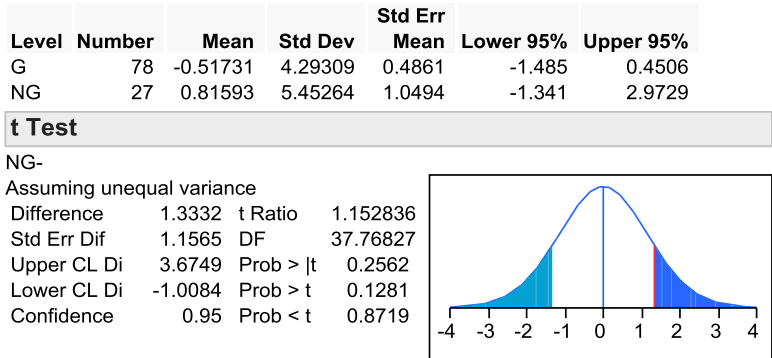




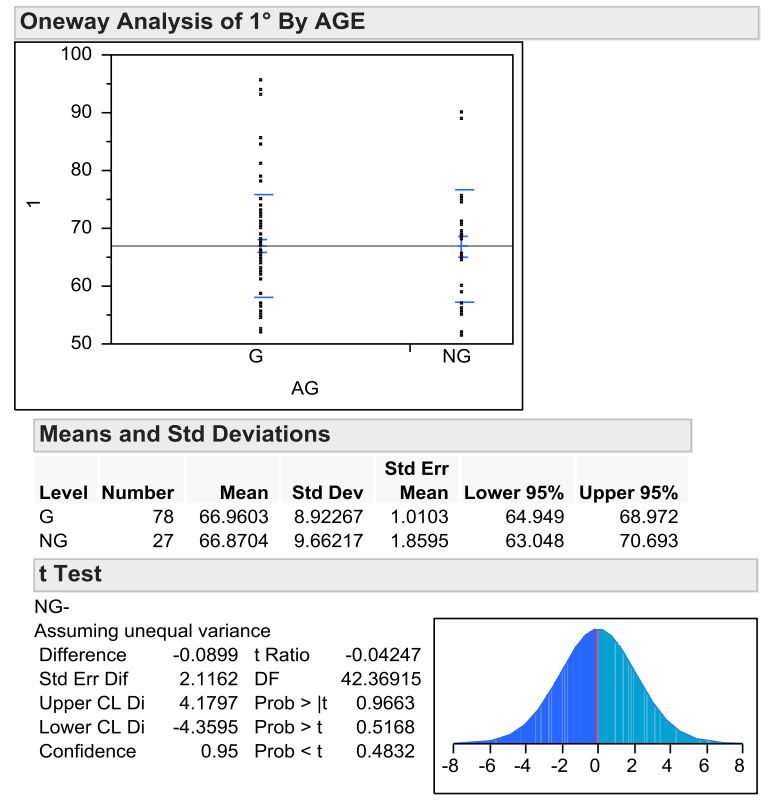

Oneway Analysis of SNB ${ }^{\circ}$ By AGE

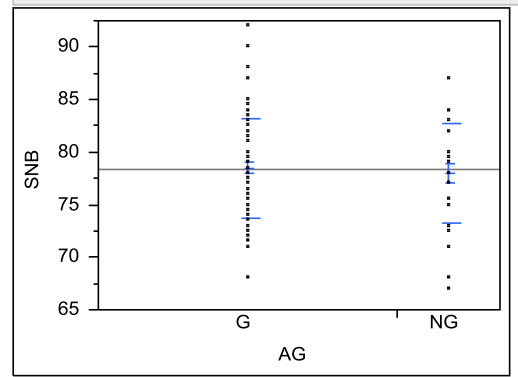

Means and Std Deviations

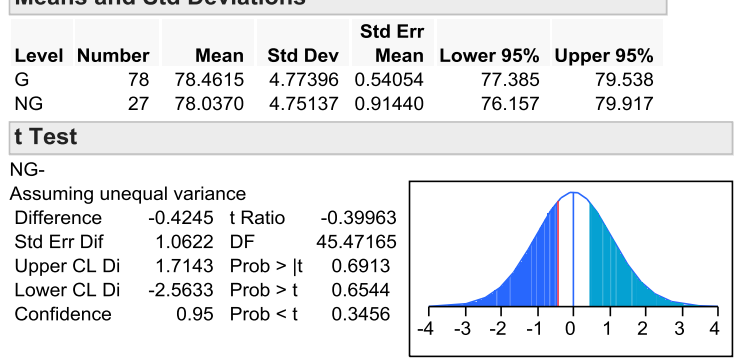

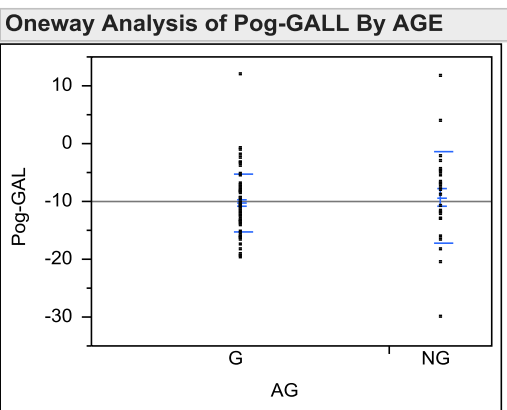

Means and Std Deviations

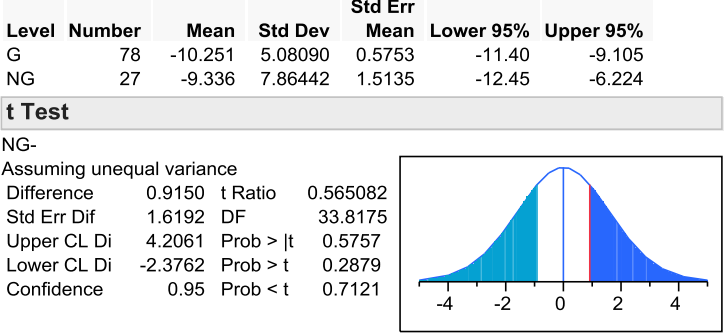

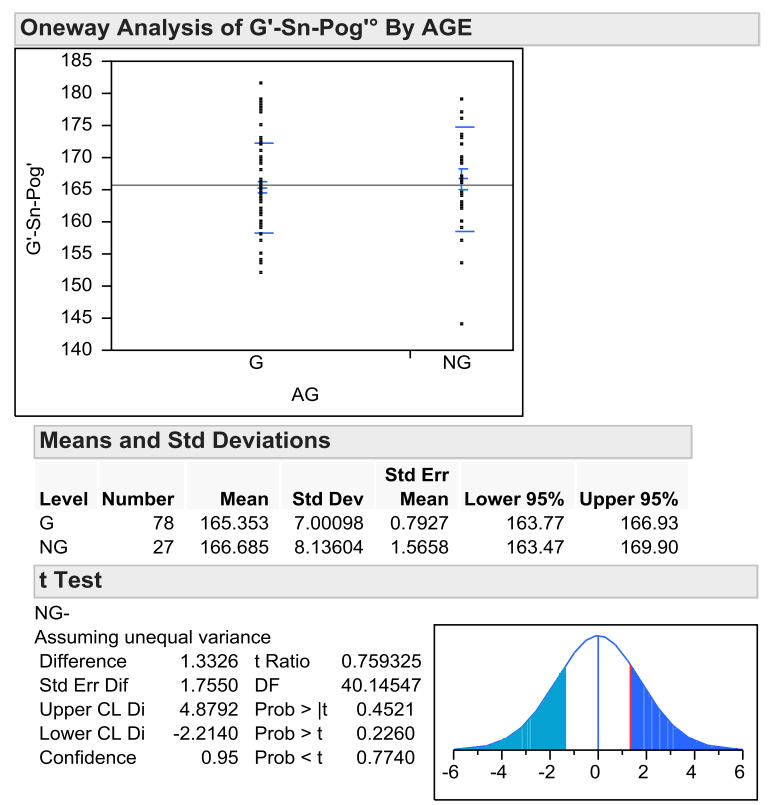



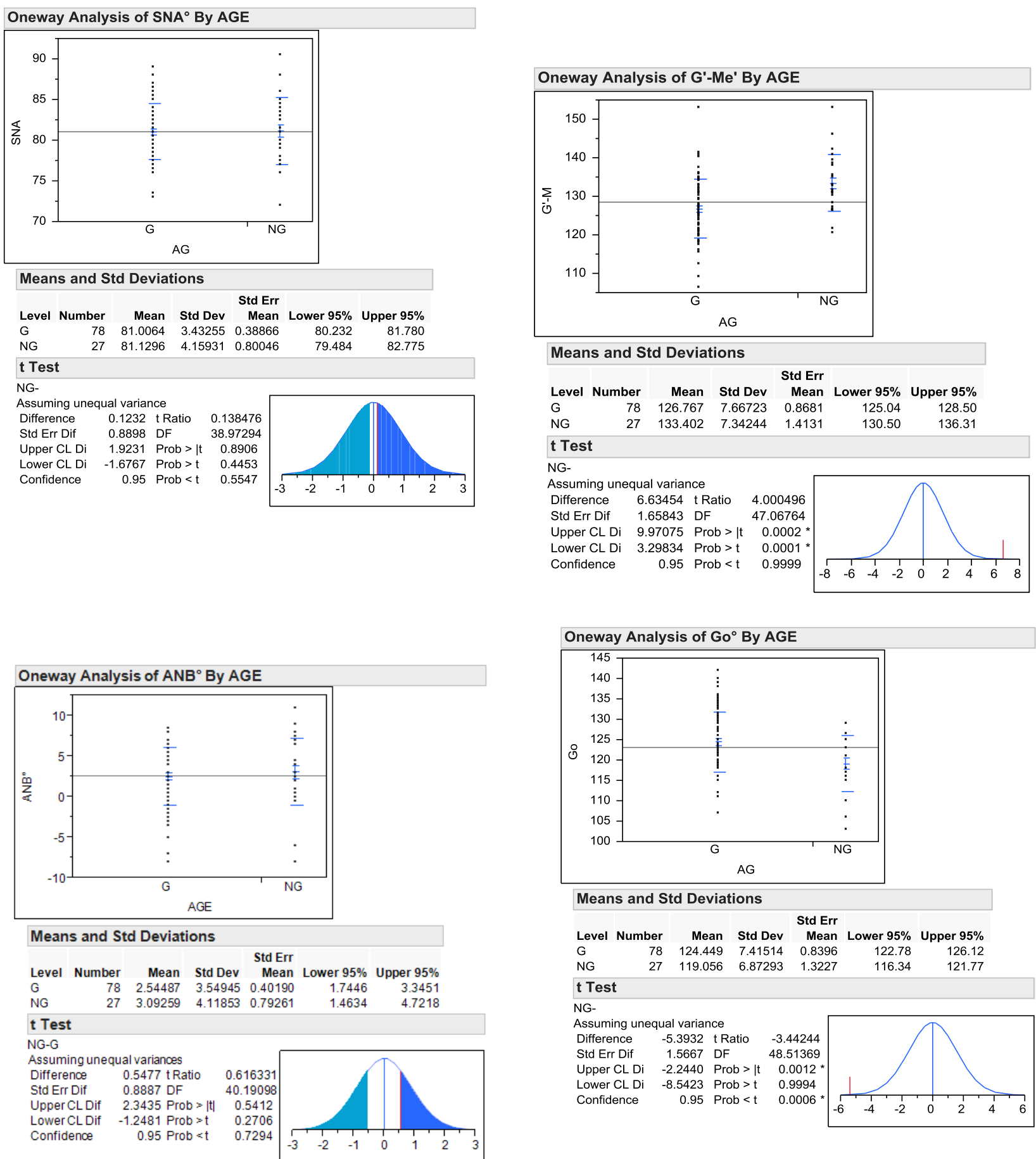


\section{Oneway Analysis of SN-MP By AGE}

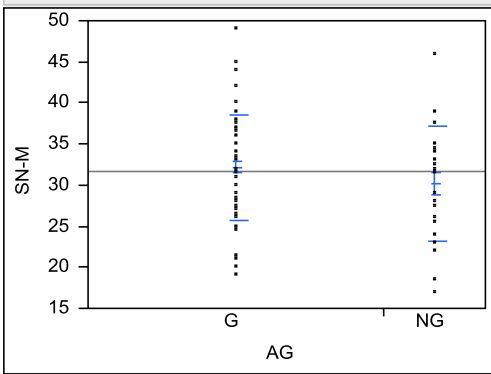

Means and Std Deviations

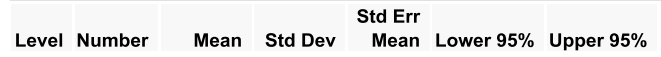

$\begin{array}{rrrrrrr}\text { Level Number } & \text { Mean } & \text { Std Dev } & \text { Mean } & \text { Lower 95\% } & \text { Upper 95\% } \\ \text { G } & 78 & 32.1731 & 6.39441 & 0.7240 & 30.731 & 33.615\end{array}$

$\begin{array}{lllllll}\text { NG } & 27 & 30.1667 & 6.98900 & 1.3450 & 27.402 & 32.931\end{array}$

t Test

NG-

Assuming unequal variance

Difference $\quad-2.0064$ t Ratio -1.31351

Std Err Dif $\quad 1.5275$ DF $\quad 42.05819$

Upper CL Di 1.0761 Prob > |t 0.1961

$\begin{array}{llll}\text { Lower CL Di } & -5.0890 & \text { Prob }>t & 0.9019\end{array}$

Confidence

$\begin{array}{rrr}0.95 & \text { Prob }<t & 0.0981\end{array}$

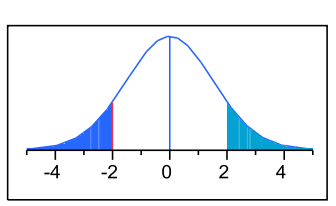

Oneway Analysis of $\mathrm{MP}^{\circ} \mathrm{By}$ AGE

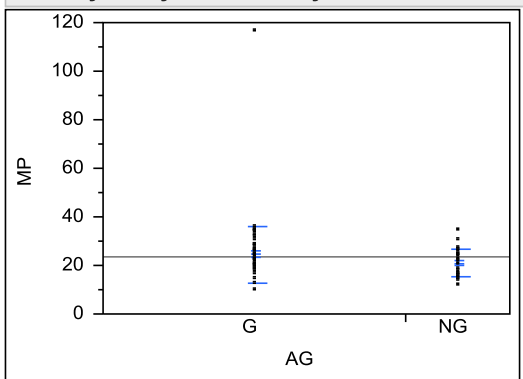

Means and Std Deviations

Std Err

Level Number Mean Std Dev Mean Lower 95\% Upper 95\%

$\begin{array}{lllllll}\text { G } & 78 & 24.4551 & 11.8138 & 1.3377 & 21.792 & 27.119\end{array}$

$\begin{array}{lllllll}\text { NG } & 27 & 20.8519 & 5.5881 & 1.0754 & 18.641 & 23.062\end{array}$

t Test

NG-

Assuming unequal variance

Difference $\quad-3.6033$ t Ratio

Std Err Dif 1.7164 DF

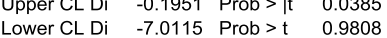

Confidence $\quad 0.95$ Prob $<t \quad 0.0192$

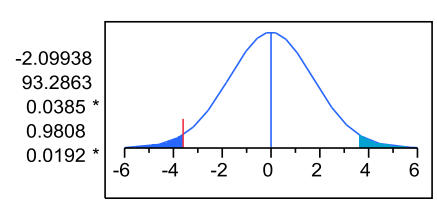

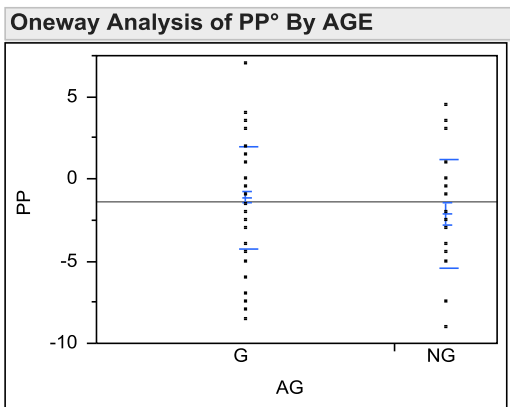

Means and Std Deviations

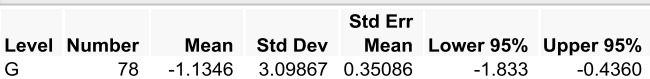

$\begin{array}{lllllrr}\text { G } & 78 & -1.1346 & 3.09867 & 0.35086 & -1.833 & -0.4360 \\ \text { NG } & 27 & -2.1296 & 3.32702 & 0.64029 & -3.446 & -0.8135\end{array}$

t Test

NG-

Assuming unequal variance

Difference $\quad-0.9950$ t Ratio -1.36282

Std Err Dif 0.7301 DF

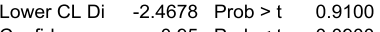

Confidence

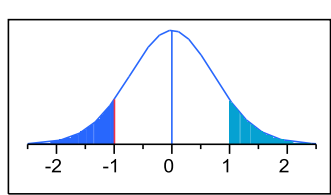

Oneway Analysis of IV Md Ant By AGE

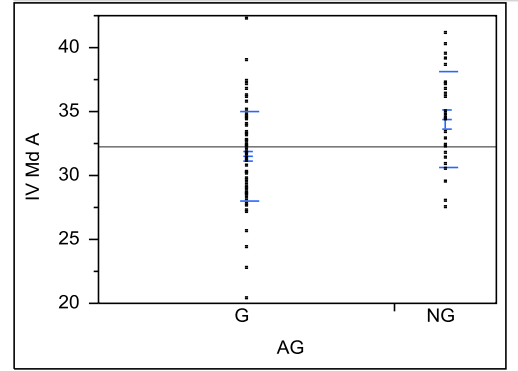

Means and Std Deviations

Level Number Mean Std Dev $\begin{gathered}\text { Std Err } \\ \text { Mean Lower } 95 \%\end{gathered}$ Upper $95 \%$ $\begin{array}{rrrrrrr}\text { Level Number } & \text { Mean } & \text { Std Dev } & \text { Mean } & \text { Lower 95\% } & \text { Upper 95\% } \\ \text { G } & 78 & 31.5037 & 3.49771 & 0.39604 & 30.715 & 32.292\end{array}$ $\begin{array}{lllllll}\text { NG } & 27 & 34.3789 & 3.72241 & 0.71638 & 32.906 & 35.851\end{array}$

t Test

NG-

Assuming unequal variance

Difference $\quad 2.87517$ t Ratio 3.512467

Std Err Dif $\quad 0.81856$ DF $\quad 42.96595$

Upper CL Di 4.52600 Prob > t 0.0011 *

$\begin{array}{llll}\text { Lower CL Di } & 1.22435 & \text { Prob }>t & 0.0005\end{array}$ *

$\begin{array}{lrll}\text { Confidence } & 0.95 & \text { Prob }<\mathrm{t} & 0.9995\end{array}$

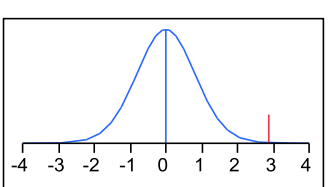



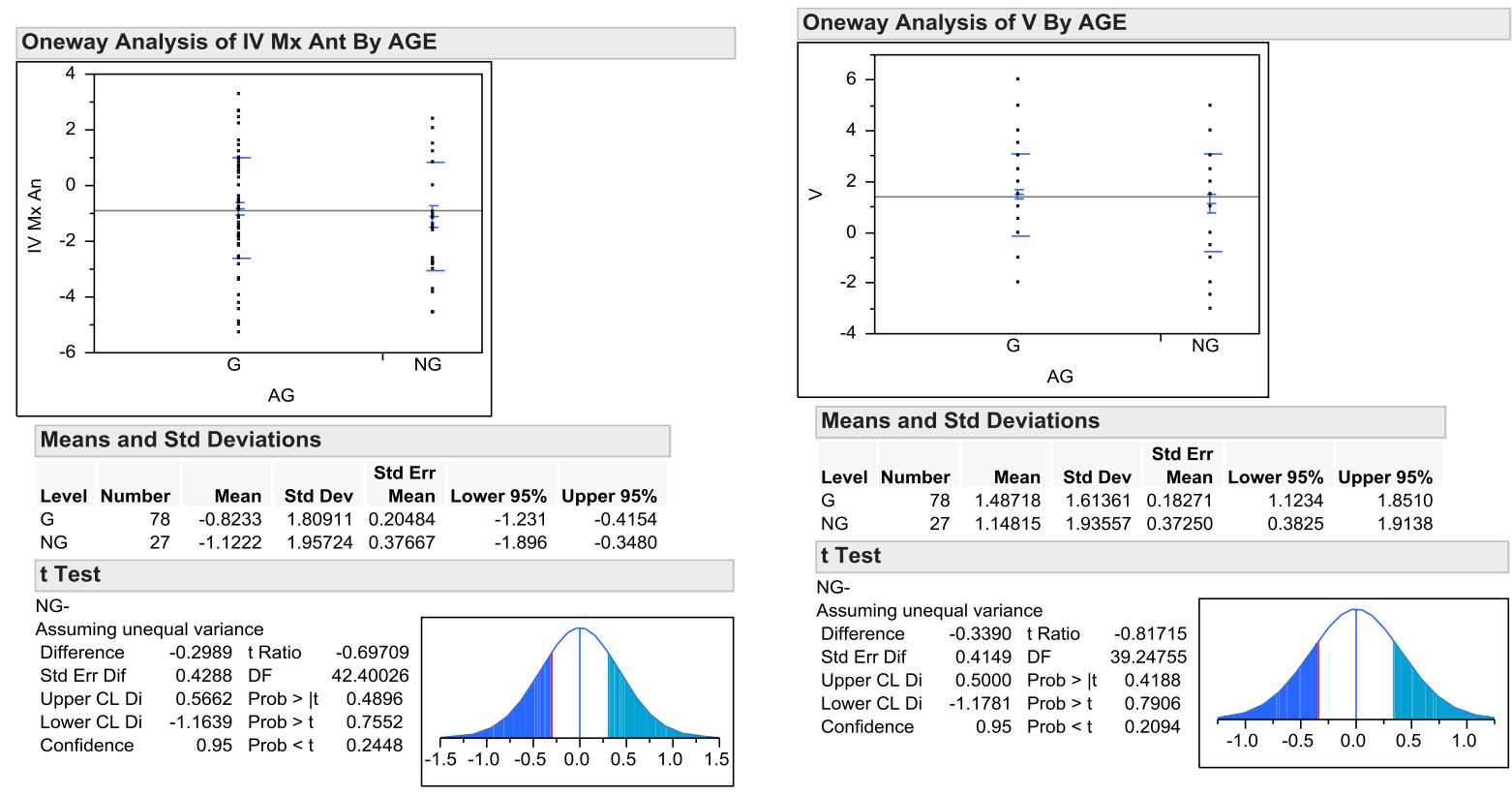

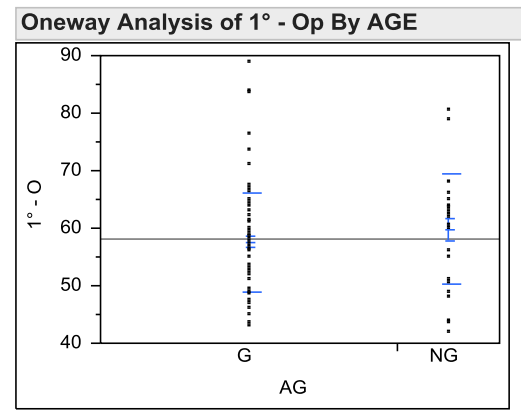

Means and Std Deviations

\section{Std Err}

Level Number Mean Std Dev Mean Lower 95\% Upper 95\%

$\begin{array}{llllllr}G & 78 & 57.5385 & 8.61960 & 0.9760 & 55.595 & 59.482\end{array}$

$\begin{array}{lllllll}\text { NG } & 27 & 59.7593 & 9.58100 & 1.8439 & 55.969 & 63.549\end{array}$

t Test

NG-

Assuming unequal variance

Difference 2.2208 t Ratio 1.06450

Std Err Dif 2.0862 DF

Upper CL Di 6.4325 Prob $>\mid t \quad 0.2933$

Lower CL Di $\quad-1.9909$ Prob $>t \quad 0.1466$

$\begin{array}{lll}\text { Confidence } \quad 0.95 \text { Prob }<t \quad 0.8534 & 0\end{array}$

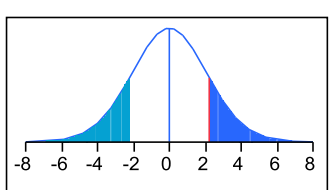

Oneway Analysis of $\bar{I}^{\circ}$ - Op By AGE
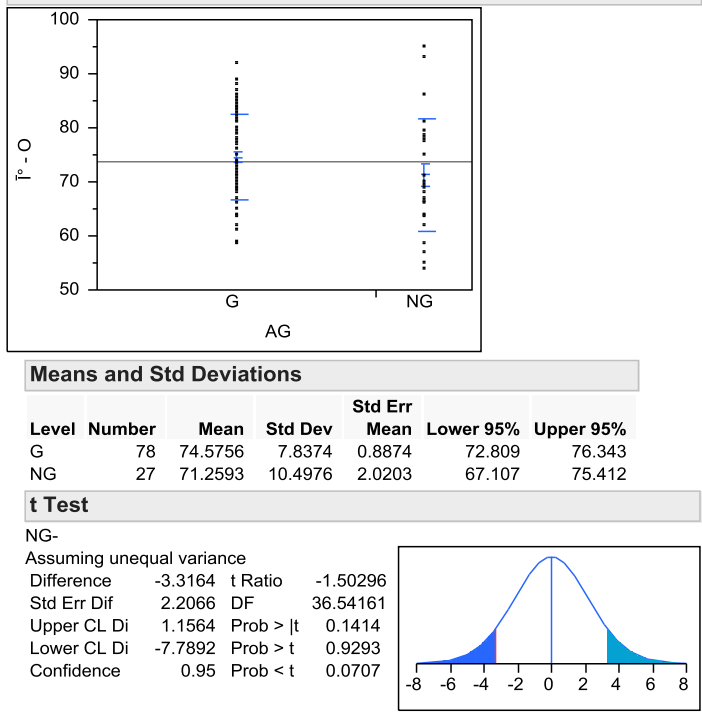
Oneway Analysis of Op-Sn By AGE

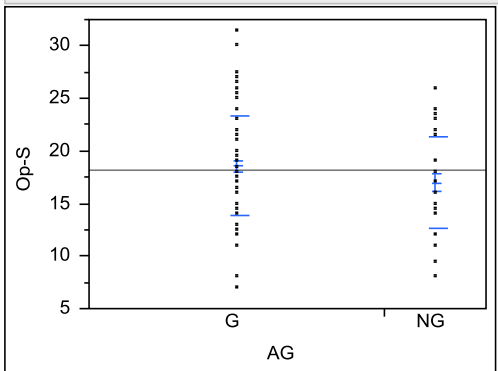

Means and Std Deviations

Std Err

Level Number Mean Std Dev Mean Lower 95\% Upper 95\%

$\begin{array}{llllllll}G & & 78 & 18.5897 & 4.70061 & 0.53224 & 17.530 & 19.650\end{array}$

$\begin{array}{lllllll}\text { G } & 78 & 18.5897 & 4.70061 & 0.53224 & 17.530 & 19.650 \\ \text { NG } & 27 & 16.9444 & 4.38163 & 0.84325 & 15.211 & 18.678\end{array}$

t Test

NG-

Assuming unequal variance

Assuming unequal variance

Difference $\quad-1.6453$ t Ratio -1.64997

Std Err Dif

0.9972 DF

$-1.64997$

0.3594 Prob $>\mid \mathrm{t} \quad 0.1054$

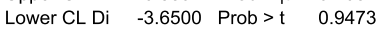

Confidence

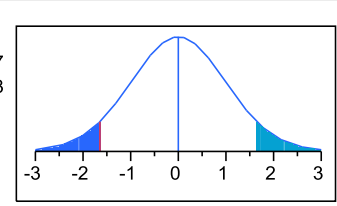

Oneway Analysis of Sn By AGE

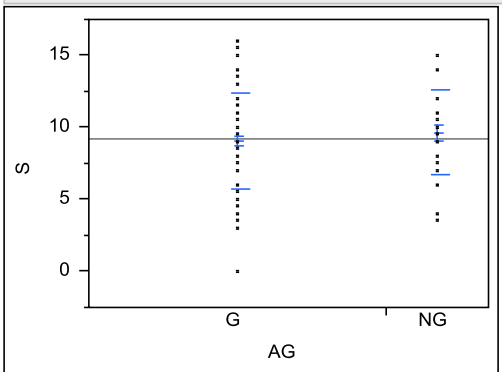

Means and Std Deviations

Std Err

Level Number Mean Std Dev Mean Lower 95\% Upper 95\%

$\begin{array}{lllllll}\text { G } & 78 & 9.05128 & 3.30838 & 0.37460 & 8.3054 & 9.797\end{array}$

t Test

NG-

Assuming unequal variance

Difference $\quad 0.5969$ t Ratio 0.881402

Std Err Dif $\quad 0.6772$ DF $\quad 50.65805$

Upper CL Di 1.9566 Prob > It 0.3823

Lower CL Di -0.7628 Prob $>t \quad 0.1$

0.95 Prob $<t \quad 0.8089$

0.95 Prob $<t \quad 0.8089$

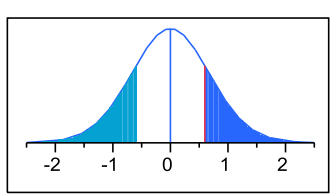




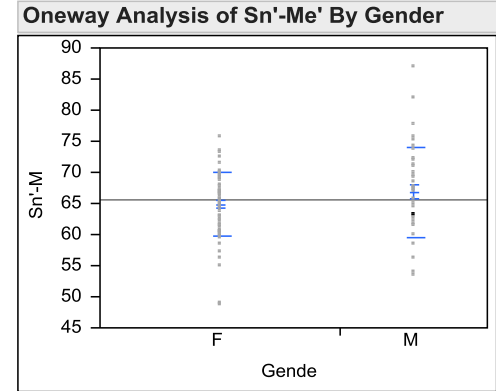

Means and Std Deviations

Std Err

Level Number Mean Std Dev Mean Lower 95\% Upper 95\%

$\begin{array}{lllllll}\text { F } & 65 & 64.8278 & 5.16513 & 0.6407 & 63.548 & 66.108\end{array}$

$\begin{array}{lllllll}M & 40 & 66.7935 & 7.18581 & 1.1362 & 64.495 & 69.092\end{array}$

t Test

Assuming unequal variance

Assuming un

Difference $\quad 1.9657$ t Ratio 1.50699

Std Err Dr 1.3044 DF 63.81165

Upper CL Di 4.5715 Prob > |t 0.1367

Lower CL Di $\quad-0.6402$ Prob $>t \quad 0.0684$

Confidence $\quad 0.95$ Prob $<\mathrm{t} \quad 0.9316$

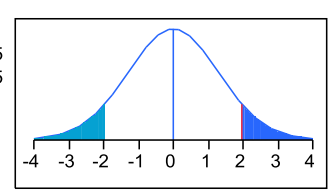

Oneway Analysis of $O p^{\circ}$ By Gender

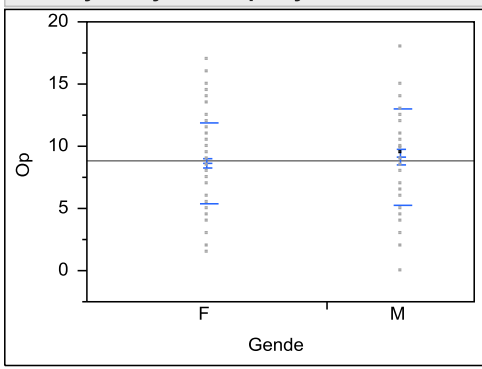

Means and Std Deviations

Level Number Mean Std Dev $\begin{gathered}\text { Std Err } \\ \text { Mean Lower 95\% Upper 95\% }\end{gathered}$

$\begin{array}{rrrrrrr}\text { F } & 65 & 8.63077 & 3.24191 & 0.40211 & 7.8275 & 9.434\end{array}$

$\begin{array}{lrrrrrr}\text { M } & 40 & 9.14750 & 3.90411 & 0.61729 & 7.8989 & 10.396\end{array}$

t Test

M-

Assuming unequal varianc

Difference $\quad 0.5167$ t Ratio $\quad 0.701402$

Std Err Dif $\quad 0.7367$ DF

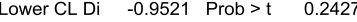

Confidence

0.95 Prob $<\mathrm{t} \quad 0.7573$

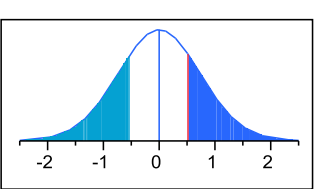

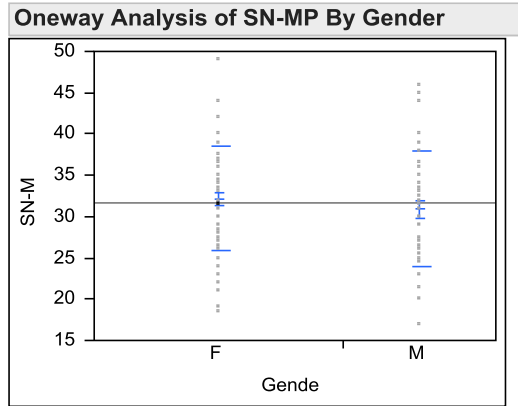

Means and Std Deviations

Std Err

Level Number Mean Std Dev Mean Lower 95\% Upper 95\%

$\begin{array}{lrrrrrr}\text { F } & 65 & 32.1385 & 6.29702 & 0.7810 & 30.578 & 33.699\end{array}$

$\begin{array}{lllllll}\mathrm{F} & 65 & 32.1385 & 6.29702 & 0.7810 & 30.578 & 33.699 \\ \mathrm{M} & 40 & 30.8750 & 7.01989 & 1.1099 & 28.630 & 33.120\end{array}$

t Test

M-

Assuming unequal variance

Difference $\quad-1.2635 \mathrm{t}$ Ratio

Std Err Dif 1.3572 DF

Prob $>t \quad 0.8226$

Confidence

0.95 Prob $<t \quad 0.177$
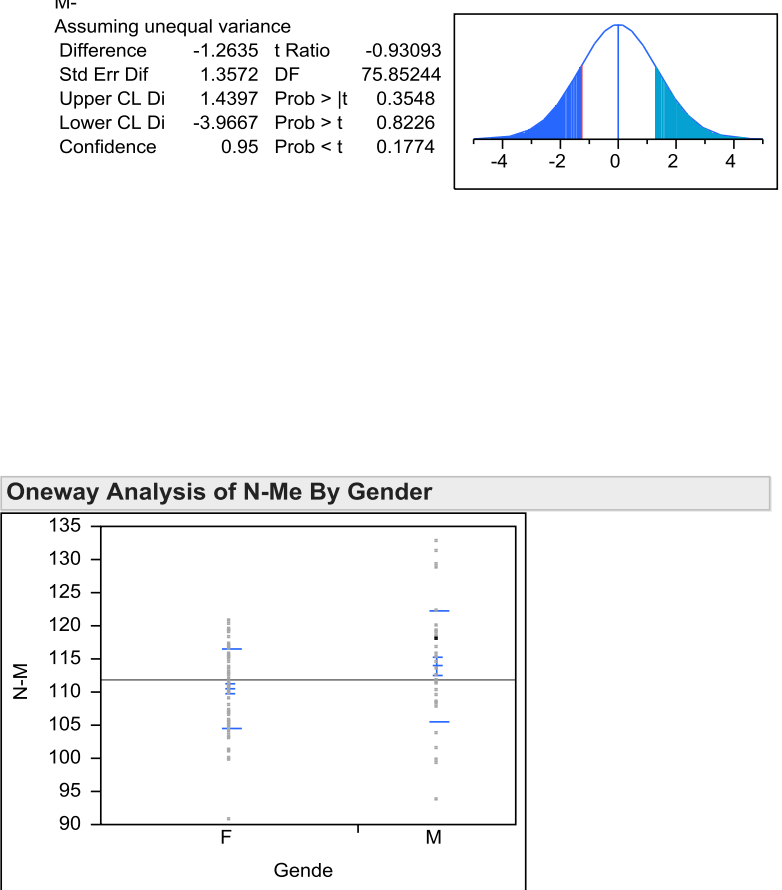

Means and Std Deviations

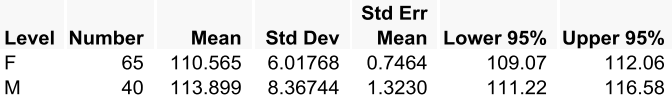

t Test

M-

Assuming unequal variance

Difference $\quad 3.33402$ t Ratio 2.194827

Std Err Dif 1.51904 DF 63.83649

Upper CL Di 6.36879 Prob > tt 0.0318 *

Lower CL Di 0.29925 Prob $>t \quad 0.0159$ *

Confidence $\quad 0.95$ Prob $<\mathrm{t} \quad 0.9841$

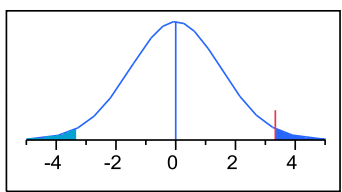



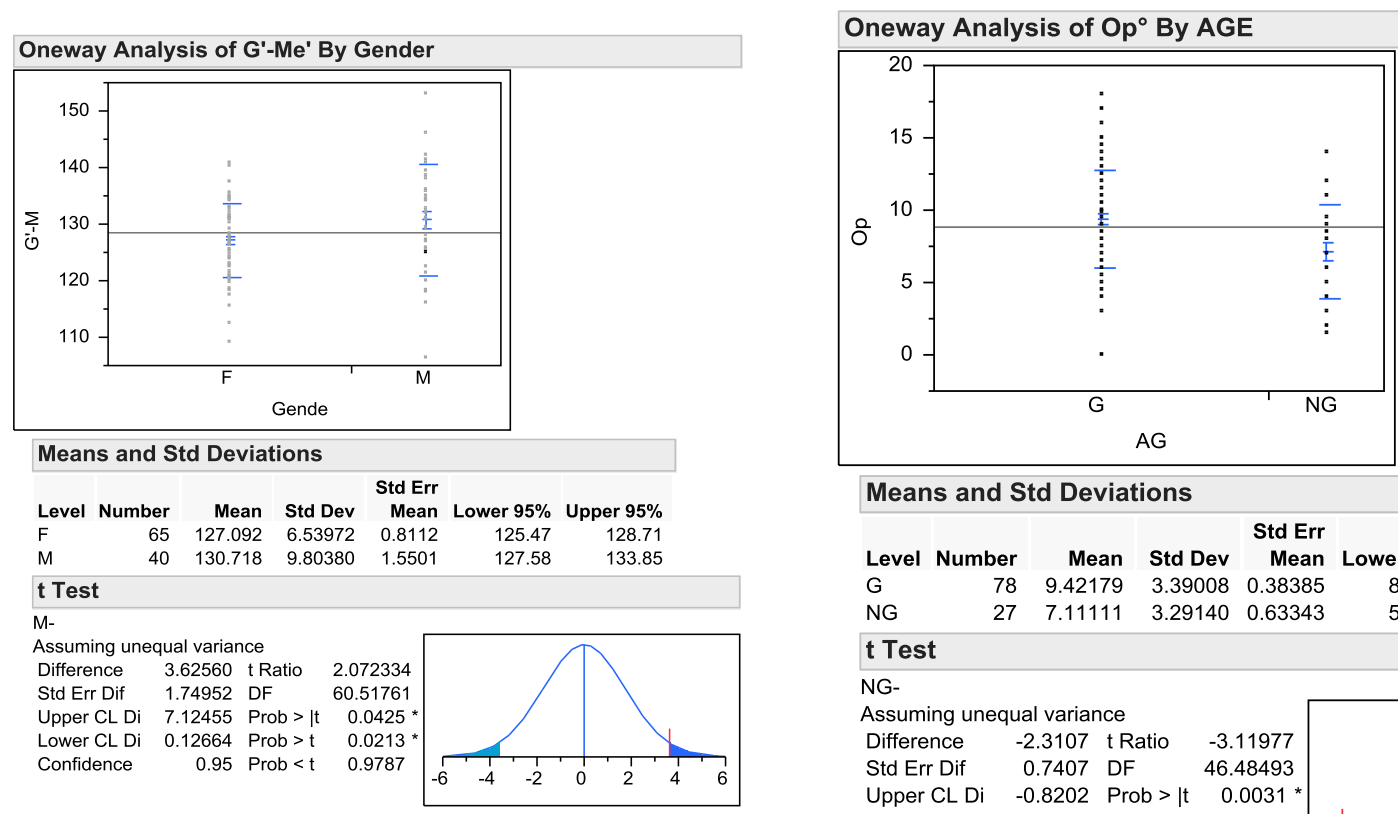

\begin{tabular}{|c|c|c|c|c|c|}
\hline \multicolumn{6}{|c|}{ Means and Std Deviations } \\
\hline \multirow{2}{*}{$\begin{array}{l}\text { Level } \\
\text { G } \\
\text { NG }\end{array}$} & Mean & Std Dev & $\begin{array}{r}\text { Std Err } \\
\text { Mean }\end{array}$ & Lower $95 \%$ & Upper $95 \%$ \\
\hline & $78 \quad 9.42179$ & 793.3900 & $08 \quad 0.38385$ & 8.6575 & 10.186 \\
\hline NG & $27 \quad 7.11111$ & $11 \quad 3.2914$ & $40 \quad 0.63343$ & 5.8091 & 8.413 \\
\hline \multicolumn{6}{|l|}{ t Test } \\
\hline \\
\hline & & \multirow{2}{*}{\multicolumn{4}{|c|}{ Assuming unequal variance }} \\
\hline Difference & -2.3107 & \multicolumn{2}{|r|}{-3.11977} & & \\
\hline \multirow{2}{*}{ Std Err Dif } & \multirow{2}{*}{$\begin{array}{r}0.7407 \\
-0.8202\end{array}$} & DF & 46.48493 & & \\
\hline & & \multirow{2}{*}{ Prob $>\mid t$} & $0.0031 *$ & & \\
\hline Lower CL Di & $-3.8011 F$ & & 0.9984 & & \\
\hline Confidence & 0.95 & Prob $<t$ & $0.0016 *$ & -2 & 0 \\
\hline
\end{tabular}
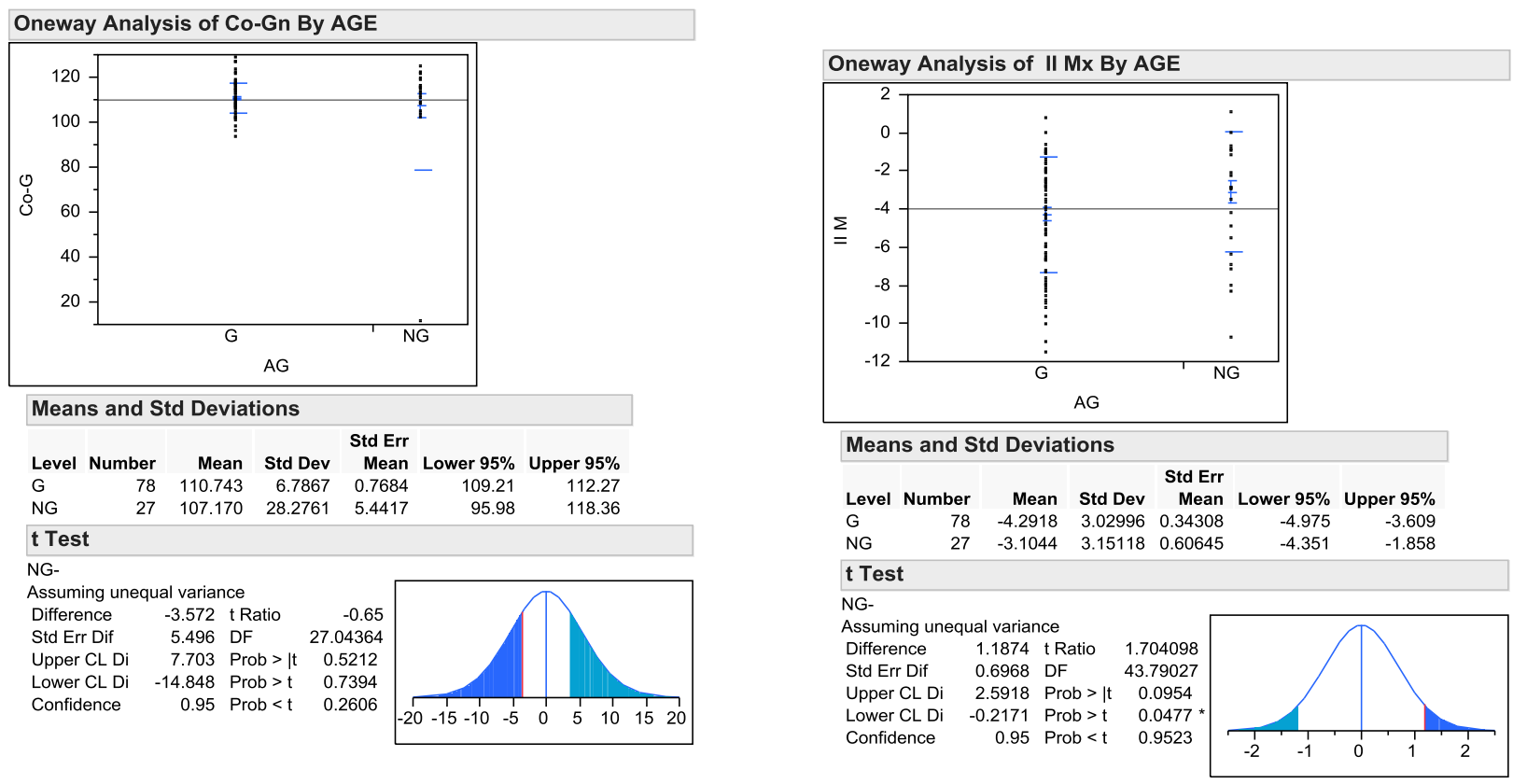
Oneway Analysis of Pog-GALL By Gender

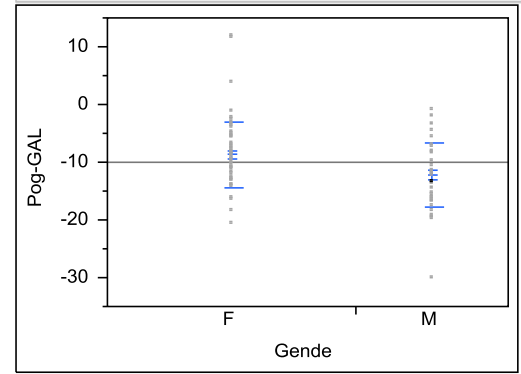

Means and Std Deviations

\begin{tabular}{lrrrrrr} 
& & \multicolumn{5}{c}{ Std Err } \\
Level Number & Mean & Std Dev & Mean & Lower 95\% & Upper 95\% \\
F & 65 & -8.690 & 5.70866 & 0.70807 & -10.10 & -7.28 \\
M & 40 & -12.168 & 5.61025 & 0.88706 & -13.96 & -10.37
\end{tabular}

t Test

M-

Assuming unequal variance

Difference $\quad-3.4775$ t Ratio -3.06389

\begin{tabular}{lll} 
Std Err Dif $\quad 1.1350$ DF $\quad 83.80036$ \\
\hline
\end{tabular}

Upper CL Di -1.2204 Prob $>$ |t 0.0029 *

$\begin{array}{lrll}\text { Lower CL Di } & -5.7347 & \text { Prob }>t & 0.9985\end{array}$

Confidence

0.95 Prob $<\mathrm{t}$

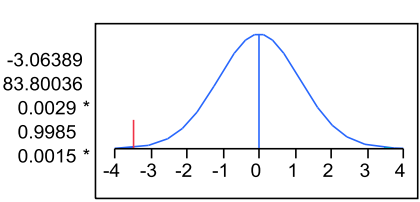

Oneway Analysis of Pog'c-GALL By Gender

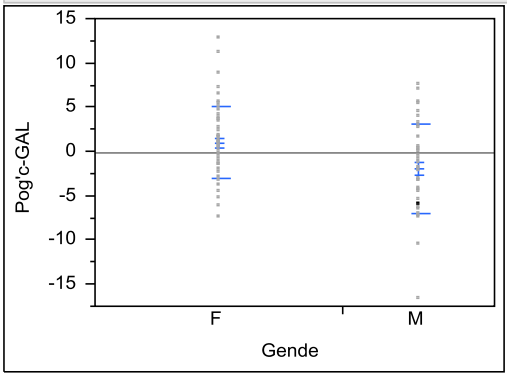

Means and Std Deviations

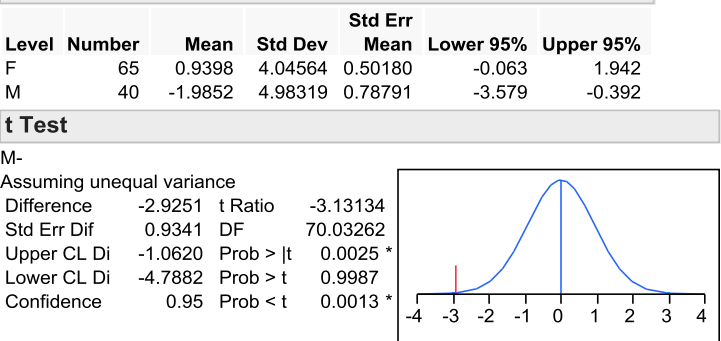

Oneway Analysis of TVL-Pog' By Gender

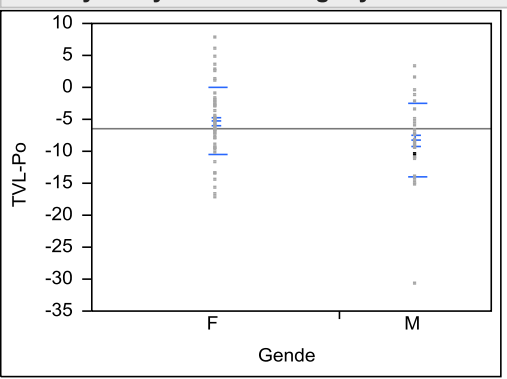

Means and Std Deviations

\section{Std Err}

Level Number Mean Std Dev Mean Lower 95\% Upper 95\%

$\begin{array}{lllllrr}\mathrm{F} & 65 & -5.3185 & 5.30525 & 0.65803 & -6.63 & -4.004 \\ \mathrm{M} & 40 & -8.3382 & 5.78228 & 0.91426 & -10.19 & -6.489\end{array}$

t Test

$\mathrm{M}$ -

Assuming unequal variance

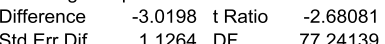

\begin{tabular}{lrlr|} 
Std Err Dif & 1.1264 & DF & 77.24139 \\
Upper CL Di & -0.7769 & Prob $>$ |t & $0.0090^{*}$ \\
\hline
\end{tabular}

$\begin{array}{llll}\text { Upper CL Di } & -0.7769 & \text { Prob }>\mid t & 0.0090 \\ \text { Lower CL Di } & -5.2627 & \text { Prob }>t & 0.9955\end{array}$

Confidence

0.95 Prob $<$

$0.0045 *$

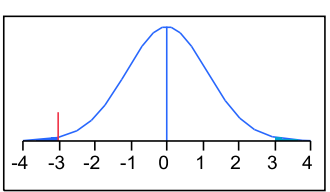

Oneway Analysis of MP-L1 By Gender

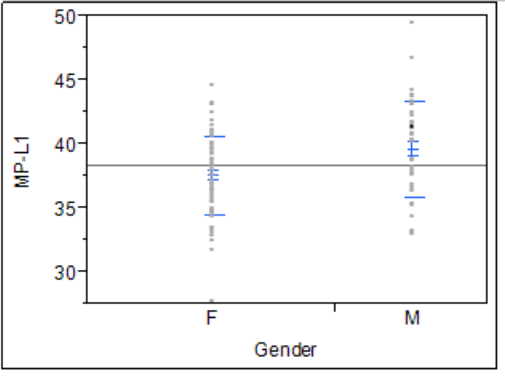

Means and Std Deviations

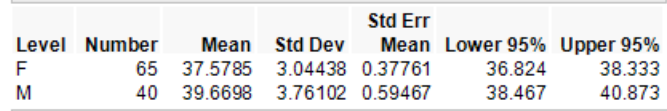

$\begin{array}{llll}40 & 39.6698 & 3.76102 & 0.59467\end{array}$

t Test

$\mathrm{M}-\mathrm{F}$

Assuming unequal varianœs

Differenœ 2.09129 t Ratio 2.968772

Std Err Dif $\quad 0.70443$ DF $\quad 69.86906$

UpperCLDif 3.49627 Prob $>|t| \quad 0.0041^{*}$

Lower CL Dif 0.68630 Prob $>t \quad 0.0020^{*}$

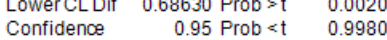

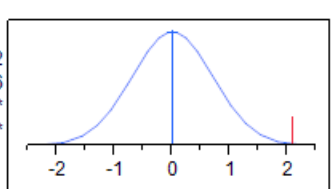


Oneway Analysis of $1^{\circ}$ By Gender

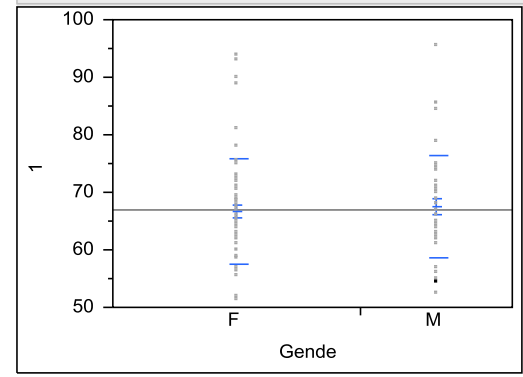

Means and Std Deviations

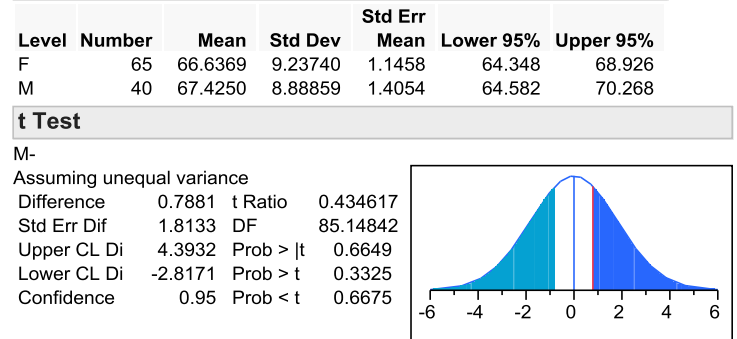

Oneway Analysis of $\bar{l}^{\circ}$ By Gender

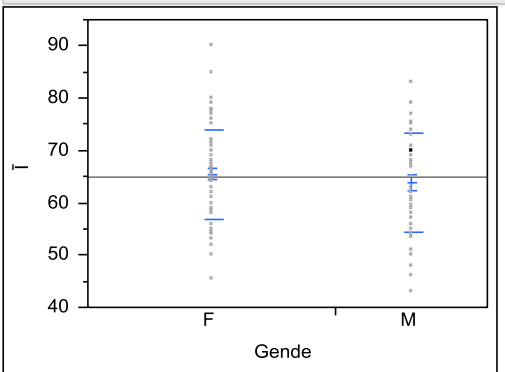

Means and Std Deviations

Std Err

Level Number Mean Std Dev Mean Lower 95\% Upper 95\% $\begin{array}{rrrrrrr}\mathrm{F} & 65 & 65.4846 & 8.54079 & 1.0594 & 63.368 & 67.601 \\ \mathrm{M} & 40 & 63.9375 & 9.45989 & 1.4957 & 6.912 & 66.963\end{array}$ $\begin{array}{lllllll}M & 40 & 63.9375 & 9.45989 & 1.4957 & 60.912 & 66.963\end{array}$

t Test

M-

Assuming unequal variance

Difference $\quad-1.5471$ t Ratio $\quad-0.84409$

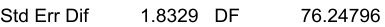

$\begin{array}{llll}\text { Upper CL Di } & 2.1032 & \text { Prob }>\mid t & 0.4013\end{array}$

$\begin{array}{lrll}\text { Lower CL Di } & -5.1974 & \text { Prob }>t & 0.7994 \\ & & \text { Prob } & 0.2006\end{array}$

$\begin{array}{lrl}\text { Confidence } & 0.95 \text { Prob }<\mathrm{t} & 0.2006\end{array}$

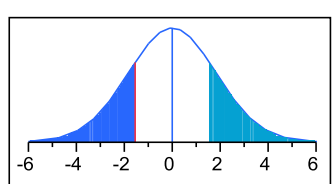

Oneway Analysis of $\mathrm{Go}^{\circ}$ By Gender

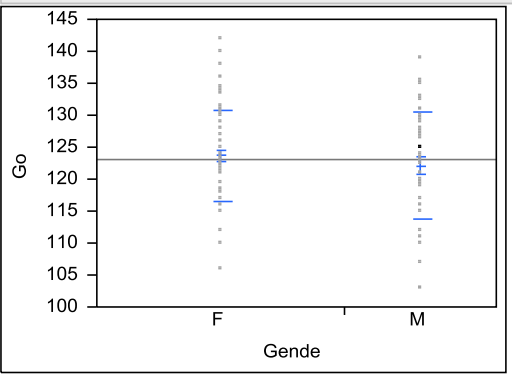

Means and Std Deviations

\begin{tabular}{lrrrrrr} 
& & & \multicolumn{3}{c}{ Std Err } \\
Level Number & Mean & Std Dev & $\begin{array}{r}\text { Mean } \\
\text { Lower 95\% }\end{array}$ & Upper 95\% \\
F & 65 & 123.669 & 7.09824 & 0.8804 & 121.91 & 125.43 \\
M & 40 & 122.075 & 8.40905 & 1.3296 & 119.39 & 124.76
\end{tabular}

t Test

$\mathrm{M}$ -

Assuming unequal variance

$\begin{array}{lll}\text { Difference } & -1.5942 \text { t Ratio } & -0.99973\end{array}$

\begin{tabular}{lll} 
Std Err Dif $\quad 1.5947$ DF $\quad 72.23669$ \\
\hline
\end{tabular}

Upper CL Di 1.5845 Prob > t 0.3208

$\begin{array}{llll}\text { Lower CL Di } & -4.7730 & \text { Prob }>t & 0.8396\end{array}$

Confidence

0.95 Prob $<t \quad 0.1604$

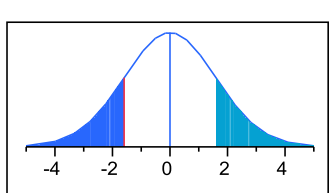

Oneway Analysis of G'-Sn-Pog' ${ }^{10}$ By Gender

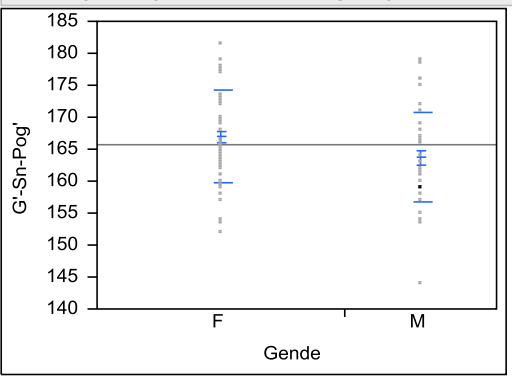

Means and Std Deviations

\begin{tabular}{lrrrrrr} 
& & \multicolumn{5}{c}{ Std Err } \\
Level & Number & Mean & Std Dev & Mean & Lower 95\% & Upper 95\% \\
F & 65 & 166.938 & 7.26050 & 0.9006 & 165.14 & 168.74 \\
M & 40 & 163.675 & 6.96746 & 1.1017 & 161.45 & 165.90
\end{tabular}

$\begin{array}{lllllll}\text { M } & 40 & 163.675 & 6.96746 & 1.1017 & 161.45 & 165.90\end{array}$

t Test

$\mathrm{M}$ -

Assuming unequal variance

Difference $\quad-3.2635$ t Ratio -2.29353

Std Err Dif $\quad 1.4229$ DF $\quad 85.32089$
U

Upper CL Di -0.4345 Prob > t 0.0243 *

$\begin{array}{llll}\text { Lower CL Di } & -6.0924 & \text { Prob }>t & 0.9879\end{array}$

$\begin{array}{lll}\text { Confidence } & 0.95 \text { Prob }<\mathrm{t} \quad 0.0121 \text { * }\end{array}$

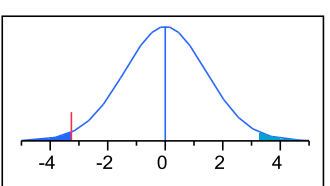


Oneway Analysis of MP By Gender

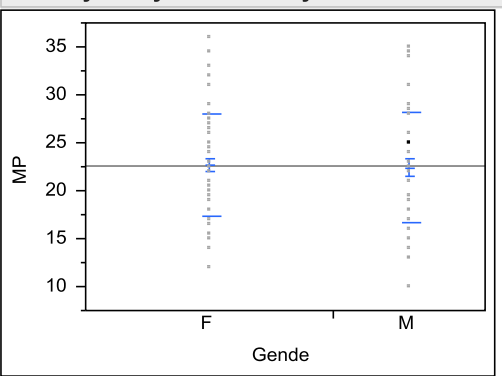

Means and Std Deviations

Std Err

Level Number Mean Std Dev Mean Lower 95\% Upper 95\%

$\begin{array}{lllllll}F & 65 & 22.6923 & 5.35001 & 0.66359 & 21.367 & 24.018\end{array}$

$\begin{array}{llllllll}M & 40 & 22.3875 & 5.76293 & 0.91120 & 20.544 & 24.231\end{array}$

t Test

Assuming unequal variance

Std Err Dif

Upper CL Di

Lower CL Di

$\begin{array}{ccc}-0.3048 & \text { t Ratio } & -0.2704 \\ 1.1272 & \text { DF } & 77.97288 \\ 1.9393 & \text { Prob }>\text { t } & 0.7876\end{array}$

1.9393 Prob $>\mid \mathrm{t} \quad 0.7876$

$\begin{array}{lll}-2.5489 & \text { Prob }>t & 0.6062\end{array}$

Confidence

0.95 Prob $<\mathrm{t} \quad 0.3938$

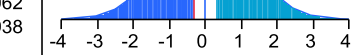

Oneway Analysis of SNA ${ }^{\circ}$ By Gender

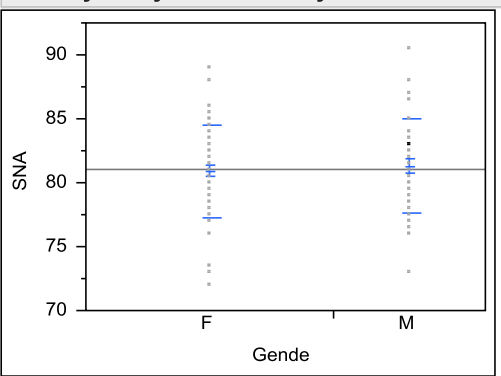

Means and Std Deviations

Std Err

Level Number Mean Std Dev Mean Lower 95\% Upper 95\% $\begin{array}{llrrrrr}\text { F } & 65 & 80.8846 & 3.59336 & 0.44570 & 79.994 & 81.775\end{array}$

$\begin{array}{lllllll}\text { M } & 40 & 81.2875 & 3.67578 & 0.58119 & 80.112 & 82.463\end{array}$

t Test

M-

Assuming unequal variance

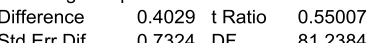

Std Err D

Upper CL Di

Lower CL Di

1.8601 Prob $>\mid \mathrm{t} \quad 0.5838$

$\begin{array}{lll} & 0.2919 \\ & \end{array}$

Confidence $\quad 0.95$ Prob $<\mathrm{t} \quad 0.7081$

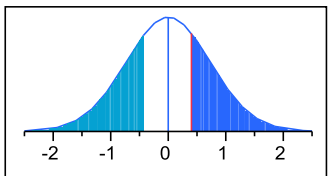

Oneway Analysis of $\mathrm{SNB}^{\circ}$ By Gender

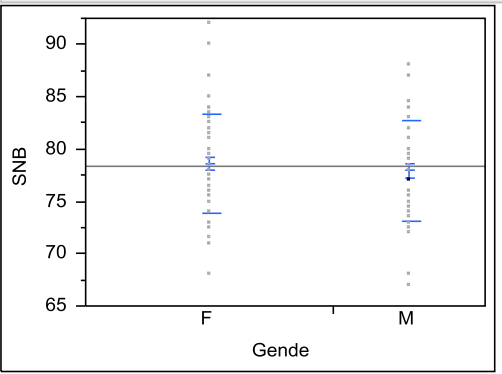

Means and Std Deviations

\begin{tabular}{|c|c|c|c|c|c|c|}
\hline & & & & Std Err & & \\
\hline & & & & M & wer $95 \%$ & er \\
\hline $\mathrm{F}$ & 65 & 78.6231 & 4.73850 & 0.58774 & 77.449 & 79.797 \\
\hline M & 40 & 77.9125 & 4.79301 & 0.75784 & 76.380 & 79.445 \\
\hline
\end{tabular}

t Test

M-

Assuming unequal variance

Difference $\quad-0.7106$ t Ratio -0.74092

Std Err Dif $\quad 0.9590$ DF $\quad 81.95605$

Upper CL Di 1.1973 Prob > t 0.4609

$\begin{array}{llll}\text { Lower CL Di } & -2.6184 & \text { Prob }>t & 0.7696\end{array}$

Confidence

0.95 Prob $<\mathrm{t} \quad 0.2304$

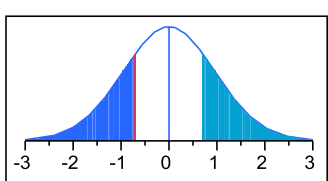

Oneway Analysis of ANB ${ }^{\circ}$ By Gender

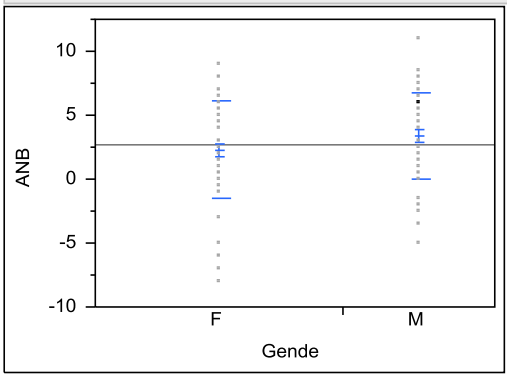

Means and Std Deviations

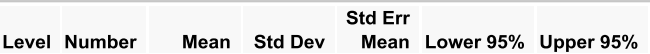

$\begin{array}{rrrrrrr}\text { Level Number } & \text { Mean } & \text { Std Dev } & \text { Mean } & \text { Lower 95\% } & \text { Upper 95\% } \\ \text { F } & 65 & 2.26154 & 3.81517 & 0.47321 & 1.3162 & 3.2069\end{array}$

$\begin{array}{lllllll}\mathrm{M} & 40 & 3.37500 & 3.41518 & 0.53999 & 2.2828 & 4.4672\end{array}$

t Test

M-

Assuming unequal variance

Difference $\quad 1.1135$ t Ratio 1.550791

$\begin{array}{llll}\text { Std Err Dif } \quad 0.7180 & \text { DF } \quad 89.67459\end{array}$

$\begin{array}{llll}\text { Upper CL Di } & 2.5400 & \text { Prob }>\mid \mathrm{t} & 0.1245\end{array}$

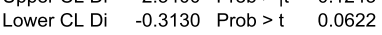

$\begin{array}{lll}\text { Confidence } & 0.95 \text { Prob }<\mathrm{t} \quad 0.9378\end{array}$

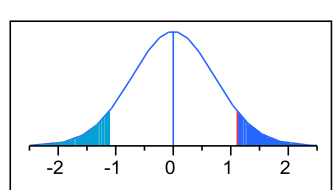


Oneway Analysis of $\mathrm{PP}^{\circ} \mathrm{By}$ Gender

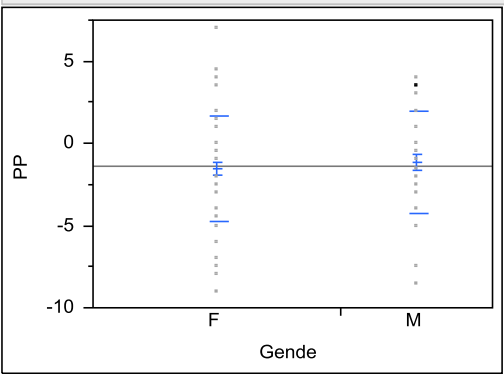

Means and Std Deviations Std Err

Level Number Mean Std Dev Mean Lower 95\% Upper 95\%

$\begin{array}{lllllll}F & 65 & -1.5462 & 3.23642 & 0.40143 & -2.348 & -0.7442\end{array}$ t Test

Assuming unequal variance

Difference $\quad 0.4087$ t Ratio 0.646201

Std Err Dif $\quad 0.6324$ DF 85.63532

Upper CL Di 1.6659 Prob > t 0.5199

$\begin{array}{lrll}\text { Lower CL Di } & -0.8486 & \text { Prob }>t & 0.2599\end{array}$

Confidence $\quad 0.95$ Prob $<\mathrm{t} \quad 0.7401$

01
Oneway Analysis of II Mx By Gender

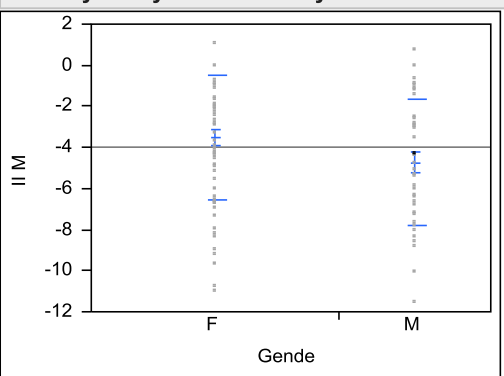

Means and Std Deviations

Level Number Mean Std Dev $\begin{gathered}\text { Std Err } \\ \text { Mean Lower } 95 \% \text { Upper } 95 \%\end{gathered}$ $\begin{array}{lllllll}\text { F } & 65 & -3.5188 & 3.02396 & 0.37508 & -4.268 & -2.769\end{array}$ $\begin{array}{lllllll}\mathrm{M} & 40 & -4.7465 & 3.08348 & 0.48754 & -5.733 & -3.760\end{array}$ t Test

M-

Assuming unequal variance

Difference -1.2277 t Ratio -1.99591

Std Err Dif $\quad 0.6151$ DF $\quad 81.44176$

$\begin{array}{lrll}\text { Upper CL Di } & -0.0039 & \text { Prob }>\mid t & 0.0493 \\ \text { Lower CL Di } & -2.4515 & \text { Prob }>t & 0.9754\end{array}$

Confidence $\quad 0.95$ Prob $<\mathrm{t} \quad 0.0246$

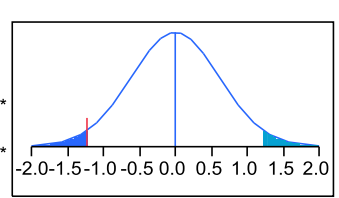

Oneway Analysis of IV Mx Ant By Gender

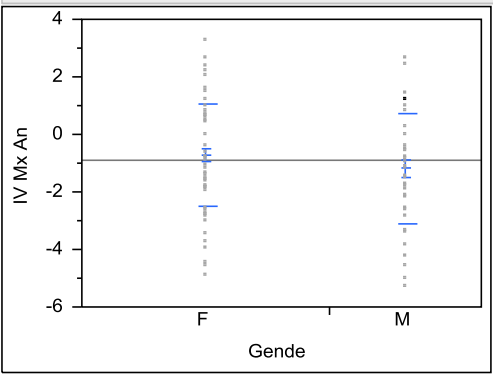

Means and Std Deviations

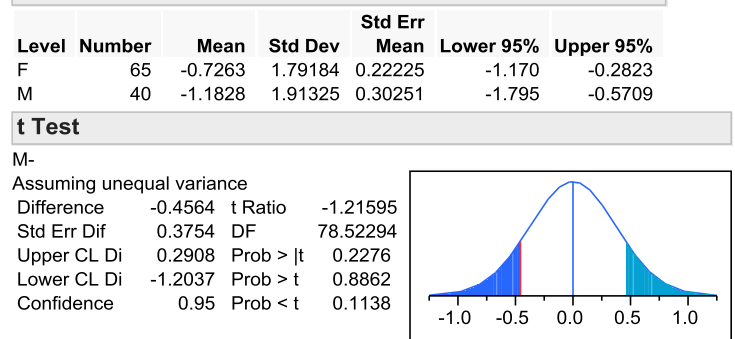

Oneway Analysis of IV Md Ant By Gender

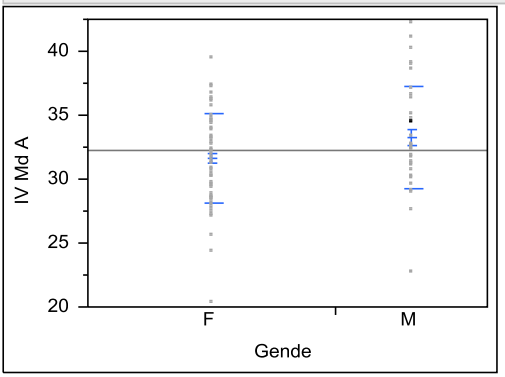

Means and Std Deviations

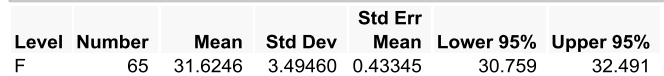
$\begin{array}{rrrrrrr}\text { F } & 65 & 31.6246 & 3.49460 & 0.43345 & 30.759 & 32.491\end{array}$ $\begin{array}{lllllll}\text { M } & 40 & 33.2480 & 3.99116 & 0.63106 & 31.972 & 34.524\end{array}$ t Test

M-

Assuming unequal variance

Difference $\quad 1.62338$ t Ratio 2.120459

Std Err Dif $\quad 0.76558$ DF $\quad 74.38992$

Upper CL Di 3.14871 Prob $>$ t 0.0373 *

Lower CL Di 0.09806 Prob $>t \quad 0.0187$ *

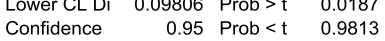

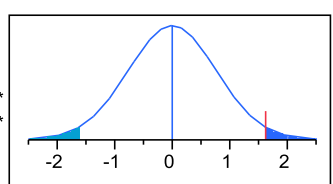




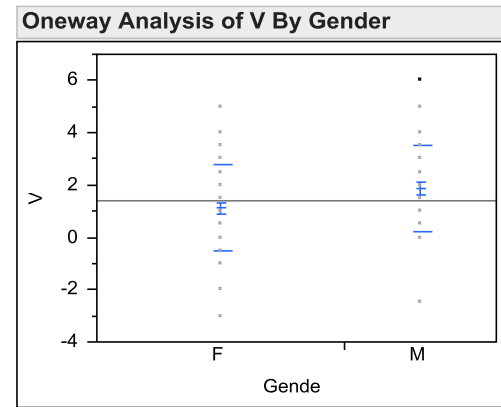

Means and Std Deviations

Std Err

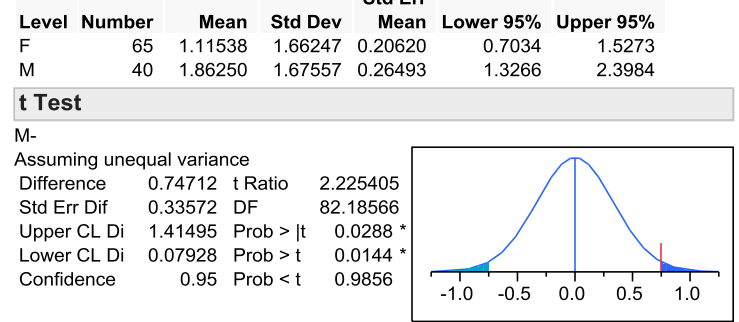

Oneway Analysis of $\bar{I}^{\circ}$ - Op By Gender

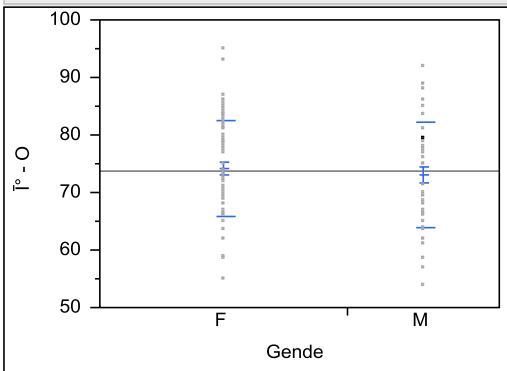

Means and Std Deviations

Std Err

Mean Std Dev Mean Lower 95\% Upper 95\%

$\begin{array}{lllllll}\text { F } & 65 & 74.1154 & 8.38235 & 1.0397 & 72.038 & 76.192\end{array}$

$\begin{array}{lllllll}\mathrm{M} & 40 & 73.0850 & 9.18788 & 1.4527 & 70.147 & 76.023\end{array}$

t Test

M-

Assuming unequal variance

-1.0304 t R

\begin{tabular}{lll} 
Std Err Dif $\quad 1.7865$ DF $\quad 76.89133$ \\
\hline
\end{tabular}

Upper CL Di 2.5270 Prob $>\mid t \quad 0.5658$

$\begin{array}{llll}\text { ower CL Di } & -4.5877 & \text { Prob }>t & 0.7171\end{array}$

0.95 Prob $<\mathrm{t} \quad 0.2829$

0.95 Prob $<\mathrm{t} \quad 0.2829$

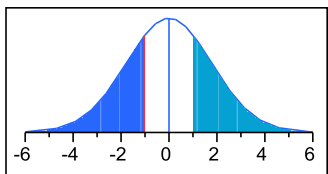

\section{Oneway Analysis of $1^{\circ}$ - Op By Gender}

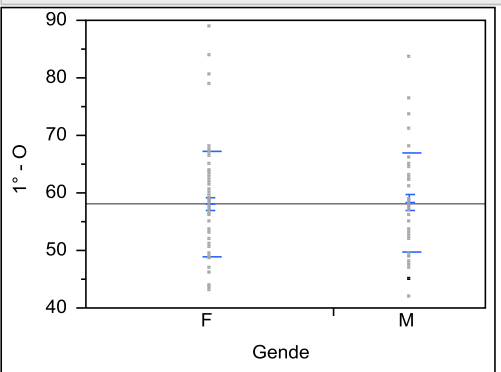

Means and Std Deviations

Level Number Mean Std Dev $\begin{array}{r}\text { Std Err } \\ \text { Mean Lower 95\% Upper 95\% }\end{array}$

$\begin{array}{rrrrrrr}\text { F } & 65 & 58.0062 & 9.15061 & 1.1350 & 55.739 & 60.274\end{array}$

$\begin{array}{lllllll}\mathrm{F} & 65 & 58.0062 & 9.15061 & 1.1350 & 55.739 & 60.274 \\ \mathrm{M} & 40 & 58.2775 & 8.54210 & 1.3506 & 55.546 & 61.009\end{array}$

t Test

$M-$

Assuming unequal variance

Difference $\quad 0.2713$ t Ratio 0.153807

Std Err Dif $\quad 1.7642$ DF $\quad 87.07119$

Upper CL Di 3.7778 Prob > t 0.8781

Lower CL Di $\quad-3.2351$ Prob $>t \quad 0.4391$

Confidence $\quad 0.95$ Prob $<\mathrm{t} \quad 0.5609$

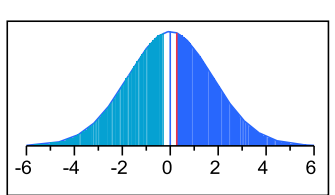

Oneway Analysis of Op-Sn By Gender

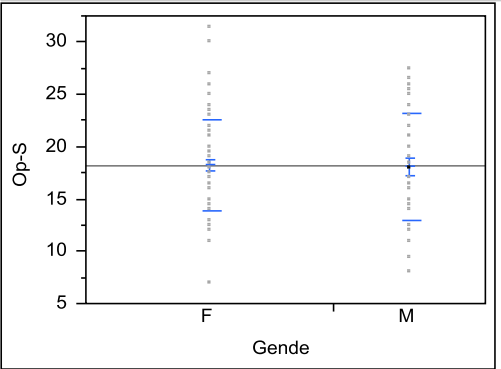

Means and Std Deviations

Level Number Mean Std Dev Std Err $\begin{array}{lllll}65 & 18.2231 & 4.35624 & 0.54032 & 17.144\end{array}$ $\begin{array}{lllllll}\text { M } & 40 & 18.0750 & 5.16342 & 0.81641 & 16.424 & 19.726\end{array}$

t Test

M-

Assuming unequal variance

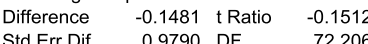

$\begin{array}{llll} & 0.9790 & \text { DF } & 72.2062 \\ \text { Upper CL Di } & 1.8035 & \text { Prob }>\text { It } & 0.8802 \\ \text { L } & & \end{array}$

Lower CL Di -2.0996 Prob $>t \quad 0.5599$

Confidence $\quad 0.95$ Prob $<\mathrm{t} \quad 0.4401$

0.95 Prob $<\mathrm{t} \quad 0.4401$

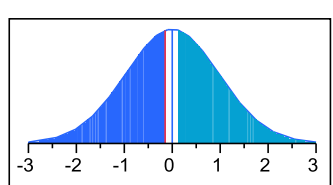


Oneway Analysis of Sn By Gender

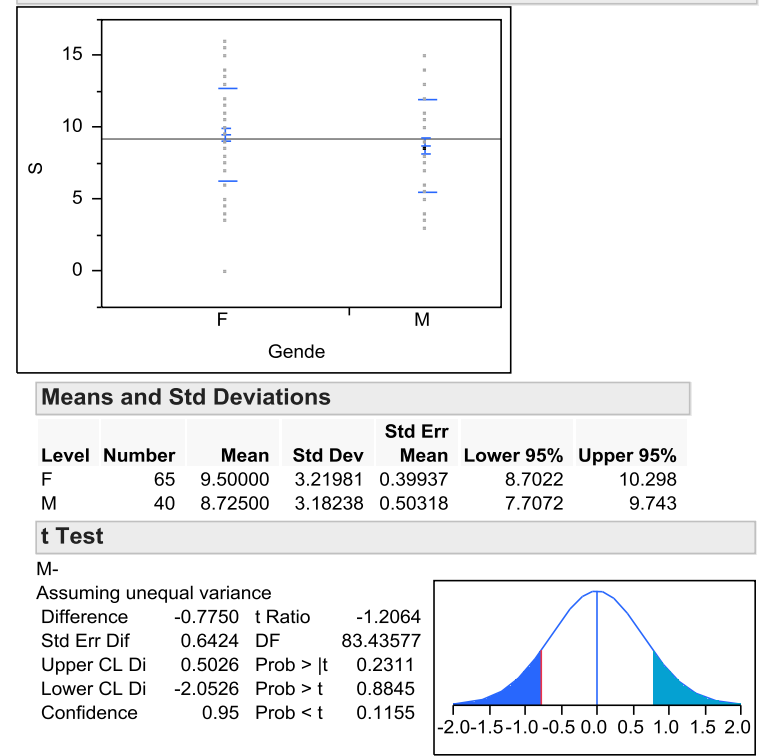

Oneway Analysis of Mp-Mic By Gender
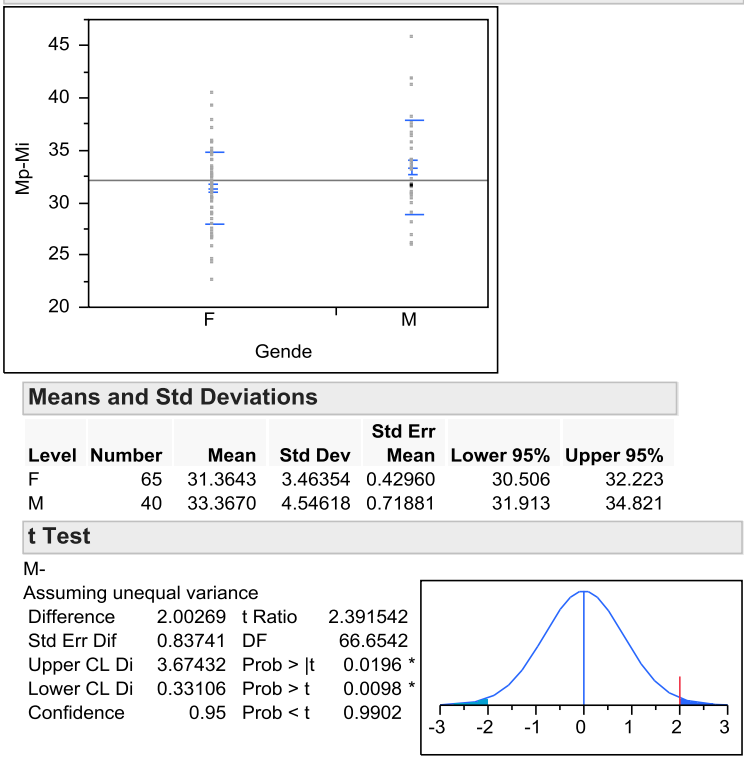

Oneway Analysis of Co-Gn By Gender

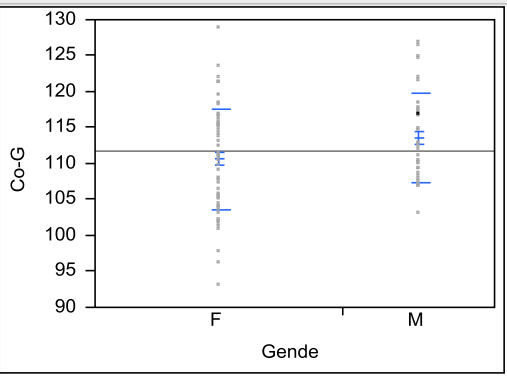

Means and Std Deviations

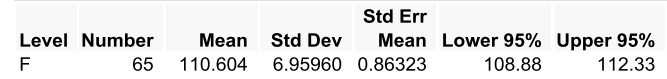
$\begin{array}{llrrrrr}\mathrm{F} & 65 & 110.604 & 6.95960 & 0.86323 & 108.88 & 112.33\end{array}$ $\begin{array}{lllllll}\text { M } & 40 & 113.556 & 6.16900 & 0.97540 & 111.58 & 115.53\end{array}$ t Test

M-

Assuming unequal variance

Difference 2.95169 t Ratio 2.266122 Std Err Dif $\quad 1.30253$ DF 90.27097 Upper CL Di 5.53929 Prob $>\mid \mathrm{t} \quad 0.0258$ * Lower CL Di 0.36409 Prob $>t \quad 0.0129$ * Lower CL Di 0.36409 Prob $>1 \quad 0.0129^{\circ}$ Confidence $\quad 0.95$ Prob $<\mathrm{t} \quad 0.9871$

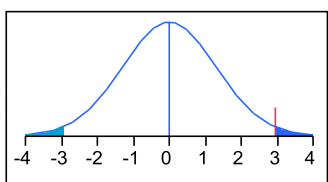

Oneway Analysis of II Md By Gender

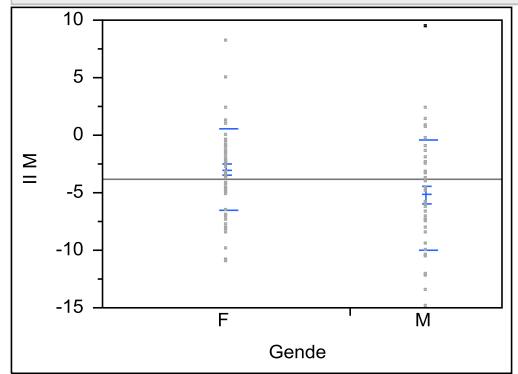

Means and Std Deviations

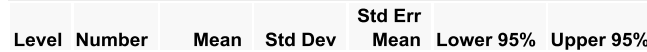

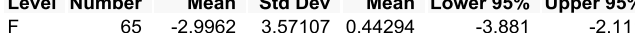
$\begin{array}{lllllll}\mathrm{F} & 65 & -2.9962 & 3.57107 & 0.44294 & -3.881 & -2.111 \\ \mathrm{M} & 40 & -5.1913 & 4.84274 & 0.76570 & -6.740 & -3.642\end{array}$

t Test M-

Assuming unequal variance Difference $\quad-2.1951$ t Ratio -2.48149 Std Err Dif $\quad 0.8846$ DF $\quad 65.03061$ Upper CL Di -0.4285 Prob $>\mid \mathrm{t} \quad 0.0157$ $\begin{array}{llll}\text { Lower CL Di } & -3.9617 & \text { Prob }>t & 0.9922\end{array}$

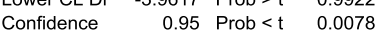

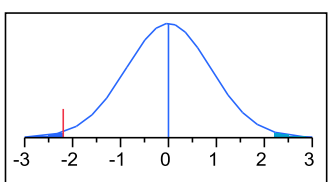




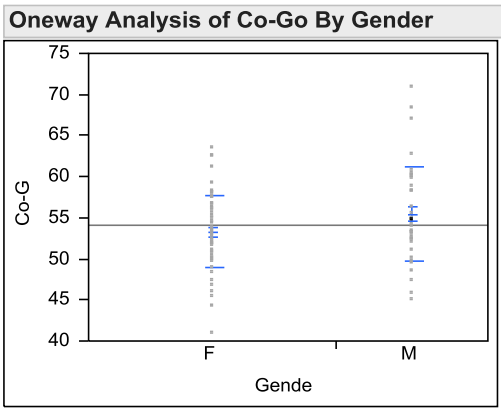

Means and Std Deviations

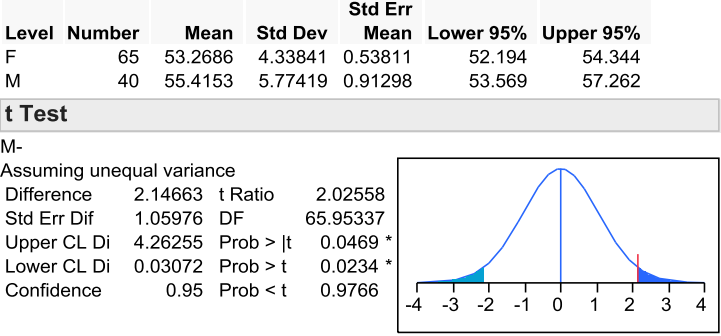

Oneway Analysis of PP-1 By Gender

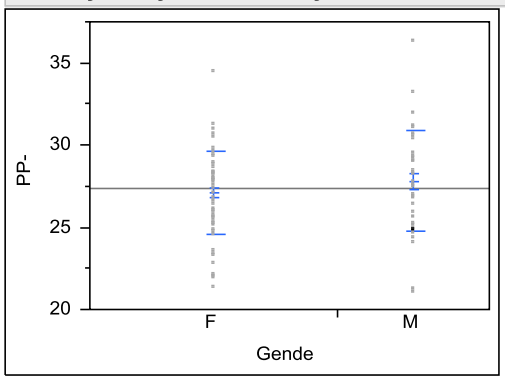

Means and Std Deviations

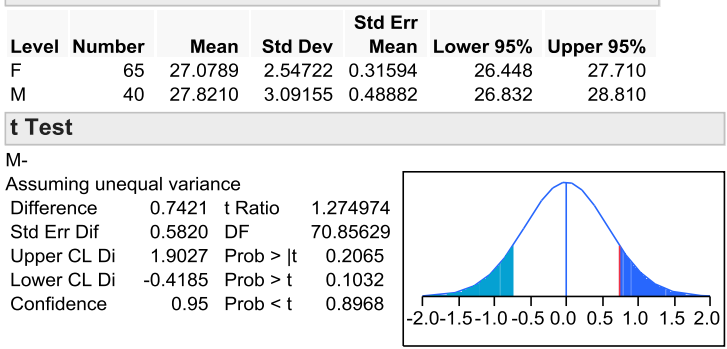

Oneway Analysis of S-Go By Gender
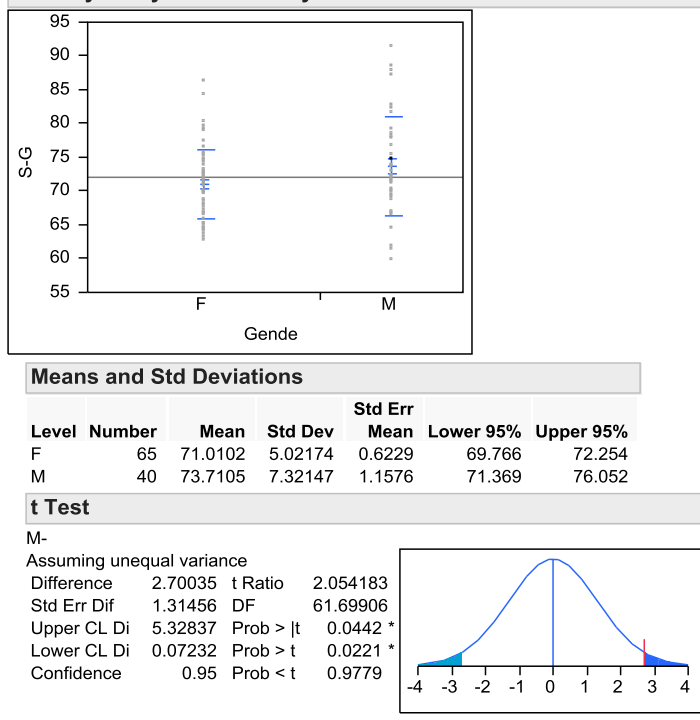

Oneway Analysis of Pog'-GALL By Gender

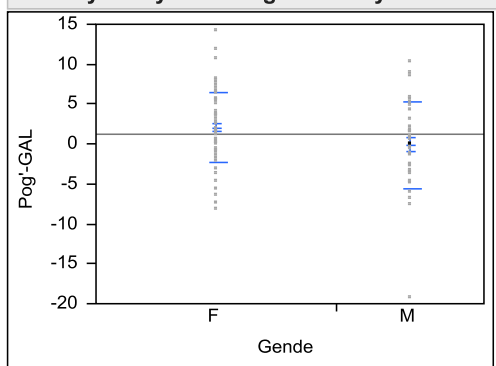

Means and Std Deviations

$$
\text { Std Err }
$$

Level Number Mean Std Dev Mean Lower 95\% Upper 95\% $\begin{array}{lllllll}\text { F } & 65 & 2.0552 & 4.32275 & 0.53617 & 0.984 & 3.1264\end{array}$ $\begin{array}{lllllll}M & 40 & -0.1227 & 5.47041 & 0.86495 & -1.872 & 1.6268\end{array}$ t Test

Assuming unequal variance Difference -2.1780 tRatio $\begin{array}{llr}\text { Diference } & -2.1780 \text { tRatio } & -2.1402 \\ \text { Std Err Dif } & 1.0177 \text { DF } & 68.56199\end{array}$ \begin{tabular}{lrr} 
Upper CL Di & -0.1476 Prob $>$ t & 0.0359 * \\
\hline
\end{tabular} $\begin{array}{llll}\text { Lower CL Di } & -0.2084 & \text { Prob }>\mid t & 0.0359 * \\ \text { Lower } & -4.2084 & 0.9821\end{array}$ Confidence $\quad 0.95$ Prob $<t \quad 0.0179$ *

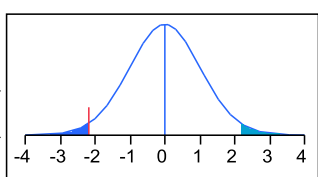




\section{Oneway Analysis of N-ANS By Gender}

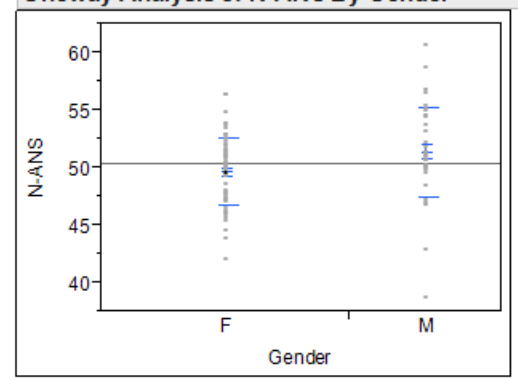

Means and Std Deviations

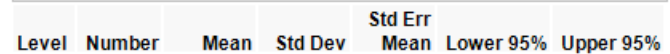

$\begin{array}{lrrrrrr}\text { Level Number } & \text { Mean } & \text { Std Dev } & \text { Mean } & \text { Lower 95\% } & \text { Upper 95\% } \\ \text { F } & 65 & 49.6920 & 2.92810 & 0.36319 & 48.966 & 50.418\end{array}$

$\begin{array}{lllllll}\mathrm{M} & 40 & 51.4133 & 3.89183 & 0.61535 & 50.169 & 52.658\end{array}$

t Test

$M-F$

Assuming unequal variances

Differenœ $\quad 1.72125$ t Ratio 2.408904

Std Err Dif $\quad 0.71454 \mathrm{DF} \quad 66.02163$

UpperCLDif 3.14786 Prob $>|t| \quad 0.0188^{*}$

LowerCL Dif 0.29464 Prob $>t \quad 0.0094^{\star}$

Confidenœ $\quad 0.95$ Prob $<\mathrm{t}$

0.9906

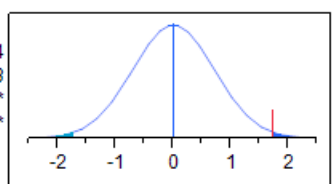

Oneway Analysis of PP-Mic By Gender

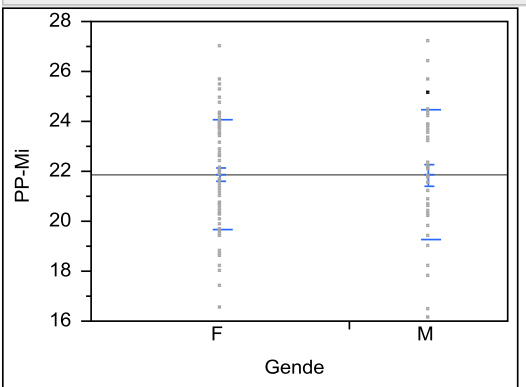

Means and Std Deviations

\begin{tabular}{|c|c|c|c|c|c|c|c|}
\hline \multirow{2}{*}{\multicolumn{2}{|c|}{ Level Number }} & & \multirow{2}{*}{ Std Dev } & Std Err & & & \\
\hline & & & & Mean & in Lower 95\% & & \\
\hline ( & 65 & 21.875 & $2.2168 \mathrm{r}-2 \mathrm{r}-\mathrm{r} \mathrm{r}$ & $\begin{array}{ll}880 & 0.27496\end{array}$ & 21.326 & 22.424 & \\
\hline $\mathrm{M}$ & 40 & 21.834 & 2.5996 & 9690.41105 & 21.003 & 22.666 & \\
\hline \multicolumn{8}{|l|}{ t Test } \\
\hline M- & & & & & & & \\
\hline \multicolumn{8}{|c|}{ Assuming unequal variance } \\
\hline Difference & & $.0403 \mathrm{t}$ & t Ratio & -0.08155 & & & \\
\hline Std Err Dif & & .4945 & DF & 72.82531 & & & \\
\hline Upper CL Di & & .9453 & Prob $>\mid t$ & 0.9352 & & & \\
\hline Lower CL Di & & 1.0260 & Prob $>t$ & 0.5324 & & & \\
\hline Confidence & & 0.95 & Prob $<t$ & 0.4676 & $.0-0.5$ & $\begin{array}{ll}1 & 1 \\
0.0 & 0.5\end{array}$ & 1.01. \\
\hline
\end{tabular}

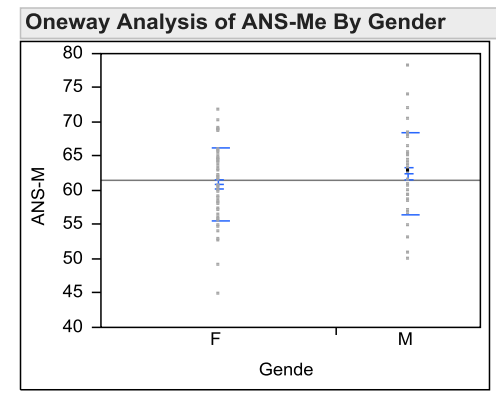

Means and Std Deviations

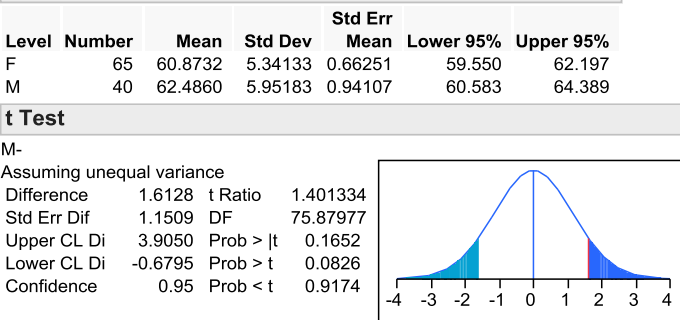

\section{Oneway Analysis of N-ANS By AGE}

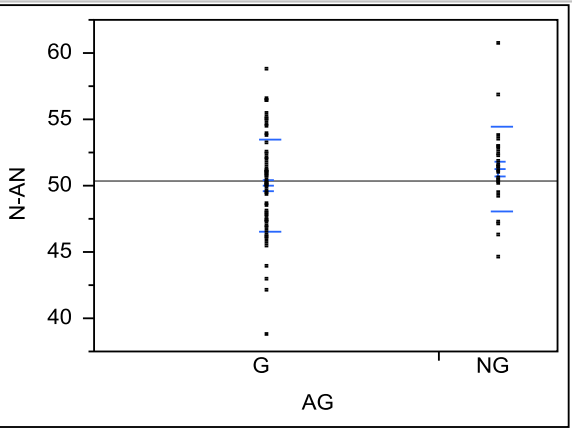

Means and Std Deviations

\section{Std Err}

Level Number Mean Std Dev Mean Lower 95\% Upper 95\%

$\begin{array}{llllllr}\mathrm{G} & 78 & 50.0386 & 3.47227 & 0.39316 & 49.256 & 50.821\end{array}$

$\begin{array}{lllllll}\text { NG } & 27 & 51.2407 & 3.13443 & 0.60322 & 50.001 & 52.481\end{array}$

\section{t Test}

NG-

Assuming unequal variance

Difference $\quad 1.2022$ t Ratio

Std Err Dif 0.7200 DF

Upper CL Di 2.6486 Prob $>\mid \mathrm{t} \quad 0.1013$

$\begin{array}{llll}\text { Lower CL Di } & -0.2443 \text { Prob }>t & 0.0506\end{array}$

Confidence

0.95 Prob $<$

0.9494

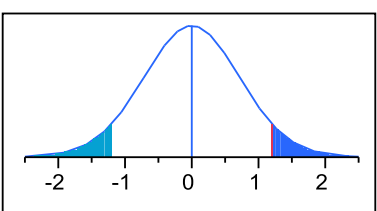




\section{Oneway Analysis of G'-Sn' By Gender}

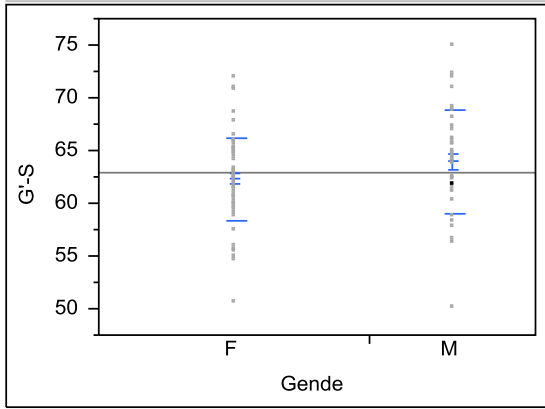

Means and Std Deviations

\begin{tabular}{|lrrrrrr|} 
& & & \multicolumn{3}{c}{ Std Err } \\
Level & Number & Mean & Std Dev & Mean & Lower 95\% & Upper 95\% \\
F & 65 & 62.2643 & 3.96366 & 0.49163 & 61.282 & 63.246 \\
M & 40 & 63.9243 & 4.87243 & 0.77040 & 62.366 & 65.483 \\
\hline t Test & & & & & &
\end{tabular}

Assuming unequal variance

Difference $\quad 1.6599$ t Ratio 1.816325

Std Err Dif 0.9139 DF

Lower CL Di $\quad-0.1627$ Prob $>t \quad 0.0368$ *

Confidence

0.95 Prob $<$

0.9632

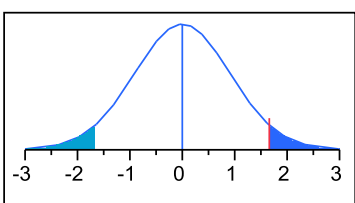

Oneway Analysis of II Md By AGE

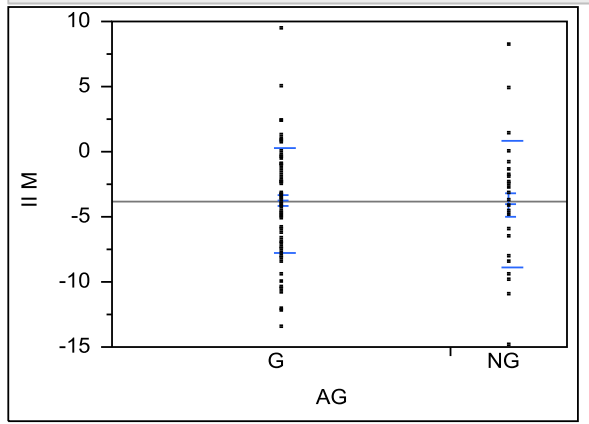

Means and Std Deviations

Level Number Mean Std Dev $\begin{gathered}\text { Std Err } \\ \text { Mean Lower 95\% Upper 95\% }\end{gathered}$

$\begin{array}{llllllr}G & 78 & -3.7473 & 3.99975 & 0.45288 & -4.649 & -2.846\end{array}$

$\begin{array}{lllllll}\text { G } & 78 & -3.7473 & 3.99975 & 0.45288 & -4.649 & -2.846 \\ \text { NG } & 27 & -4.0781 & 4.86775 & 0.93680 & -6.004 & -2.153\end{array}$

t Test

NG-

Assuming unequal variance

$\begin{array}{lll}\text { Assuming unequal variance } & \\ \text { Difference } & -0.3308 \text { t Ratio } & -0.31796 \\ \text { Std Err Dif } & 1.0405 \text { DF } & 38.85647\end{array}$

Std Err Dif 1.0405 DF

Upper CL Di 1.7741 Prob > It 0.7522

$\begin{array}{llll}\text { Lower CL Di } & -2.4358 & \text { Prob }>t & 0.6239\end{array}$

$\begin{array}{lll}\text { Confidence } & 0.95 \text { Prob }<\mathrm{t} \quad 0.3761\end{array}$

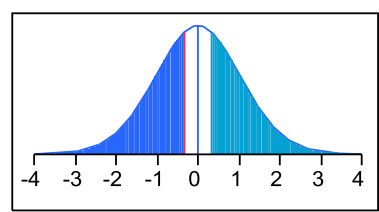


Reliability:

\section{Multivariate Variable $=$ II Mx}

\section{Cronbach's a}

Entire set

$$
\begin{array}{r}
\alpha \\
0.9961
\end{array}
$$

Excluded

$\mathbf{\alpha}$

Col

First

Second

\section{Pairwise Correlations}

\section{Variable by Variable}

Second

First

\section{Correlation}

0.9931
Lower 95\%

0.9699
Upper 95\%

0.9984
Signif Prob $<.0001^{*}$

\section{Multivariate Variable $=1^{\circ}$}

Cronbach's a

Entire set

$$
\begin{array}{r}
\text { a Plot Alpha } \\
0.9989
\end{array}
$$

\section{Excluded \\ a Plot Alpha}

First

Second

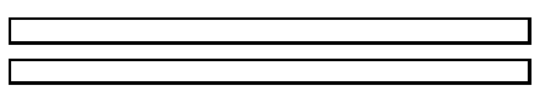

\section{Pairwise Correlations}

\section{Variable by Variable}

Second First
Count Lower 95\%

0.9903
Upper 95\%

0.9995

\section{Signif Prob} $<.0001^{*}$

Multivariate Variable $=1^{\circ}$ - Op

Cronbach's a

Entire set

a Plot Alpha

Excluded

0.9987

Col

First

Second

a Plot Alpha

Pairwise Correlations

Variable by Variable

Second First

\section{Correlation}

0.9976
Count

10

\section{Lower $95 \%$}

0.9894
Upper 95\%

0.9994
Signif Prob $<.0001^{*}$ 
Multivariate Variable $=1^{\circ}$ - ${ }^{\circ} \circ$

Cronbach's a

$\begin{array}{lc}\text { Entire set } & \alpha \text { Plot Alpha } \\ \text { Excluded } & \alpha .9993 \\ \text { Col } & \alpha \text { Plot Alpha } \\ \text { First } & \\ \text { Second } & .\end{array}$

Pairwise Correlations

Variable by Variable

Second

First

Correlation

Count

Lower 95\%

Upper 95\%

0.9987

0.9942

0.9997

Signif Prob $<.0001^{*}$

Multivariate Variable $=$ ANB $^{\circ}$

Cronbach's $\alpha$

Entire set

a Plot Alpha

Excluded

0.9787

Col

First

Second

a Plot Alpha

\section{Pairwise Correlations}

Variable by Variable

Second First

Correlation Count Lower 95\%

Upper 95\%

Signif Prob

0.9905

$<.0001^{*}$

Multivariate Variable=ANS-Me

Cronbach's a

Entire set

a Plot Alpha

Excluded

0.9992

0.9588

0.8307

$<.0001^{*}$

Col

First

Second

a Plot Alpha

\section{Pairwise Correlations}

Variable by Variable

Second First

Correlation

0.9986

Count

Lower 95\%

0.9939

Upper 95\%

0.9997
Signif Prob $<.0001^{*}$

Multivariate Variable=Co-Gn

Cronbach's $\alpha$

a Plot Alpha 


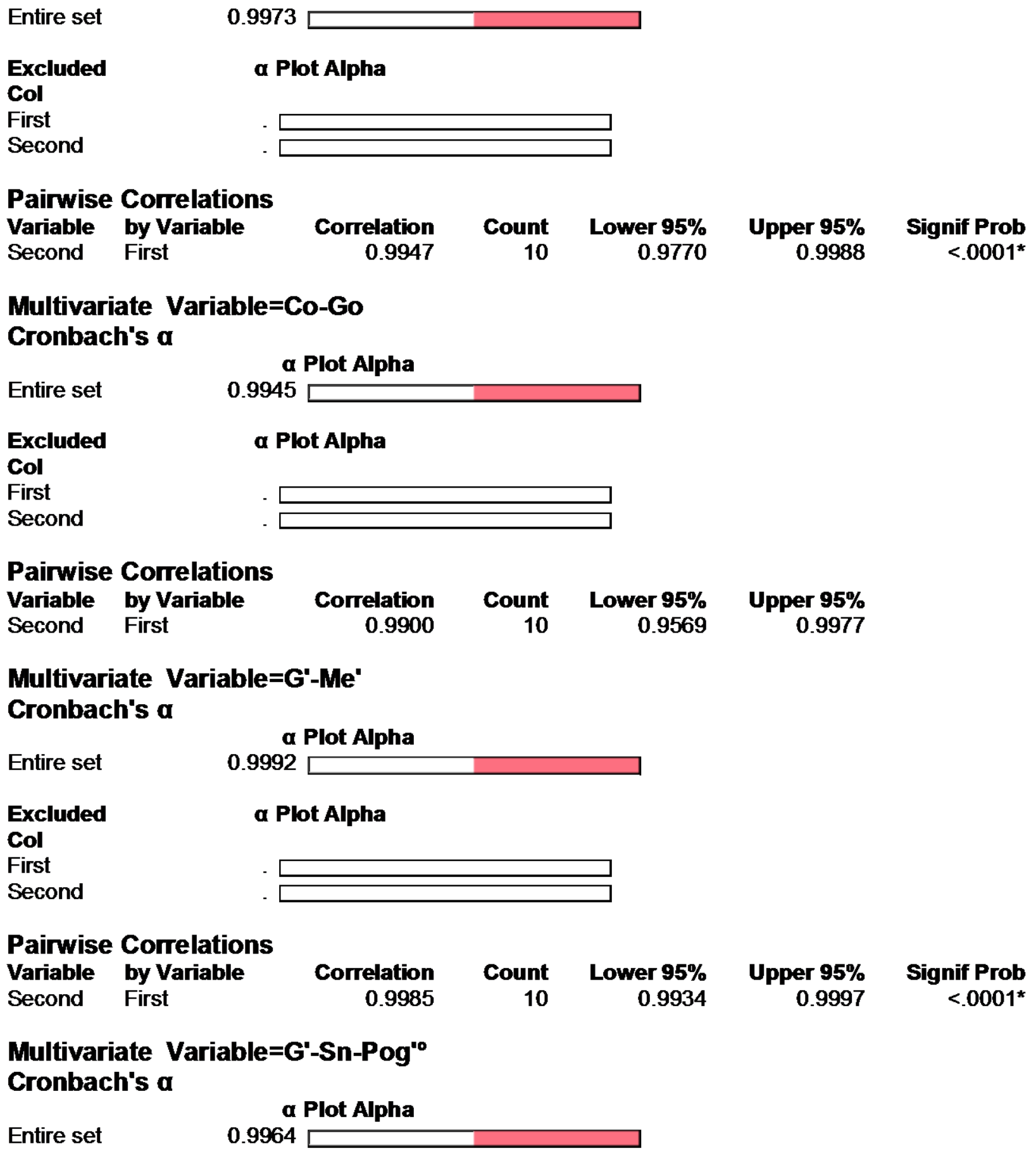




\section{Multivariate Variable=II Md}

Cronbach's a

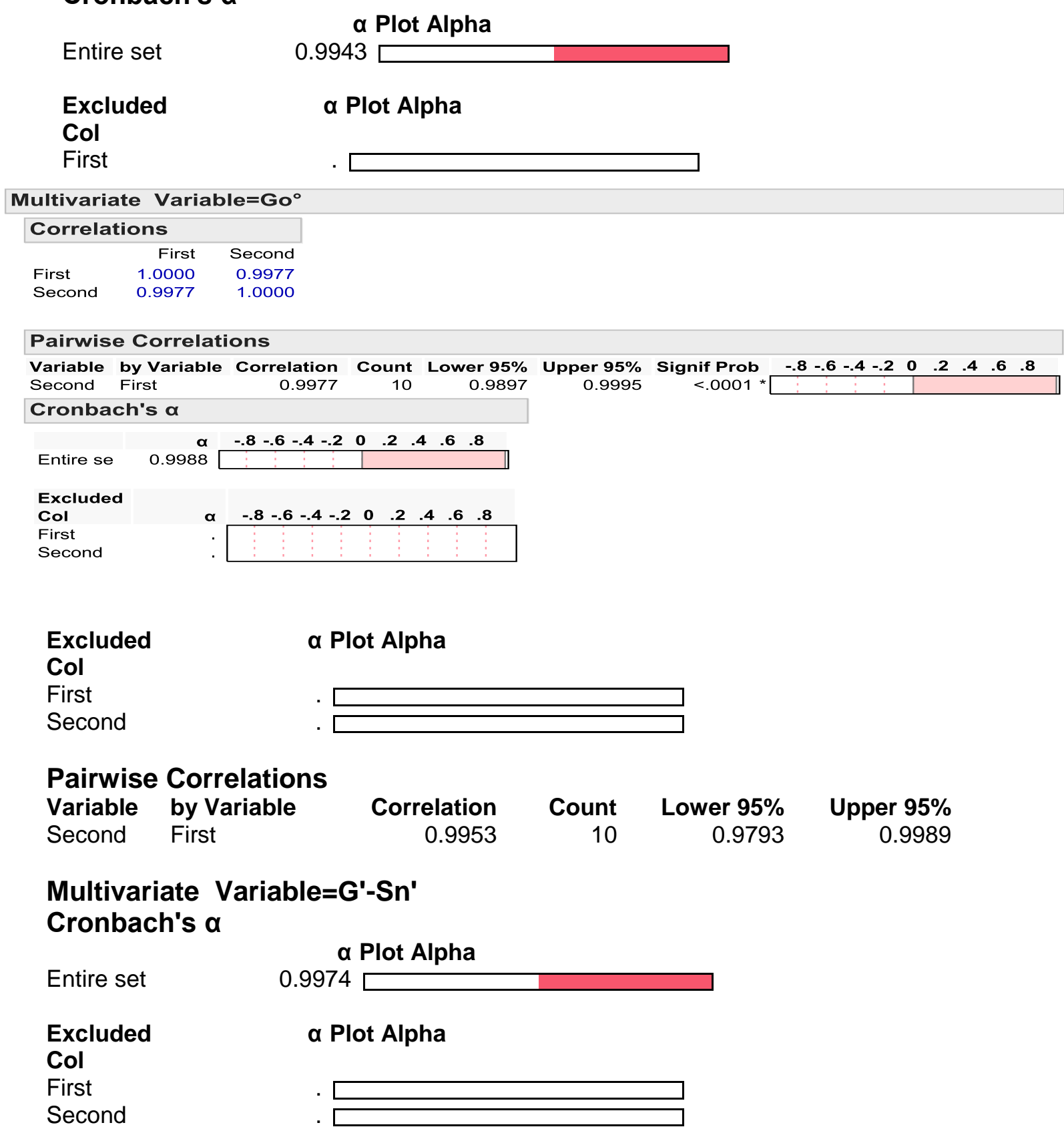

Pairwise Correlations Variable by Variable Second First

$\begin{array}{rrrrr}\text { Correlation } & \text { Count } & \text { Lower 95\% } & \text { Upper 95\% } & \text { Signif Prob } \\ 0.9955 & 10 & 0.9805 & 0.9990 & <.0001^{*}\end{array}$


Pairwise Correlations

Variable by Variable

Second First

Correlation

0.9963

Count

Lower 95\%

0.9836

Upper 95\%

0.9991

Signif Prob

$<.0001^{*}$

Multivariate Variable=IV Md Ant

Cronbach's $\alpha$

Entire set

a Plot Alpha

Excluded

0.9956

Col

a Plot Alpha

First

Second

\section{Pairwise Correlations}

Variable by Variable

Second

First

Correlation

0.9914
Lower 95\%

0.9626
Upper 95\%

0.9980
Signif Prob $<.0001^{*}$

Multivariate Variable=IV Mx Ant

\section{Cronbach's $\alpha$}

Entire set
Excluded
Col
First
Second

a Plot Alpha

0.9873

a Plot Alpha

\section{Pairwise Correlations}

Variable by Variable

Second

First

Correlation

0.9783

Count

Lower 95\%

0.9081

Upper 95\%

0.9950

\section{Signif Prob} $<.0001^{*}$

Multivariate Variable=MP-L1

Cronbach's a

Entire set

a Plot Alpha

Excluded

0.9944

Col

First

Second

a Plot Alpha 
Pairwise Correlations

Variable by Variable

Second First
Correlation

0.9888
Count

10

Lower 95\%

0.9517
Upper $95 \%$

0.9974
Signif Prob $<.0001^{*}$

Multivariate Variable $=\mathrm{Mp}-\mathrm{Mic}$

Cronbach's a

Entire set

a Plot Alpha

Excluded

Col

First

Second

$$
0.9932
$$

a Plot Alpha

\section{Pairwise Correlations}

Variable by Variable

Second First
Correlation

0.9877

\section{Count}

10

Lower 95\%

0.9468
Upper 95\%

0.9972
Signif Prob $<.0001^{*}$

Multivariate Variable $=\mathrm{MP}^{\circ}$

Cronbach's $\alpha$

Entire set

a Plot Alpha

Excluded

Col

First

Second

$$
0.9982
$$

a Plot Alpha

\section{Pairwise Correlations}

Variable by Variable

Second First

\section{Count}

10

Lower 95\%

0.9944

Upper 95\%

0.9997
Signif Prob $<.0001^{*}$

\section{Multivariate Variable=N-ANS}

\section{Cronbach's a}

Entire set

a Plot Alpha

Excluded

0.9973

Col

$$
\text { a Plot Alpha }
$$

First

Second

Pairwise Correlations

Variable by Variable 
Second First

0.9949

10

0.9779

0.9988

$<.0001^{*}$

Multivariate Variable $=\mathrm{N}-\mathrm{Me}$

Cronbach's a

Entire set

a Plot Alpha

Entire set

0.9994

Excluded

a Plot Alpha

Col

First

Second

Pairwise Correlations

Variable by Variable

Correlation

Count

Lower 95\%

Upper $95 \%$

0.9988

0.9948

0.9997

Signif Prob $<.0001^{*}$

Multivariate Variable $=O p-S n$

Cronbach's a

Entire set
Excluded
Col
First
Second

a Plot Alpha

0.9821

a Plot Alpha

Pairwise Correlations

Variable by Variable

Second

First

Correlation

Count

Lower 95\%

0.8975

Upper 95\%

0.9944

Signif Prob $<.0001^{*}$

Multivariate Variable $=O p^{\circ}$

Cronbach's a

Entire set

a Plot Alpha

Excluded

0.9912

0.9758

10

(2.9.9.

$<.0001^{*}$

Col

First

Second

a Plot Alpha

Pairwise Correlations

Variable by Variable

Second

First

Correlation

Count

Lower 95\%

0.9859

0.9394

Upper 95\%

0.9968

Signif Prob $<.0001^{*}$ 
Multivariate Variable=PFH:AFH

Cronbach's $\alpha$

Entire set

a Plot Alpha

Excluded

0.9945

Col

First

Second

a Plot Alpha

Pairwise Correlations

Variable by Variable

Second First

Correlation

Count Lower 95\%

Upper 95\%

0.9892

0.9531

0.9975

Signif Prob

$<.0001^{*}$

Multivariate Variable=Pog-GALL

Cronbach's a

Entire set

a Plot Alpha

Excluded

0.9968

Col

First

Second

a Plot Alpha

Pairwise Correlations

Variable by Variable

Second First

Correlation Count Lower 95\%

0.9960

0.9825

Upper 95\%

0.9991

Signif Prob $<.0001^{*}$

Multivariate Variable=Pog'-GALL

Cronbach's a

a Plot Alpha

Entire set

0.9948

Excluded

a Plot Alpha

Col

First

Second

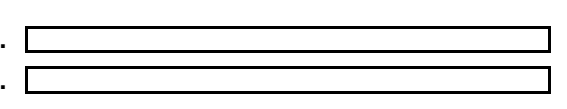

Pairwise Correlations

Variable by Variable

Second First

Correlation Count Lower 95\%

0.9574

Upper 95\%

0.9978

Signif Prob $<.0001^{*}$

Multivariate Variable=Pog'c-GALL

Cronbach's a

a Plot Alpha 
Excluded

a Plot Alpha

Col

First

Second

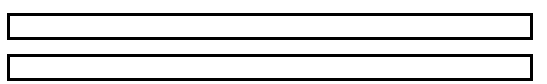

Pairwise Correlations

Variable by Variable

Correlation Count Lower 95\% Upper 95\%

Signif Prob

Second First

0.9888

0.9515

0.9974

$<.0001^{*}$

Multivariate Variable=PP-1

Cronbach's $\alpha$

a Plot Alpha

Entire set

0.9959

10

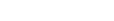

0.9974

$+.0001^{*}$

Excluded

Col

First

Second

$$
\text { a Plot Alpha }
$$

\section{Pairwise Correlations}

Variable by Variable

Second First $\begin{array}{rrr}\text { Correlation } & \text { Count } & \text { Lower 95\% } \\ 0.9924 & 10 & 0.9668\end{array}$
Upper 95\%

0.9983
Signif Prob $<.0001^{*}$

\section{Multivariate Variable=PP-Mic}

\section{Cronbach's a}

Entire set

a Plot Alpha

Excluded a Plot Alpha

Col

First

Second

0.9922

\section{Pairwise Correlations}

Variable by Variable

Second First
Count

10
Lower $95 \%$
0.9348

0.9848

0.9348
Upper 95\%

0.9965
Signif Prob $<.0001^{*}$

Multivariate Variable $=\mathbf{P P}^{\circ}$

Cronbach's a

Entire set

a Plot Alpha

0.9964 


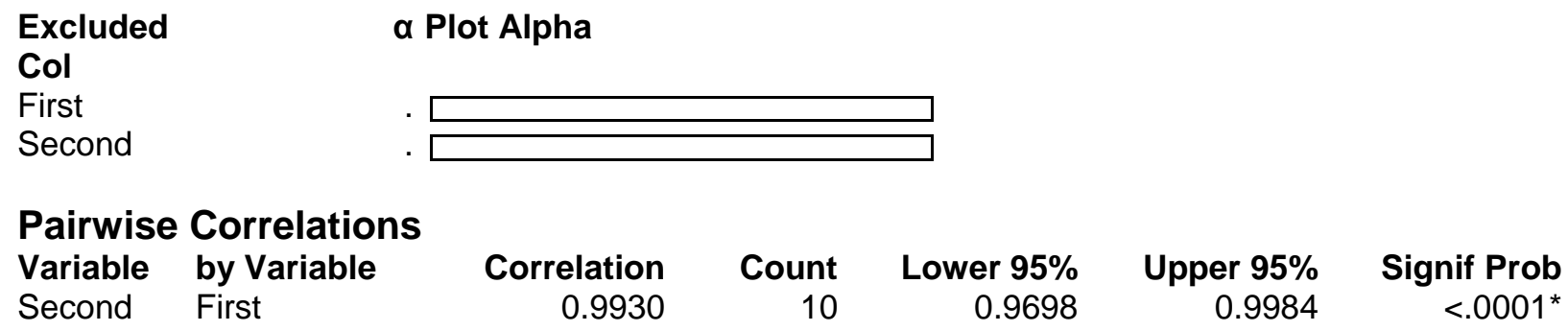

Multivariate Variable=S-Go

Cronbach's a

Entire set

a Plot Alpha

Excluded

0.9988

Col

a Plot Alpha

First

Second

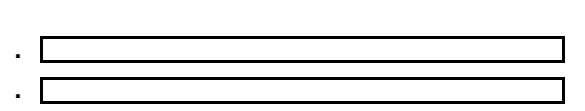

Pairwise Correlations

Variable by Variable

Second First

Correlation

0.9976

Count

10

Lower $95 \%$

0.9893

Upper 95\%

0.9994
Signif Prob $<.0001^{*}$

\section{Multivariate Variable $=\mathrm{SN}$}

Cronbach's a

Entire set

a Plot Alpha

Excluded

0.9958

Col

First

Second

a Plot Alpha

Pairwise Correlations

Variable by Variable

Second

First
Correlation

0.9931
Count

10
Lower 95\%

0.9698
Upper 95\%

0.9984
Signif Prob $<.0001^{*}$

\section{Multivariate Variable=SN-MP}

Cronbach's a

Entire set

a Plot Alpha

Excluded

0.9980

a Plot Alpha

Col

First 
Pairwise Correlations

Variable by Variable

Second First

Correlation

0.9963

Count

Lower 95\%

0.9838

Upper 95\%

0.9992

Signif Prob $<.0001^{*}$

Multivariate Variable=Sn'-Me'

Cronbach's $\alpha$

Entire set
Excluded
Col
First
Second

a Plot Alpha

0.9994

a Plot Alpha

\section{Pairwise Correlations}

Variable by Variable

Second

First

Correlation

0.9988
Lower $95 \%$

0.9947
Upper $95 \%$

0.9997
Signif Prob $<.0001^{*}$

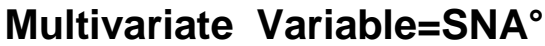

\section{Cronbach's $\alpha$}

Entire set
Excluded
Col
First
Second

a Plot Alpha

0.9841

a Plot Alpha

\section{Pairwise Correlations}

Multivariate ${\text { Variable }=S^{\prime}{ }^{\circ}}^{\circ}$

Cronbach's a

Entire set

a Plot Alpha

Excluded

Col

First

Second
0.9896
a Plot Alpha

Pairwise Correlations

Variable by Variable

Correlation Count Lower 95\% Upper 95\%

Signif Prob 


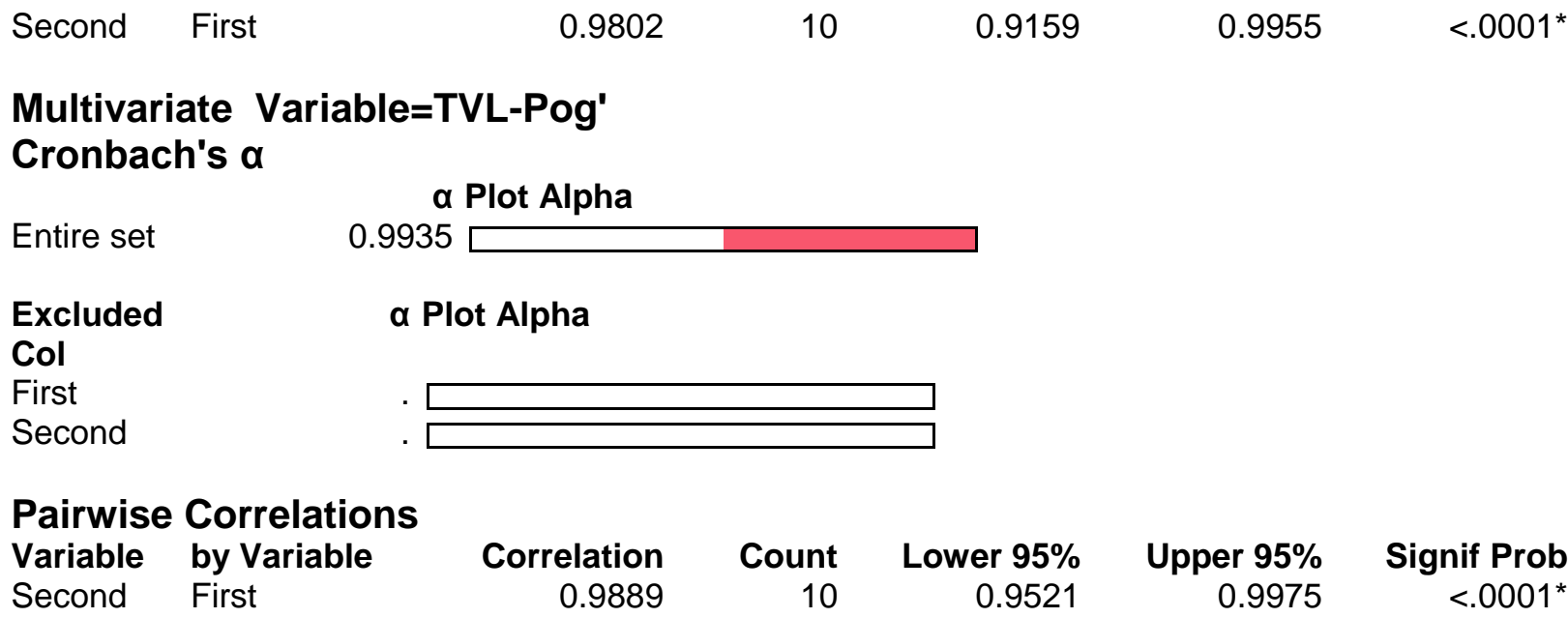

Multivariate Variable $=V$

Cronbach's a

Entire set

a Plot Alpha

Excluded

Col

First

Second

$$
0.9796
$$

a Plot Alpha

\section{Pairwise Correlations}

Variable by Variable

Second First

Correlation Count Lower 95\%

0.8364

Upper 95\%

0.9908

Signif Prob $<.0001^{*}$

Multivariate Variable $=\overline{\bar{I}} \circ$

\section{Cronbach's a}

Entire set

a Plot Alpha

Excluded

Col

First

Second

$$
0.9980
$$

a Plot Alpha

\section{Pairwise Correlations}

Variable by Variable

Second
Correlation

0.9963
Count

10
Lower $95 \%$
0.9836
Upper 95\%

0.9991
Signif Prob $<.0001^{*}$ 


\section{Multivariate Variable $=\bar{I}^{\circ}-$ Op \\ Cronbach's a}

Entire set

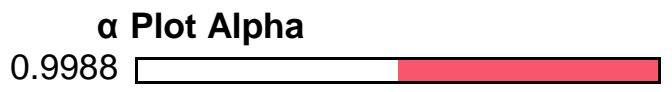

Excluded

a Plot Alpha

Col

First

Second

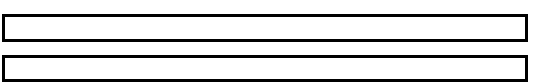

Pairwise Correlations

Variable by Variable

Second First

Correlation Count Lower 95\% Upper 95\%

Signif Prob

$\begin{array}{lllll}0.9975 & 10 & 0.9892 & 0.9994 & <.0001^{*}\end{array}$

Pairwise Correlation Coefficients for all measurements

\section{Pairwise Correlations}

\begin{tabular}{|c|c|c|c|c|c|c|}
\hline Variable & by Variable & Correlation & Count & Lower $95 \%$ & Upper 95\% & Signif Prob \\
\hline $\mathrm{Go}^{\circ}$ & ANS-Me & 0.1913 & 105 & -0.0004 & 0.3694 & 0.0506 \\
\hline $\mathrm{Go}^{\circ}$ & Co-Gn & 0.1245 & 105 & -0.0688 & 0.3088 & 0.2058 \\
\hline $\mathrm{Go}^{\circ}$ & Co-Go & -0.4256 & 105 & -0.5707 & -0.2547 & $<.0001^{*}$ \\
\hline $\mathrm{Go}^{\circ}$ & G'-Me' & 0.0657 & 105 & -0.1275 & 0.2542 & 0.5053 \\
\hline $\mathrm{Go}^{\circ}$ & $\mathrm{G}^{\prime}-S n^{\prime}$ & -0.0609 & 105 & -0.2496 & 0.1323 & 0.5373 \\
\hline $\mathrm{Go}^{\circ}$ & $\mathrm{L}^{\circ}{ }^{\circ}$ & 0.0808 & 105 & -0.1126 & 0.2683 & 0.4124 \\
\hline $\mathrm{Go}^{\circ}$ & MP-L1 & -0.0583 & 105 & -0.2472 & 0.1349 & 0.5547 \\
\hline $\mathrm{Go}^{\circ}$ & Mp-Mic & -0.0508 & 105 & -0.2401 & 0.1423 & 0.607 \\
\hline $\mathrm{Go}^{\circ}$ & N-ANS & -0.1579 & 105 & -0.3393 & 0.0348 & 0.1077 \\
\hline $\mathrm{Go}^{\circ}$ & $\mathrm{N}-\mathrm{Me}$ & 0.0746 & 105 & -0.1188 & 0.2625 & 0.4494 \\
\hline $\mathrm{Go}^{\circ}$ & $O p^{\circ}$ & 0.288 & 105 & 0.1019 & 0.4546 & $0.0029 *$ \\
\hline $\mathrm{Go}^{\circ}$ & PFH:AFH & -0.4578 & 105 & -0.597 & -0.2917 & $<.0001^{*}$ \\
\hline $\mathrm{Go}^{\circ}$ & Pog'c-GALL & 0.156 & 105 & -0.0368 & 0.3376 & 0.112 \\
\hline $\mathrm{Go}^{\circ}$ & Pog'-GALL & 0.053 & 105 & -0.14 & 0.2422 & 0.591 \\
\hline $\mathrm{Go}^{\circ}$ & Pog-GALL & -0.0144 & 105 & -0.2055 & 0.1778 & 0.8842 \\
\hline $\mathrm{Go}^{\circ}$ & PP-Mic & -0.0172 & 105 & -0.2082 & 0.175 & 0.8615 \\
\hline
\end{tabular}




\begin{tabular}{|c|c|c|c|c|c|c|}
\hline $\mathrm{Go}^{\circ}$ & PP-U1 & 0.0479 & 105 & -0.1451 & 0.2373 & 0.6278 \\
\hline $\mathrm{Go}^{\circ}$ & S-Go & -0.3556 & 105 & -0.5123 & -0.1759 & $0.0002 *$ \\
\hline $\mathrm{Go}^{\circ}$ & $S n^{\prime}-M e^{\prime}$ & 0.1319 & 105 & -0.0614 & 0.3156 & 0.18 \\
\hline $\mathrm{Go}^{\circ}$ & TVL-Pog' & 0.0983 & 105 & -0.0952 & 0.2846 & 0.3187 \\
\hline $\mathrm{Go}^{\circ}$ & $\mathrm{U} 1^{\circ}$ & -0.1872 & 105 & -0.3657 & 0.0046 & 0.0558 \\
\hline II $M x$ & $\mathrm{Go}^{\circ}$ & -0.1954 & 105 & -0.3731 & -0.0039 & $0.0457^{*}$ \\
\hline II $M x$ & $\mathrm{ANB}^{\circ}$ & 0.4552 & 105 & 0.2887 & 0.595 & $<.0001^{*}$ \\
\hline II Mx & ANS-Me & 0.1376 & 105 & -0.0555 & 0.3208 & 0.1616 \\
\hline II $M x$ & Co-Gn & -0.2169 & 105 & -0.3923 & -0.0263 & $0.0263 *$ \\
\hline II $M x$ & Co-Go & -0.0739 & 105 & -0.2619 & 0.1194 & 0.4536 \\
\hline II $M x$ & G'-Me' & -0.0952 & 105 & -0.2818 & 0.0982 & 0.3339 \\
\hline II $M x$ & $\mathrm{G}^{\prime}-\mathrm{Sn}^{\prime}$ & -0.3012 & 105 & -0.466 & -0.1163 & $0.0018^{*}$ \\
\hline II $M x$ & $\mathrm{G}^{\prime}-\mathrm{Sn}-\mathrm{Pog}^{\prime \circ}$ & -0.4045 & 105 & -0.5533 & -0.2307 & $<.0001^{*}$ \\
\hline II $M x$ & $\mathrm{~L} 1-\mathrm{Op}^{\circ}$ & -0.4529 & 105 & -0.5931 & -0.2861 & $<.0001^{*}$ \\
\hline II $M x$ & $\mathrm{~L}^{\circ}$ & -0.3611 & 105 & -0.5169 & -0.182 & $0.0002 *$ \\
\hline II $M x$ & $\mathrm{MP}^{\circ}$ & -0.1079 & 105 & -0.2935 & 0.0856 & 0.2734 \\
\hline II $M x$ & MP-L1 & 0.0697 & 105 & -0.1236 & 0.2579 & 0.4798 \\
\hline II $M x$ & Mp-Mic & 0.0849 & 105 & -0.1086 & 0.2721 & 0.3893 \\
\hline II $M x$ & N-ANS & -0.1248 & 105 & -0.3091 & 0.0685 & 0.2045 \\
\hline II Mx & $\mathrm{N}-\mathrm{Me}$ & 0.0483 & 105 & -0.1447 & 0.2377 & 0.6248 \\
\hline II $M x$ & $O p^{\circ}$ & -0.2048 & 105 & -0.3815 & -0.0137 & $0.0361 *$ \\
\hline II $M x$ & $\mathrm{Op}-\mathrm{Sn}^{\circ}$ & 0.1796 & 105 & -0.0125 & 0.3589 & 0.0668 \\
\hline II $M x$ & PFH:AFH & -0.0238 & 105 & -0.2145 & 0.1686 & 0.8094 \\
\hline II $M x$ & Pog'c-GALL & 0.1095 & 105 & -0.0839 & 0.295 & 0.2661 \\
\hline II $M x$ & Pog'-GALL & 0.0209 & 105 & -0.1714 & 0.2117 & 0.8322 \\
\hline II $M x$ & Pog-GALL & 0.1368 & 105 & -0.0564 & 0.32 & 0.1642 \\
\hline II $M x$ & $\mathrm{PP}^{\circ}$ & -0.4311 & 105 & -0.5753 & -0.261 & $<.0001^{*}$ \\
\hline II $M x$ & PP-Mic & 0.1224 & 105 & -0.0709 & 0.3069 & 0.2136 \\
\hline II $M x$ & PP-U1 & 0.3515 & 105 & 0.1714 & 0.5089 & $0.0002 *$ \\
\hline II $M x$ & S-Go & -0.0787 & 105 & -0.2664 & 0.1147 & 0.4248 \\
\hline II $M x$ & $\mathrm{Sn}^{\circ}$ & 0.4864 & 105 & 0.325 & 0.6202 & $<.0001^{*}$ \\
\hline II $M x$ & $\mathrm{SNA}^{\circ}$ & 0.0794 & 105 & -0.114 & 0.267 & 0.4206 \\
\hline II $M x$ & $\mathrm{SNB}^{\circ}$ & -0.2934 & 105 & -0.4593 & -0.1078 & $0.0024^{*}$ \\
\hline II $M x$ & $S n^{\prime}-M e^{\prime}$ & 0.0908 & 105 & -0.1026 & 0.2777 & 0.3568 \\
\hline II $M x$ & SN-MP & 0.1524 & 105 & -0.0405 & 0.3343 & 0.1207 \\
\hline II $M x$ & TVL-Pog' & -0.2681 & 105 & -0.4373 & -0.0805 & 0.0057 \\
\hline II $M x$ & U1 - Op & 0.1489 & 105 & -0.0441 & 0.3311 & 0.1296 \\
\hline II $M x$ & $\mathrm{U} 1^{\circ}$ & 0.0668 & 105 & -0.1265 & 0.2552 & 0.4986 \\
\hline $\mathrm{ANB}^{\circ}$ & $\mathrm{Go}^{\circ}$ & -0.1759 & 105 & -0.3555 & 0.0164 & 0.0728 \\
\hline $\mathrm{ANB}^{\circ}$ & ANS-Me & 0.1341 & 105 & -0.0591 & 0.3176 & 0.1726 \\
\hline $\mathrm{ANB}^{\circ}$ & Co-Gn & -0.2969 & 105 & -0.4623 & -0.1116 & $0.0021 *$ \\
\hline $\mathrm{ANB}^{\circ}$ & Co-Go & -0.0138 & 105 & -0.2049 & 0.1784 & 0.8892 \\
\hline $\mathrm{ANB}^{\circ}$ & G'-Me' & 0.1592 & 105 & -0.0335 & 0.3404 & 0.1049 \\
\hline
\end{tabular}




\begin{tabular}{|c|c|c|c|c|c|c|}
\hline $\mathrm{ANB}^{\circ}$ & $G^{\prime}-S n^{\prime}$ & 0.071 & 105 & -0.1224 & 0.2591 & 0.4718 \\
\hline $\mathrm{ANB}^{\circ}$ & $\mathrm{G}^{\prime}-\mathrm{Sn}-\mathrm{Pog}^{\prime \circ}$ & -0.6751 & 105 & -0.7675 & -0.5553 & $<.0001^{*}$ \\
\hline $\mathrm{ANB}^{\circ}$ & $\mathrm{L}^{\circ}{ }^{\circ}$ & -0.4846 & 105 & -0.6188 & -0.3229 & $<.0001^{*}$ \\
\hline $\mathrm{ANB}^{\circ}$ & $\mathrm{MP}^{\circ}$ & 0.1318 & 105 & -0.0614 & 0.3155 & 0.1802 \\
\hline $\mathrm{ANB}^{\circ}$ & MP-L1 & 0.2295 & 105 & 0.0395 & 0.4034 & $0.0185^{*}$ \\
\hline $\mathrm{ANB}^{\circ}$ & Mp-Mic & 0.278 & 105 & 0.0912 & 0.4459 & $0.0041 *$ \\
\hline $\mathrm{ANB}^{\circ}$ & N-ANS & 0.2068 & 105 & 0.0157 & 0.3832 & $0.0343 *$ \\
\hline $\mathrm{ANB}^{\circ}$ & $\mathrm{N}-\mathrm{Me}$ & 0.2038 & 105 & 0.0126 & 0.3806 & $0.037^{*}$ \\
\hline $\mathrm{ANB}^{\circ}$ & $O p^{\circ}$ & 0.2684 & 105 & 0.0809 & 0.4375 & $0.0056^{*}$ \\
\hline $\mathrm{ANB}^{\circ}$ & PFH:AFH & -0.1853 & 105 & -0.364 & 0.0066 & 0.0585 \\
\hline $\mathrm{ANB}^{\circ}$ & Pog'c-GALL & -0.5346 & 105 & -0.6587 & -0.3821 & $<.0001^{*}$ \\
\hline $\mathrm{ANB}^{\circ}$ & Pog'-GALL & -0.5726 & 105 & -0.6887 & -0.428 & $<.0001^{*}$ \\
\hline $\mathrm{ANB}^{\circ}$ & Pog-GALL & -0.618 & 105 & -0.7239 & -0.4837 & $<.0001^{*}$ \\
\hline $\mathrm{ANB}^{\circ}$ & PP-Mic & 0.1246 & 105 & -0.0687 & 0.3089 & 0.2052 \\
\hline $\mathrm{ANB}^{\circ}$ & PP-U1 & 0.4722 & 105 & 0.3085 & 0.6088 & $<.0001^{*}$ \\
\hline $\mathrm{ANB}^{\circ}$ & S-Go & -0.0339 & 105 & -0.2241 & 0.1588 & 0.7315 \\
\hline $\mathrm{ANB}^{\circ}$ & $\mathrm{SNA}^{\circ}$ & 0.1547 & 105 & -0.0381 & 0.3364 & 0.1152 \\
\hline $\mathrm{ANB}^{\circ}$ & $\mathrm{SNB}^{\circ}$ & -0.6596 & 105 & -0.7558 & -0.5357 & $<.0001^{*}$ \\
\hline $\mathrm{ANB}^{\circ}$ & $S n^{\prime}-M e^{\prime}$ & 0.1612 & 105 & -0.0314 & 0.3423 & 0.1003 \\
\hline $\mathrm{ANB}^{\circ}$ & TVL-Pog' & -0.6658 & 105 & -0.7604 & -0.5434 & $<.0001^{*}$ \\
\hline $\mathrm{ANB}^{\circ}$ & $\mathrm{U} 1^{\circ}$ & 0.3639 & 105 & 0.1852 & 0.5194 & $0.0001 *$ \\
\hline ANS-Me & N-ANS & 0.2105 & 105 & 0.0197 & 0.3866 & $0.0311^{*}$ \\
\hline ANS-Me & $O p^{\circ}$ & -0.0281 & 105 & -0.2186 & 0.1645 & 0.776 \\
\hline ANS-Me & Pog'c-GALL & -0.007 & 105 & -0.1984 & 0.1849 & 0.9435 \\
\hline ANS-Me & Pog'-GALL & -0.0828 & 105 & -0.2702 & 0.1106 & 0.4009 \\
\hline ANS-Me & Pog-GALL & -0.2565 & 105 & -0.4272 & -0.0682 & $0.0083^{*}$ \\
\hline ANS-Me & TVL-Pog' & -0.0691 & 105 & -0.2573 & 0.1242 & 0.4838 \\
\hline Co-Gn & ANS-Me & 0.5219 & 105 & 0.367 & 0.6487 & $<.0001^{*}$ \\
\hline Co-Gn & Co-Go & 0.6436 & 105 & 0.5156 & 0.7436 & $<.0001^{*}$ \\
\hline Co-Gn & $\mathrm{G}^{\prime}-\mathrm{Me}^{\prime}$ & 0.5916 & 105 & 0.451 & 0.7035 & $<.0001^{*}$ \\
\hline Co-Gn & $G^{\prime}-S n^{\prime}$ & 0.3813 & 105 & 0.2046 & 0.534 & $<.0001^{*}$ \\
\hline Co-Gn & N-ANS & 0.2615 & 105 & 0.0735 & 0.4315 & $0.0071 *$ \\
\hline Co-Gn & $\mathrm{N}-\mathrm{Me}$ & 0.534 & 105 & 0.3813 & 0.6583 & $<.0001^{*}$ \\
\hline Co-Gn & $O p^{\circ}$ & -0.2566 & 105 & -0.4272 & -0.0683 & $0.0082 *$ \\
\hline Co-Gn & Pog'c-GALL & 0.3167 & 105 & 0.1331 & 0.4793 & $0.001 *$ \\
\hline Co-Gn & Pog'-GALL & 0.3822 & 105 & 0.2056 & 0.5347 & $<.0001^{*}$ \\
\hline Co-Gn & Pog-GALL & 0.104 & 105 & -0.0895 & 0.2899 & 0.2912 \\
\hline Co-Gn & S-Go & 0.5629 & 105 & 0.4162 & 0.6811 & $<.0001^{*}$ \\
\hline Co-Gn & $S n^{\prime}-M e^{\prime}$ & 0.5142 & 105 & 0.3578 & 0.6426 & $<.0001^{*}$ \\
\hline Co-Gn & TVL-Pog' & 0.4016 & 105 & 0.2275 & 0.5509 & $<.0001^{*}$ \\
\hline Co-Go & ANS-Me & 0.3108 & 105 & 0.1267 & 0.4742 & $0.0013^{*}$ \\
\hline Co-Go & $\mathrm{G}^{\prime}-\mathrm{Me}^{\prime}$ & 0.4934 & 105 & 0.3332 & 0.6258 & $<.0001^{*}$ \\
\hline Co-Go & $G^{\prime}-S n^{\prime}$ & 0.4678 & 105 & 0.3033 & 0.6052 & $<.0001^{*}$ \\
\hline
\end{tabular}




\begin{tabular}{|c|c|c|c|c|c|c|}
\hline Co-Go & N-ANS & 0.4263 & 105 & 0.2555 & 0.5713 & $<.0001^{*}$ \\
\hline Co-Go & $\mathrm{N}-\mathrm{Me}$ & 0.4471 & 105 & 0.2794 & 0.5884 & $<.0001^{*}$ \\
\hline Co-Go & $O p^{\circ}$ & -0.3231 & 105 & -0.4847 & -0.1401 & $0.0008 *$ \\
\hline Co-Go & Pog'c-GALL & -0.0449 & 105 & -0.2346 & 0.148 & 0.6491 \\
\hline Co-Go & Pog'-GALL & 0.0557 & 105 & -0.1374 & 0.2448 & 0.5724 \\
\hline Co-Go & Pog-GALL & -0.0344 & 105 & -0.2246 & 0.1583 & 0.7273 \\
\hline Co-Go & $S n^{\prime}-M e^{\prime}$ & 0.3205 & 105 & 0.1372 & 0.4825 & $0.0009 *$ \\
\hline Co-Go & TVL-Pog' & 0.0582 & 105 & -0.135 & 0.2471 & 0.5554 \\
\hline G'-Me' & ANS-Me & 0.7904 & 105 & 0.7057 & 0.8529 & $<.0001^{*}$ \\
\hline$G^{\prime}-M e^{\prime}$ & $G^{\prime}-S n^{\prime}$ & 0.6766 & 105 & 0.5572 & 0.7686 & $<.0001^{*}$ \\
\hline G'-Me' & N-ANS & 0.5404 & 105 & 0.3891 & 0.6634 & $<.0001^{*}$ \\
\hline G'-Me' & $\mathrm{N}-\mathrm{Me}$ & 0.8776 & 105 & 0.8247 & 0.9153 & $<.0001^{*}$ \\
\hline G'-Me' & $O p^{\circ}$ & 0.01 & 105 & -0.1821 & 0.2012 & 0.9197 \\
\hline G'-Me' & Pog'c-GALL & -0.0931 & 105 & -0.2798 & 0.1004 & 0.345 \\
\hline G'-Me' & Pog'-GALL & -0.1452 & 105 & -0.3277 & 0.0478 & 0.1396 \\
\hline G'-Me' & Pog-GALL & -0.3576 & 105 & -0.514 & -0.1781 & $0.0002 *$ \\
\hline G'-Me' & Sn'-Me' & 0.8461 & 105 & 0.7811 & 0.893 & $<.0001^{*}$ \\
\hline G'-Me' & TVL-Pog' & -0.1158 & 105 & -0.3008 & 0.0776 & 0.2394 \\
\hline$G^{\prime}-S n^{\prime}$ & ANS-Me & 0.2195 & 105 & 0.029 & 0.3945 & $0.0245^{*}$ \\
\hline$G^{\prime}-S n^{\prime}$ & N-ANS & 0.6926 & 105 & 0.5777 & 0.7807 & $<.0001^{*}$ \\
\hline$G^{\prime}-S n^{\prime}$ & $\mathrm{N}-\mathrm{Me}$ & 0.5027 & 105 & 0.3442 & 0.6333 & $<.0001^{*}$ \\
\hline$G^{\prime}-S n^{\prime}$ & $O p^{\circ}$ & 0.0839 & 105 & -0.1096 & 0.2712 & 0.395 \\
\hline$G^{\prime}-S n^{\prime}$ & Pog'c-GALL & -0.2241 & 105 & -0.3987 & -0.0339 & $0.0215^{*}$ \\
\hline$G^{\prime}-S n^{\prime}$ & Pog'-GALL & -0.1907 & 105 & -0.3689 & 0.001 & 0.0514 \\
\hline$G^{\prime}-S n^{\prime}$ & Pog-GALL & -0.2552 & 105 & -0.426 & -0.0668 & $0.0086^{*}$ \\
\hline$G^{\prime}-S n^{\prime}$ & TVL-Pog' & -0.1469 & 105 & -0.3293 & 0.046 & 0.1347 \\
\hline G'-Sn-Pog $^{\prime \circ}$ & $\mathrm{Go}^{\circ}$ & 0.1311 & 105 & -0.0621 & 0.3148 & 0.1826 \\
\hline G'-Sn-Pog $^{\prime \circ}$ & ANS-Me & 0.0549 & 105 & -0.1382 & 0.244 & 0.5782 \\
\hline$G^{\prime}-S n-P o g^{10}$ & Co-Gn & 0.3996 & 105 & 0.2252 & 0.5492 & $<.0001^{*}$ \\
\hline G'-Sn-Pog $^{\prime \circ}$ & Co-Go & 0.0865 & 105 & -0.1069 & 0.2736 & 0.3803 \\
\hline G'-Sn-Pog $^{\prime \circ}$ & $\mathrm{G}^{\prime}-\mathrm{Me}^{\prime}$ & 0.0066 & 105 & -0.1853 & 0.198 & 0.9465 \\
\hline G'-Sn-Pog $^{\prime \circ}$ & $\mathrm{G}^{\prime}-S n^{\prime}$ & -0.0988 & 105 & -0.2851 & 0.0947 & 0.316 \\
\hline G'-Sn-Pog $^{\prime \circ}$ & $\mathrm{L}^{\circ}{ }^{\circ}$ & 0.5301 & 105 & 0.3767 & 0.6552 & $<.0001^{*}$ \\
\hline G'-Sn-Pog $^{\prime \circ}$ & MP-L1 & -0.0688 & 105 & -0.257 & 0.1245 & 0.4858 \\
\hline G'-Sn-Pog $^{\prime \circ}$ & Mp-Mic & -0.1981 & 105 & -0.3755 & -0.0067 & $0.0428 *$ \\
\hline G'-Sn-Pog $^{\prime \circ}$ & N-ANS & -0.3109 & 105 & -0.4743 & -0.1268 & $0.0012 *$ \\
\hline G'-Sn-Pog' $^{\prime}$ & $\mathrm{N}-\mathrm{Me}$ & -0.1054 & 105 & -0.2912 & 0.088 & 0.2846 \\
\hline G'-Sn-Pog $^{\prime \circ}$ & $O p^{\circ}$ & -0.3539 & 105 & -0.5109 & -0.1741 & $0.0002 *$ \\
\hline$G^{\prime}-S n-P o g^{10}$ & PFH:AFH & 0.2008 & 105 & 0.0095 & 0.3779 & $0.04^{*}$ \\
\hline G'-Sn-Pog $^{\prime}$ & Pog'c-GALL & 0.6383 & 105 & 0.5089 & 0.7395 & $<.0001^{*}$ \\
\hline$G^{\prime}-S n-P o g^{10}$ & Pog'-GALL & 0.691 & 105 & 0.5756 & 0.7795 & $<.0001^{*}$ \\
\hline$G^{\prime}-S n-P o g^{10}$ & Pog-GALL & 0.4757 & 105 & 0.3126 & 0.6116 & $<.0001^{*}$ \\
\hline G'-Sn-Pog $^{\prime \circ}$ & PP-Mic & 0.0907 & 105 & -0.1028 & 0.2775 & 0.3576 \\
\hline
\end{tabular}




\begin{tabular}{|c|c|c|c|c|c|c|}
\hline $\mathrm{G}^{\prime}-\mathrm{Sn}-\mathrm{Pog}^{\prime \circ}$ & PP-U1 & -0.2826 & 105 & -0.4499 & -0.0961 & $0.0035^{*}$ \\
\hline $\mathrm{G}^{\prime}-\mathrm{Sn}-\mathrm{Pog}^{\prime \circ}$ & S-Go & 0.1824 & 105 & -0.0096 & 0.3615 & 0.0625 \\
\hline $\mathrm{G}^{\prime}-\mathrm{Sn}-\mathrm{Pog}^{\prime \circ}$ & $S n^{\prime}-M e^{\prime}$ & 0.0804 & 105 & -0.113 & 0.2679 & 0.415 \\
\hline G'-Sn-Pog'o $^{\prime}$ & TVL-Pog' & 0.8854 & 105 & 0.8355 & 0.9208 & $<.0001 *$ \\
\hline$G^{\prime}-S n-P o g^{\prime 0}$ & $\mathrm{U} 1^{\circ}$ & -0.1775 & 105 & -0.357 & 0.0147 & 0.0701 \\
\hline II Md & $\mathrm{Go}^{\circ}$ & 0.2334 & 105 & 0.0437 & 0.4069 & $0.0166^{*}$ \\
\hline II Md & II Mx & 0.1357 & 105 & -0.0575 & 0.319 & 0.1676 \\
\hline II Md & $\mathrm{ANB}^{\circ}$ & -0.4577 & 105 & -0.597 & -0.2917 & $<.0001^{*}$ \\
\hline II Md & ANS-Me & -0.054 & 105 & -0.2432 & 0.1391 & 0.5842 \\
\hline II Md & Co-Gn & 0.1837 & 105 & -0.0083 & 0.3626 & 0.0607 \\
\hline II Md & Co-Go & -0.2374 & 105 & -0.4104 & -0.0479 & $0.0148 *$ \\
\hline II Md & $\mathrm{G}^{\prime}-\mathrm{Me}^{\prime}$ & -0.2384 & 105 & -0.4113 & -0.049 & $0.0143 *$ \\
\hline II Md & $G^{\prime}-S n^{\prime}$ & -0.255 & 105 & -0.4258 & -0.0666 & $0.0087^{*}$ \\
\hline II Md & $\mathrm{G}^{\prime}-\mathrm{Sn}-\mathrm{Pog}^{\prime \circ}$ & 0.3676 & 105 & 0.1893 & 0.5225 & $0.0001 *$ \\
\hline II Md & L1 - Op & 0.3791 & 105 & 0.2021 & 0.5321 & $<.0001^{*}$ \\
\hline II Md & $\mathrm{L}^{\circ}{ }^{\circ}$ & 0.3717 & 105 & 0.1939 & 0.5259 & $<.0001^{*}$ \\
\hline II Md & $\mathrm{MP}^{\circ}$ & 0.0793 & 105 & -0.1141 & 0.2669 & 0.4213 \\
\hline II Md & MP-L1 & -0.2846 & 105 & -0.4517 & -0.0983 & $0.0033^{*}$ \\
\hline II Md & Mp-Mic & -0.2086 & 105 & -0.3849 & -0.0176 & $0.0327^{*}$ \\
\hline II Md & N-ANS & -0.2157 & 105 & -0.3912 & -0.0251 & $0.0271 *$ \\
\hline II Md & $\mathrm{N}-\mathrm{Me}$ & -0.1453 & 105 & -0.3278 & 0.0477 & 0.1391 \\
\hline II Md & $O p^{\circ}$ & -0.0052 & 105 & -0.1966 & 0.1867 & 0.9584 \\
\hline II Md & $\mathrm{Op}-\mathrm{Sn}^{\circ}$ & -0.0566 & 105 & -0.2456 & 0.1365 & 0.5661 \\
\hline II Md & PFH:AFH & -0.0218 & 105 & -0.2126 & 0.1706 & 0.8252 \\
\hline II Md & Pog'c-GALL & 0.705 & 105 & 0.5936 & 0.7899 & $<.0001^{*}$ \\
\hline II Md & Pog'-GALL & 0.6886 & 105 & 0.5725 & 0.7776 & $<.0001^{*}$ \\
\hline II Md & Pog-GALL & 0.5949 & 105 & 0.4552 & 0.7061 & $<.0001^{*}$ \\
\hline II Md & $\mathrm{PP}^{\circ}$ & 0.1612 & 105 & -0.0315 & 0.3423 & 0.1005 \\
\hline II Md & PP-Mic & -0.0739 & 105 & -0.2618 & 0.1195 & 0.4539 \\
\hline II Md & PP-U1 & -0.2999 & 105 & -0.4649 & -0.1149 & $0.0019 *$ \\
\hline II Md & S-Go & -0.1922 & 105 & -0.3702 & -0.0005 & $0.0495^{*}$ \\
\hline II Md & $\mathrm{Sn}^{\circ}$ & -0.0501 & 105 & -0.2394 & 0.143 & 0.612 \\
\hline II Md & $\mathrm{SNA}^{\circ}$ & 0.1405 & 105 & -0.0526 & 0.3235 & 0.1528 \\
\hline II Md & $\mathrm{SNB}^{\circ}$ & 0.4627 & 105 & 0.2974 & 0.6011 & $<.0001^{*}$ \\
\hline II Md & $S n^{\prime}-M e^{\prime}$ & -0.1339 & 105 & -0.3174 & 0.0593 & 0.1732 \\
\hline II Md & $\mathrm{SN}-\mathrm{MP}^{\circ}$ & 0.0443 & 105 & -0.1486 & 0.234 & 0.6537 \\
\hline II Md & TVL-Pog' & 0.5396 & 105 & 0.3881 & 0.6627 & $<.0001^{*}$ \\
\hline II Md & U1 - Op & -0.2192 & 105 & -0.3943 & -0.0287 & $0.0247^{*}$ \\
\hline II Md & $\mathrm{U} 1^{\circ}$ & -0.2166 & 105 & -0.392 & -0.0261 & $0.0264 *$ \\
\hline IV Md Ant & $\mathrm{Go}^{\circ}$ & 0.105 & 105 & -0.0885 & 0.2908 & 0.2865 \\
\hline IV Md Ant & II Mx & 0.0977 & 105 & -0.0958 & 0.284 & 0.3214 \\
\hline IV Md Ant & $\mathrm{ANB}^{\circ}$ & 0.0687 & 105 & -0.1246 & 0.257 & 0.486 \\
\hline IV Md Ant & ANS-Me & 0.9053 & 105 & 0.8635 & 0.9348 & $<.0001^{*}$ \\
\hline
\end{tabular}




\begin{tabular}{|c|c|c|c|c|c|c|}
\hline IV Md Ant & Co-Gn & 0.6016 & 105 & 0.4633 & 0.7112 & $<.0001^{*}$ \\
\hline IV Md Ant & Co-Go & 0.4157 & 105 & 0.2434 & 0.5625 & $<.0001^{*}$ \\
\hline IV Md Ant & $\mathrm{G}^{\prime}-\mathrm{Me}^{\prime}$ & 0.8052 & 105 & 0.7255 & 0.8636 & $<.0001^{*}$ \\
\hline IV Md Ant & $G^{\prime}-S n^{\prime}$ & 0.3369 & 105 & 0.1553 & 0.4965 & $0.0004 *$ \\
\hline IV Md Ant & $\mathrm{G}^{\prime}-\mathrm{Sn}-\mathrm{Pog}{ }^{10}$ & 0.0842 & 105 & -0.1092 & 0.2715 & 0.3932 \\
\hline IV Md Ant & II Md & -0.0312 & 105 & -0.2216 & 0.1614 & 0.7519 \\
\hline IV Md Ant & IV Mx Ant & -0.0508 & 105 & -0.2401 & 0.1423 & 0.6071 \\
\hline IV Md Ant & $\mathrm{L} 1-O p^{\circ}$ & -0.2683 & 105 & -0.4375 & -0.0808 & $0.0057 *$ \\
\hline IV Md Ant & $\mathrm{L}^{\circ}$ & -0.1917 & 105 & -0.3698 & 0 & 0.0501 \\
\hline IV Md Ant & $\mathrm{MP}^{\circ}$ & 0.3418 & 105 & 0.1607 & 0.5007 & $0.0004 *$ \\
\hline IV Md Ant & MP-L1 & 0.7973 & 105 & 0.7148 & 0.8579 & $<.0001^{*}$ \\
\hline IV Md Ant & Mp-Mic & 0.7917 & 105 & 0.7073 & 0.8538 & $<.0001^{*}$ \\
\hline IV Md Ant & N-ANS & 0.3453 & 105 & 0.1645 & 0.5036 & $0.0003 *$ \\
\hline IV Md Ant & $\mathrm{N}-\mathrm{Me}$ & 0.8746 & 105 & 0.8204 & 0.9132 & $<.0001^{*}$ \\
\hline IV Md Ant & $O p^{\circ}$ & -0.1776 & 105 & -0.3571 & 0.0145 & 0.0699 \\
\hline IV Md Ant & $\mathrm{Op}-\mathrm{Sn}^{\circ}$ & -0.0861 & 105 & -0.2733 & 0.1073 & 0.3824 \\
\hline IV Md Ant & PFH:AFH & -0.107 & 105 & -0.2927 & 0.0864 & 0.2773 \\
\hline IV Md Ant & Pog'c-GALL & 0.0547 & 105 & -0.1384 & 0.2438 & 0.5797 \\
\hline IV Md Ant & Pog'-GALL & -0.0196 & 105 & -0.2105 & 0.1727 & 0.8429 \\
\hline IV Md Ant & Pog-GALL & -0.2095 & 105 & -0.3857 & -0.0186 & $0.032 *$ \\
\hline IV Md Ant & $\mathrm{PP}^{\circ}$ & -0.0849 & 105 & -0.2721 & 0.1086 & 0.3893 \\
\hline IV Md Ant & PP-Mic & 0.6225 & 105 & 0.4892 & 0.7274 & $<.0001^{*}$ \\
\hline IV Md Ant & PP-U1 & 0.4722 & 105 & 0.3084 & 0.6088 & $<.0001^{*}$ \\
\hline IV Md Ant & S-Go & 0.516 & 105 & 0.3599 & 0.6439 & $<.0001 *$ \\
\hline IV Md Ant & $\mathrm{Sn}^{\circ}$ & 0.0325 & 105 & -0.1602 & 0.2228 & 0.7421 \\
\hline IV Md Ant & $\mathrm{SNA}^{\circ}$ & -0.0052 & 105 & -0.1966 & 0.1867 & 0.9583 \\
\hline IV Md Ant & $\mathrm{SNB}^{\circ}$ & -0.0574 & 105 & -0.2463 & 0.1358 & 0.5611 \\
\hline IV Md Ant & $S n^{\prime}-M e^{\prime}$ & 0.8317 & 105 & 0.7614 & 0.8827 & $<.0001^{*}$ \\
\hline IV Md Ant & SN-MP & 0.3007 & 105 & 0.1157 & 0.4655 & $0.0018 *$ \\
\hline IV Md Ant & TVL-Pog' & -0.0252 & 105 & -0.2158 & 0.1673 & 0.7986 \\
\hline IV Md Ant & U1 - Op & -0.004 & 105 & -0.1955 & 0.1878 & 0.9677 \\
\hline IV Md Ant & $\mathrm{U} 1^{\circ}$ & -0.0724 & 105 & -0.2605 & 0.1209 & 0.4627 \\
\hline IV Mx Ant & $\mathrm{Go}^{\circ}$ & 0.1813 & 105 & -0.0107 & 0.3604 & 0.0642 \\
\hline IV Mx Ant & II Mx & -0.0392 & 105 & -0.2291 & 0.1537 & 0.6916 \\
\hline IV Mx Ant & $\mathrm{ANB}^{\circ}$ & 0.0354 & 105 & -0.1574 & 0.2255 & 0.7203 \\
\hline IV Mx Ant & ANS-Me & 0.1288 & 105 & -0.0644 & 0.3128 & 0.1903 \\
\hline IV Mx Ant & Co-Gn & -0.1177 & 105 & -0.3025 & 0.0757 & 0.232 \\
\hline IV Mx Ant & Co-Go & -0.2417 & 105 & -0.4142 & -0.0525 & $0.013^{*}$ \\
\hline IV Mx Ant & $\mathrm{G}^{\prime}-\mathrm{Me}^{\prime}$ & -0.084 & 105 & -0.2713 & 0.1094 & 0.3943 \\
\hline IV Mx Ant & $\mathrm{G}^{\prime}-S n^{\prime}$ & -0.2627 & 105 & -0.4326 & -0.0748 & $0.0068 *$ \\
\hline IV Mx Ant & $\mathrm{G}^{\prime}-\mathrm{Sn}-\mathrm{Pog}{ }^{10}$ & -0.0591 & 105 & -0.248 & 0.1341 & 0.5491 \\
\hline IV Mx Ant & II Md & 0.0634 & 105 & -0.1298 & 0.252 & 0.5205 \\
\hline IV Mx Ant & L1 - Op ${ }^{\circ}$ & 0.0578 & 105 & -0.1354 & 0.2467 & 0.5583 \\
\hline
\end{tabular}




\begin{tabular}{|c|c|c|c|c|c|c|}
\hline IV Mx Ant & $\mathrm{L}^{\circ}{ }^{\circ}$ & -0.1125 & 105 & -0.2977 & 0.0809 & 0.2532 \\
\hline IV Mx Ant & $\mathrm{MP}^{\circ}$ & 0.3326 & 105 & 0.1506 & 0.4929 & $0.0005^{*}$ \\
\hline IV Mx Ant & MP-L1 & -0.0449 & 105 & -0.2346 & 0.148 & 0.649 \\
\hline IV Mx Ant & Mp-Mic & 0.017 & 105 & -0.1752 & 0.208 & 0.8631 \\
\hline IV Mx Ant & N-ANS & -0.1191 & 105 & -0.3038 & 0.0743 & 0.2263 \\
\hline IV Mx Ant & $\mathrm{N}-\mathrm{Me}$ & 0.0441 & 105 & -0.1488 & 0.2338 & 0.6547 \\
\hline IV Mx Ant & $O p^{\circ}$ & 0.4288 & 105 & 0.2584 & 0.5734 & $<.0001^{*}$ \\
\hline IV Mx Ant & $\mathrm{Op}-\mathrm{Sn}^{\circ}$ & 0.3822 & 105 & 0.2056 & 0.5347 & $<.0001^{*}$ \\
\hline IV Mx Ant & PFH:AFH & -0.2931 & 105 & -0.459 & -0.1074 & $0.0024 *$ \\
\hline IV Mx Ant & Pog'c-GALL & -0.1566 & 105 & -0.3381 & 0.0362 & 0.1107 \\
\hline IV Mx Ant & Pog'-GALL & -0.1868 & 105 & -0.3654 & 0.0051 & 0.0564 \\
\hline IV Mx Ant & Pog-GALL & -0.1817 & 105 & -0.3608 & 0.0103 & 0.0635 \\
\hline IV Mx Ant & $\mathrm{PP}^{\circ}$ & -0.0369 & 105 & -0.2269 & 0.1559 & 0.709 \\
\hline IV Mx Ant & PP-Mic & 0.0873 & 105 & -0.1061 & 0.2744 & 0.3759 \\
\hline IV Mx Ant & PP-U1 & 0.2878 & 105 & 0.1018 & 0.4544 & $0.0029 *$ \\
\hline IV Mx Ant & S-Go & -0.3191 & 105 & -0.4813 & -0.1357 & $0.0009 *$ \\
\hline IV Mx Ant & $\mathrm{Sn}^{\circ}$ & 0.1096 & 105 & -0.0838 & 0.2951 & 0.2657 \\
\hline IV Mx Ant & $\mathrm{SNA}^{\circ}$ & -0.1772 & 105 & -0.3568 & 0.0149 & 0.0705 \\
\hline IV Mx Ant & $\mathrm{SNB}^{\circ}$ & -0.1623 & 105 & -0.3433 & 0.0303 & 0.0981 \\
\hline IV Mx Ant & Sn'-Me' & 0.078 & 105 & -0.1154 & 0.2657 & 0.4292 \\
\hline IV Mx Ant & $\mathrm{SN}-\mathrm{MP}^{\circ}$ & 0.3569 & 105 & 0.1774 & 0.5135 & $0.0002 *$ \\
\hline IV Mx Ant & TVL-Pog' & -0.0888 & 105 & -0.2757 & 0.1047 & 0.3679 \\
\hline IV Mx Ant & U1 - Op & -0.1828 & 105 & -0.3618 & 0.0092 & 0.062 \\
\hline IV Mx Ant & $\mathrm{U} 1^{\circ}$ & -0.0136 & 105 & -0.2047 & 0.1786 & 0.8907 \\
\hline $\mathrm{L} 1-O \mathrm{p}^{\circ}$ & $\mathrm{Go}^{\circ}$ & 0.1991 & 105 & 0.0078 & 0.3764 & $0.0417^{*}$ \\
\hline $\mathrm{L} 1-O p^{\circ}$ & $\mathrm{ANB}^{\circ}$ & -0.3886 & 105 & -0.54 & -0.2127 & $<.0001^{*}$ \\
\hline $\mathrm{L} 1-O p^{\circ}$ & ANS-Me & -0.284 & 105 & -0.4511 & -0.0977 & $0.0033 *$ \\
\hline $\mathrm{L} 1-O p^{\circ}$ & Co-Gn & 0.1317 & 105 & -0.0615 & 0.3154 & 0.1804 \\
\hline $\mathrm{L} 1-O p^{\circ}$ & Co-Go & -0.1298 & 105 & -0.3137 & 0.0634 & 0.1869 \\
\hline $\mathrm{L} 1-O p^{\circ}$ & $\mathrm{G}^{\prime}-\mathrm{Me}^{\prime}$ & -0.2016 & 105 & -0.3787 & -0.0104 & $0.0391 *$ \\
\hline $\mathrm{L} 1-O \mathrm{p}^{\circ}$ & $G^{\prime}-S n^{\prime}$ & 0.0063 & 105 & -0.1856 & 0.1977 & 0.9493 \\
\hline $\mathrm{L} 1-O p^{\circ}$ & $\mathrm{G}^{\prime}-\mathrm{Sn}-\mathrm{Pog}^{10}$ & 0.4007 & 105 & 0.2264 & 0.5501 & $<.0001^{*}$ \\
\hline $\mathrm{L} 1-O p^{\circ}$ & $\mathrm{L}^{\circ}{ }^{\circ}$ & 0.9208 & 105 & 0.8855 & 0.9456 & $<.0001^{*}$ \\
\hline $\mathrm{L} 1-O p^{\circ}$ & $\mathrm{MP}^{\circ}$ & -0.0512 & 105 & -0.2405 & 0.1419 & 0.604 \\
\hline $\mathrm{L} 1-O p^{\circ}$ & MP-L1 & -0.1433 & 105 & -0.326 & 0.0498 & 0.1448 \\
\hline $\mathrm{L} 1-O p^{\circ}$ & Mp-Mic & -0.3893 & 105 & -0.5406 & -0.2136 & $<.0001^{*}$ \\
\hline $\mathrm{L} 1-O \mathrm{p}^{\circ}$ & N-ANS & -0.064 & 105 & -0.2526 & 0.1293 & 0.5167 \\
\hline $\mathrm{L} 1-O p^{\circ}$ & $\mathrm{N}-\mathrm{Me}$ & -0.2532 & 105 & -0.4243 & -0.0647 & $0.0092 *$ \\
\hline $\mathrm{L} 1-O p^{\circ}$ & $O p^{\circ}$ & 0.1381 & 105 & -0.055 & 0.3212 & 0.1601 \\
\hline $\mathrm{L} 1-O \mathrm{p}^{\circ}$ & PFH:AFH & 0.1197 & 105 & -0.0736 & 0.3044 & 0.2238 \\
\hline $\mathrm{L} 1-O p^{\circ}$ & Pog'c-GALL & 0.2668 & 105 & 0.0792 & 0.4362 & $0.0059 *$ \\
\hline $\mathrm{L} 1-O p^{\circ}$ & Pog'-GALL & 0.4088 & 105 & 0.2356 & 0.5568 & $<.0001^{*}$ \\
\hline $\mathrm{L} 1-O p^{\circ}$ & Pog-GALL & 0.2832 & 105 & 0.0967 & 0.4504 & $0.0034 *$ \\
\hline
\end{tabular}




\begin{tabular}{|c|c|c|c|c|c|c|}
\hline L1 - Op & $\mathrm{PP}^{\circ}$ & 0.2583 & 105 & 0.0701 & 0.4287 & $0.0078^{*}$ \\
\hline L1 - Op & PP-Mic & -0.2545 & 105 & -0.4254 & -0.0661 & $0.0088^{*}$ \\
\hline L1 - Op & PP-U1 & -0.3606 & 105 & -0.5166 & -0.1815 & $0.0002 *$ \\
\hline L1 - Op ${ }^{\circ}$ & S-Go & -0.0509 & 105 & -0.2402 & 0.1422 & 0.6064 \\
\hline L1 - Op & $\mathrm{SNA}^{\circ}$ & 0.0625 & 105 & -0.1307 & 0.2512 & 0.5264 \\
\hline L1 - Op & $\mathrm{SNB}^{\circ}$ & 0.3496 & 105 & 0.1693 & 0.5073 & $0.0003^{*}$ \\
\hline L1 - Op & $S n^{\prime}-M e^{\prime}$ & -0.2739 & 105 & -0.4423 & -0.0868 & $0.0047^{*}$ \\
\hline L1 - Op & SN-MP ${ }^{\circ}$ & -0.1969 & 105 & -0.3745 & -0.0055 & $0.044^{*}$ \\
\hline L1 - Op & TVL-Pog' & 0.473 & 105 & 0.3094 & 0.6094 & $<.0001^{*}$ \\
\hline L1 - Op ${ }^{\circ}$ & U1 - Op & 0.1474 & 105 & -0.0456 & 0.3297 & 0.1335 \\
\hline L1 - Op & $\mathrm{U} 1^{\circ}$ & 0.1976 & 105 & 0.0062 & 0.3751 & $0.0433^{*}$ \\
\hline $\mathrm{L}^{\circ}$ & ANS-Me & -0.2659 & 105 & -0.4354 & -0.0783 & $0.0061 *$ \\
\hline $\mathrm{L}^{\circ}{ }^{\circ}$ & Co-Gn & 0.2295 & 105 & 0.0396 & 0.4034 & $0.0185^{*}$ \\
\hline $\mathrm{L}^{\circ}$ & Co-Go & 0.0006 & 105 & -0.1911 & 0.1923 & 0.9951 \\
\hline $\mathrm{L}^{\circ}$ & G'-Me' & -0.2006 & 105 & -0.3777 & -0.0092 & $0.0402 *$ \\
\hline $\mathrm{L}^{\circ}{ }^{\circ}$ & $\mathrm{G}^{\prime}-S n^{\prime}$ & -0.0269 & 105 & -0.2174 & 0.1656 & 0.7854 \\
\hline $\mathrm{L}^{\circ}{ }^{\circ}$ & MP-L1 & -0.0693 & 105 & -0.2576 & 0.124 & 0.4823 \\
\hline $\mathrm{L}^{\circ}{ }^{\circ}$ & Mp-Mic & -0.4364 & 105 & -0.5796 & -0.2671 & $<.0001 *$ \\
\hline $\mathrm{L}^{\circ}$ & N-ANS & -0.1068 & 105 & -0.2925 & 0.0867 & 0.2783 \\
\hline $\mathrm{L}^{\circ}$ & $\mathrm{N}-\mathrm{Me}$ & -0.2594 & 105 & -0.4297 & -0.0713 & $0.0075^{*}$ \\
\hline $\mathrm{L}^{\circ}$ & $O p^{\circ}$ & -0.259 & 105 & -0.4294 & -0.0709 & $0.0076 *$ \\
\hline $\mathrm{L}^{\circ}{ }^{\circ}$ & PFH:AFH & 0.2927 & 105 & 0.1071 & 0.4587 & $0.0024 *$ \\
\hline $\mathrm{L}^{\circ}$ & Pog'c-GALL & 0.4248 & 105 & 0.2538 & 0.5701 & $<.0001^{*}$ \\
\hline $\mathrm{L}^{\circ}{ }^{\circ}$ & Pog'-GALL & 0.5789 & 105 & 0.4356 & 0.6936 & $<.0001^{*}$ \\
\hline $\mathrm{L}^{\circ}{ }^{\circ}$ & Pog-GALL & 0.4381 & 105 & 0.2691 & 0.581 & $<.0001^{*}$ \\
\hline $\mathrm{L}^{\circ}{ }^{\circ}$ & PP-Mic & -0.1968 & 105 & -0.3744 & -0.0054 & $0.0441 *$ \\
\hline $\mathrm{L}^{\circ}{ }^{\circ}$ & PP-U1 & -0.427 & 105 & -0.5719 & -0.2564 & $<.0001^{*}$ \\
\hline $\mathrm{L}^{\circ}{ }^{\circ}$ & S-Go & 0.101 & 105 & -0.0925 & 0.2871 & 0.3054 \\
\hline $\mathrm{L}^{\circ}{ }^{\circ}$ & Sn'-Me' & -0.2485 & 105 & -0.4201 & -0.0596 & $0.0106^{*}$ \\
\hline $\mathrm{L}^{\circ}{ }^{\circ}$ & TVL-Pog' & 0.6253 & 105 & 0.4927 & 0.7295 & $<.0001^{*}$ \\
\hline $\mathrm{L}^{\circ}{ }^{\circ}$ & $\mathrm{U} 1^{\circ}$ & 0.0958 & 105 & -0.0976 & 0.2823 & 0.3309 \\
\hline $\mathrm{MP}^{\circ}$ & $\mathrm{Go}^{\circ}$ & 0.694 & 105 & 0.5795 & 0.7817 & $<.0001^{*}$ \\
\hline $\mathrm{MP}^{\circ}$ & ANS-Me & 0.4418 & 105 & 0.2733 & 0.584 & $<.0001^{*}$ \\
\hline $\mathrm{MP}^{\circ}$ & Co-Gn & 0.0266 & 105 & -0.1659 & 0.2171 & 0.7878 \\
\hline $\mathrm{MP}^{\circ}$ & Co-Go & -0.4059 & 105 & -0.5544 & -0.2323 & $<.0001 *$ \\
\hline $\mathrm{MP}^{\circ}$ & $\mathrm{G}^{\prime}-\mathrm{Me}^{\prime}$ & 0.3021 & 105 & 0.1172 & 0.4667 & $0.0017^{*}$ \\
\hline $\mathrm{MP}^{\circ}$ & $G^{\prime}-S n^{\prime}$ & 0.0655 & 105 & -0.1278 & 0.254 & 0.5068 \\
\hline $\mathrm{MP}^{\circ}$ & $\mathrm{G}^{\prime}-\mathrm{Sn}-\mathrm{Pog}^{10}$ & -0.1352 & 105 & -0.3186 & 0.0579 & 0.169 \\
\hline $\mathrm{MP}^{\circ}$ & $\mathrm{L}^{\circ}$ & -0.2714 & 105 & -0.4402 & -0.0841 & $0.0051 *$ \\
\hline $\mathrm{MP}^{\circ}$ & MP-L1 & 0.1374 & 105 & -0.0557 & 0.3206 & 0.1622 \\
\hline $\mathrm{MP}^{\circ}$ & Mp-Mic & 0.336 & 105 & 0.1543 & 0.4957 & $0.0005^{*}$ \\
\hline $\mathrm{MP}^{\circ}$ & N-ANS & 0.1159 & 105 & -0.0775 & 0.3009 & 0.2389 \\
\hline $\mathrm{MP}^{\circ}$ & $\mathrm{N}-\mathrm{Me}$ & 0.4017 & 105 & 0.2275 & 0.5509 & $<.0001^{*}$ \\
\hline
\end{tabular}




\begin{tabular}{|c|c|c|c|c|c|c|}
\hline $\mathrm{MP}^{\circ}$ & $O p^{\circ}$ & 0.5626 & 105 & 0.4158 & 0.6809 & $<.0001^{*}$ \\
\hline $\mathrm{MP}^{\circ}$ & PFH:AFH & -0.7107 & 105 & -0.7942 & -0.6008 & $<.0001^{*}$ \\
\hline $\mathrm{MP}^{\circ}$ & Pog'c-GALL & -0.1617 & 105 & -0.3427 & 0.031 & 0.0994 \\
\hline $\mathrm{MP}^{\circ}$ & Pog'-GALL & -0.3327 & 105 & -0.4929 & -0.1506 & $0.0005^{*}$ \\
\hline $\mathrm{MP}^{\circ}$ & Pog-GALL & -0.3797 & 105 & -0.5326 & -0.2028 & $<.0001^{*}$ \\
\hline $\mathrm{MP}^{\circ}$ & PP-Mic & 0.2046 & 105 & 0.0134 & 0.3813 & $0.0363 *$ \\
\hline $\mathrm{MP}^{\circ}$ & PP-U1 & 0.3655 & 105 & 0.1869 & 0.5207 & $0.0001 *$ \\
\hline $\mathrm{MP}^{\circ}$ & S-Go & -0.3905 & 105 & -0.5416 & -0.2149 & $<.0001^{*}$ \\
\hline $\mathrm{MP}^{\circ}$ & $S n^{\prime}-M e^{\prime}$ & 0.3561 & 105 & 0.1765 & 0.5128 & $0.0002 *$ \\
\hline $\mathrm{MP}^{\circ}$ & TVL-Pog' & -0.2646 & 105 & -0.4342 & -0.0768 & 0.0064 \\
\hline $\mathrm{MP}^{\circ}$ & $\mathrm{U} 1^{\circ}$ & -0.0186 & 105 & -0.2095 & 0.1737 & 0.8505 \\
\hline MP-L1 & ANS-Me & 0.7696 & 105 & 0.6779 & 0.8377 & $<.0001^{*}$ \\
\hline MP-L1 & Co-Gn & 0.4746 & 105 & 0.3113 & 0.6108 & $<.0001^{*}$ \\
\hline MP-L1 & Co-Go & 0.4784 & 105 & 0.3156 & 0.6137 & $<.0001^{*}$ \\
\hline MP-L1 & G'-Me' & 0.6879 & 105 & 0.5716 & 0.7771 & $<.0001^{*}$ \\
\hline MP-L1 & $G^{\prime}-S n^{\prime}$ & 0.3106 & 105 & 0.1264 & 0.474 & $0.0013^{*}$ \\
\hline MP-L1 & Mp-Mic & 0.6987 & 105 & 0.5855 & 0.7852 & $<.0001^{*}$ \\
\hline MP-L1 & N-ANS & 0.3735 & 105 & 0.1959 & 0.5275 & $<.0001^{*}$ \\
\hline MP-L1 & $\mathrm{N}-\mathrm{Me}$ & 0.7816 & 105 & 0.6939 & 0.8465 & $<.0001^{*}$ \\
\hline MP-L1 & $O p^{\circ}$ & -0.1789 & 105 & -0.3582 & 0.0133 & 0.0679 \\
\hline MP-L1 & PFH:AFH & 0.0929 & 105 & -0.1006 & 0.2795 & 0.3461 \\
\hline MP-L1 & Pog'c-GALL & -0.1598 & 105 & -0.3411 & 0.0328 & 0.1034 \\
\hline MP-L1 & Pog'-GALL & -0.1301 & 105 & -0.3139 & 0.0632 & 0.1859 \\
\hline MP-L1 & Pog-GALL & -0.2736 & 105 & -0.4421 & -0.0865 & $0.0047^{*}$ \\
\hline MP-L1 & PP-Mic & 0.5486 & 105 & 0.3989 & 0.6698 & $<.0001^{*}$ \\
\hline MP-L1 & PP-U1 & 0.5338 & 105 & 0.3811 & 0.6581 & $<.0001^{*}$ \\
\hline MP-L1 & S-Go & 0.597 & 105 & 0.4577 & 0.7077 & $<.0001^{*}$ \\
\hline MP-L1 & $S n^{\prime}-M e^{\prime}$ & 0.6941 & 105 & 0.5795 & 0.7818 & $<.0001^{*}$ \\
\hline MP-L1 & TVL-Pog' & -0.1425 & 105 & -0.3253 & 0.0506 & 0.147 \\
\hline Mp-Mic & ANS-Me & 0.8041 & 105 & 0.724 & 0.8628 & $<.0001^{*}$ \\
\hline Mp-Mic & Co-Gn & 0.3818 & 105 & 0.2051 & 0.5343 & $<.0001^{*}$ \\
\hline Mp-Mic & Co-Go & 0.4154 & 105 & 0.2431 & 0.5623 & $<.0001^{*}$ \\
\hline Mp-Mic & G'-Me' & 0.7492 & 105 & 0.651 & 0.8227 & $<.0001^{*}$ \\
\hline Mp-Mic & $\mathrm{G}^{\prime}-S n^{\prime}$ & 0.403 & 105 & 0.2291 & 0.5521 & $<.0001^{*}$ \\
\hline Mp-Mic & N-ANS & 0.4007 & 105 & 0.2265 & 0.5502 & $<.0001^{*}$ \\
\hline Mp-Mic & $\mathrm{N}-\mathrm{Me}$ & 0.8217 & 105 & 0.7478 & 0.8755 & $<.0001^{*}$ \\
\hline Mp-Mic & $O p^{\circ}$ & 0.1442 & 105 & -0.0488 & 0.3268 & 0.1422 \\
\hline Mp-Mic & PFH:AFH & -0.0705 & 105 & -0.2587 & 0.1228 & 0.4749 \\
\hline Mp-Mic & Pog'c-GALL & -0.2255 & 105 & -0.3999 & -0.0354 & $0.0207^{*}$ \\
\hline Mp-Mic & Pog'-GALL & -0.3136 & 105 & -0.4767 & -0.1298 & $0.0011 *$ \\
\hline Mp-Mic & Pog-GALL & -0.4258 & 105 & -0.5708 & -0.2549 & $<.0001^{*}$ \\
\hline Mp-Mic & PP-Mic & 0.5258 & 105 & 0.3715 & 0.6518 & $<.0001^{*}$ \\
\hline Mp-Mic & PP-U1 & 0.5452 & 105 & 0.3948 & 0.6672 & $<.0001^{*}$ \\
\hline
\end{tabular}




\begin{tabular}{|c|c|c|c|c|c|c|}
\hline Mp-Mic & S-Go & 0.5054 & 105 & 0.3474 & 0.6355 & $<.0001^{*}$ \\
\hline Mp-Mic & $S n^{\prime}-M^{\prime}$ & 0.7091 & 105 & 0.5988 & 0.793 & $<.0001^{*}$ \\
\hline Mp-Mic & TVL-Pog' & -0.3241 & 105 & -0.4856 & -0.1412 & $0.0007^{*}$ \\
\hline N-ANS & $O p^{\circ}$ & 0.1127 & 105 & -0.0807 & 0.2979 & 0.2523 \\
\hline N-ANS & Pog'c-GALL & -0.3014 & 105 & -0.4661 & -0.1164 & $0.0018^{*}$ \\
\hline N-ANS & Pog'-GALL & -0.2885 & 105 & -0.455 & -0.1025 & $0.0028 *$ \\
\hline N-ANS & Pog-GALL & -0.3155 & 105 & -0.4782 & -0.1318 & $0.001^{*}$ \\
\hline N-ANS & TVL-Pog' & -0.3411 & 105 & -0.5001 & -0.1599 & $0.0004 *$ \\
\hline $\mathrm{N}-\mathrm{Me}$ & ANS-Me & 0.8845 & 105 & 0.8342 & 0.9201 & $<.0001^{*}$ \\
\hline $\mathrm{N}-\mathrm{Me}$ & N-ANS & 0.6424 & 105 & 0.514 & 0.7426 & $<.0001^{*}$ \\
\hline $\mathrm{N}-\mathrm{Me}$ & $O p^{\circ}$ & 0.0318 & 105 & -0.1609 & 0.2221 & 0.7476 \\
\hline $\mathrm{N}-\mathrm{Me}$ & Pog'c-GALL & -0.1493 & 105 & -0.3315 & 0.0436 & 0.1284 \\
\hline $\mathrm{N}-\mathrm{Me}$ & Pog'-GALL & -0.2026 & 105 & -0.3796 & -0.0114 & $0.0382 *$ \\
\hline $\mathrm{N}-\mathrm{Me}$ & Pog-GALL & -0.3517 & 105 & -0.509 & -0.1716 & $0.0002 *$ \\
\hline $\mathrm{N}-\mathrm{Me}$ & TVL-Pog' & -0.217 & 105 & -0.3923 & -0.0264 & $0.0262^{*}$ \\
\hline $\mathrm{Op}-\mathrm{Sn}^{\circ}$ & $\mathrm{Go}^{\circ}$ & 0.1435 & 105 & -0.0495 & 0.3262 & 0.1441 \\
\hline $\mathrm{Op}-\mathrm{Sn}^{\circ}$ & $\mathrm{ANB}^{\circ}$ & 0.4295 & 105 & 0.2592 & 0.5739 & $<.0001^{*}$ \\
\hline $\mathrm{Op}-\mathrm{Sn}^{\circ}$ & ANS-Me & 0.0723 & 105 & -0.1211 & 0.2603 & 0.4637 \\
\hline $\mathrm{Op}-\mathrm{Sn}^{\circ}$ & Co-Gn & -0.4455 & 105 & -0.587 & -0.2775 & $<.0001^{*}$ \\
\hline $\mathrm{Op}-\mathrm{Sn}^{\circ}$ & Co-Go & -0.3513 & 105 & -0.5087 & -0.1711 & $0.0002 *$ \\
\hline $\mathrm{Op}-\mathrm{Sn}^{\circ}$ & G'-Me' & 0.0278 & 105 & -0.1647 & 0.2183 & 0.7781 \\
\hline $\mathrm{Op}-\mathrm{Sn}^{\circ}$ & $\mathrm{G}^{\prime}-\mathrm{Sn}$ & 0.007 & 105 & -0.1849 & 0.1984 & 0.9437 \\
\hline $\mathrm{Op}-\mathrm{Sn}^{\circ}$ & $G^{\prime}-S n-P o g^{\prime \circ}$ & -0.517 & 105 & -0.6448 & -0.3611 & $<.0001^{*}$ \\
\hline $\mathrm{Op}-\mathrm{Sn}^{\circ}$ & L1 - Op ${ }^{\circ}$ & -0.1008 & 105 & -0.287 & 0.0926 & 0.3061 \\
\hline $\mathrm{Op}-\mathrm{Sn}^{\circ}$ & $\mathrm{L}^{\circ}{ }^{\circ}$ & -0.3836 & 105 & -0.5358 & -0.2071 & $<.0001^{*}$ \\
\hline $\mathrm{Op}-\mathrm{Sn}^{\circ}$ & $\mathrm{MP}^{\circ}$ & 0.4368 & 105 & 0.2676 & 0.58 & $<.0001^{*}$ \\
\hline $\mathrm{Op}-\mathrm{Sn}^{\circ}$ & MP-L1 & -0.0606 & 105 & -0.2494 & 0.1326 & 0.5389 \\
\hline $\mathrm{Op}-\mathrm{Sn}^{\circ}$ & Mp-Mic & 0.154 & 105 & -0.0389 & 0.3357 & 0.1169 \\
\hline $\mathrm{Op}-\mathrm{Sn}^{\circ}$ & N-ANS & 0.2437 & 105 & 0.0546 & 0.4159 & $0.0122 *$ \\
\hline $\mathrm{Op}-\mathrm{Sn}^{\circ}$ & $\mathrm{N}-\mathrm{Me}$ & 0.173 & 105 & -0.0193 & 0.3529 & 0.0776 \\
\hline $\mathrm{Op}-\mathrm{Sn}^{\circ}$ & $O p^{\circ}$ & 0.7245 & 105 & 0.6188 & 0.8045 & $<.0001^{*}$ \\
\hline $\mathrm{Op}-\mathrm{Sn}^{\circ}$ & PFH:AFH & -0.5586 & 105 & -0.6777 & -0.4109 & $<.0001^{*}$ \\
\hline $\mathrm{Op}-\mathrm{Sn}^{\circ}$ & Pog'c-GALL & -0.3982 & 105 & -0.548 & -0.2236 & $<.0001^{*}$ \\
\hline $\mathrm{Op}-\mathrm{Sn}^{\circ}$ & Pog'-GALL & -0.4637 & 105 & -0.6019 & -0.2986 & $<.0001^{*}$ \\
\hline $\mathrm{Op}-\mathrm{Sn}^{\circ}$ & Pog-GALL & -0.3747 & 105 & -0.5284 & -0.1972 & $<.0001^{*}$ \\
\hline $\mathrm{Op}-\mathrm{Sn}^{\circ}$ & $P P^{\circ}$ & -0.1046 & 105 & -0.2904 & 0.0889 & 0.2884 \\
\hline $\mathrm{Op}-\mathrm{Sn}^{\circ}$ & PP-Mic & -0.1293 & 105 & -0.3132 & 0.0639 & 0.1886 \\
\hline $\mathrm{Op}-\mathrm{Sn}^{\circ}$ & PP-U1 & 0.3612 & 105 & 0.1821 & 0.5171 & $0.0002 *$ \\
\hline $\mathrm{Op}-\mathrm{Sn}^{\circ}$ & S-Go & -0.4599 & 105 & -0.5988 & -0.2942 & $<.0001^{*}$ \\
\hline $\mathrm{Op}-\mathrm{Sn}^{\circ}$ & $\mathrm{SNA}^{\circ}$ & -0.5185 & 105 & -0.646 & -0.3629 & $<.0001^{*}$ \\
\hline $\mathrm{Op}-\mathrm{Sn}^{\circ}$ & $\mathrm{SNB}^{\circ}$ & -0.7283 & 105 & -0.8073 & -0.6237 & $<.0001^{*}$ \\
\hline $\mathrm{Op}-\mathrm{Sn}^{\circ}$ & Sn'-Me' & 0.0321 & 105 & -0.1605 & 0.2224 & 0.7449 \\
\hline $\mathrm{Op}-\mathrm{Sn}^{\circ}$ & SN-MP & 0.7012 & 105 & 0.5887 & 0.7871 & $<.0001^{*}$ \\
\hline
\end{tabular}




\begin{tabular}{|c|c|c|c|c|c|c|}
\hline $\mathrm{Op}-\mathrm{Sn}^{\circ}$ & TVL-Pog' & -0.5214 & 105 & -0.6483 & -0.3663 & $<.0001^{*}$ \\
\hline $\mathrm{Op}-\mathrm{Sn}^{\circ}$ & U1 - Op & -0.0591 & 105 & -0.248 & 0.134 & 0.549 \\
\hline $\mathrm{Op}-\mathrm{Sn}^{\circ}$ & $\mathrm{U} 1^{\circ}$ & 0.2216 & 105 & 0.0313 & 0.3964 & $0.0231 *$ \\
\hline PFH:AFH & ANS-Me & -0.2135 & 105 & -0.3892 & -0.0227 & $0.0288 *$ \\
\hline PFH:AFH & Co-Gn & 0.1357 & 105 & -0.0575 & 0.3191 & 0.1675 \\
\hline PFH:AFH & Co-Go & 0.4864 & 105 & 0.3251 & 0.6203 & $<.0001^{*}$ \\
\hline PFH:AFH & $\mathrm{G}^{\prime}-\mathrm{Me}^{\prime}$ & -0.2434 & 105 & -0.4157 & -0.0543 & $0.0124^{*}$ \\
\hline PFH:AFH & $\mathrm{G}^{\prime}-S n^{\prime}$ & -0.0782 & 105 & -0.2659 & 0.1152 & 0.4277 \\
\hline PFH:AFH & N-ANS & -0.0725 & 105 & -0.2606 & 0.1208 & 0.4622 \\
\hline PFH:AFH & $\mathrm{N}-\mathrm{Me}$ & -0.202 & 105 & -0.379 & -0.0107 & $0.0388 *$ \\
\hline PFH:AFH & $O p^{\circ}$ & -0.447 & 105 & -0.5882 & -0.2792 & $<.0001^{*}$ \\
\hline PFH:AFH & Pog'c-GALL & 0.116 & 105 & -0.0774 & 0.301 & 0.2387 \\
\hline PFH:AFH & Pog'-GALL & 0.2596 & 105 & 0.0715 & 0.4298 & $0.0075^{*}$ \\
\hline PFH:AFH & Pog-GALL & 0.2756 & 105 & 0.0887 & 0.4439 & $0.0044^{*}$ \\
\hline PFH:AFH & S-Go & 0.6758 & 105 & 0.5562 & 0.768 & $<.0001^{*}$ \\
\hline PFH:AFH & $S n^{\prime}-M e^{\prime}$ & -0.2685 & 105 & -0.4377 & -0.081 & $0.0056 *$ \\
\hline PFH:AFH & TVL-Pog' & 0.2332 & 105 & 0.0435 & 0.4067 & $0.0166^{*}$ \\
\hline Pog'c-GALL & $O p^{\circ}$ & -0.4182 & 105 & -0.5646 & -0.2463 & $<.0001^{*}$ \\
\hline Pog'c-GALL & Pog'-GALL & 0.9376 & 105 & 0.9093 & 0.9572 & $<.0001^{*}$ \\
\hline Pog'c-GALL & Pog-GALL & 0.6731 & 105 & 0.5528 & 0.766 & $<.0001^{*}$ \\
\hline Pog'c-GALL & TVL-Pog' & 0.8158 & 105 & 0.7398 & 0.8712 & $<.0001^{*}$ \\
\hline Pog'-GALL & $O p^{\circ}$ & -0.4578 & 105 & -0.5971 & -0.2917 & $<.0001^{*}$ \\
\hline Pog-GALL & $O p^{\circ}$ & -0.4114 & 105 & -0.559 & -0.2386 & $<.0001^{*}$ \\
\hline Pog-GALL & Pog'-GALL & 0.7329 & 105 & 0.6298 & 0.8107 & $<.0001^{*}$ \\
\hline $\mathrm{PP}^{\circ}$ & $\mathrm{Go}^{\circ}$ & -0.0227 & 105 & -0.2135 & 0.1697 & 0.8179 \\
\hline $\mathrm{PP}^{\circ}$ & $\mathrm{ANB}^{\circ}$ & -0.1561 & 105 & -0.3377 & 0.0367 & 0.1118 \\
\hline $\mathrm{PP}^{\circ}$ & ANS-Me & -0.2632 & 105 & -0.4331 & -0.0754 & 0.0067 \\
\hline $\mathrm{PP}^{\circ}$ & Co-Gn & 0.2026 & 105 & 0.0114 & 0.3795 & $0.0382 *$ \\
\hline $\mathrm{PP}^{\circ}$ & Co-Go & 0.1177 & 105 & -0.0756 & 0.3026 & 0.2316 \\
\hline $\mathrm{PP}^{\circ}$ & $\mathrm{G}^{\prime}-\mathrm{Me}^{\prime}$ & 0.0206 & 105 & -0.1717 & 0.2115 & 0.8345 \\
\hline $\mathrm{PP}^{\circ}$ & $\mathrm{G}^{\prime}-\mathrm{Sn}^{\prime}$ & 0.3841 & 105 & 0.2077 & 0.5363 & $<.0001^{*}$ \\
\hline $\mathrm{PP}^{\circ}$ & $\mathrm{G}^{\prime}-\mathrm{Sn}-\mathrm{Pog}^{10}$ & 0.0506 & 105 & -0.1424 & 0.2399 & 0.6082 \\
\hline $\mathrm{PP}^{\circ}$ & $\mathrm{L}^{\circ}{ }^{\circ}$ & 0.1231 & 105 & -0.0703 & 0.3075 & 0.2111 \\
\hline $\mathrm{PP}^{\circ}$ & $\mathrm{MP}^{\circ}$ & 0.0713 & 105 & -0.122 & 0.2595 & 0.4696 \\
\hline $\mathrm{PP}^{\circ}$ & MP-L1 & -0.161 & 105 & -0.3421 & 0.0316 & 0.1008 \\
\hline $\mathrm{PP}^{\circ}$ & Mp-Mic & 0.0276 & 105 & -0.1649 & 0.2182 & 0.7795 \\
\hline $\mathrm{PP}^{\circ}$ & N-ANS & 0.3055 & 105 & 0.1209 & 0.4697 & $0.0015^{*}$ \\
\hline $\mathrm{PP}^{\circ}$ & $\mathrm{N}-\mathrm{Me}$ & -0.0606 & 105 & -0.2493 & 0.1327 & 0.5395 \\
\hline $\mathrm{PP}^{\circ}$ & $O p^{\circ}$ & 0.3273 & 105 & 0.1447 & 0.4883 & $0.0007^{*}$ \\
\hline $\mathrm{PP}^{\circ}$ & PFH:AFH & 0.0974 & 105 & -0.0961 & 0.2838 & 0.3229 \\
\hline $\mathrm{PP}^{\circ}$ & Pog'c-GALL & -0.0685 & 105 & -0.2568 & 0.1248 & 0.4873 \\
\hline $\mathrm{PP}^{\circ}$ & Pog'-GALL & -0.0262 & 105 & -0.2168 & 0.1663 & 0.7906 \\
\hline $\mathrm{PP}^{\circ}$ & Pog-GALL & -0.032 & 105 & -0.2223 & 0.1606 & 0.7457 \\
\hline
\end{tabular}




\begin{tabular}{|c|c|c|c|c|c|c|}
\hline $\mathrm{PP}^{\circ}$ & PP-Mic & -0.0026 & 105 & -0.1941 & 0.1892 & 0.9793 \\
\hline $\mathrm{PP}^{\circ}$ & PP-U1 & -0.4525 & 105 & -0.5928 & -0.2856 & $<.0001^{*}$ \\
\hline $\mathrm{PP}^{\circ}$ & S-Go & 0.0938 & 105 & -0.0997 & 0.2804 & 0.3412 \\
\hline $\mathrm{PP}^{\circ}$ & SNA $^{\circ}$ & 0.2907 & 105 & 0.1049 & 0.4569 & $0.0026 *$ \\
\hline $\mathrm{PP}^{\circ}$ & $\mathrm{SNB}^{\circ}$ & 0.3425 & 105 & 0.1614 & 0.5012 & $0.0003 *$ \\
\hline $\mathrm{PP}^{\circ}$ & $S n^{\prime}-M e^{\prime}$ & -0.2505 & 105 & -0.4219 & -0.0617 & $0.01 *$ \\
\hline $\mathrm{PP}^{\circ}$ & $\mathrm{SN}-\mathrm{MP}^{\circ}$ & -0.1928 & 105 & -0.3708 & -0.0012 & $0.0487^{*}$ \\
\hline $\mathrm{PP}^{\circ}$ & TVL-Pog' & 0.0398 & 105 & -0.153 & 0.2297 & 0.6869 \\
\hline $\mathrm{PP}^{\circ}$ & $\mathrm{U} 1^{\circ}$ & 0.141 & 105 & -0.0521 & 0.3239 & 0.1514 \\
\hline PP-Mic & ANS-Me & 0.7142 & 105 & 0.6054 & 0.7968 & $<.0001 *$ \\
\hline PP-Mic & Co-Gn & 0.4522 & 105 & 0.2852 & 0.5925 & $<.0001^{*}$ \\
\hline PP-Mic & Co-Go & 0.3449 & 105 & 0.1641 & 0.5033 & $0.0003 *$ \\
\hline PP-Mic & G'-Me' & 0.6424 & 105 & 0.514 & 0.7426 & $<.0001^{*}$ \\
\hline PP-Mic & $G^{\prime}-S n^{\prime}$ & 0.2221 & 105 & 0.0318 & 0.3969 & $0.0228 *$ \\
\hline PP-Mic & N-ANS & 0.1575 & 105 & -0.0352 & 0.3389 & 0.1086 \\
\hline PP-Mic & $\mathrm{N}-\mathrm{Me}$ & 0.6351 & 105 & 0.5048 & 0.737 & $<.0001^{*}$ \\
\hline PP-Mic & $O p^{\circ}$ & -0.1304 & 105 & -0.3143 & 0.0628 & 0.1847 \\
\hline PP-Mic & PFH:AFH & -0.0532 & 105 & -0.2424 & 0.1399 & 0.5896 \\
\hline PP-Mic & Pog'c-GALL & 0.0029 & 105 & -0.1889 & 0.1945 & 0.9765 \\
\hline PP-Mic & Pog'-GALL & -0.0446 & 105 & -0.2342 & 0.1484 & 0.6517 \\
\hline PP-Mic & Pog-GALL & -0.1756 & 105 & -0.3553 & 0.0166 & 0.0732 \\
\hline PP-Mic & PP-U1 & 0.5577 & 105 & 0.4098 & 0.677 & $<.0001 *$ \\
\hline PP-Mic & S-Go & 0.4413 & 105 & 0.2727 & 0.5836 & $<.0001^{*}$ \\
\hline PP-Mic & Sn'-Me' & 0.6974 & 105 & 0.5838 & 0.7842 & $<.0001^{*}$ \\
\hline PP-Mic & TVL-Pog' & -0.0037 & 105 & -0.1952 & 0.1881 & 0.9704 \\
\hline PP-U1 & ANS-Me & 0.7108 & 105 & 0.601 & 0.7943 & $<.0001^{*}$ \\
\hline PP-U1 & Co-Gn & 0.089 & 105 & -0.1045 & 0.2759 & 0.3667 \\
\hline PP-U1 & Co-Go & 0.1 & 105 & -0.0934 & 0.2862 & 0.31 \\
\hline PP-U1 & $\mathrm{G}^{\prime}-\mathrm{Me}^{\prime}$ & 0.5038 & 105 & 0.3455 & 0.6342 & $<.0001^{*}$ \\
\hline PP-U1 & $G^{\prime}-S n^{\prime}$ & 0.0323 & 105 & -0.1603 & 0.2226 & 0.7434 \\
\hline PP-U1 & N-ANS & 0.0329 & 105 & -0.1598 & 0.2231 & 0.7392 \\
\hline PP-U1 & $\mathrm{N}-\mathrm{Me}$ & 0.5729 & 105 & 0.4283 & 0.689 & $<.0001^{*}$ \\
\hline PP-U1 & $O p^{\circ}$ & 0.1914 & 105 & -0.0002 & 0.3695 & $0.0504 *$ \\
\hline PP-U1 & PFH:AFH & -0.3496 & 105 & -0.5073 & -0.1693 & $0.0003^{*}$ \\
\hline PP-U1 & Pog'c-GALL & -0.2875 & 105 & -0.4542 & -0.1015 & $0.0029 *$ \\
\hline PP-U1 & Pog'-GALL & -0.3454 & 105 & -0.5037 & -0.1646 & $0.0003^{*}$ \\
\hline PP-U1 & Pog-GALL & -0.3932 & 105 & -0.5439 & -0.218 & $<.0001^{*}$ \\
\hline PP-U1 & S-Go & 0.082 & 105 & -0.1114 & 0.2694 & 0.4056 \\
\hline PP-U1 & Sn'-Me' & 0.6496 & 105 & 0.5231 & 0.7481 & $<.0001^{*}$ \\
\hline PP-U1 & TVL-Pog' & -0.3749 & 105 & -0.5285 & -0.1974 & $<.0001^{*}$ \\
\hline S-Go & ANS-Me & 0.4139 & 105 & 0.2414 & 0.5611 & $<.0001^{*}$ \\
\hline S-Go & Co-Go & 0.795 & 105 & 0.7118 & 0.8562 & $<.0001^{*}$ \\
\hline S-Go & G'-Me' & 0.5474 & 105 & 0.3974 & 0.6689 & $<.0001^{*}$ \\
\hline
\end{tabular}




\begin{tabular}{|c|c|c|c|c|c|c|}
\hline S-Go & $G^{\prime}-S n^{\prime}$ & 0.4411 & 105 & 0.2724 & 0.5834 & $<.0001^{*}$ \\
\hline S-Go & N-ANS & 0.3397 & 105 & 0.1584 & 0.4989 & $0.0004 *$ \\
\hline S-Go & $\mathrm{N}-\mathrm{Me}$ & 0.4867 & 105 & 0.3254 & 0.6205 & $<.0001^{*}$ \\
\hline S-Go & $O p^{\circ}$ & -0.3825 & 105 & -0.5349 & -0.2059 & $<.0001^{*}$ \\
\hline S-Go & Pog'c-GALL & 0.0432 & 105 & -0.1497 & 0.233 & 0.6616 \\
\hline S-Go & Pog'-GALL & 0.1264 & 105 & -0.0669 & 0.3105 & 0.1988 \\
\hline S-Go & Pog-GALL & -0.0271 & 105 & -0.2176 & 0.1654 & 0.7838 \\
\hline S-Go & $S n^{\prime}-M e^{\prime}$ & 0.412 & 105 & 0.2392 & 0.5595 & $<.0001^{*}$ \\
\hline S-Go & TVL-Pog' & 0.122 & 105 & -0.0713 & 0.3065 & 0.215 \\
\hline $\mathrm{Sn}^{\circ}$ & $\mathrm{Go}^{\circ}$ & -0.0886 & 105 & -0.2755 & 0.1049 & 0.369 \\
\hline $\mathrm{Sn}^{\circ}$ & $\mathrm{ANB}^{\circ}$ & 0.3243 & 105 & 0.1415 & 0.4858 & $0.0007^{*}$ \\
\hline $\mathrm{Sn}^{\circ}$ & ANS-Me & 0.1031 & 105 & -0.0904 & 0.289 & 0.2955 \\
\hline $\mathrm{Sn}^{\circ}$ & Co-Gn & -0.4051 & 105 & -0.5538 & -0.2314 & $<.0001^{*}$ \\
\hline $\mathrm{Sn}^{\circ}$ & Co-Go & -0.1942 & 105 & -0.372 & -0.0026 & $0.0471 *$ \\
\hline $\mathrm{Sn}^{\circ}$ & G'-Me' & -0.0043 & 105 & -0.1958 & 0.1875 & 0.9653 \\
\hline $\mathrm{Sn}^{\circ}$ & $\mathrm{G}^{\prime}-S n^{\prime}$ & -0.0979 & 105 & -0.2842 & 0.0956 & 0.3206 \\
\hline $\mathrm{Sn}^{\circ}$ & $\mathrm{G}^{\prime}-\mathrm{Sn}-\mathrm{Pog}^{10}$ & -0.3815 & 105 & -0.5341 & -0.2048 & $<.0001^{*}$ \\
\hline $\mathrm{Sn}^{\circ}$ & $\mathrm{L} 1-\mathrm{Op}^{\circ}$ & -0.2967 & 105 & -0.4621 & -0.1114 & $0.0021 *$ \\
\hline $\mathrm{Sn}^{\circ}$ & $\mathrm{L}^{\circ}{ }^{\circ}$ & -0.2875 & 105 & -0.4542 & -0.1015 & $0.0029 *$ \\
\hline $\mathrm{Sn}^{\circ}$ & $\mathrm{MP}^{\circ}$ & 0.0286 & 105 & -0.164 & 0.219 & 0.7723 \\
\hline $\mathrm{Sn}^{\circ}$ & MP-L1 & 0.0611 & 105 & -0.1321 & 0.2499 & 0.5357 \\
\hline $\mathrm{Sn}^{\circ}$ & Mp-Mic & 0.0541 & 105 & -0.139 & 0.2432 & 0.5839 \\
\hline $\mathrm{Sn}^{\circ}$ & N-ANS & 0.2216 & 105 & 0.0313 & 0.3965 & $0.0231 *$ \\
\hline $\mathrm{Sn}^{\circ}$ & $\mathrm{N}-\mathrm{Me}$ & 0.1866 & 105 & -0.0053 & 0.3652 & 0.0567 \\
\hline $\mathrm{Sn}^{\circ}$ & $O p^{\circ}$ & -0.0046 & 105 & -0.1961 & 0.1873 & 0.9631 \\
\hline $\mathrm{Sn}^{\circ}$ & $\mathrm{Op}-\mathrm{Sn}^{\circ}$ & 0.6731 & 105 & 0.5528 & 0.766 & $<.0001^{*}$ \\
\hline $\mathrm{Sn}^{\circ}$ & PFH:AFH & -0.3393 & 105 & -0.4985 & -0.1579 & $0.0004 *$ \\
\hline $\mathrm{Sn}^{\circ}$ & Pog'c-GALL & -0.1023 & 105 & -0.2883 & 0.0912 & 0.2993 \\
\hline $\mathrm{Sn}^{\circ}$ & Pog'-GALL & -0.1676 & 105 & -0.3481 & 0.0249 & 0.0875 \\
\hline $\mathrm{Sn}^{\circ}$ & Pog-GALL & -0.0633 & 105 & -0.2519 & 0.1299 & 0.5212 \\
\hline $\mathrm{Sn}^{\circ}$ & $\mathrm{PP}^{\circ}$ & -0.4935 & 105 & -0.6259 & -0.3333 & $<.0001^{*}$ \\
\hline $\mathrm{Sn}^{\circ}$ & PP-Mic & -0.0735 & 105 & -0.2615 & 0.1198 & 0.456 \\
\hline $\mathrm{Sn}^{\circ}$ & PP-U1 & 0.2803 & 105 & 0.0937 & 0.4479 & $0.0038 *$ \\
\hline $\mathrm{Sn}^{\circ}$ & S-Go & -0.292 & 105 & -0.458 & -0.1063 & $0.0025^{*}$ \\
\hline $\mathrm{Sn}^{\circ}$ & $\mathrm{SNA}^{\circ}$ & -0.7266 & 105 & -0.806 & -0.6215 & $<.0001 *$ \\
\hline $\mathrm{Sn}^{\circ}$ & $\mathrm{SNB}^{\circ}$ & -0.8049 & 105 & -0.8634 & -0.7251 & $<.0001^{*}$ \\
\hline $\mathrm{Sn}^{\circ}$ & $S n^{\prime}-M e^{\prime}$ & 0.0651 & 105 & -0.1282 & 0.2536 & 0.5094 \\
\hline $\mathrm{Sn}^{\circ}$ & SN-MP & 0.5051 & 105 & 0.347 & 0.6352 & $<.0001^{*}$ \\
\hline $\mathrm{Sn}^{\circ}$ & TVL-Pog' & -0.304 & 105 & -0.4684 & -0.1193 & $0.0016^{*}$ \\
\hline $\mathrm{Sn}^{\circ}$ & $\mathrm{U} 1-O p^{\circ}$ & 0.0211 & 105 & -0.1713 & 0.2119 & 0.831 \\
\hline $\mathrm{Sn}^{\circ}$ & $\mathrm{U} 1^{\circ}$ & 0.0189 & 105 & -0.1734 & 0.2098 & 0.8484 \\
\hline $\mathrm{SNA}^{\circ}$ & $\mathrm{Go}^{\circ}$ & 0.0074 & 105 & -0.1845 & 0.1988 & 0.9401 \\
\hline $\mathrm{SNA}^{\circ}$ & ANS-Me & -0.04 & 105 & -0.2299 & 0.1529 & 0.6857 \\
\hline
\end{tabular}




\begin{tabular}{|c|c|c|c|c|c|c|}
\hline $\mathrm{SNA}^{\circ}$ & Co-Gn & 0.2935 & 105 & 0.1079 & 0.4593 & $0.0024^{*}$ \\
\hline $\mathrm{SNA}^{\circ}$ & Co-Go & 0.1457 & 105 & -0.0472 & 0.3282 & 0.1379 \\
\hline $\mathrm{SNA}^{\circ}$ & G'-Me' & -0.0195 & 105 & -0.2104 & 0.1728 & 0.8434 \\
\hline $\mathrm{SNA}^{\circ}$ & $G^{\prime}-S n^{\prime}$ & -0.0605 & 105 & -0.2493 & 0.1327 & 0.5395 \\
\hline $\mathrm{SNA}^{\circ}$ & $\mathrm{G}^{\prime}-\mathrm{Sn}-\mathrm{Pog}^{10}$ & 0.1104 & 105 & -0.083 & 0.2958 & 0.2623 \\
\hline $\mathrm{SNA}^{\circ}$ & $\mathrm{L}^{\circ}$ & 0.0749 & 105 & -0.1185 & 0.2628 & 0.4476 \\
\hline $\mathrm{SNA}^{\circ}$ & $\mathrm{MP}^{\circ}$ & -0.079 & 105 & -0.2666 & 0.1144 & 0.4231 \\
\hline $\mathrm{SNA}^{\circ}$ & MP-L1 & -0.016 & 105 & -0.207 & 0.1762 & 0.8715 \\
\hline $\mathrm{SNA}^{\circ}$ & Mp-Mic & 0.0125 & 105 & -0.1796 & 0.2037 & 0.8989 \\
\hline $\mathrm{SNA}^{\circ}$ & N-ANS & -0.303 & 105 & -0.4675 & -0.1182 & $0.0017^{*}$ \\
\hline $\mathrm{SNA}^{\circ}$ & $\mathrm{N}-\mathrm{Me}$ & -0.1759 & 105 & -0.3556 & 0.0163 & 0.0726 \\
\hline $\mathrm{SNA}^{\circ}$ & $O p^{\circ}$ & -0.0354 & 105 & -0.2255 & 0.1573 & 0.7199 \\
\hline $\mathrm{SNA}^{\circ}$ & PFH:AFH & 0.3061 & 105 & 0.1215 & 0.4701 & $0.0015 *$ \\
\hline $\mathrm{SNA}^{\circ}$ & Pog'c-GALL & 0.1939 & 105 & 0.0024 & 0.3718 & $0.0474 *$ \\
\hline $\mathrm{SNA}^{\circ}$ & Pog'-GALL & 0.2173 & 105 & 0.0267 & 0.3926 & $0.026 *$ \\
\hline $\mathrm{SNA}^{\circ}$ & Pog-GALL & 0.0472 & 105 & -0.1458 & 0.2367 & 0.6327 \\
\hline $\mathrm{SNA}^{\circ}$ & PP-Mic & 0.1143 & 105 & -0.0791 & 0.2994 & 0.2455 \\
\hline $\mathrm{SNA}^{\circ}$ & PP-U1 & -0.0802 & 105 & -0.2678 & 0.1132 & 0.4159 \\
\hline $\mathrm{SNA}^{\circ}$ & S-Go & 0.2578 & 105 & 0.0696 & 0.4283 & $0.0079 *$ \\
\hline $\mathrm{SNA}^{\circ}$ & $S n^{\prime}-M e^{\prime}$ & 0.0178 & 105 & -0.1745 & 0.2087 & 0.8573 \\
\hline $\mathrm{SNA}^{\circ}$ & TVL-Pog' & 0.1556 & 105 & -0.0372 & 0.3372 & 0.113 \\
\hline $\mathrm{SNA}^{\circ}$ & $\mathrm{U} 1^{\circ}$ & 0.0995 & 105 & -0.0939 & 0.2858 & 0.3124 \\
\hline $\mathrm{SNB}^{\circ}$ & $\mathrm{Go}^{\circ}$ & 0.1423 & 105 & -0.0507 & 0.3251 & 0.1475 \\
\hline $\mathrm{SNB}^{\circ}$ & ANS-Me & -0.1346 & 105 & -0.3181 & 0.0585 & 0.1709 \\
\hline $\mathrm{SNB}^{\circ}$ & Co-Gn & 0.454 & 105 & 0.2874 & 0.594 & $<.0001^{*}$ \\
\hline $\mathrm{SNB}^{\circ}$ & Co-Go & 0.1216 & 105 & -0.0718 & 0.3061 & 0.2167 \\
\hline $\mathrm{SNB}^{\circ}$ & $\mathrm{G}^{\prime}-\mathrm{Me}^{\prime}$ & -0.1386 & 105 & -0.3217 & 0.0546 & 0.1587 \\
\hline $\mathrm{SNB}^{\circ}$ & $\mathrm{G}^{\prime}-\mathrm{Sn}^{\prime}$ & -0.1012 & 105 & -0.2873 & 0.0922 & 0.3042 \\
\hline $\mathrm{SNB}^{\circ}$ & $\mathrm{G}^{\prime}-\mathrm{Sn}-\mathrm{Pog}^{10}$ & 0.6087 & 105 & 0.4722 & 0.7168 & $<.0001 *$ \\
\hline $\mathrm{SNB}^{\circ}$ & $\mathrm{L}^{\circ}$ & 0.4337 & 105 & 0.2639 & 0.5773 & $<.0001 *$ \\
\hline $\mathrm{SNB}^{\circ}$ & $\mathrm{MP}^{\circ}$ & -0.1625 & 105 & -0.3435 & 0.0301 & 0.0976 \\
\hline $\mathrm{SNB}^{\circ}$ & MP-L1 & -0.1905 & 105 & -0.3687 & 0.0012 & 0.0516 \\
\hline $\mathrm{SNB}^{\circ}$ & Mp-Mic & -0.2065 & 105 & -0.3831 & -0.0155 & $0.0345 *$ \\
\hline $\mathrm{SNB}^{\circ}$ & N-ANS & -0.3912 & 105 & -0.5422 & -0.2157 & $<.0001 *$ \\
\hline $\mathrm{SNB}^{\circ}$ & $\mathrm{N}-\mathrm{Me}$ & -0.2923 & 105 & -0.4583 & -0.1066 & $0.0025 *$ \\
\hline $\mathrm{SNB}^{\circ}$ & $O p^{\circ}$ & -0.2355 & 105 & -0.4088 & -0.046 & $0.0156 *$ \\
\hline $\mathrm{SNB}^{\circ}$ & PFH:AFH & 0.3768 & 105 & 0.1996 & 0.5302 & $<.0001^{*}$ \\
\hline $\mathrm{SNB}^{\circ}$ & Pog'c-GALL & 0.5631 & 105 & 0.4163 & 0.6812 & $<.0001 *$ \\
\hline $\mathrm{SNB}^{\circ}$ & Pog'-GALL & 0.6104 & 105 & 0.4742 & 0.7181 & $<.0001^{*}$ \\
\hline $\mathrm{SNB}^{\circ}$ & Pog-GALL & 0.5163 & 105 & 0.3603 & 0.6442 & $<.0001^{*}$ \\
\hline $\mathrm{SNB}^{\circ}$ & PP-Mic & -0.0099 & 105 & -0.2012 & 0.1821 & 0.9201 \\
\hline $\mathrm{SNB}^{\circ}$ & PP-U1 & -0.4281 & 105 & -0.5728 & -0.2576 & $<.0001^{*}$ \\
\hline $\mathrm{SNB}^{\circ}$ & S-Go & 0.2225 & 105 & 0.0322 & 0.3972 & $0.0225^{*}$ \\
\hline
\end{tabular}




\begin{tabular}{|c|c|c|c|c|c|c|}
\hline $\mathrm{SNB}^{\circ}$ & $\mathrm{SNA}^{\circ}$ & 0.6405 & 105 & 0.5117 & 0.7412 & $<.0001^{*}$ \\
\hline $\mathrm{SNB}^{\circ}$ & $S n^{\prime}-M e^{\prime}$ & -0.1118 & 105 & -0.2971 & 0.0816 & 0.2561 \\
\hline $\mathrm{SNB}^{\circ}$ & TVL-Pog' & 0.6358 & 105 & 0.5058 & 0.7376 & $<.0001^{*}$ \\
\hline $\mathrm{SNB}^{\circ}$ & $\mathrm{U} 1^{\circ}$ & -0.2072 & 105 & -0.3836 & -0.0162 & $0.034 *$ \\
\hline Sn'-Me' & ANS-Me & 0.897 & 105 & 0.8518 & 0.929 & $<.0001^{*}$ \\
\hline Sn'-Me' & G'-Sn' & 0.18 & 105 & -0.0121 & 0.3593 & 0.0661 \\
\hline Sn'-Me' & N-ANS & 0.2206 & 105 & 0.0302 & 0.3955 & $0.0237^{*}$ \\
\hline Sn'-Me' & $\mathrm{N}-\mathrm{Me}$ & 0.8085 & 105 & 0.73 & 0.866 & $<.0001^{*}$ \\
\hline Sn'-Me' & $O p^{\circ}$ & -0.0474 & 105 & -0.2369 & 0.1456 & 0.6311 \\
\hline$S n^{\prime}-M e^{\prime}$ & Pog'c-GALL & 0.0379 & 105 & -0.1549 & 0.2279 & 0.7013 \\
\hline Sn'-Me' & Pog'-GALL & -0.0559 & 105 & -0.2449 & 0.1372 & 0.5711 \\
\hline Sn'-Me' & Pog-GALL & -0.293 & 105 & -0.4589 & -0.1073 & $0.0024 *$ \\
\hline Sn'-Me' & TVL-Pog' & -0.0483 & 105 & -0.2378 & 0.1447 & 0.6244 \\
\hline SN-MP & $\mathrm{Go}^{\circ}$ & 0.5389 & 105 & 0.3873 & 0.6622 & $<.0001^{*}$ \\
\hline SN-MP ${ }^{\circ}$ & $\mathrm{ANB}^{\circ}$ & 0.2615 & 105 & 0.0735 & 0.4315 & 0.0071 \\
\hline SN-MP ${ }^{\circ}$ & ANS-Me & 0.4106 & 105 & 0.2377 & 0.5584 & $<.0001^{*}$ \\
\hline SN-MP ${ }^{\circ}$ & Co-Gn & -0.1911 & 105 & -0.3692 & 0.0006 & $0.0508 *$ \\
\hline SN-MP ${ }^{\circ}$ & Co-Go & -0.4461 & 105 & -0.5875 & -0.2782 & $<.0001^{*}$ \\
\hline SN-MP & G'-Me' & 0.2306 & 105 & 0.0407 & 0.4044 & $0.018^{*}$ \\
\hline SN-MP & $\mathrm{G}^{\prime}-S n^{\prime}$ & -0.0139 & 105 & -0.2051 & 0.1782 & 0.8878 \\
\hline SN-MP ${ }^{\circ}$ & G'-Sn-Pog' $^{\prime 0}$ & -0.3132 & 105 & -0.4763 & -0.1293 & $0.0011^{*}$ \\
\hline SN-MP & $\mathrm{L}^{\circ}{ }^{\circ}$ & -0.381 & 105 & -0.5337 & -0.2042 & $<.0001^{*}$ \\
\hline SN-MP ${ }^{\circ}$ & $\mathrm{MP}^{\circ}$ & 0.8513 & 105 & 0.7883 & 0.8967 & $<.0001^{*}$ \\
\hline SN-MP & MP-L1 & 0.1328 & 105 & -0.0604 & 0.3164 & 0.177 \\
\hline SN-MP ${ }^{\circ}$ & Mp-Mic & 0.2926 & 105 & 0.1069 & 0.4586 & $0.0025 *$ \\
\hline SN-MP & N-ANS & 0.1966 & 105 & 0.0051 & 0.3741 & $0.0445 *$ \\
\hline SN-MP ${ }^{\circ}$ & $\mathrm{N}-\mathrm{Me}$ & 0.4158 & 105 & 0.2435 & 0.5626 & $<.0001^{*}$ \\
\hline SN-MP & $O p^{\circ}$ & 0.4798 & 105 & 0.3174 & 0.6149 & $<.0001^{*}$ \\
\hline SN-MP & PFH:AFH & -0.7658 & 105 & -0.835 & -0.673 & $<.0001^{*}$ \\
\hline SN-MP & Pog'c-GALL & -0.1961 & 105 & -0.3737 & -0.0046 & $0.045^{*}$ \\
\hline SN-MP & Pog'-GALL & -0.3742 & 105 & -0.528 & -0.1967 & $<.0001^{*}$ \\
\hline SN-MP & Pog-GALL & -0.3486 & 105 & -0.5065 & -0.1682 & $0.0003 *$ \\
\hline SN-MP & PP-Mic & 0.1107 & 105 & -0.0828 & 0.2961 & 0.2611 \\
\hline SN-MP & PP-U1 & 0.4351 & 105 & 0.2656 & 0.5785 & $<.0001^{*}$ \\
\hline SN-MP & S-Go & -0.4895 & 105 & -0.6227 & -0.3287 & $<.0001^{*}$ \\
\hline SN-MP & $\mathrm{SNA}^{\circ}$ & -0.4349 & 105 & -0.5783 & -0.2653 & $<.0001^{*}$ \\
\hline SN-MP & $\mathrm{SNB}^{\circ}$ & -0.534 & 105 & -0.6583 & -0.3814 & $<.0001^{*}$ \\
\hline SN-MP & Sn'-Me' & 0.3181 & 105 & 0.1347 & 0.4805 & $0.0009 *$ \\
\hline SN-MP & TVL-Pog' & -0.38 & 105 & -0.5329 & -0.2031 & $<.0001^{*}$ \\
\hline SN-MP & $\mathrm{U} 1^{\circ}$ & -0.0445 & 105 & -0.2342 & 0.1484 & 0.6521 \\
\hline TVL-Pog' & $O p^{\circ}$ & -0.4166 & 105 & -0.5633 & -0.2445 & $<.0001^{*}$ \\
\hline TVL-Pog' & Pog'-GALL & 0.8862 & 105 & 0.8367 & 0.9214 & $<.0001^{*}$ \\
\hline TVL-Pog' & Pog-GALL & 0.6091 & 105 & 0.4727 & 0.7171 & $<.0001^{*}$ \\
\hline
\end{tabular}




\begin{tabular}{|c|c|c|c|c|c|c|}
\hline U1 - Op & $\mathrm{Go}^{\circ}$ & -0.3046 & 105 & -0.4689 & -0.12 & $0.0016^{*}$ \\
\hline U1 - Op & $\mathrm{ANB}^{\circ}$ & 0.2659 & 105 & 0.0782 & 0.4354 & $0.0061^{*}$ \\
\hline $\mathrm{U} 1-O \mathrm{p}^{\circ}$ & ANS-Me & -0.0184 & 105 & -0.2093 & 0.1739 & 0.8523 \\
\hline $\mathrm{U} 1-O p^{\circ}$ & Co-Gn & -0.0467 & 105 & -0.2362 & 0.1463 & 0.6363 \\
\hline$U 1-O p^{\circ}$ & Co-Go & 0.164 & 105 & -0.0286 & 0.3448 & 0.0946 \\
\hline U1 - Op & G'-Me' & 0.106 & 105 & -0.0874 & 0.2918 & 0.2817 \\
\hline$U 1-O p^{\circ}$ & $\mathrm{G}^{\prime}-S n^{\prime}$ & 0.2435 & 105 & 0.0543 & 0.4157 & $0.0123^{*}$ \\
\hline $\mathrm{U} 1-O p^{\circ}$ & G'-Sn-Pog' $^{\prime 0}$ & -0.0418 & 105 & -0.2316 & 0.1511 & 0.672 \\
\hline U1 - Op & $\mathrm{L}^{\circ}$ & 0.1999 & 105 & 0.0086 & 0.3771 & $0.0409 *$ \\
\hline $\mathrm{U} 1-O \mathrm{p}^{\circ}$ & $\mathrm{MP}^{\circ}$ & -0.2407 & 105 & -0.4133 & -0.0514 & $0.0134 *$ \\
\hline$U 1-O p^{\circ}$ & MP-L1 & 0.1122 & 105 & -0.0812 & 0.2975 & 0.2545 \\
\hline U1 - Op & Mp-Mic & 0.0261 & 105 & -0.1664 & 0.2167 & 0.7916 \\
\hline$U 1-O p^{\circ}$ & N-ANS & 0.1254 & 105 & -0.0679 & 0.3096 & 0.2024 \\
\hline U1 - Op & $\mathrm{N}-\mathrm{Me}$ & 0.0454 & 105 & -0.1475 & 0.2351 & 0.6454 \\
\hline $\mathrm{U} 1$ - Op & $O p^{\circ}$ & -0.1427 & 105 & -0.3254 & 0.0504 & 0.1466 \\
\hline $\mathrm{U} 1$ - Op & PFH:AFH & 0.1246 & 105 & -0.0687 & 0.3089 & 0.2052 \\
\hline $\mathrm{U} 1$ - Op & Pog'c-GALL & -0.1346 & 105 & -0.3181 & 0.0586 & 0.1709 \\
\hline $\mathrm{U} 1$ - Op & Pog'-GALL & -0.0399 & 105 & -0.2298 & 0.153 & 0.6864 \\
\hline U1 - Op & Pog-GALL & -0.0529 & 105 & -0.2421 & 0.1402 & 0.5922 \\
\hline $\mathrm{U} 1$ - Op & $\mathrm{PP}^{\circ}$ & 0.0151 & 105 & -0.1771 & 0.2061 & 0.8788 \\
\hline $\mathrm{U} 1-O p^{\circ}$ & PP-Mic & 0.0143 & 105 & -0.1778 & 0.2054 & 0.8847 \\
\hline $\mathrm{U} 1$ - Op & PP-U1 & 0.1821 & 105 & -0.0099 & 0.3612 & 0.0629 \\
\hline U1 - Op & S-Go & 0.1958 & 105 & 0.0042 & 0.3734 & $0.0454^{*}$ \\
\hline U1 - Op & $\mathrm{SNA}^{\circ}$ & 0.1156 & 105 & -0.0778 & 0.3006 & 0.2403 \\
\hline $\mathrm{U} 1-O p^{\circ}$ & $\mathrm{SNB}^{\circ}$ & -0.1188 & 105 & -0.3035 & 0.0746 & 0.2276 \\
\hline U1 - Op & $S n^{\prime}-M e^{\prime}$ & -0.0346 & 105 & -0.2248 & 0.1581 & 0.7261 \\
\hline $\mathrm{U} 1-O p^{\circ}$ & $\mathrm{SN}-\mathrm{MP}^{\circ}$ & -0.2345 & 105 & -0.4078 & -0.0448 & $0.0161 *$ \\
\hline U1 - Op & TVL-Pog' & -0.0306 & 105 & -0.2209 & 0.162 & 0.7568 \\
\hline $\mathrm{U} 1-O \mathrm{p}^{\circ}$ & $\mathrm{U} 1^{\circ}$ & 0.9242 & 105 & 0.8903 & 0.948 & $<.0001^{*}$ \\
\hline $\mathrm{U} 1^{\circ}$ & ANS-Me & -0.0289 & 105 & -0.2193 & 0.1637 & 0.7702 \\
\hline $\mathrm{U} 1^{\circ}$ & Co-Gn & -0.1447 & 105 & -0.3273 & 0.0483 & 0.1408 \\
\hline $\mathrm{U} 1^{\circ}$ & Co-Go & 0.0359 & 105 & -0.1568 & 0.226 & 0.7159 \\
\hline $\mathrm{U} 1^{\circ}$ & $\mathrm{G}^{\prime}-\mathrm{Me}^{\prime}$ & 0.1077 & 105 & -0.0858 & 0.2933 & 0.2743 \\
\hline $\mathrm{U} 1^{\circ}$ & $\mathrm{G}^{\prime}-\mathrm{Sn} \mathbf{n}^{\prime}$ & 0.2708 & 105 & 0.0834 & 0.4396 & $0.0052^{*}$ \\
\hline $\mathrm{U} 1^{\circ}$ & MP-L1 & 0.0409 & 105 & -0.152 & 0.2307 & 0.679 \\
\hline $\mathrm{U} 1^{\circ}$ & Mp-Mic & 0.0812 & 105 & -0.1122 & 0.2687 & 0.4103 \\
\hline $\mathrm{U} 1^{\circ}$ & N-ANS & 0.1663 & 105 & -0.0262 & 0.3469 & 0.09 \\
\hline $\mathrm{U} 1^{\circ}$ & $\mathrm{N}-\mathrm{Me}$ & 0.0568 & 105 & -0.1364 & 0.2457 & 0.5653 \\
\hline $\mathrm{U} 1^{\circ}$ & $O p^{\circ}$ & 0.2461 & 105 & 0.0571 & 0.418 & $0.0114^{*}$ \\
\hline $\mathrm{U} 1^{\circ}$ & PFH:AFH & -0.0504 & 105 & -0.2397 & 0.1427 & 0.6098 \\
\hline $\mathrm{U} 1^{\circ}$ & Pog'c-GALL & -0.2932 & 105 & -0.459 & -0.1075 & $0.0024^{*}$ \\
\hline $\mathrm{U} 1^{\circ}$ & Pog'-GALL & -0.2157 & 105 & -0.3912 & -0.025 & $0.0271^{*}$ \\
\hline $\mathrm{U} 1^{\circ}$ & Pog-GALL & -0.2105 & 105 & -0.3866 & -0.0196 & $0.0311 *$ \\
\hline
\end{tabular}




\begin{tabular}{|c|c|c|c|c|c|c|}
\hline $\mathrm{U} 1^{\circ}$ & PP-Mic & -0.0363 & 105 & -0.2264 & 0.1565 & 0.7132 \\
\hline $\mathrm{U} 1^{\circ}$ & PP-U1 & 0.2522 & 105 & 0.0636 & 0.4234 & $0.0094 *$ \\
\hline $\mathrm{U} 1^{\circ}$ & S-Go & 0.0441 & 105 & -0.1488 & 0.2338 & 0.6548 \\
\hline $\mathrm{U} 1^{\circ}$ & $S n^{\prime}-M e^{\prime}$ & -0.0522 & 105 & -0.2414 & 0.1409 & 0.5972 \\
\hline $\mathrm{U} 1^{\circ}$ & TVL-Pog' & -0.1907 & 105 & -0.3688 & 0.001 & 0.0514 \\
\hline V & $\mathrm{Go}^{\circ}$ & -0.2725 & 105 & -0.4411 & -0.0853 & $0.0049 *$ \\
\hline V & II Mx & -0.2381 & 105 & -0.411 & -0.0487 & $0.0144 *$ \\
\hline V & $\mathrm{ANB}^{\circ}$ & -0.1898 & 105 & -0.3681 & 0.0019 & $0.0525 *$ \\
\hline V & ANS-Me & -0.219 & 105 & -0.3941 & -0.0285 & $0.0248 *$ \\
\hline V & Co-Gn & 0.2358 & 105 & 0.0462 & 0.409 & $0.0155^{*}$ \\
\hline V & Co-Go & 0.2825 & 105 & 0.096 & 0.4498 & $0.0035 *$ \\
\hline V & G'-Me' & -0.1637 & 105 & -0.3445 & 0.0289 & 0.0952 \\
\hline V & $\mathrm{G}^{\prime}-\mathrm{Sn} \mathrm{n}^{\prime}$ & 0.0625 & 105 & -0.1308 & 0.2511 & 0.5267 \\
\hline V & $G^{\prime}-S n-P o g^{\prime \circ}$ & 0.2474 & 105 & 0.0585 & 0.4192 & $0.0109 *$ \\
\hline V & II Md & 0.0588 & 105 & -0.1344 & 0.2477 & 0.5512 \\
\hline V & IV Md Ant & -0.2052 & 105 & -0.3818 & -0.0141 & $0.0357^{*}$ \\
\hline V & IV Mx Ant & -0.1104 & 105 & -0.2958 & 0.0831 & 0.2624 \\
\hline V & L1 - Op ${ }^{\circ}$ & 0.4483 & 105 & 0.2807 & 0.5893 & $<.0001^{*}$ \\
\hline V & $\mathrm{L}^{\circ}$ & 0.5067 & 105 & 0.349 & 0.6366 & $<.0001^{*}$ \\
\hline V & $\mathrm{MP}^{\circ}$ & -0.5158 & 105 & -0.6438 & -0.3597 & $<.0001^{*}$ \\
\hline V & MP-L1 & 0.0615 & 105 & -0.1317 & 0.2502 & 0.5331 \\
\hline V & Mp-Mic & -0.2872 & 105 & -0.4539 & -0.1011 & $0.003 *$ \\
\hline V & N-ANS & -0.0083 & 105 & -0.1996 & 0.1837 & 0.9333 \\
\hline V & $\mathrm{N}-\mathrm{Me}$ & -0.1756 & 105 & -0.3553 & 0.0166 & 0.0731 \\
\hline V & $O p^{\circ}$ & -0.1767 & 105 & -0.3563 & 0.0155 & 0.0714 \\
\hline V & $\mathrm{Op}-\mathrm{Sn}^{\circ}$ & -0.2483 & 105 & -0.4199 & -0.0594 & $0.0107^{*}$ \\
\hline V & PFH:AFH & 0.4301 & 105 & 0.2599 & 0.5744 & $<.0001^{*}$ \\
\hline V & Pog'c-GALL & -0.0291 & 105 & -0.2195 & 0.1635 & 0.7684 \\
\hline V & Pog'-GALL & 0.3203 & 105 & 0.1371 & 0.4824 & $0.0009 *$ \\
\hline V & Pog-GALL & 0.2731 & 105 & 0.0859 & 0.4416 & $0.0048 *$ \\
\hline V & $\mathrm{PP}^{\circ}$ & 0.1113 & 105 & -0.0821 & 0.2966 & 0.2583 \\
\hline V & PP-Mic & -0.136 & 105 & -0.3194 & 0.0571 & 0.1664 \\
\hline V & PP-U1 & -0.2094 & 105 & -0.3856 & -0.0185 & $0.032 *$ \\
\hline V & S-Go & 0.2456 & 105 & 0.0566 & 0.4176 & $0.0116^{*}$ \\
\hline V & $\mathrm{Sn}^{\circ}$ & -0.2032 & 105 & -0.3801 & -0.012 & $0.0376^{*}$ \\
\hline V & SNA $^{\circ}$ & 0.0962 & 105 & -0.0973 & 0.2826 & 0.329 \\
\hline V & $\mathrm{SNB}^{\circ}$ & 0.2207 & 105 & 0.0303 & 0.3956 & $0.0237^{*}$ \\
\hline V & Sn'-Me' & -0.2639 & 105 & -0.4336 & -0.076 & $0.0065 *$ \\
\hline V & SN-MP & -0.5415 & 105 & -0.6642 & -0.3904 & $<.0001^{*}$ \\
\hline V & TVL-Pog' & 0.3251 & 105 & 0.1423 & 0.4864 & $0.0007^{*}$ \\
\hline V & U1 - Op & 0.2521 & 105 & 0.0635 & 0.4233 & $0.0095 *$ \\
\hline V & $\mathrm{U} 1^{\circ}$ & 0.1787 & 105 & -0.0134 & 0.3581 & 0.0681 \\
\hline
\end{tabular}




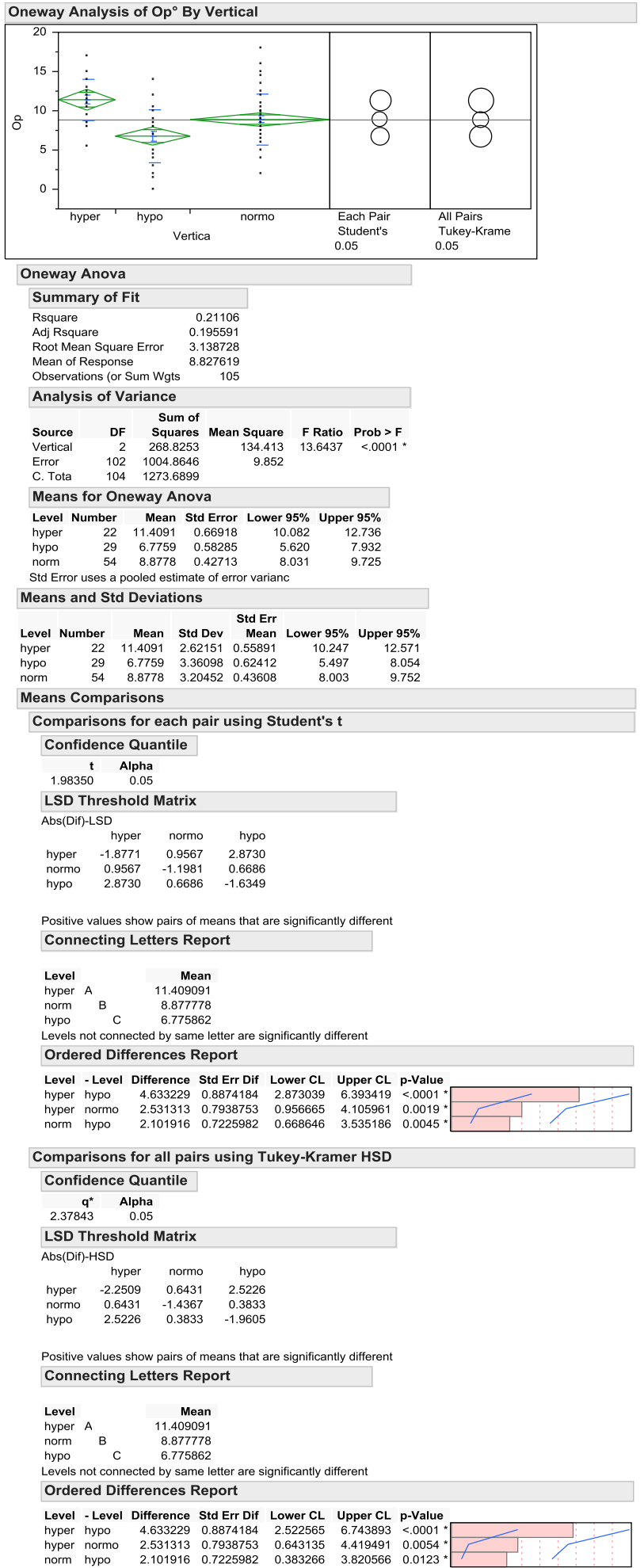

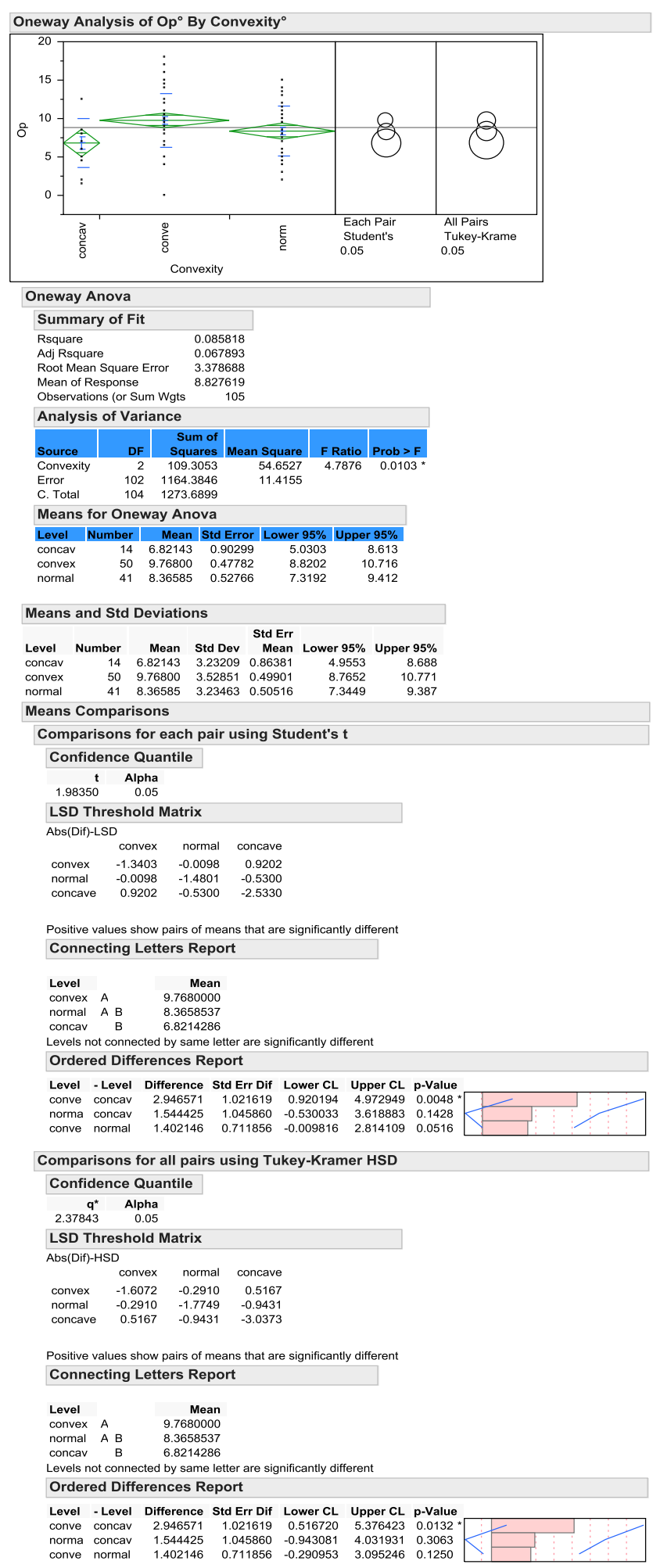




\section{Oneway Analysis of Op By Category}

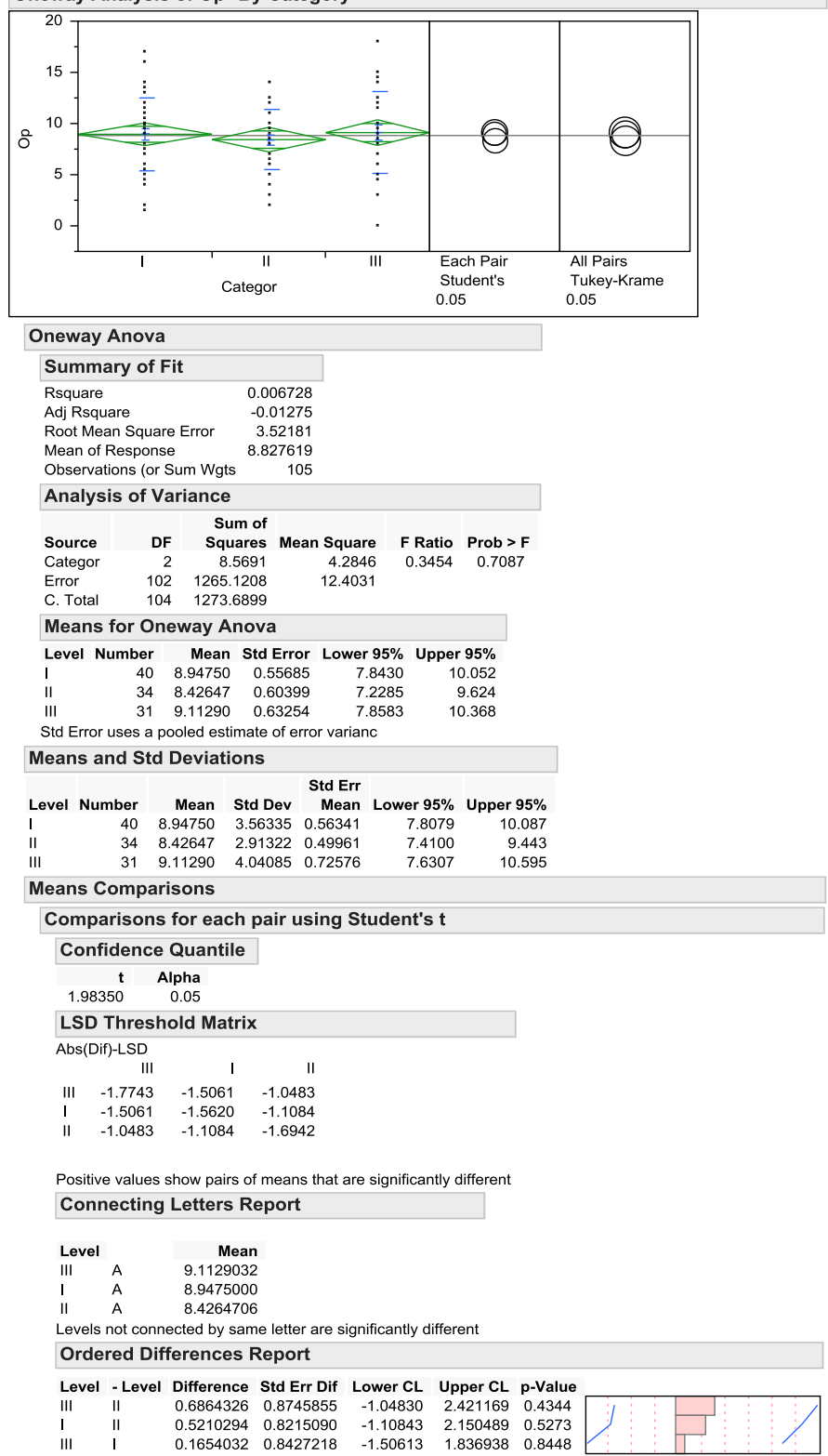

$\begin{array}{llllll}0.5210294 & 0.8215090 & -1.10843 & 2.150489 & 0.5273 \\ 0.1654032 & 0.8427218 & -1.50613 & 1.836938 & 0.8448\end{array}$

Comparisons for all pairs using Tukey-Kramer HSD

Confidence Quantile

$\begin{array}{rr}\mathbf{q}^{*} & \text { Alpha } \\ 2.37843 & 0.05\end{array}$

LSD Threshold Matrix

Abs(Dif)-HSD

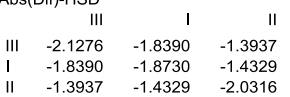

Positive values show pairs of means that are significantly differen

Connecting Letters Report

$\begin{array}{lrr}\text { Level } & & \text { Mean } \\ \text { III } & \text { A } & 9.1129032 \\ \text { I } & \text { A } & 8.9475000 \\ \text { II } & \text { A } & 8.4264706\end{array}$

Levels not connected by same letter are significantly different

Ordered Differences Report

Level - Level Difference Std Err Dif Lower CL Upper CL p-Value

$\begin{array}{llllllll}\text { III II } & 0.6864326 & 0.8745855 & -1.39371 & 2.766574 & 0.7132 \\ \text { I } & \text { II } & 0.5210294 & 0.8215090 & -1.43287 & 2.474932 & 0.8016 \\ & \text { II } & & 0.165432 & 0.84278 & -1.8385 & 2.959 & 0.9790\end{array}$

$\begin{array}{llllllll}\text { I } & \text { II } & 0.5210294 & 0.8215090 & -1.43287 & 2.474932 & 0.8016 \\ \text { III } & \text { I } & & 0.1654032 & 0.8427218 & -1.83895 & 2.169759 & 0.9790\end{array}$
Oneway Analysis of $O p^{\circ}$ By Skeletal CLASS

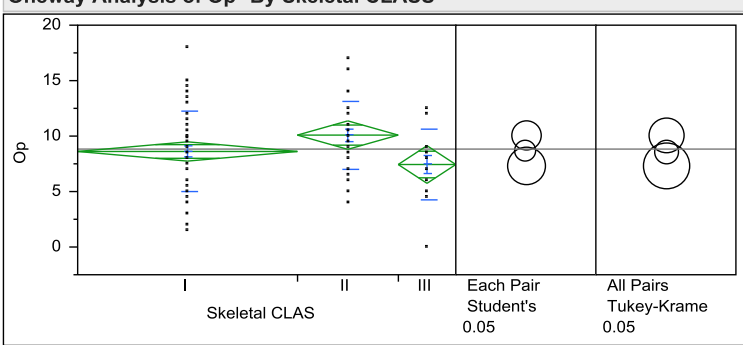

Oneway Anova

Summary of Fit

Rsquare

Root Mean Square Error $\quad 3.423382$

\begin{tabular}{lr} 
Mean of Response & 8.827619 \\
\hline
\end{tabular}

Analysis of Variance

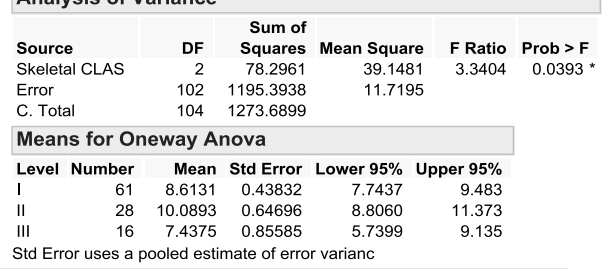

Means and Std Deviations

Level Number Mean Std Dev $\begin{gathered}\text { Std Err } \\ \text { Mean Lower 95\% Upper 95\% }\end{gathered}$

\begin{tabular}{rrrrrrr}
61 & 8.6131 & 3.62843 & 0.46457 & 7.6838 & 9.542 \\
\hline & 18 & 10.0893 & 3.04611 & 0.57566 & 8.981 & 11.270
\end{tabular}

$\begin{array}{lrrrrrr}\text { II } & 28 & 10.0893 & 3.04611 & 0.57566 & 8.9081 & 11.270 \\ \text { III } & 16 & 7.4375 & 3.21390 & 0.80348 & 5.7249 & 9.150\end{array}$

Means Comparisons

Comparisons for each pair using Student's t

Confidence Quantile

$\begin{array}{rr}\mathbf{t} & \text { Alpha } \\ 1.98350 & 0.05\end{array}$

LSD Threshold Matrix

Abs(Dif)-LSD

$\begin{array}{rrrr}\text { II } & -1.8148 & -0.0739 & 0.5238\end{array}$

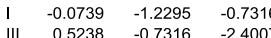

Positive values show pairs of means that are significantly different

Connecting Letters Report

\begin{tabular}{llr} 
Level & Mean \\
II A & 10.089286 \\
\hline & A B & 8.613115
\end{tabular}

$\begin{array}{rrr}\text { I } & \text { A B } & 8.613115 \\ \text { III } & \text { B } & 7.437500\end{array}$

Levels not connected by same letter are significantly different

Ordered Differences Report

Level - Level Difference Std Err Dif Lower CL Upper CL p-Value

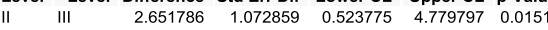

$\begin{array}{lllllll}\text { III } & 1.476171 & 0.781460 & -0.073850 & 3.026192 & 0.0617 \\ \text { III } & 1.175615 & 0.961559 & -0.731633 & 3.082862 & 0.2243\end{array}$

Comparisons for all pairs using Tukey-Kramer HSD

Confidence Quantile

$\begin{array}{rr}\mathbf{q}^{*} & \text { Alpha } \\ 2.37843 & 0.05\end{array}$

LSD Threshold Matrix

Abs(Dif)-HSD

$\begin{array}{lrrr} & \text { II } & \text { I } & \text { II } \\ \text { II } & -2.1761 & -0.3825 & 0.1001\end{array}$

I $\quad-0.3825$

Positive values show pairs of means that are significantly different

Connecting Letters Report

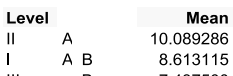

Levels not connected by same letter are significantly different

Ordered Differences Report

Level - Level Difference Std Err Dif Lower CL Upper CL p-Value

$\begin{array}{llllllll}\text { II III } & 2.651786 & 1.072859 & 0.10006 & 5.203508 & 0.0397 \\ & \text { II } & 1.476171 & 0.7846 & -0.3828 & 3.334819 & 0.1471\end{array}$

$\begin{array}{lllllll}\text { II III } & 1.476171 & 0.781460 & -0.38248 & 3.334819 & 0.1471 \\ \text { | } & 1.175615 & 0.961559 & -1.11139 & 3.462616 & 0.4426\end{array}$

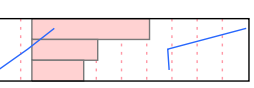


Stepwise Regression Analysis

Stepwise Fit for $\mathrm{Op}^{\circ}$

Stepwise Regression Control

\author{
Prob to $\quad 0.05$ \\ Enter \\ Prob to 0.05 \\ Leave \\ Direction: Mixed
}

\title{
Current Estimates
}

\section{Entere Parameter}

d

\section{Estimate}

$\mathrm{X}$

Intercept
PFH:AFH
N-ANS
ANS-Me
G'-Sn' $^{\prime}$ Sn'-Me' $^{\prime}$
Co-Go
S-Go
PP-1
PP-MiC
Mp-MiC
MP-L1
Pog'-GALL
Pog-GALL
Pog'-TVL
Pog' C-GALL
$1^{\circ}$
$\bar{I}^{\circ}$
$1^{\circ}-\bar{I}^{\circ}$
Go $^{\circ}$
$G^{\prime}-S n-$
Pog'
MP $^{\circ}$
SNA $^{\circ}$
SNB $^{\circ}$
SN-MP $^{\circ}$
PP $^{\circ}$

II $\mathrm{Mx}$

5.23289944

0

0

0

0

0.2078999

0

0.48704104

$-0.5411415$

0.27989329

\section{"F
Ratio"}

0.000

0.378

0.026

1.897

0.881

9.918

0.028

1.646

17.608

19.868

10.947

0.003

0.070

0.154

0.440

1.097

0.673

0.928

1.131

0.377

0.747

"Prob>F"

\section{"Prob>}

0.5403

0.87262

0.17173

0.35033

0.00219

0.86717

0.20272

$6.15 e-5$

$2.29 e-5$

0.00133

0.95966

0.79188

0.69582

0.50858

0.29755

0.41424

0.33787

0.29028

0.54058

0.3897

2.535

0.11476

0.034

0.85321

0.41

0.27761029

0.685

$2.6 e-11$

0.61557339

57.183

2. $4 \mathrm{e}-10$

50.358

0.514

0.47518 


$\begin{array}{llrrr}\begin{array}{l}\text { Entere } \\ \text { d }\end{array} & \text { Parameter } & \text { Estimate } & \begin{array}{r}\text { "F } \\ \text { Ratio" }\end{array} & \text { "Prob>F" } \\ & \text { II Md } & 0 & 3.228 & 0.07562 \\ \text { X } & \text { IV MX Ant } & 0.21578033 & 4.069 & 0.04653 \\ \text { X } & \text { IV Md Ant } & -0.6848812 & 40.189 & 7.95 e-9 \\ \text { X } & \text { Sn } & -0.2232288 & 9.109 & 0.00327 \\ \text { X } & \text { Co-Gn } & -0.03727 & 4.031 & 0.04754\end{array}$

$\begin{array}{rllrr}\begin{array}{r}\text { Step History } \\ \text { Step }\end{array} & \begin{array}{l}\text { Parameter } \\ \text { Action }\end{array} & \text { "Sig Prob" } & \text { RSquare } \\ 1 & \text { SN-MP } & \begin{array}{l}\text { Entere } \\ \text { d }\end{array} & 0.0000 & 0.2302 \\ 2 & \text { PP }^{\circ} & \begin{array}{l}\text { Entere } \\ \text { d }\end{array} & 0.0000 & 0.4133 \\ 3 & \text { IV Md Ant } & \begin{array}{l}\text { Entere } \\ \text { d }\end{array} & 0.0000 & 0.5191 \\ 4 & \text { Mp-Mic } & \begin{array}{l}\text { Entere } \\ \text { d }\end{array} & 0.0000 & 0.6399 \\ 5 & \text { PP-1 } & \begin{array}{l}\text { Entere } \\ \text { d }\end{array} & 0.0002 & 0.6868 \\ 6 & \text { Sn } & \begin{array}{l}\text { Entere } \\ \text { d }\end{array} & 0.0030 & 0.7138 \\ 7 & \text { PP-MiC } & \begin{array}{l}\text { Entere } \\ \text { d }\end{array} & 0.0032 & 0.7384 \\ 8 & \text { Sn'-Me' } & \begin{array}{l}\text { Entere } \\ \text { d }\end{array} & 0.0067 & 0.7578 \\ 9 & \text { IV Mx Ant } & \begin{array}{l}\text { Entere } \\ \text { d }\end{array} & 0.0226 & 0.7707 \\ 10 & \text { Co-Gn } & \begin{array}{l}\text { Entere } \\ \text { d }\end{array} & 0.0475 & 0.7802 \\ & & & & \end{array}$

Response $\mathrm{Op}^{\circ}$

Summary of Fit

$\begin{array}{lr}\text { RSquare } & 0.780168 \\ \text { RSquare Adj } & 0.756781 \\ \text { Root Mean Square Error } & 1.725892 \\ \text { Mean of Response } & 8.827619 \\ \text { Observations (or Sum } & 105\end{array}$

Wgts )

Analysis of Variance

$\begin{array}{llrrr}\text { Source } & \text { DF } & \begin{array}{r}\text { Sum of } \\ \text { Squares }\end{array} & \begin{array}{r}\text { Mean } \\ \text { Square }\end{array} & \text { F Ratio } \\ \text { Model } & 10 & 993.6918 & 99.3692 & 33.3599\end{array}$




$\begin{array}{lrrrr}\text { Source } & \text { DF } & \begin{array}{r}\text { Sum of } \\ \text { Squares }\end{array} & \begin{array}{r}\text { Mean } \\ \text { Square }\end{array} & \text { F Ratio } \\ \text { Error } & 94 & 279.9981 & 2.9787 & \text { Prob > F } \\ \text { C. } & 104 & 1273.6899 & & <.0001^{*} \\ \text { Total } & & & & \end{array}$

\begin{tabular}{|c|c|c|c|c|}
\hline Term & Estimate & Std Error & t Ratio & Prob $>|t|$ \\
\hline $\begin{array}{l}\text { Intercep } \\
t\end{array}$ & 5.2328994 & 2.574106 & 2.03 & $0.0449 *$ \\
\hline $\mathrm{Sn}{ }^{\prime}-\mathrm{Me} e^{\prime}$ & 0.2078999 & 0.066015 & 3.15 & $0.0022 *$ \\
\hline $\mathrm{PP}-1$ & 0.487041 & 0.116068 & 4.20 & $<.0001 *$ \\
\hline PP-MiC & -0.541141 & 0.121405 & -4.46 & $<.0001 *$ \\
\hline $\mathrm{Mp}-\mathrm{MiC}$ & 0.2798933 & 0.084594 & 3.31 & $0.0013 *$ \\
\hline $\mathrm{SN}-\mathrm{MP}$ & 0.2776103 & 0.036712 & 7.56 & $<.0001 *$ \\
\hline $\mathrm{PP}^{\circ}$ & 0.6155734 & 0.086746 & 7.10 & $<.0001 *$ \\
\hline $\begin{array}{l}\text { IV Mx } \\
\text { Ant }\end{array}$ & 0.2157803 & 0.106973 & 2.02 & $0.0465 *$ \\
\hline $\begin{array}{l}\text { IV } \mathrm{Md} \\
\text { Ant }\end{array}$ & -0.684881 & 0.108034 & -6.34 & $<.0001^{\star}$ \\
\hline $\mathrm{Sn}$ & -0.223229 & 0.073964 & -3.02 & $0.0033 *$ \\
\hline $\mathrm{Co}-\mathrm{Gn}$ & -0.03727 & 0.018563 & -2.01 & $0.0475 *$ \\
\hline
\end{tabular}

$\begin{array}{lrrrr}\text { Sorted } & \text { Parameter Estimates } & \\ \text { Term } & \text { Estimate } & \text { Std Error } & \text { t Ratio } & \text { Prob |t| } \\ \text { SN-MP } & 0.2776103 & 0.036712 & 7.56 & <.0001^{*} \\ \text { PP } & 0.6155734 & 0.086746 & 7.10 & <.0001^{*} \\ \text { IV Md } & -0.684881 & 0.108034 & -6.34 & <.0001^{*} \\ \text { Ant } & & & & \\ \text { PP-Mic } & -0.541141 & 0.121405 & -4.46 & <.0001^{*} \\ \text { PP-1 } & 0.487041 & 0.116068 & 4.20 & <.0001^{*} \\ \text { Mp-Mic } & 0.2798933 & 0.084594 & 3.31 & 0.0013^{*} \\ \text { Sn'-Me' } & 0.2078999 & 0.066015 & 3.15 & 0.0022^{*} \\ \text { Sn } & -0.223229 & 0.073964 & -3.02 & 0.0033^{*} \\ \text { IV Mx } & 0.2157803 & 0.106973 & 2.02 & 0.0465^{*} \\ \text { Ant } & & & & \\ \text { Co-Gn } & -0.03727 & 0.018563 & -2.01 & 0.0475^{*}\end{array}$




\section{Statistical Analyses: Pogonion Prominence Measurements}

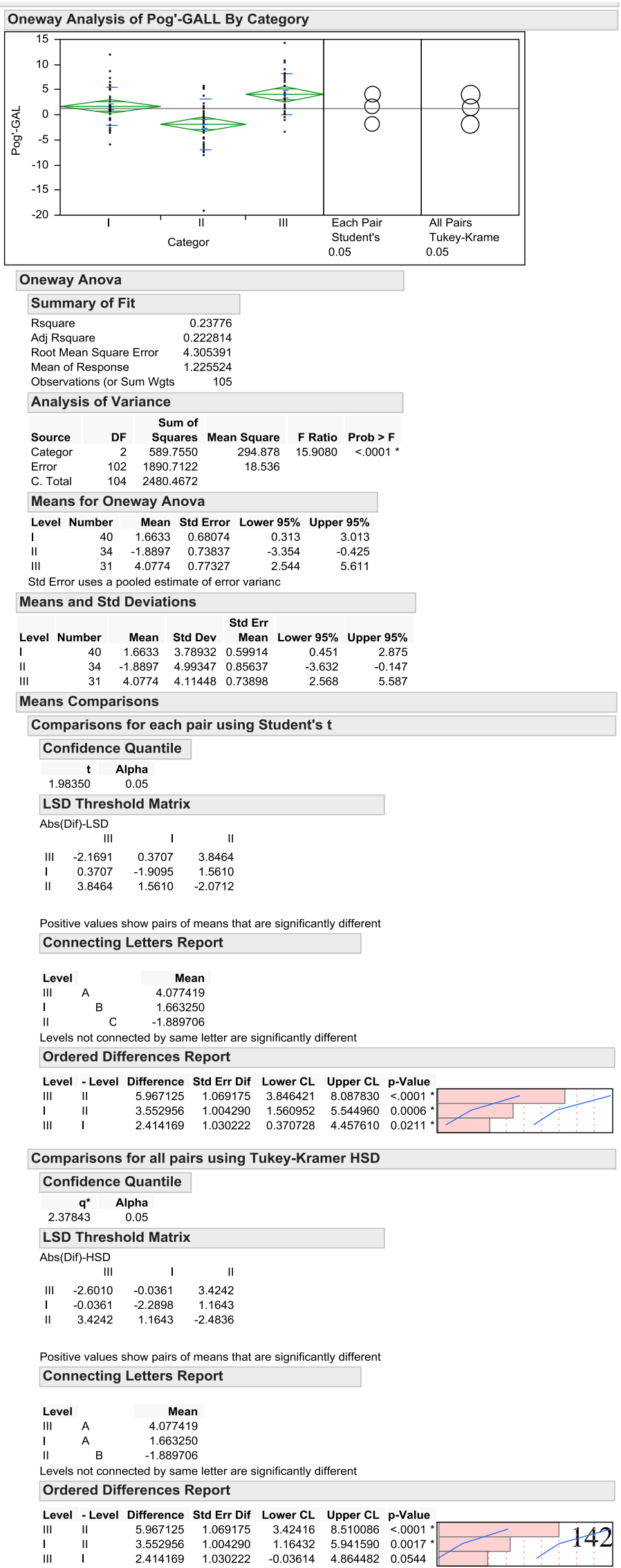

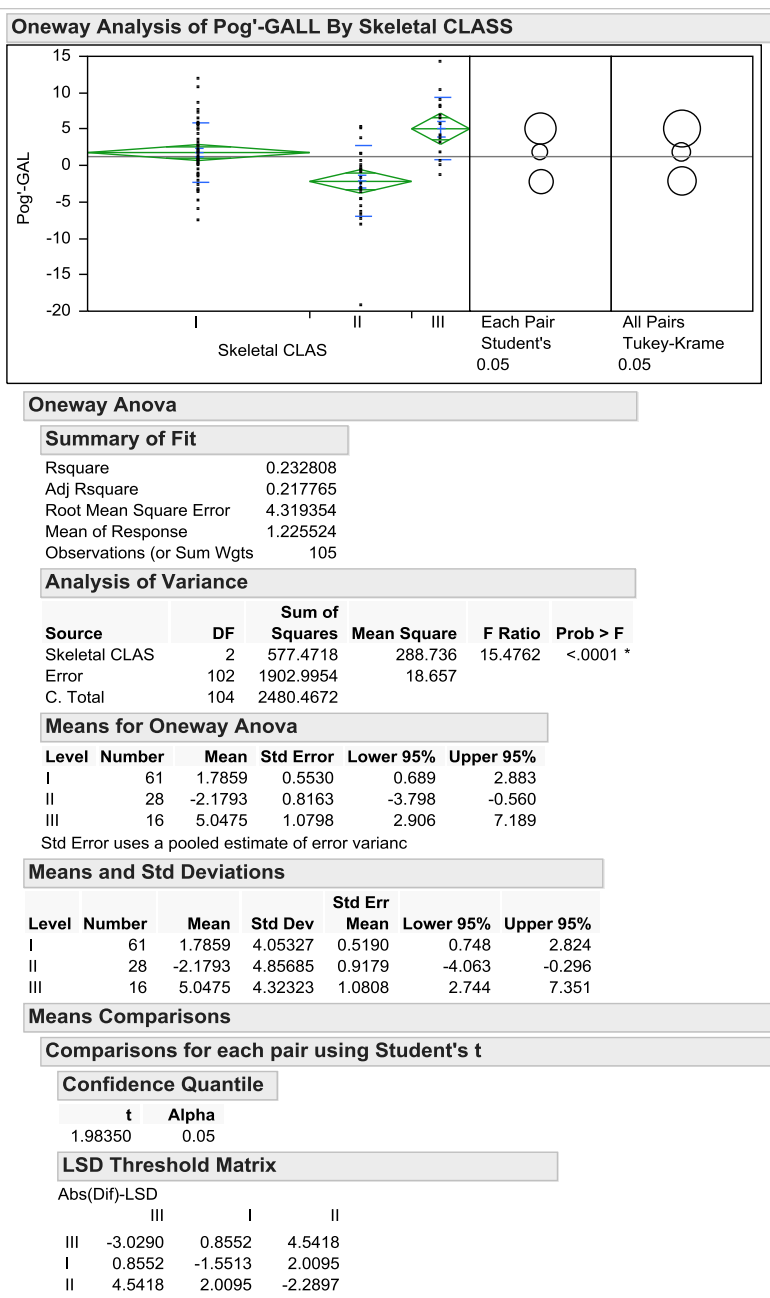

Positive values show pairs of means that are significantly different Connecting Letters Report

\begin{tabular}{lrrrr} 
Level & & & \multicolumn{1}{c}{ Mean } \\
III & & & 5.047500 \\
II & B & 1.785902 \\
II & C & -2.179286 \\
Levels not connected by same letter are significantly different
\end{tabular}

Ordered Differences Report

Level - Level Difference Std Err Dif Lower CL Upper CL p-Value

$\begin{array}{lllllll}\text { III II } & 7.226786 & 1.353649 & 4.541829 & 9.911742 & <.0001 \\ \text { I } & 3.965187 & 0.985984 & 2.009493 & 5.920882 & 0.0001\end{array}$

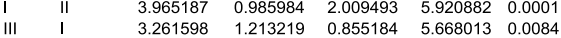

Comparisons for all pairs using Tukey-Kramer HSD Confidence Quantile

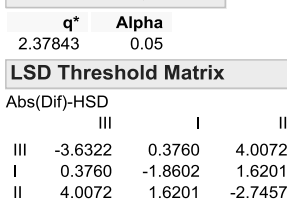

Positive values show pairs of means that are significantly different Connecting Letters Report

\begin{tabular}{lrrrr} 
Level & & \multicolumn{1}{c}{$\begin{array}{c}\text { Mean } \\
\text { III }\end{array}$ A } & 5.047500 \\
II & B & 1.785902 \\
II & C & -2.179286 \\
Levels not connected by same letter are significantly different
\end{tabular}

Ordered Differences Report

Level - Level Difference Std Err Dif Lower CL Upper CL p-Value

$\begin{array}{lllllll}\text { III } & \text { II } & 7.226786 & 1.353649 & 4.007224 & 10.44635 & <.0001\end{array}$

$\begin{array}{lllllll}\text { I I } & 3.965187 & 0.985984 & 1.620092 & 6.31028 & 0.0003 *\end{array}$ 
Fit $Y$ by $X$ Group
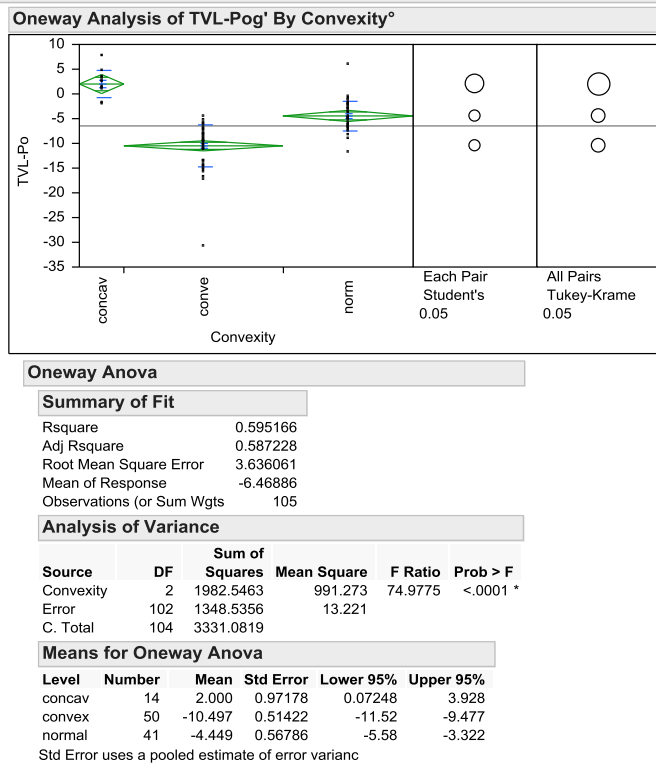

$\begin{array}{llll}\text { normal } & 41 & -4.449 & 0.56786 \\ \text { Std Error uses a pooled estimate of error varianc }\end{array}$

Means and Std Deviations

\begin{tabular}{lrrrrrr} 
& \multicolumn{7}{c}{ Std Err } \\
Level & Number & Mean & Std Dev & Mean Lower 95\% & Upper 95\% \\
concav & 14 & 2.000 & 2.68451 & 0.71747 & 0.45 & 3.550 \\
convex & 50 & -10.497 & 4.25328 & 0.60150 & -11.71 & -9.288 \\
normal & 41 & -4.449 & 3.03488 & 0.47397 & -5.41 & -3.491
\end{tabular}

Means Comparisons

Comparisons for each pair using Student's t

Confidence Quantile

$\begin{array}{rr}\mathbf{t} & \text { Alpha } \\ 1.98350 & 0.05\end{array}$

LSD Threshold Matrix

Abs(Dif)-LSD

$\begin{array}{lrrr} & \text { concave normal convex } \\ \text { concave } & -2.726 & 4.216 & 10.316\end{array}$

$\begin{array}{lrrr}\text { concave } & -2.726 & 4.216 & 10.316 \\ \text { normal } & 4.216 & -1.593 & 4.528 \\ \text { convex } & 10.316 & 4.528 & -1.442\end{array}$

Positive values show pairs of means that are significantly different

Connecting Letters Report

Level

$\begin{array}{lrr}\text { normal } & \text { B } & -4.44878 \\ \text { convex } & \text { C } & -10.49660\end{array}$

Levels not connected by same letter are significantly differen

Ordered Differences Report

Level - Level Difference Std Err Dif Lower CL Upper CL $p$-Value

\begin{tabular}{rrrrrrr} 
concav & convex & 12.49660 & 1.099441 & 10.31586 & 14.67734 & $<.0101$ \\
concav normal & 6.44878 & 1.125529 & 421630 & 8.68126 & $<0001$ \\
\hline
\end{tabular}

normal convex $\quad 6.04782 \quad 0.766081 \quad 4.52830 \quad 7.56734<0.0001$.

Comparisons for all pairs using Tukey-Kramer HSD

Confidence Quantile

$\begin{array}{rr}\mathbf{q}^{*} & \text { Alpha } \\ 2.37843 & 0.05\end{array}$

LSD Threshold Matrix

Abs(Dif)-HSD

$\begin{array}{lrrr} & \text { concave } & \text { normal } & \text { convex } \\ \text { concave } & -3.2687 & 3.7718 & 9.8817\end{array}$

\begin{tabular}{ll|l|l|l} 
normal & 3.7718 & -1.9101 & 4.2257 \\
\hline convex & 9.817 & 4.257 & -1.7296
\end{tabular}

Positive values show pairs of means that are significantly differen

Connecting Letters Report

Level

Mean
2.00000

$\begin{array}{lrr}\text { concav A } & & 2.00000 \\ \text { normal } & \text { B } & -4.44878 \\ \text { convex } & \text { C } & -10.49660\end{array}$

Levels not connected by same letter

Ordered Differences Report

(a) different

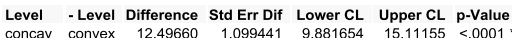

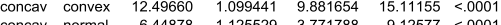

$\begin{array}{lllllll}\text { normal convex } & 6.04782 & 0.766081 & 4.225748 & 7.86989 & <.0001\end{array}$
Oneway Analysis of TVL-Pog' By Skeletal CLASS

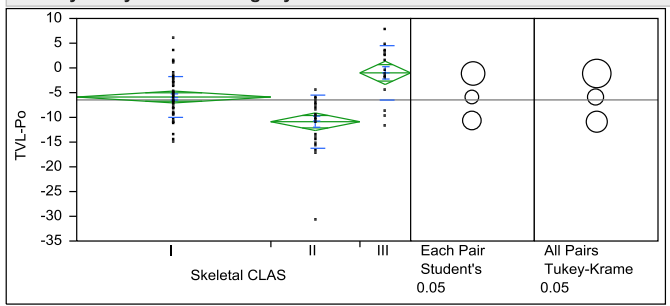

Oneway Anova

Summary of Fit

$\begin{array}{ll}\text { Rsquare } & 0.313088 \\ \text { Adj Rsquare } & 0.299619\end{array}$

Root Mean Square Error $\quad 4.736344$

$\begin{array}{lr}\text { Mean of Response } & -6.46886 \\ \text { Observations (or Sum Wgts } & 105\end{array}$

Analysis of Variance

$\begin{array}{lrrrrr}\text { Source } & \text { DF } & \begin{array}{r}\text { Sum of } \\ \text { Squares }\end{array} & \text { Mean Square } & \text { F Ratio } & \text { Prob }>\text { F } \\ \text { Skeletal CLAS } & 2 & 1042.9203 & 521.460 & 23.2453 & <.0001 \text { * }\end{array}$

$\begin{array}{lrrrrr}\text { Skeletal CLAS } & 2 & 1042.9203 & 521.460 & 23.2453 & <.0001 \\ \text { Error } & 102 & 2288.1616 & 22.433 & & \end{array}$

Means for Oneway Anova

Level Number Mean Std Error Lower 95\% Upper 95\%

$\begin{array}{rr}-7.08 & -4.679 \\ -12.65 & -9.098\end{array}$

$\begin{array}{lrrrrr}\text { II } & 28 & -10.874 & 0.8951 & -12.65 & -9.098 \\ \text { III } & 16 & -0.999 & 1.1841 & -3.35 & 1.349\end{array}$

Std Error uses a pooled estimate of error varianc

Means and Std Deviations

\begin{tabular}{llll} 
& \multicolumn{3}{c}{ Std Err } \\
Level Number Mean Std Dev & Mean Lower 95\% Upper 95\%
\end{tabular}

$\begin{array}{lrrrrrr}\text { Level } & \text { Number } & \text { Mean } & \text { Std Dev } & \text { Mean } & \text { Lower 95\% } & \text { Upper 95\% } \\ \text { I } & 61 & -5.882 & 4.23046 & 0.5417 & -6.97 & -4.798 \\ \text { II } & 28 & -10.874 & 5.33735 & 1.0087 & -12.94 & -8.804 \\ \text { III } & 16 & -0.999 & 5.44793 & 1.3620 & -3.90 & 1.904\end{array}$

Means Comparisons

Comparisons for each pair using Student's t

Confidence Quantile

$\begin{array}{rr}\mathbf{t} & \text { Alpha } \\ 1.98350 & 0.05\end{array}$

LSD Threshold Matrix

Abs(Dif)-LSD

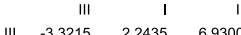

$\begin{array}{rrrr}\text { IIII } & -3.3215 & 2.2435 & 6.9300 \\ \text { II } & 2.2435 & -1.7011 & 2.8474 \\ \text { II } & 6.9300 & 2.8474 & -2.5108\end{array}$

Positive values show pairs of means that are significantly differen

Connecting Letters Report

$\begin{array}{llr}\text { Level } & & \text { Mean } \\ \text { III } & \text { A } & -0.99938 \\ \text { I } & \text { B } & -5.88164\end{array}$

II $\quad \begin{array}{rr}-5.88164 \\ \quad \text { C } & -10.87357\end{array}$

are significantly differen

Ordered Differences Report

Level - Level Difference Std Err Dif Lower CL Upper CL $p$-Value

$\begin{array}{lllllll}\text { III I } & \quad & 4.991932 & 1.081171 & 2.847435 & 7.13643 & <.0001 \\ & & 4.882264 & 1.330343 & 2.243535 & 7.52099 & 0.0004\end{array}$

Comparisons for all pairs using Tukey-Kramer HSD

Confidence Quantile

$\begin{array}{rr}q^{*} & \text { Alpha } \\ 2.37843 & 0.05\end{array}$

LSD Threshold Matrix

Abs(Dif)-HSD

$\begin{array}{lll}211 & \text { III }\end{array}$

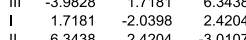

Positive values show pairs of means that are significantly different Connecting Letters Report

$$
\begin{array}{lrrr}
\text { Level } & & & \text { Mean } \\
\text { III } & & \begin{array}{r}
r \\
\text { I }
\end{array} & -0.99938 \\
\text { I } & \text { B } & -5.88164 \\
\text { II } & \text { C } & -10.87357 \\
\text { Levels not connected by same le }
\end{array}
$$

Levels not connected by same letter are significantly different

Ordered Differences Report

Level - Level Difference Std Err Dif Lower CL Upper CL p-Value

III II $\quad \begin{array}{lllllll}9.874196 & 1.484330 & 6.343818 & 13.40457 & <.0001 \text { * }\end{array}$

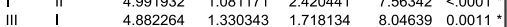




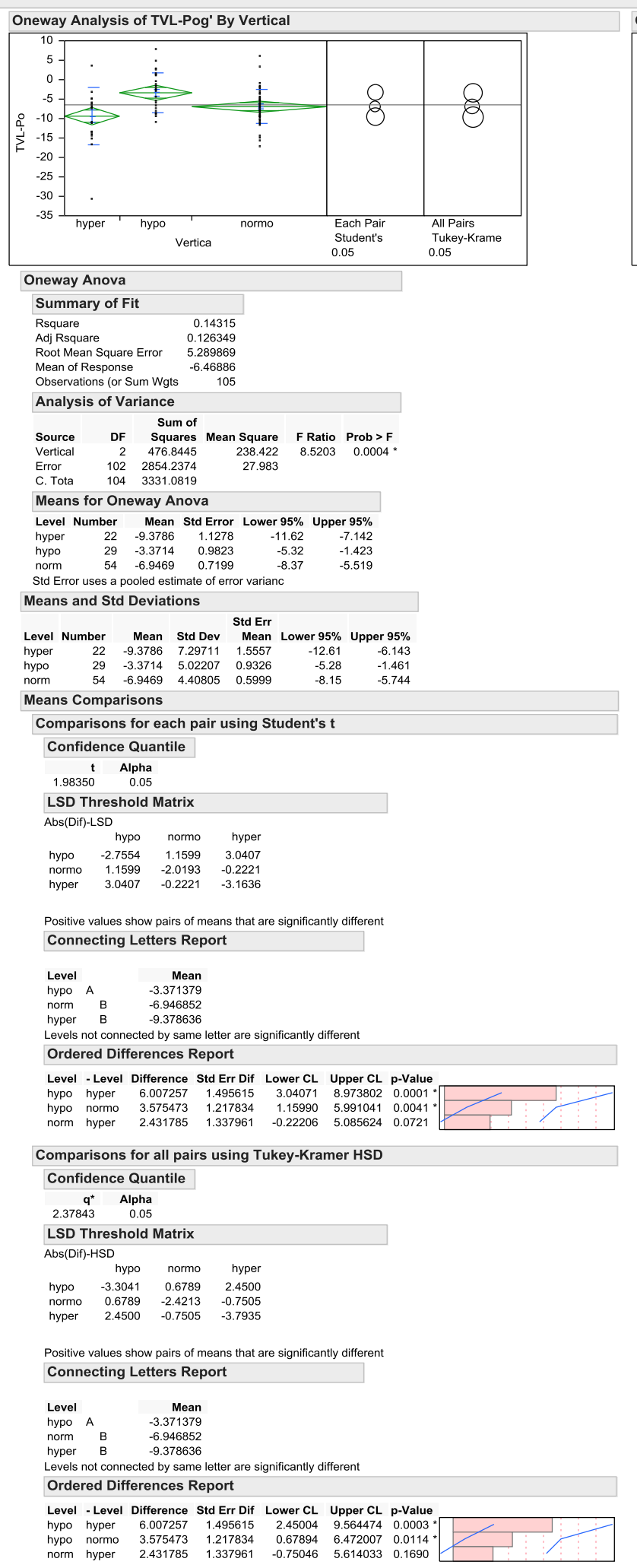

\section{Oneway Analysis of TVL-Pog' By Category}
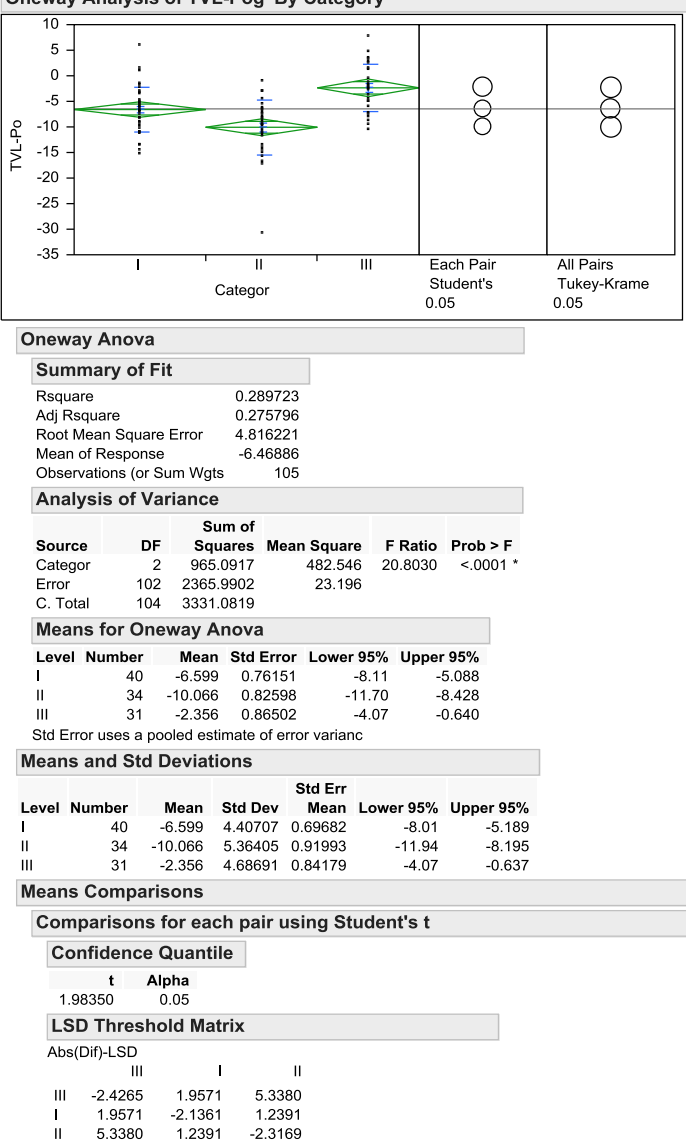

Positive values show pairs of means that are significantly different Connecting Letters Report

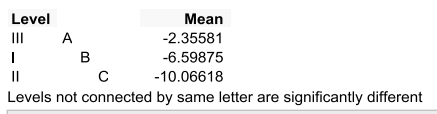

Ordered Differences Report

$\begin{array}{llrrrr}\text { Level } & \text { - Level Difference } & \text { Std Err Dif } & \text { Lower } \mathrm{CL} & \text { Upper } \mathrm{CL} & \mathrm{p} \text {-Value } \\ \text { III II } & 7.710370 & 1.196032 & 5.338046 & 10.08269 & <.0001 * \\ \text { III II } & 4.242944 & 1.152457 & 1.957051 & 6.52884 & 0.0004\end{array}$

Comparisons for all pairs using Tukey-Kramer HSD

Confidence Quantile

$\begin{array}{rr}\mathbf{q}^{*} & \text { Alpha } \\ 2.37843 & 0.05\end{array}$

LSD Threshold Matrix

Abs(Dif)-HSD

111

$\begin{array}{rrrr}\text { III } & -2.9096 & 1.5019 & 4.8657 \\ \text { I } & 1.5019 & -2.5614 & 0.7954\end{array}$

II $\quad \begin{array}{rrr}1.8619 & -2.5614 & 0.7954 \\ & 0.7954 & -2.7783\end{array}$

Positive values show pairs of means that are significantly different

Connecting Letters Report

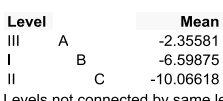

Levels not connected by same letter are significantly different

Ordered Differences Report

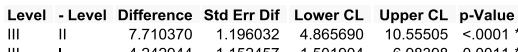

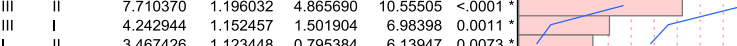




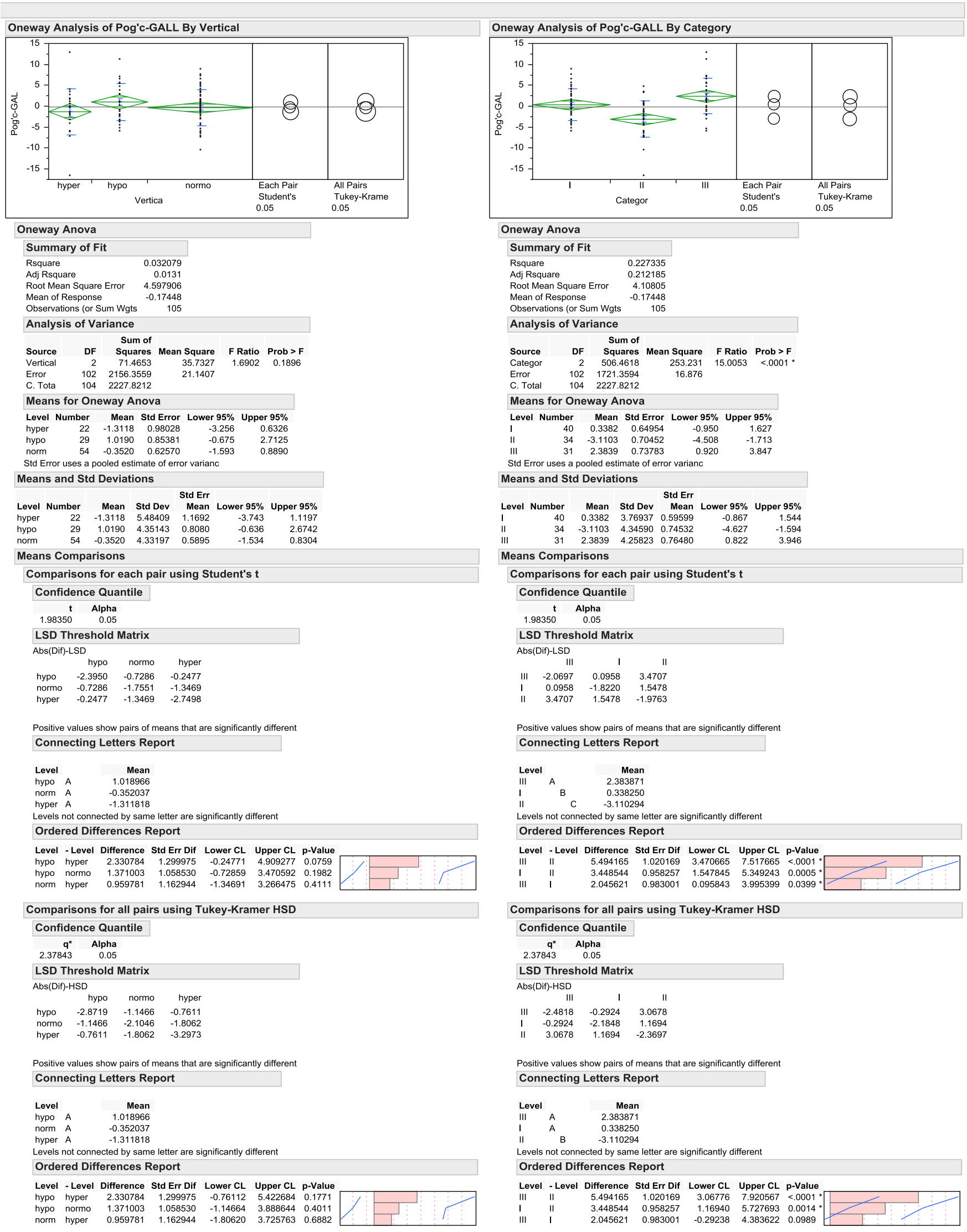


Fit $Y$ by $X$ Group

Oneway Analysis of Pog'c-GALL By Convexity ${ }^{\circ}$

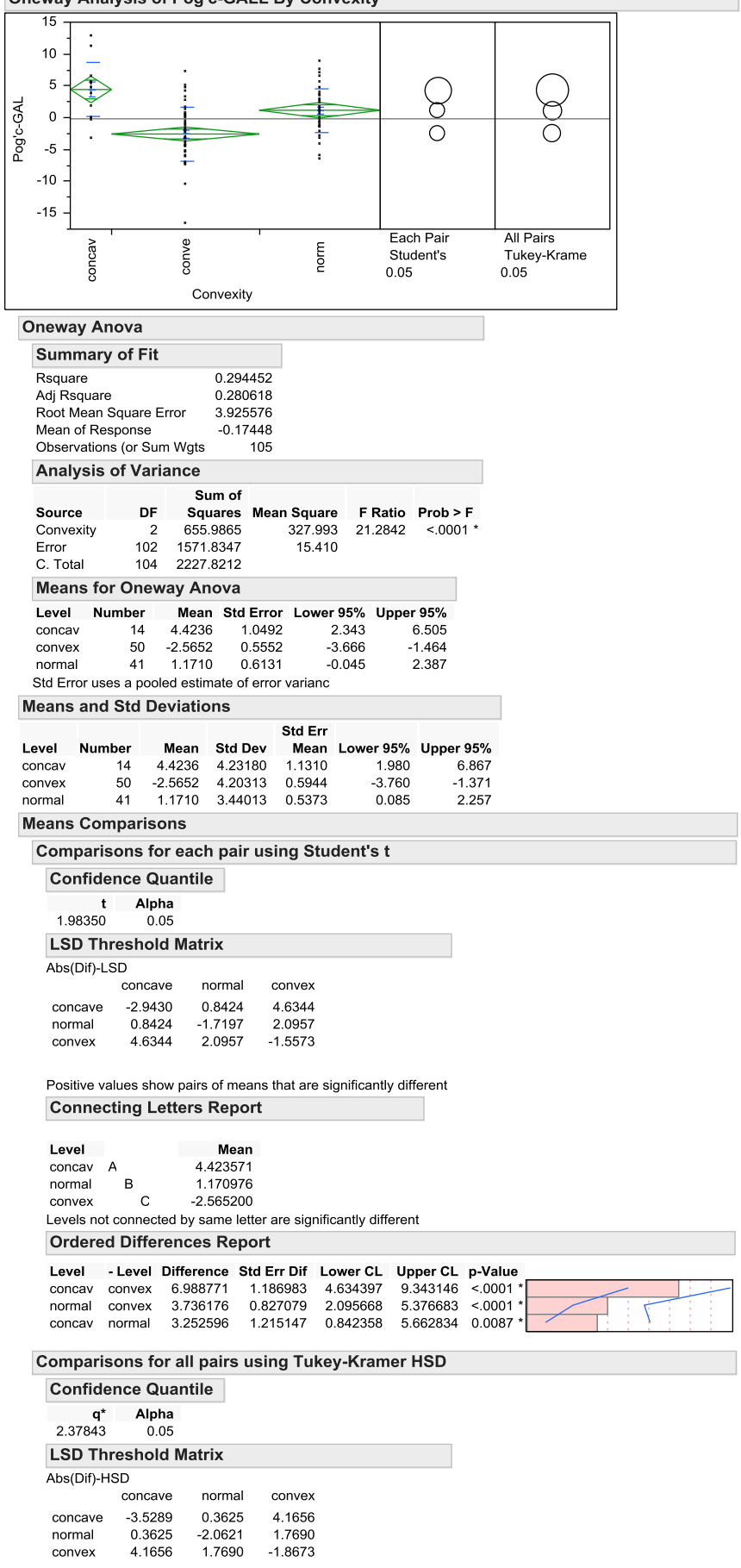

Positive values show pairs of means that are significantly different

Connecting Letters Report

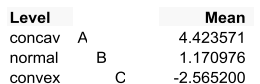

convex C $\quad-2.565200$

Ordered Differences Report

Level - Level Difference Std Err Dif Lower CL Upper CL p-Value

$\begin{array}{lllllll}\text { concav convex } & 6.988771 & 1.186983 & 4.165615 & 9.811928 & <.0001\end{array}$

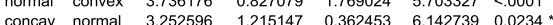

Oneway Analysis of Pog'c-GALL By Skeletal CLASS

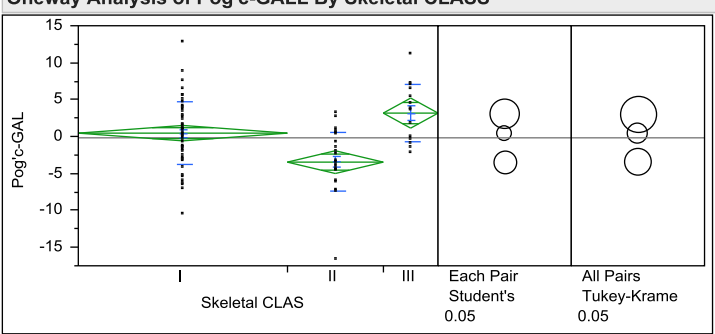

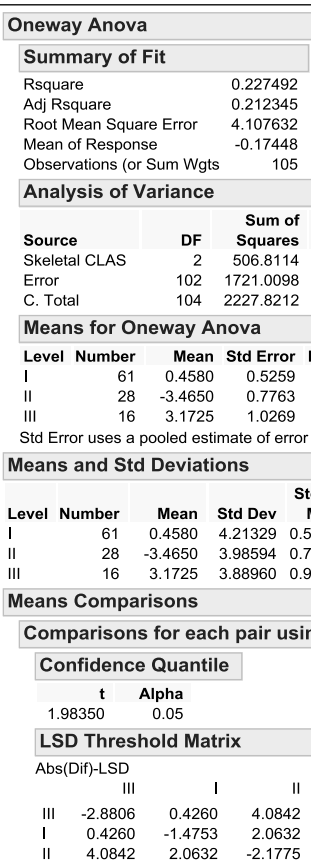

Positive values show pairs of means that are significantly different Connecting Letters Report

$\begin{array}{llr}\text { Level } & & \text { Mean } \\ \text { III } & \text { A } & 3.172500 \\ \text { I } & \text { B } & 0.458033\end{array}$

II $\begin{array}{cc}C & -3.465000\end{array}$

Levels not connected by same letter are significantly differen

Ordered Differences Report

Level - Level Difference Std Err Dif Lower CL Upper CL $\mathrm{p}$-Value

III II $\quad \begin{array}{lllllll}6.637500 & 1.287297 & 4.084152 & 9.190848 & <.0001 \\ \text { II } & & 3.923033 & 0.937654 & 2.063200 & 5.782865 & <.0001\end{array}$

$\begin{array}{llllllll}\text { III } & \text { I } & 2.714467 & 1.153751 & 0.426008 & 5.002927 & 0.0206\end{array}$

Comparisons for all pairs using Tukey-Kramer HSD Confidence Quantile

$\begin{array}{rr}\mathbf{q}^{*} & \text { Alpha } \\ 2.37843 & 0.05\end{array}$

LSD Threshold Matrix

Abs(Dif)-HSD

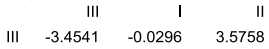

\begin{tabular}{rrr}
-0.0296 & -1.7690 & 1.6929 \\
\hline & & -02758
\end{tabular}

Positive values show pairs of means that are significantly different

Connecting Letters Report

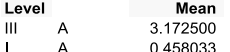

$\begin{array}{llr}\text { I } & \text { A } & 0.458033 \\ \text { II } & \text { B } & -3.465000\end{array}$

Levels not connected by same letter are significantly different Ordered Differences Report

Level - Level Difference Std Err Dif Lower CL Upper CL p-Value

III II $\quad 6.637500 \quad 1.287297 \quad 3.57575 \quad 9.699249<0001$ <

\begin{tabular}{lllllllll}
\hline & II & 3.923033 & 0.937654 & 1.69289 & 6.153179 & $0.0002 *$ \\
\hline
\end{tabular} 
Fit $Y$ by $X$ Group

Oneway Analysis of Pog-GALL By Convexity ${ }^{\circ}$

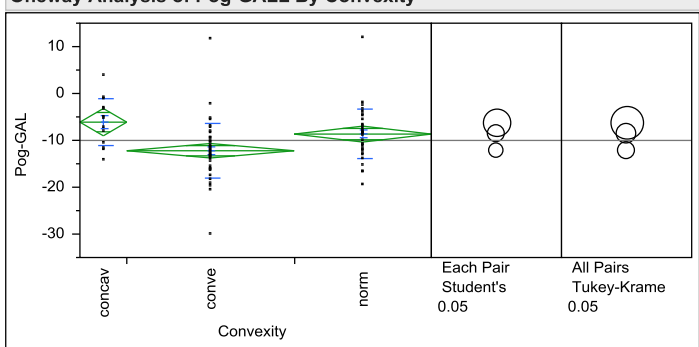

Oneway Anova

Summary of Fit

Rsquare

0.12993
Root Mean Square Error $\quad 5.497609$

$\begin{array}{lr}\text { Mean of Response } & -10.0152 \\ \text { Observations (or Sum Wgts } & 105\end{array}$

Analysis of Variance

$\begin{array}{lrrrrr}\text { Source } & \text { DF } & \begin{array}{r}\text { Sum of } \\ \text { Squares }\end{array} & \text { Mean Square } & \text { F Ratio } & \text { Prob }>\text { F } \\ \text { Convexity } & 2 & 529.8412 & 264.921 & 8.7653 & 0.0003 \text { * } \\ \text { Error } & 102 & 3082.8180 & 30.224 & & \\ \text { C. Total } & 104 & 3612.6592 & & & \end{array}$

Means for Oneway Anova

Level Number Mean Std Error Lower 95\% Upper 95\%

$\begin{array}{llrrrr}\text { concav } & 14 & -6.116 & 1.4693 & -9.03 & -3.20 \\ \text { convex } & 50 & -12216 & 0.7775 & -13.76 & -10.67 \\ & 41 & -8.663 & 0.8586 & -10.37 & -6.96\end{array}$

$\begin{array}{llllll}\text { convex } & 50 & -12.216 & 0.7775 & -13.76 & -10.67 \\ \text { normal } & 41 & -8.663 & 0.8586 & -10.37 & -6.96\end{array}$

Std Error uses a pooled estimate of error vart

Means and Std Deviations

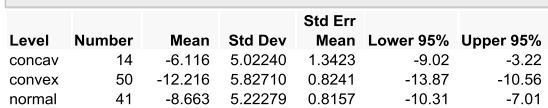

Means Comparisons

Comparisons for each pair using Student's t

Confidence Quantile

$\begin{array}{rr}t & \text { Alpha } \\ 1.98350 & 0.05\end{array}$

LSD Threshold Matrix

Abs(Dif)-LSD

$\begin{array}{lrrr} & \text { concave } & \text { normal } & \text { convex } \\ \text { concave } & -4.1215 & -0.8287 & 2.8020 \\ \text { normal } & -0.8287 & -2.4084 & 1.2550 \\ \text { con } & 2.820 & 1.2550 & -2.2809\end{array}$

$\begin{array}{lrrr}\text { normal } & -0.8287 & -2.4084 & 1.2550 \\ \text { convex } & 2.8020 & 1.2550 & -2.1809\end{array}$

Positive values show pairs of means that are significantly different

Connecting Letters Report

Level

Mean

normal A $\quad-8.66317$

Levels not connected by same letter are significantly differen

Ordered Differences Report

Level - Level Difference Std Err Dif Lower CL Upper CL p-Value

$\begin{array}{lllllllll}\text { concav convex } & 6.099171 & 1.662321 & 2.80197 & 9.396377 & 0.0004 & \text { * }\end{array}$

$\begin{array}{lllllll}\text { normal } & \text { convex } & 3.552429 & 1.158291 & 1.25496 & 5.849894 & 0.0028 \\ \text { concav } & \text { normal } & 2.546742 & 1.701764 & -0.82870 & 5.922182 & 0.1376\end{array}$

Comparisons for all pairs using Tukey-Kramer HSD Confidence Quantile

$\begin{array}{rr}\mathbf{q}^{*} & \text { Alpha } \\ 2.37843 & 0.05\end{array}$

LSD Threshold Matrix

Abs(Dif)-HSD

$\begin{array}{lrrr} & \text { concave } & \text { normal } & \text { convex } \\ \text { concave } & -4.9421 & -1.5008 & 2.1455 \\ \text { normal } & -1.5008 & -2.8879 & 0.7975 \\ \text { convex } & 2.1455 & 0.7975 & -2.6151\end{array}$

Positive values show pairs of means that are significantly different

Connecting Letters Report

$\begin{array}{lrr}\text { Level } & \text { Mean } \\ \text { concav } & A & -6.11643\end{array}$

$\begin{array}{lrr}\text { concav } & \text { A } & -6.11643 \\ \text { normal } & \text { A } & -8.66317 \\ \text { convex } & \text { B } & -12.21560\end{array}$

Levels not connected by same letter are significantly different

Ordered Differences Report

Level - Level Difference Std Err Dif Lower CL Upper CL p-Value

$\begin{array}{llllllll} & \text { concav convex } & 6.099171 & 1.662321 & 2.14546 & 10.05289 & 0.0011^{*}\end{array}$

$\begin{array}{llllllll}\text { concav normal } & 2.546742 & 1.701764 & -1.50079 & 6.59427 & 0.2968\end{array}$

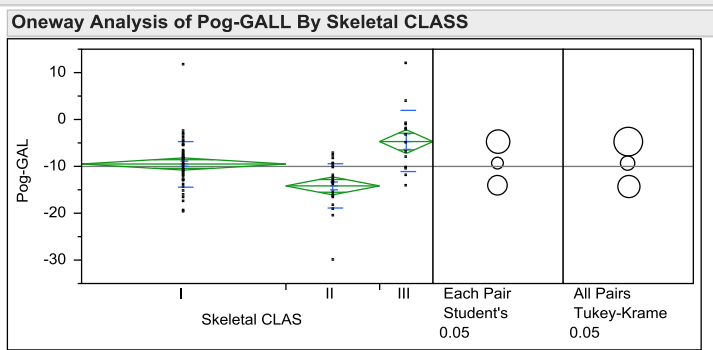

Oneway Anova

Summary of Fit

Rsquare

Adj Rsquare $\quad 0.262827$

0.248373
Root Mean Square Error $\quad 5.109732$

$\begin{array}{lr}\text { Mean of Response } & -10.0152 \\ \text { Observations (or Sum Wgts } & 105\end{array}$

Analysis of Variance

$\begin{array}{lrrrrrr}\text { Source } & \text { DF } & \begin{array}{c}\text { Sum of } \\ \text { Squares }\end{array} & \text { Mean Square } & \text { F Ratio } & \text { Prob }>\text { F } \\ \text { Skeletal CLAS } & 2 & 949.5045 & 474.752 & 18.1832 & <.0001 \text { * } \\ \text { Error } & 102 & 2663.1548 & 26.109 & & \\ \text { C. Total } & 104 & 3612.6592 & & & \end{array}$

Means for Oneway Anova

Level Number Mean Std Error Lower 95\% Upper 95\%

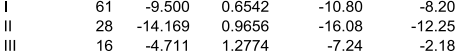

Std Error uses a pooled estimate of error varianc

Means and Std Deviations

Std Err

Level Number Mean Std Dev Mean Lower 95\% Upper 95\%

$\begin{array}{llrllrr}\text { II } & 61 & -9.500 & 4.86464 & 0.6229 & -10.75 & -8.25 \\ \text { II } & 28 & -14.169 & 4.73710 & 0.8952 & -16.01 & -12.33 \\ \text { III } & 16 & -4.711 & 651863 & 1.6297 & -8.18 & -1.24\end{array}$

Means Comparisons

Comparisons for each pair using Student's t

Confidence Quantile

$\begin{array}{rr}\text { t } & \text { Alpha } \\ 1.98350 & 0.05\end{array}$

LSD Threshold Matrix

Abs(Dif)-LSD

$\begin{array}{rrrr} & \text { III } & \text { I } & \text { II } \\ \text { III } & -3.5833 & 1.9426 & 6.2820 \\ \text { II } & 1.9426 & -1.8352 & 2.3554\end{array}$

$\begin{array}{rrrr}\text { II } & 1.9426 & -1.8352 & 2.3554 \\ \text { II } & 6.2820 & 2.3554 & -2.7087\end{array}$

Positive values show pairs of means that are significantly different

Connecting Letters Report

$\begin{array}{lrrr}\text { Level } & & & \text { Mean } \\ \text { III } & & & -4.71063 \\ \text { I } & & & -9.50000 \\ \text { II } & & \text { B } & -14.16893\end{array}$

Levels not connected by same letter are significantly different

Ordered Differences Report

Level - Level Difference Std Err Dif Lower CL Upper CL $p$-Value

\begin{tabular}{llllll}
9.458304 & 1.601347 & 6.282039 & 12.63457 & $<.0001$ \\
\hline 4.69375 & 1.45220 & 1.232622 &
\end{tabular}

$\begin{array}{llllll}\text { III I I } & 4.789375 & 1.435220 & 1.942622 & 7.63613 & 0.0012 \\ \text { II } & 4.668929 & 1.166405 & 2.355371 & 6.98249 & 0.0001\end{array}$

Comparisons for all pairs using Tukey-Kramer HSD

Confidence Quantile

$\begin{array}{rr}\mathbf{q}^{*} & \text { Alpha } \\ 2.37843 & 0.05\end{array}$

LSD Threshold Matrix

Abs(Dif)-HSD

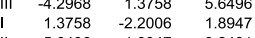

Positive values show pairs of means that are significantly different

Connecting Letters Report

$\begin{array}{lrr}\text { Level } & \text { Mean } \\ \text { III } & & -4.71063 \\ \text { I } & -9.50000\end{array}$

\begin{tabular}{llr} 
II & B & -9.50000 \\
\hline & C & -14.16893
\end{tabular}

Levels not connected by same letter are significantly differen

Ordered Differences Report

Level - Level Difference Std Err Dif Lower CL Upper CL p-Value

III I $\quad \begin{array}{lllllll}9.458304 & 1.601347 & 5.649610 & 13.26700 & <.0001 * \\ \text { II } & 4.789375 & 1.435220 & 1.375802 & 8.20295 & 0.0034 *\end{array}$ 


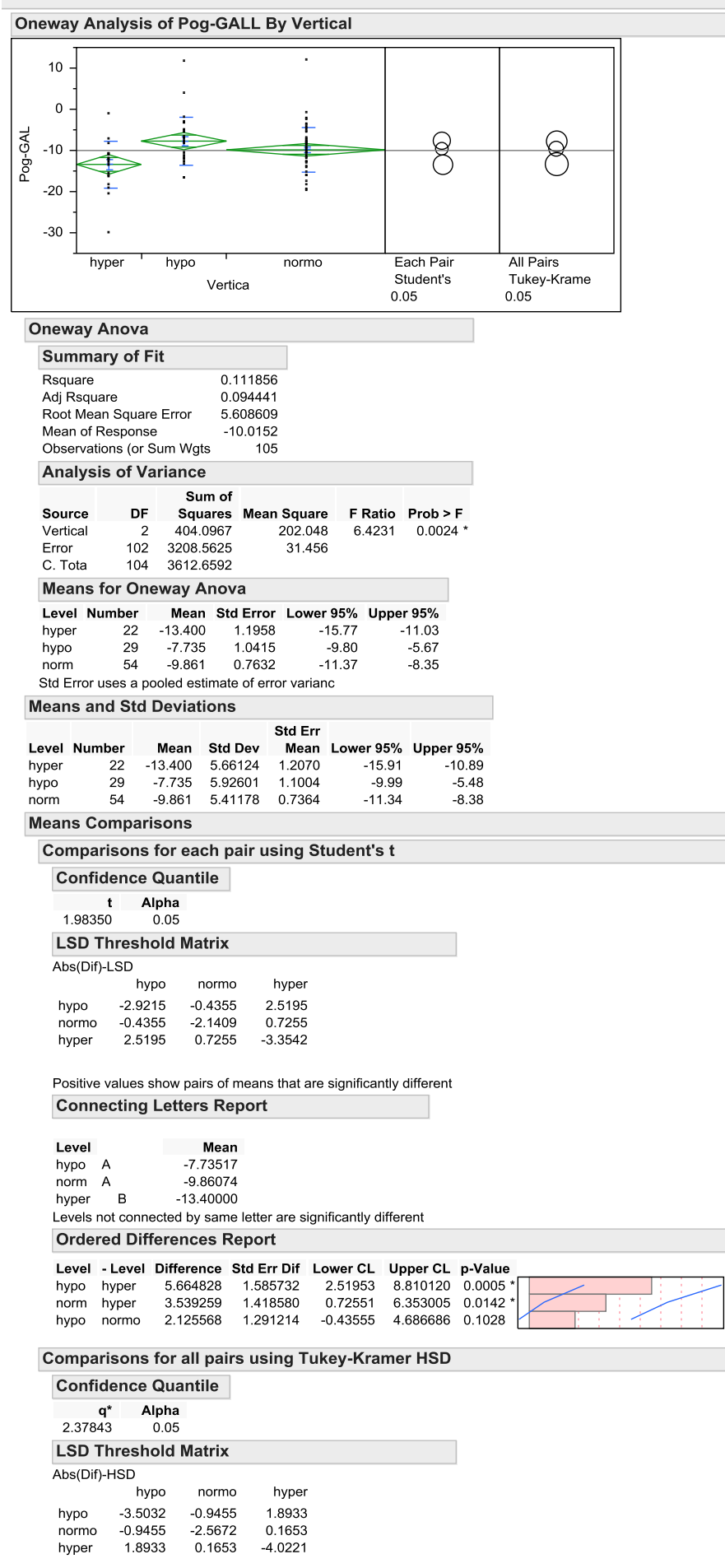

Oneway Analysis of Pog-GALL By Category
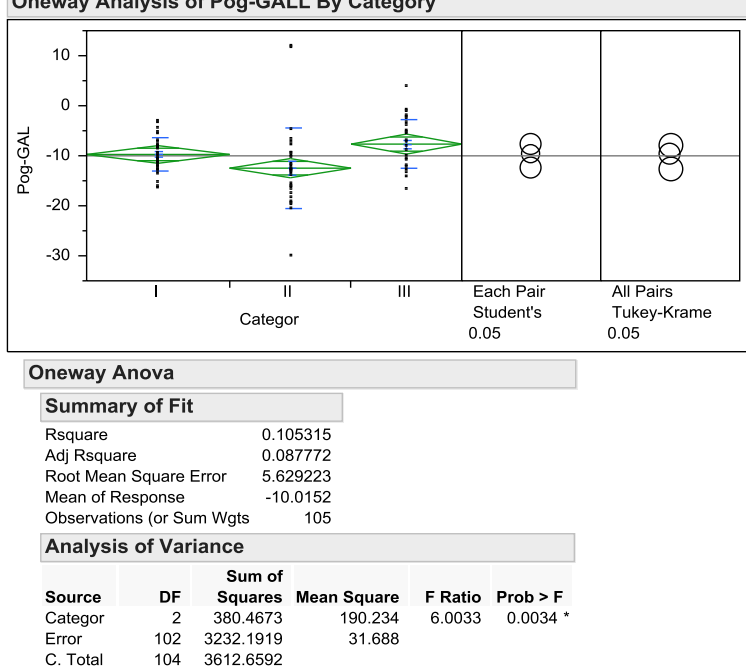

Means for Oneway Anova

Level Number Mean Std Error Lower 95\% Upper 95\%

$\begin{array}{llrrrr}\text { I } & 40 & -9.740 & 0.8901 & -11.51 & -7.97 \\ \text { II } & 34 & -12.480 & 0.9654 & -14.39 & -10.57\end{array}$

$\begin{array}{lllll}1110 & 1.0110 & -9.67 & -5.66\end{array}$

Std Error uses a pooled estimate of error varianc

Means and Std Deviations

Level Number Mean Std Dev $\begin{gathered}\text { Std Err } \\ \text { Mean Lower 95\% Upper 95\% }\end{gathered}$

$\begin{array}{lllllll}1 & 40 & -9.740 & 3.37864 & 0.5342 & -10.82 & -8.659\end{array}$

$\begin{array}{llrrrrr}\text { II } & 34 & -9.480 & 7.99049 & 1.3704 & -15.27 & -8.9692 \\ \text { III } & 31 & -7.667 & 4.76102 & 0.8551 & -9.41 & -5.921\end{array}$

Means Comparisons

Comparisons for each pair using Student's $\mathbf{t}$

Confidence Quantile

$\begin{array}{rr}t & \text { Alpha } \\ 1.98350 & 0.05\end{array}$

LSD Threshold Matrix

Abs(Dif)-LSD

$\begin{array}{lrrr} & \text { III } & \text { I } & \text { II } \\ \text { III } & -2.8360 & -0.5994 & 2.0398 \\ \text { I } & -0.5994 & -2.4967 & 0.1357 \\ \text { II } & 2.0398 & 0.1357 & -2.7080\end{array}$

Positive values show pairs of means that are significantly different

Connecting Letters Report

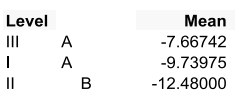

Levels not connected by same letter are significantly different

Ordered Differences Report

Level - Level Difference Std Err Dif Lower CL Upper CL $\mathrm{p}$-Value

$\begin{array}{lllllll}\text { III II } & 4.812581 & 1.397928 & 2.03980 & 7.585365 & 0.0008 \text { * } \\ \text { II } & 2.740250 & 1.313091 & 0.13574 & 5344760 & 0.0394 \text {, }\end{array}$

III I I $\quad \begin{array}{lllllll}\text { II } & 2.072331 & 1.346998 & -0.59943 & 4.744094 & 0.1270\end{array}$

Comparisons for all pairs using Tukey-Kramer HSD Confidence Quantile

$\begin{array}{rr}q^{*} & \text { Alpha } \\ 2.37843 & 0.05\end{array}$

LSD Threshold Matrix

Abs(Dif)-HSD

$\begin{array}{rrrr} & \text { III } & \text { I } & \text { II } \\ \text { III } & -3.4007 & -1.1314 & 1.4877 \\ \text { I } & -1.1314 & -2.9938 & -0.3828 \\ \text { II } & 1.4877 & -0.3828 & -3.2472\end{array}$

Positive values show pairs of means that are significantly different

Connecting Letters Report

$\begin{array}{llr}\text { Level } & & \text { Mean } \\ \text { III } & \text { A } & -7.66742 \\ \text { I } & \text { A B } & -9.73975\end{array}$

II A $\quad-12.48000$

Levels not connected by same letter are significantly different

Ordered Differences Report

Level - Level Difference Std Err Dif Lower CL Upper CL p-Value

$\begin{array}{llllllll}\text { III II } & 4.812581 & 1.397928 & 1.48770 & 8.137457 & 0.0024\end{array}$

$\begin{array}{lllllll}\text { I II } & \text { I } & 2.740250 & 1.313091 & -0.38285 & 5.863347 & 0.0976 \\ \text { III } & \text { I } & 2.072331 & 1.346998 & -1.13141 & 5.276072 & 0.2774\end{array}$ 


\section{CURRICULUM VITAE}

Name:

Date of Birth:

Place of Birth:

Education:

August 1999-May 2003

August 2005-May2009

July 2009 - Present

\section{Professional Memberships:}

August 2005 - May 2009

May 2009 - present

July 2009 - present
Holly Renee Eppard, DDS.

January 29, 1981

Charlottesville, Virginia

United States

Virginia Tech

Blacksburg, Virginia

Bachelor of Science, Biology

West Virginia University

School of Dentistry

Morgantown, West Virginia

Doctorate of Dental Surgery

West Virginia University

School of Dentistry

Department of Orthodontics

Morgantown, WV

Master of Science (anticipated May 2012)

American Student Dental Association

American Dental Association

American Association of Orthodontists 


\title{
The Occlusal Plane Inclination Relative to Craniofacial Form: A Cephalometric Investigation
}

\author{
Holly R. Eppard, D.D.S.
}

Thesis Submitted to the

School of Dentistry at West Virginia University

In partial fulfillment of the requirements

For the degree of Master of Science

APPROVAL OF EXAMINING COMMITTEE

Timothy Tremont, D.M.D.,M.S. Advisor

Peter Ngan, D.M.D., Chairman

Chris Martin, D.D.S., M.S

Bryan Weaver, D.D.S., M.D.

Date 
